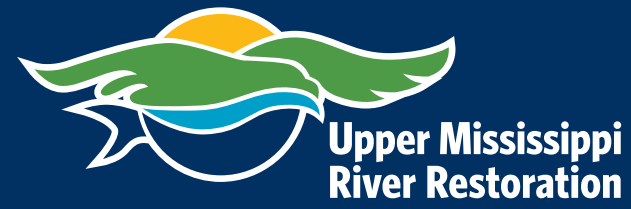

Prepared in cooperation with the U.S. Army Corps of Engineers' Upper Mississippi River Restoration Program

\title{
Indicators of Ecosystem Structure and Function for the Upper Mississippi River System
}

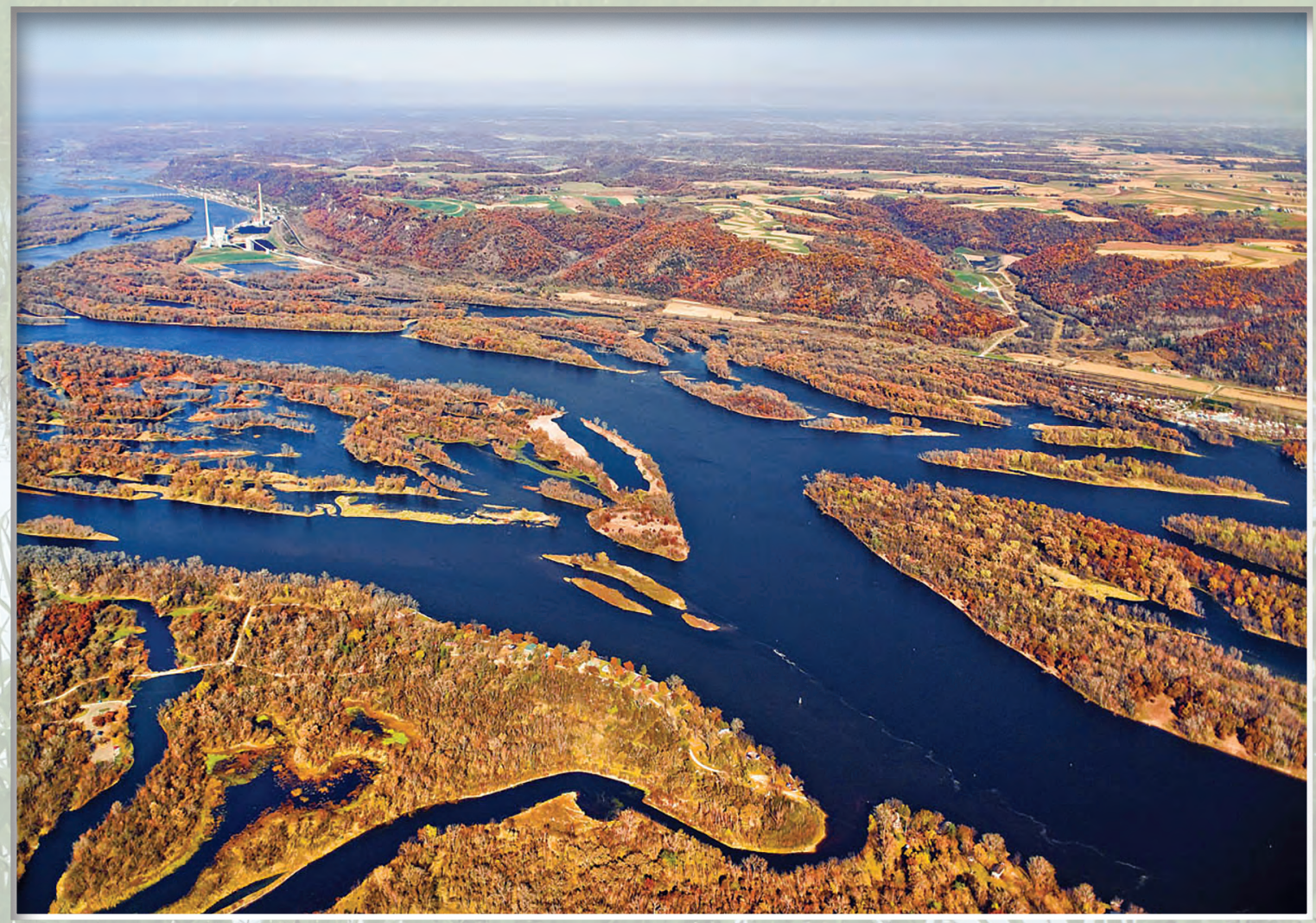

Open-File Report 2018-1143

U.S. Department of the Interior

U.S. Geological Survey 
Cover photograph, inset. Aerial view of a portion of the Upper Mississippi River.

The Upper Mississippi River is a nationally significant mosaic of floodplain forests, emergent marshes, and diverse aquatic areas. It also supports a nationally significant commercial navigation system. Photoraph from the U.S. Army Corps of Engineers.

Cover photograph, background. Wild rice (Zizania aquatica) with the bluffs of the Upper Mississippi River valley in the background. Photoraph taken by Erin Hoy, U.S. Geological Survey. 


\section{Indicators of Ecosystem Structure and Function for the Upper Mississippi River System}

By Nathan R. De Jager, James T. Rogala, Jason J. Rohweder, Molly Van Appledorn, Kristen L. Bouska, Jeffrey N. Houser, Kathi Jo Jankowski

Prepared in cooperation with the U.S. Army Corps of Engineers'

Upper Mississippi River Restoration Program

Open-File Report 2018-1143 


\title{
U.S. Department of the Interior \\ RYAN K. ZINKE, Secretary
}

\author{
U.S. Geological Survey \\ James F. Reilly II, Director
}

U.S. Geological Survey, Reston, Virginia: 2018

For more information on the USGS - the Federal source for science about the Earth, its natural and living resources, natural hazards, and the environment—visit https://www.usgs.gov or call 1-888-ASK-USGS.

For an overview of USGS information products, including maps, imagery, and publications, visit https://store.usgs.gov.

Any use of trade, firm, or product names is for descriptive purposes only and does not imply endorsement by the U.S. Government.

Although this information product, for the most part, is in the public domain, it also may contain copyrighted materials as noted in the text. Permission to reproduce copyrighted items must be secured from the copyright owner.

Suggested citation:

De Jager, N.R., Rogala, J.T., Rohweder, J.J., Van Appledorn, M., Bouska, K.L., Houser, Jeffrey, N., and Jankowski, K., 2018, Indicators of ecosystem structure and function for the Upper Mississippi River System: U.S. Geological Survey Open-File Report 2018-1143, 115 p. including 4 appendixes, https://doi.org/10.3133/ofr20181143.

ISSN 0076-8952 (print) ISSN 2331-1258 (online) 


\section{Acknowledgments}

The authors would like to thank the members of the Habitat Needs Assessment II (HNA-II) management team (Marvin E. Hubbell [U.S. Army Corps of Engineers (USACE)], Kathryn McCain [USACE], Sara Schmuecker [U.S. Fish and Wildlife Service (USFWS)], and Timothy P. Eagan [USACE]) for semi-weekly meetings that guided the development of this document. In addition, the HNA-II Steering Committee (Stephen Winter [USFWS], Levi Solomon [Illinois Natural History

Survey], Kirk Hansen [lowa Department of Natural Resources], Matt Vitello [Missouri Department of Conservation], Kathy Kowal [U.S. Environmental Protection Agency], Martin Adkins [United States Department of Agriculture-Natural Resources Conservation Service], Jeff Janvrin [Wisconsin Department of Natural Resources], Kirsten Mickelsen [Upper Mississippi River Basin Association], Mark Gaikowski [U.S. Geological Survey (USGS)], Dan Dieterman [Minnesota Department of Natural Resources], and Megan McGuire [USACE]) provided valuable guidance periodically throughout the data and indicator development process. The members of the Upper Mississippi River Restoration Coordinating Committee provided valuable feedback at quarterly meetings throughout the process. Janis Ruhser (USGS) made valuable contributions to the methods outlined in appendix 1. Andrew Meier, Benjamin Vandermyde (USACE), Lyle Guyon (National Great Rivers Research and Education Center), Robert Cosgriff (USACE), Yao Yin (USGS), and Timothy Fox (USGS) made valuable contributions to the methods outlined in appendix 4. Previous versions of this report were reviewed by Paul Seelbach, Megan Moore, Levi Solomon, Nerissa McClelland, and Karen Hagerty. Funding was provided for this work by the USACE'S Upper Mississippi River Restoration Program. 



\section{Contents}

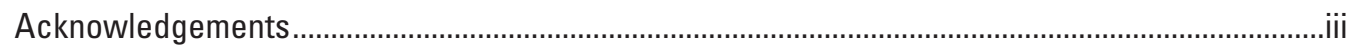

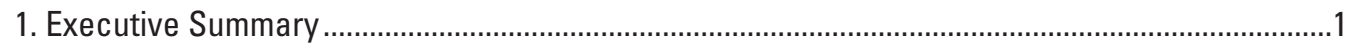

Methods

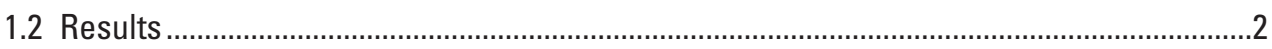

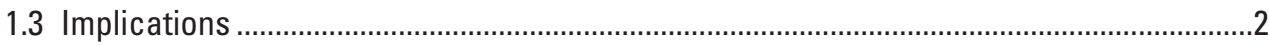

2. Introduction to the Upper Mississippi River System and Upper Mississippi

River Restoration Program ............................................................................................

2.1 Report Objectives, Approach, and Rationale ..................................................................

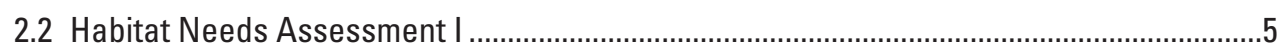

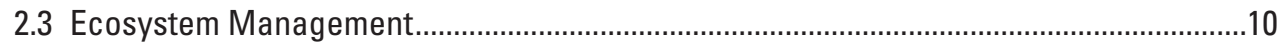

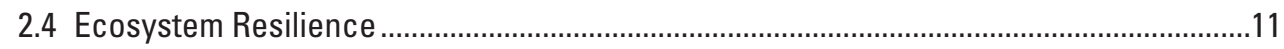

2.5 Merging Previous Efforts and Concepts to Form an Approach.....................................13

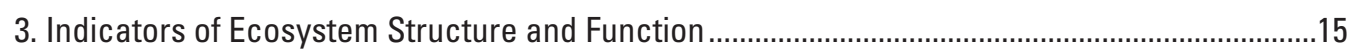

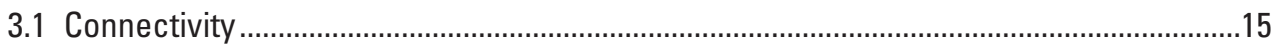

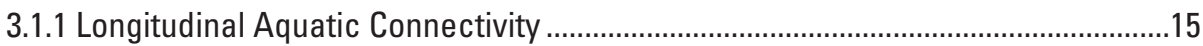

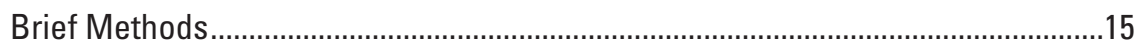

Brief Results and Discussion ..............................................................................15

3.1.2 Longitudinal Floodplain Connectivity......................................................................15

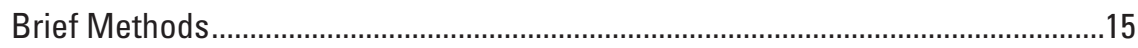

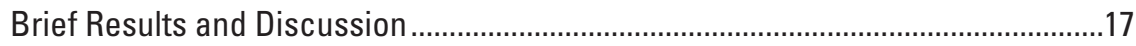

3.1.3 Lateral River Floodplain Connectivity ......................................................................17

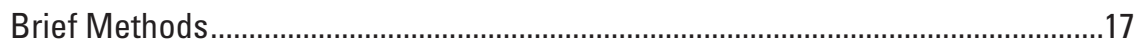

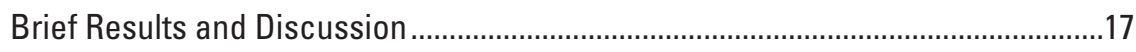

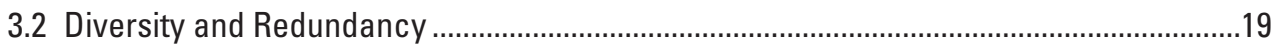

3.2.1 Aquatic Areas and Functional Classes .............................................................19



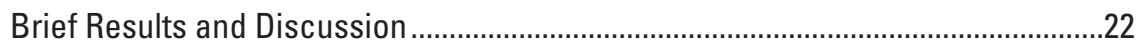

Synthesis of Aquatic Functional Class Distribution ..............................................26

3.2.2 Aquatic Vegetation Diversity ...............................................................................

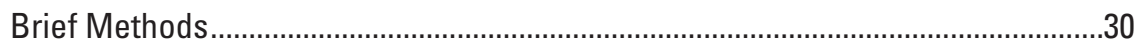

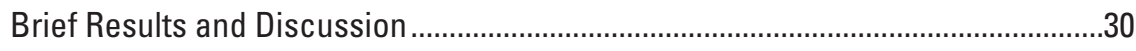

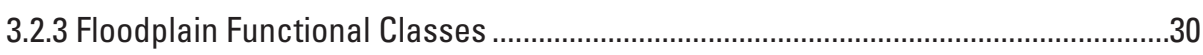

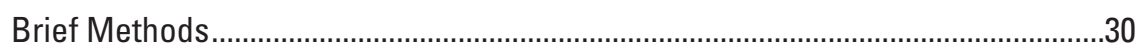

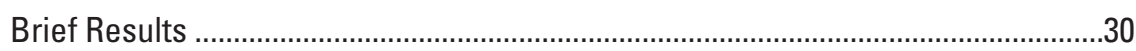

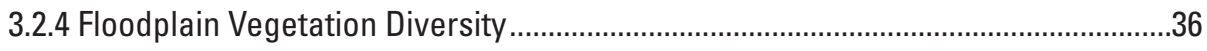

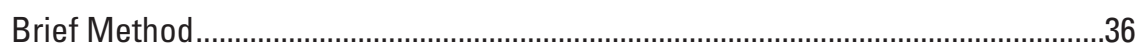

Brief Results and Discussion ................................................................................36

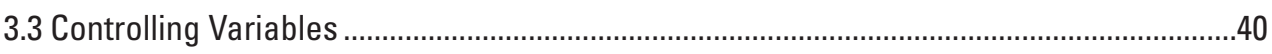

3.3.1 Water-Surface Elevation Fluctuations …………...............................................40

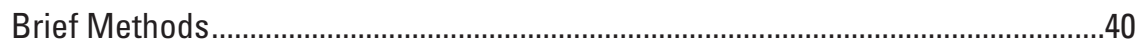

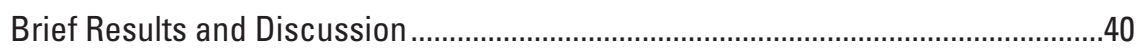


3.3.2 Total Suspended Solids Concentrations ..................................................................41

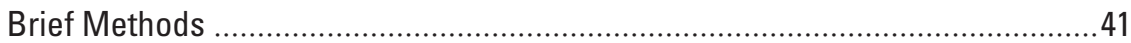



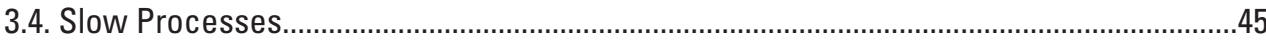

3.4.1 Sedimentation in Off-Channel Areas ....................................................................45

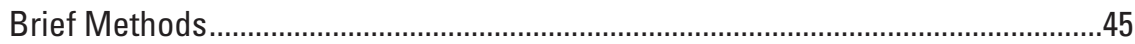

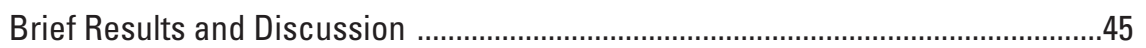

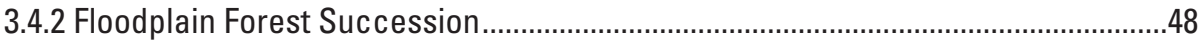

Brief Methods .................................................................................................

Brief Results and Discussion ..............................................................................49

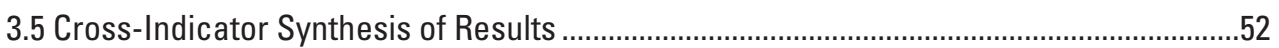

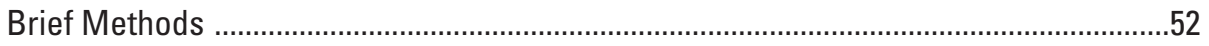

Brief Results and Discussion .....................................................................................53

Upper Impounded Pools (P3-9, 13) .......................................................................53

Middle Impounded Pools (P10-12, 14, 16, 19) …………….....................................53

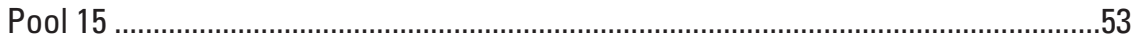

Lower Impounded Pools (P17, 18, 20-26)...............................................................53

Open River Reaches (OR1 and OR2) .................................................................56

Upper Illinois Pools (Dresden (dre), Marseilles, (mar), Starved Rock(sta)) ............56

Lower Illinois Pools (Peoria (peo), La Grange (laf), Alton (alt)) ...............................56

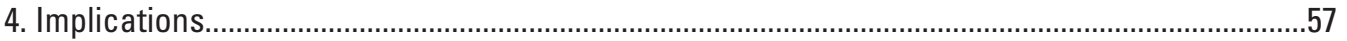

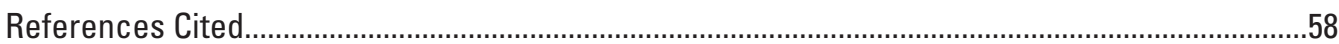

Appendix 1. An Aquatic Areas Classification for the Upper Mississippi River System ...............65

Appendix 2 Methods for Floodplain-Inundation Modeling ...........................................................

Appendix 3. Methods for Backwater Sedimentation Forecast Modeling .......................................93

Appendix 4. Methods for Forest Simulation Modeling ....................................................................99 


\section{Figures}

1. The information contained within this report covers the entire Upper Mississippi River System (inset). Data were developed to characterize the diversity of broad-scale hydrogeomorphic areas, including navigation infrastructure, for the year 2010 in a manner consistent with data developed for previous assessments. Navigation pools 8 and 25 are shown as examples of the mosaic of hydrogeomorphic areas, but also the impacts of navigation infrastructure (river-training structures and impounded areas in pool 8 and levees in pool 25)...

2. For the Upper Mississippi River Restoration Habitat Needs Assessment II, datasets and indicators derived from those datasets were developed to quantify existing Upper Mississippi River System goals and objectives and related essential ecosystem characteristics. In addition, information from an ongoing resilience assessment was considered when developing data and indicators. The diagram is adapted from Harwell and others (1999) to illustrate the increasing contribution of society and stakeholders in the development of goals, objectives, and targets and the increasing contribution of scientific information in the development of data and indicators. This report summarizes efforts aimed at developing hydrogeomorphic datasets and indicators of ecosystem structure and function in support of Habitat Needs Assessment II

3. A generalization of the relations among spatial and temporal scales and different levels of biological organization (adapted from Harwell and others, 1999). At fine spatial and temporal scales, very specific information can be collected to quantify the density, age structure, life-history attributes, and genetic diversity of individual species. At a broader scale, data can be collected to evaluate the diversity and trophic structure of communities (made up of different species), along with processes such as invasion, predation, and competition among species. At even broader and more generalizable scales, data can be collected to characterize collections of communities and processes that operate on communities and species (such as succession and hydrogeomorphic change). Finally, at the broadest scales, landscape are collections of species, communities, and ecosystem types. For this report, data and indicators were developed to assess the Upper Mississippi River System at the ecosystem and landscape levels of biological organization.

4. The percentage of annual days that downriver dams on the Upper Mississippi River System were in open river conditions from 1985-94 and from 2006-15 was used to quantify longitudinal aquatic connectivity (for example, the ability of some organisms to longitudinally traverse the Upper Mississippi River System)

5. The hectares per river mile within the navigation pools of the Upper Mississippi River System that are in vegetation classes not associated with direct anthropogenic impacts (for example, nondeveloped and nonagricultural areas) for the years 1989, 2000, and 2010 is shown in the lower panel. Also shown in the lower panel is the total floodplain area (including all cover types) for Upper Mississippi River System navigation pools. The map displays the proportion of total floodplain area in natural land-cover types for each navigation pool (pool widths not to scale). These data were used to quantify longitudinal floodplain connectivity (the ability of organisms to longitudinally traverse the Upper Mississippi River System floodplain) ...

6. The hectares per river mile for navigation pools of the Upper Mississippi River System in open water and behind Federal levees for the years 1989 and 2010. Also shown is the hectares per river mile for the total navigation pool area. These data were used to quantify patterns of lateral river floodplain connectivity (for example, ability of water, energy, nutrients, and organisms to mover laterally across the river floodplain template) 
7. The hectares per river mile of each general aquatic area within each navigation pool of the Upper Mississippi River System for 1989 (middle panel) and 2010 (lower panel), along with Simpson's diversity index derived from the data (top panel)

8. Navigation pool 8 of the Upper Mississippi River System showing the distribution of aquatic areas in 1989 (left) and 2010 (right). Note the increase in the contiguous floodplain shallow-aquatic class in the lower portion of the pool, reflecting island construction during the 1990s and early 2000s.

9. Examples of selected aquatic functional classes in navigation pools 8 and 25 . Aquatic functional classes are not mutually exclusive (regions within the maps can belong to multiple classes). Therefore, only a few classes are mapped here and some backwaters are not in any of the mapped classes (denoted as "Not in selected functional classes")

10. The hectares per river mile of lentic shallow areas and lentic areas with wooded shorelines See table 5 for criteria for shallow and wooded shoreline.

11. The hectares per river mile of lentic deep areas. See table 5 for criteria for deep, depression and borrow pit.

12. The area of lentic functional classes primarily defined by connectivity measures that reflect water exchange ratesThe low connectivity and shallow with flow (higher connectivity) classes are measured in hectares per river mile, but the large with flow (higher connectivity, for example, impounded areas) is measured in hectares per navigation pool. See table 5 for criteria for each class

13. The area in hectares per river mile of lotic functional classes characterized as shallow and containing wooded shoreline. See table 5 for the criteria for each class.

14. The hectares per river mile of lotic functional classes primarily defined by deep depths or structures. Classes include deep lotic, lotic with structure, and lotic with structure scours. Structures include wing dams and closing dams. See table 5 for criteria for each class.

15. Results from a multivariate cluster analysis based on the area of each aquatic functional class (table in lower panel) for Upper Mississippi River System navigation pools. Pools that clustered together $(P=0.05)$ have the same color. The table provides the mean area (hectare per linear river mile) for the navigation pools in each aquatic functional class

16. Navigation pools 8 and 25 of the Upper Mississippi River System, illustrating the widespread distribution of aquatic vegetation in the spatially extensive lentic areas of the northern Upper Mississippi River System (pool 8) and the lack of vegetation in the relatively more lotic conditions found in the southern Upper Mississippi River System (pool 25)

17. Simpson's diversity index (top panel) and the area (hectare per linear river mile) of vegetated and unvegetated aquatic areas within navigation pools of the Upper Mississippi River System for 1989, 2000, and 2010 (progressively lower panels).

18. Floodplain functional classes, defined by the mean total duration of inundation during the growing season and for the past 40 years, shown here for navigation pools 10 and 25 in the Upper Mississippi River System.

19. The area (hectare per linear river mile) of different 40-year mean growing season flood inundation zones (for example, floodplain functional classes) and Simpson's diversity index (top panel) applied to all inundation zones for each navigation pool within the Upper Mississippi River System. Note different y-axis scales among different panels. 
20. Maps illustrating the distribution of different floodplain vegetation types in navigation pool 8 in the northern portion of the Upper Mississippi River System and pool 25 in the south.

21. Simpson's diversity (top panel) and the area (hectare per linear river mile) of different floodplain vegetation classes within the navigation pools of the UMRS for 1989, 2000, and 2010 (progressively lower panels). Also shown is the total floodplain area in the background of the lower three panels.

22. Mean annual maximum growing season water-surface elevation fluctuations for pool gages on the Upper Mississippi River System for two periods (1985-94 and 2006-15) to match the other 1989 and 2010 datasets included in this report, along with estimated prelock and dam fluctuations (red line in lower panel). The map and colors represent the departure from prelock and dam conditions, with the dammed navigation pools typically having less variability (negative values) in water-surface elevation fluctuations than during prelock and dam conditions

23. Mean annual maximum growing season water-surface elevation fluctuations for tailwater gages on the Upper Mississippi River System during 1985-94 and during 2006-15, along with estimated prelock and dam fluctuations (red line in the lower panel). The map and colors represent the departure from prelock and dam conditions, with the lower river reaches typically having more variability (positive values) in water-surface elevation fluctuations than during prelock and dam conditions and values closer to prelock and dam conditions.

24. Total suspended solids concentrations collected at select dams on the Upper Mississippi River System (top panel) and in the main channel in select navigation pools of the Upper Mississippi River System sampled by the Upper Mississippi River Restoration Long Term Resource Monitoring (bottom panel). Shown on the lower panel are five reaches of the Upper Mississippi River (pool 4 [p04] through the open river reach [or]) and one reach of the Illinois River (lag).

25. Present (dark blue) and simulated future (light blue) area per linear river mile of lentic area in the shallow (upper panel) and deep (lower panel) functional classes. Note that these area estimates exclude large lentic areas with flow (for example, impounded areas)

26. Present (dark blue) and simulated future (light blue) area per linear river mile of lentic area greater than 0.5 mile (upper panel) and greater than 1.0 mile (lower panel). Note that these area estimates exclude large lentic areas with flow (for example, impounded areas).

27. The area (hectare per linear river mile) of four forest types, along with the area in total forest cover (across all four types) for year 0 (initial conditions for year 2010, see 3.2.5 Floodplain Vegetation Diversity) and years 50 and 100 resulting from model simulations for the navigation pools of the Upper Mississippi River System.......50

28. The area (hectares) of four forest types, along with the area in total forest cover (across all four types) for year 0 (initial conditions for year 2010, see 3.2.5 Floodplain Vegetation Diversity) and years 50 and 100 resulting from model simulations for 7 floodplain functional classes (see section 3.2.4 Floodplain Functional Classes). Class 0 experienced no flooding during model simulations, class 10 experienced an average of 0.1 to 10 days of flooding annually, with similar ranges of durations for all other classes, except for class 70 , which experienced an average between 60.1 and 180 days of flooding annually 
29. Results of multivariate cluster analysis based on indicators describing different aspects of connectivity, diversity and redundancy, and slow variables and feedbacks (see text for details). Navigation pools are colored according to significant $(P=0.05)$ differences among pool groupings. Mean values of the indicators used in the analysis are provided in the table (lower panel) and characterize each group of pools

30. Rescaled values for each indicator describing different aspects of connectivity (natural area, open water, levee area, gates open), diversity and redundancy (Aquatic Functional Class 1, Aquatic Functional Class 2, aquatic vegetation, floodplain vegetation), and slow variables and feedbacks (Tailwater flux, pool flux, total suspended solids). Gray areas represent the average for each cluster group and the series within each plot represent each navigation pool within each group......55

1.1 Maps depicting the development of level 1 and level 2 aquatic areas databases .........67

1.2 Graphical depiction of methods used to produce structured versus unstructured channel border segments

1.3 Diagram and calculations describing development of polygonal sinuosity metric (Tim Fox, written/oral commun., 2018)... .70

1.4 Map depicting metrics calculated specific to lentic aquatic areas .71

1.5 Map depicting various water depth related metrics calculated for level 3 aquatic areas.

1.6 Map depicting wet forest adjacency metrics developed for level 3 aquatic areas...............75

1.7 Map depicting various connectivity and aquatic vegetation metrics developed for level 3 aquatic areas

1.8 Map depicting various river-training structure metrics developed for level 3 lotic aquatic areas.

2.1 The development of floodplain functional classes was accomplished in two complimentary parts. Part 1 consisted of the development of a system-wide spatially explicit inundation model. The inundation model combined two dataset inputs (daily water-surface elevations from the U.S. Army Corps of Engineers' gages and terrain data in the form of Upper Mississippi River Systemtopo-bathymetry) to describe multiple attributes of inundation for all nonaquatic areas. In Part 2, we analyzed distributions of inundation duration to identify and map areas of the floodplain expected to experience similar patterns of flooding.

2.2 The planar surface model to mapping inundation patterns is based on the relationship between spatially-explicit water-surface elevations and topobathymetry. Inundation is detected at site A, where the water-surface elevation is greater than the terrain elevation, but not for site $B$ which has a terrain elevation that exceeds the water-surface elevation. Inundation extent and depth can therefore be measured in a spatially continuous way throughout the study domain for any time step for which water-surface elevations are known

2.3 An example of differences between water-surface elevation profiles from the UNET 1-D hydraulic model (U.S. Army Corps of Engineers, 2004) and linear interpolations between gages (used in the Upper Mississippi River System Inundation Model) for 2-, 5-, 10- and 25-year flows in navigation pools 3-10. High values indicate water-surface elevations are underpredicted by linear interpolation methods; low values indicate overprediction by linear interpolation. Multiple observations at a given river mile location reflect the range of elevation differences across flow magnitudes. 
2.4 The Upper Mississippi River System inundation model uses a modified bathtub approach to map summary statistics of dynamic inundation patterns.

First, $A$, a Height Above Nearest Drainage (HAND) map is computed for the floodplain surface. HAND is a detrended, hydrologically enforced relative elevation surface in which the values represent the elevation difference between any given point in the landscape (black square) and the elevation of the entry point to the navigation channel (black circle) into which it flows (flow path as solid line). Next, $B$, inundation is defined at the point in which a given cell's relative elevation is exceeded by the stage of the navigation channel into which that cell flows. Knowing this relationship, $C$, inundation is modeled dynamically over any period of record by referencing the stage hydrograph of the navigation channel and summarizing attributes of inundation events defined by the relative elevation at which a cell is expected to become inundated (star and red line). Many inundation attributes may be computed and expressed spatially, including, $D$, measures describing duration, timing variability, and depth distributions across inundation events

3.1 Relationship between mean sedimentation rates in areas greater than 0.5 meters and areas greater than 1.0 meters for all transects in pools 4 and 8 . .95

3.2 Distribution of the standard deviation for the mean of each transect

4.1 A diagram of major processes within the LANDIS-II modelling platform. Forest successional processes, such as establishment, growth, competition, and succession are simulated by the core LANDIS-II model and the Biomass Succession extension (see text for details). Additional species and age-specific mortality occurs in response to various disturbances. In the Upper Mississippi River System floodplain, effects of flooding and insects were simulated for Habitat Needs Assessment II.

4.2 An example of the distribution of forest types based on land-cover data for a section of the Upper Mississippi River floodplain. Forest inventory (plot) data was randomly imputed into the cells of each like forest type to estimate the location of each species-age cohort across the landscape.

4.3 Example of the ecoregion/flood duration zone map for a portion of the Upper Mississippi River System. Areas with no data include permanently aquatic areas, areas outside of the Upper Mississippi River System floodplain, and areas in nonforest cover. Each flood duration zone is defined by the average duration of flooding that occurred during the growing seasons of 1972 to $2011 .$.

4.4 Probability of establishment coefficients used in LANDIS-II modelling for species typically considered highly flood tolerant (upper panel), flood tolerant (middle panel) and less flood tolerant (lower panel). Ecoregions were defined by 10-day increments of mean growing season flood inundation duration (fig. D-3). The last zone (70) consists of any flood duration lasting longer than 60 days.

4.5 User-supplied establishment coefficients (multipliers) as a function of an index of canopy closure (percent of ecoregion maximum biomass). The establishment of shade intolerant species (shade class 1 ) is reduced to 0 when a site reaches 20 percent or more of its maximum possible biomass. For shade tolerant species (shade class 4), establishment is reduced to 0 when a site reaches 80 percent or more of its maximum possible biomass (see table D-2 for Upper Mississippi River species shade tolerance classes)

4.6 Plots of age-biomass relationships for forest inventory data (dots) and simulated time-biomass relationships using the LANDIS-II Site Utility (see text for details). Species-specific parameters were developed by fitting the simulated results to the upper-bound of the plot-level estimates. 
4.7 Relationships between mean (plus or minus a standard deviation) predicted biomass from LANDIS-II Biomass Succession and biomass estimated from forest inventory plots. The $y$-axis is the estimated observed biomass from forest permanent plot data for individual species or groups of species (see text) within a given forest type and reach of the Upper Mississippi River System (see figure explanation). The $\mathrm{x}$-axis is the LANDIS-II simulated biomass for individual species or groups of species within a given forest type and reach of the Upper Mississippi River System.

4.8 Multiple logistic regression model results for mortality of three groups of species as a function of tree size (expressed here as age) and annual growing season flood inundation duration. More tolerant species generally have lower mortality rates for all flood durations and sizes. However, all species are generally more tolerant of inundation as they age.

\section{Tables}

1. The main objectives of this report reflect past and ongoing conceptual frameworks adopted by the Upper Mississippi River Restoration Program, recommendations from a previous habitat needs assessment, and the need for a broad-scale and quantitative approach to ecosystem management on the Upper Mississippi River System

2. Information needs identified in Habitat Needs Assessment-I. In most cases, data were developed to improve understanding and characterization of the river and floodplain hydrogeomorphic template. Information pertaining to improved species-habitat models was not pursued given a general shift in the focus of the Upper Mississippi River Restoration Program away from species-focused management and towards ecosystem management as well as the lack of data appropriate for developing species-habitat models

3. Datasets, indicators derived from datasets, and descriptions and sources for each dataset used in this report.

4. Essential ecosystem characteristics and related management and restoration objectives from the 2011 UMRS Ecosystem Restoration Objectives report. Indicators (quantification of specific objectives) and categories that address each objective within the context of resilience principles (see Section 2.5) are also listed

5. Criteria used to assign regions (polygons) to aquatic functional classes based on geographic information system-calculated metrics (metric definitions below) Area thresholds (those not a percentage) for depth, size, sill, and TPI are in hectares; fetch is in kilometers; econ is dimensionless (0-100; high values are more connected); and $\mathrm{Str}$ is the count of wingdams and closing dams. A full description of all metrics developed for the 2010 aquatic areas data set are provided in appendix 1

6. The floodplain vegetation community types used in the analysis of floodplain vegetation diversity, along with the plant species commonly found within each community type

7. Correlation coefficients quantifying associations between the area (hectare/river mile) in different floodplain functional classes in navigation pools of the Upper Mississippi River System and the area (hectare/river mile) in different floodplain vegetation types in navigation pools of the Upper Mississippi River System.

2.1 Five flood regime attributes, the definitions used to calculate them within the Upper Mississippi River System inundation model, and select studies demonstrating their ecological importance in driving patterns of floodplain vegetation. 
3.1 Names of transects surveyed in 2016 or 2017.

3.2 Mean sedimentation rate (centimeter per year) for areas greater than 0.5 meter deep along 24 transects in Pools 4 and 8 from 1997-2017

4.1 The species selected for LANDIS-II modelling on the Upper Mississippi River floodplain. Some rare species were grouped with other species (LANDIS-II symbol) in order to retain their local role in modifying forest succession. Y-intercepts, slopes, r-square values, and sample sizes (N) are for regression equations that relate the $\ln (\mathrm{dbh})$ to $\ln (\mathrm{age})$ for cored trees. For species without adequate sample sizes, 'like' species were used to generate relationships. Any species with identical regression equations were grouped to derive age based on diameter. Any species with identical LANDIS-II symbols were grouped for modeling purposes based on small sample size

4.2 Basic life history attributes relevant to forest simulation modelling on the UMRS

4.3 Final species-specific growth and mortality parameters..............................................111

4.4 Final species-specific growth and mortality parameters..............................................112 



\title{
Indicators of Ecosystem Structure and Function for the Upper Mississippi River System
}

\author{
By Nathan R. De Jager, James T. Rogala, Jason J. Rohweder, Molly Van Appledorn, Kristen L. Bouska, \\ Jeffrey N. Houser, Kathi Jo Jankowski
}

\section{Executive Summary}

This report documents the development of quantitative measures (indicators) of ecosystem structure and function for use in a Habitat Needs Assessment (HNA) for the Upper Mississippi River System (UMRS). HNAs are led periodically by the U.S. Army Corps of Engineers' Upper Mississippi River Restoration (UMRR) Program, which is the primary habitat restoration program on the UMRS. The UMRR Program helps determine how Federal, State and nongovernmental agencies can best address environmental issues on one of the world's largest and most diverse river systems. Each indicator in this report represents at least one management objective developed for the river system. These objectives were developed in a previous planning effort using an ecosystem management conceptual framework (USACE, 2011). The objectives represent five essential ecosystem characteristics: hydraulics and hydrology, biogeochemistry, geomorphology, habitat, and biota. Subsequent to the 2011 planning effort, the UMRR increased its focus on improving the health and resilience of the UMRS (Bouska et al. 2018). The indicators presented here are based on the five essential ecosystem characteristics and four aspects of ecosystems thought to support general ecosystem resilience (the ability of an ecosystem to adapt and respond to disturbances): (1) connectivity, (2) diversity and redundancy, (3) controlling variables, and (4) slow processes. Thus, we developed indicators that quantify both essential ecosystem characteristics and characteristics of a resilient river system. The indicators documented in this report focus on important aspects of river floodplain hydrogeomorphology, given the fundamental role hydrogeomorphology plays in determining habitat conditions and ecosystem health and resilience at broad geographic scales. The information contained within this report provides a broader scale (for example, systemwide) context for management decisions made at finer scales (for example, within river reaches or at project sites) and is designed for use in the formal system-wide Habitat Needs Assessment II (HNA-II) led by the UMRR Program.

\subsection{Methods}

Three primary datasets were generated from a broad combination of existing data, and the datasets were used to support the development of indicators of ecosystem structure and function for the Upper Mississippi and Illinois Rivers. These datasets include daily river-stage data from UMRS gages, an aquatic area geographic information system (GIS) dataset that characterizes aquatic hydrogeomorphic areas (such as deepwell-connected lentic areas, shallow-structured channel areas), and an inundation model that was used to map ecologically meaningful gradients in floodplain surface-water connectivity. In addition, two simulation modelling studies were done to better understand two slow processes: (1) the consequences of observed sedimentation rates on future water depth conditions in lentic areas and (2) the long-term (50 and 100 year) response of floodplain forest succession to temporal and spatial variability in flood inundation and an exotic invasive wood boring insect Agrilus planipennis (emerald ash borer). This report is a summarization of these efforts and, as such, utilizes only a small fraction of the information generated.

These datasets and others (such as land-cover data) were used to generate 13 indicators that characterize the following: connectivity (longitudinal aquatic, longitudinal floodplain, and lateral river floodplain), diversity and redundancy (general aquatic hydrogeomorphic areas, more specific lentic and lotic hydrogeomophic areas, aquatic vegetation, floodplain hydrogeomorphic areas, and floodplain vegetation), and controlling variables and slow processes (total suspended solids [TSS], water-surface elevation fluctuations, sedimentation in off-channel areas, and forest succession). Each indicator was quantified at the scale of the navigation pool (river/ floodplain reach between two locks and dams for impounded reaches and reaches of similar size in the undammed sections), and systemic data plots were used to summarize longitudinal gradients. Data were incorporated for multiple periods where available. These periods were typically the years 1989, 2000, and 2010. Finally, a hierarchical cluster analysis was applied to the 2010 data to synthesize results across multiple indicators and provide a better understanding of the basic structure and function of the river system. 


\subsection{Results}

Multivariate analyses done across all indicators for 2010 revealed six navigation pool clusters, along with one outlier (pool 15). The characteristics of these clusters were largely defined by navigation infrastructure differences (for example, locks and dams or levees) and other historical anthropogenic modifications that occurred within the river, floodplain, and Upper Mississippi River Basin (UMRB; for example, urban development and agricultural land uses). Upper impounded pools (pools $3-9,13$ ) were characterized by large amounts of deep lentic area, stable water levels, clear water conditions, and a floodplain that was highly connected to the river (few levees). These physical features reflect the construction of dams in the northern Upper Mississippi River (UMR) in the late 1930s and early 1940s, as well as an abundance of land in public ownership, and correspond with diverse aquatic and floodplain plant communities. Middle impounded pools (pools 10-12, 14, 16, 19) shared similarities with the upper impounded pools, but also had characteristics similar to lower impounded pools (pools 17, 18, 20-26). These characteristics included less lentic area, more structured channel area, reduced water clarity, and less river floodplain connectivity (more levees). These physical features reflect a combination of historical dam construction and use of channel training structures and levees, a larger watershed area contributing sediment, and far less aquatic vegetation than found in the northern reaches. Two stretches of open river downriver from pool 26 were characterized by the lack of dams (high degrees of longitudinal aquatic connectivity), reduced river floodplain connectivity (for example, more levees), a high amount of structured channel area, poor water clarity, and high waterlevel variability. Similar to the lower impounded pools, these river reaches lack aquatic vegetation. Because the floodplain of the UMRS widens from upriver to downriver, the lower impounded pools and open river reaches continue to maintain diverse floodplain hydrogeomorphic conditions and associated plant communities. However, the area supporting these features is much reduced from historical conditions given that much of the floodplain is now disconnected from the river by levees. The Illinois River consisted of two groups of navigation pools: the three upper-most pools, which are shorter and have a steep gradient; and the three lower pools, which are longer and have a shallower gradient. The lower pools contained more levees, larger open water (lentic) areas, and a wider and more diverse floodplain than the upper pools.

Temporal analyses done for individual indicators from the years 1989 to 2010 showed very minor changes in the basic structure of the UMRS. The only notable temporal changes were found in the upper impounded pools of the UMR, where increases in the abundance and diversity of aquatic vegetation communities since 1989 were associated with substantial improvements in water clarity in these reaches. In the lower UMR, there was an increase in the abundance of early successional cottonwood and willow communities, perhaps because the flood of 1993 created new land form features or resulted in agricultural land abandonment and succession to these communities. These changes in floodplain vegetation communities corresponded with an increase in the diversity of floodplain vegetation in those reaches.

Simulation modelling of sedimentation rates suggested that sedimentation in lentic areas may result in significant losses of deep lentic areas and increases in shallow lentic areas as backwaters fill in during the next 50 years. Projected changes due to sedimentation were greatest in the northern portion of the UMR (pools 3-11, 13), where the amount of deep lentic area in 2010 was greatest. Forest succession simulation modelling results indicated that early successional cottonwood communities should transition to more shade tolerant and longer-lived Acer saccharinum L. (silver maple) and oak-hickory (Quercus spp. and Carya spp.) forests across the entire river system within the next 50 years. Importantly, the distribution of forest cover does not appear to be at equilibrium with the modern hydrologic regime of the UMRS maintained by the navigation locks and dams. Across the entire river system, some areas that experience extended periods of inundation ( $>40$ days during the growing season) are projected to convert from forest cover to herbaceous communities during the next 50 to 100 years because of the lack of tree recruitment. Model simulation results indicated that between 0.5 and 3 percent of existing forest cover during the next 50 years and between 1 and 10 percent of exiting forest cover after 100 years would convert to herbaceous communities.

\subsection{Implications}

The information summarized in this report is intended for use in a formal HNA led by the UMRR Program. The indicators presented here can be used to evaluate differences across the river system. The summarization of information across multiple indicators could inform a more comprehensive management approach to the UMRR Program by considering a broader collection of ecosystem attributes. Overall, this report provides information that can be used to help to identify areas that have been highly impacted by navigation infrastructure, areas that differ with respect to availability and assortment of potential habitats, and areas projected to change during the next 50 to 100 years, thereby fostering a more strategic and quantitative approach to restoration and management on the UMRS. In addition, the data developed in support of this report provide the most comprehensive and scalable characterization of UMRS river and floodplain hydrogeomorphic areas to date (2010) and can be used in many aspects of river research, monitoring, and restoration. 


\section{Introduction to the Upper Mississippi River System and Upper Mississippi River Restoration Program}

The Upper Mississippi River System (UMRS) is a large, floodplain-river ecosystem, comprising a diverse mosaic of river channels, backwater lakes, floodplain forests, and emergent marshes (fig. 1). These features have been formed by a history of extreme spatial and temporal variability in hydrologic, hydraulic, and geomorphic conditions (Chen and Simmons, 1986; Fremling and others, 1989). These features formed the still-dynamic template upon which various biotic communities establish, interact with each other, and change through time. The interspersion of such a wide range of hydrogeomorphic conditions supports regionally unique sets of species and ecological functions. For example, the UMRS is known as a continentally important migratory corridor for both waterfowl and land birds (Beatty and others, 2015; Fink and others, 2010). The UMRS also contains diverse aquatic communities, some of which depend on flowing water (rheophilic species) and others that depend on more lentic conditions (limnophilic species) (Littlejohn and others, 1985). Both groups of species support important cultural, recreational, and commercial activities (Garvey and others, 2010; Schramm and Ickes, 2016). Similarly, a variety of plant communities are found in the UMRS, ranging from those uniquely adapted to frequent periods of inundation to those less tolerant of flooding (De Jager and others, 2015a). The UMRS floodplain contains both wetland and upland characteristics. The UMRS, like other large floodplain-river ecosystems, is a landscape mosaic of multiple ecosystem types, making it a nationally significant biodiversity hotspot.

In 1986, Congress passed the Water Resources Development Act of 1986 which designated the UMRS (which consists of the UMR and Illinois Rivers and several important tributaries; fig. 1) as both a nationally significant ecosystem and a nationally significant navigation system Navigation infrastructure and other anthropogenic influences have heavily modified the degree of spatial and temporal variability in hydrologic and geomorphic conditions in many areas of the river system. The most prominent changes arising from navigation infrastructure on the UMRS occur through much of the northern portion of the system (fig. 1). The navigation infrastructure creates large impounded areas and extensive off-channel aquatic areas (such as backwaters and lakes) because of locks and dams. These locks and dams also modify the seasonal flow regime and can act as barriers to fish migration. Throughout the system, the use of channel training structures constricts the main channel. In the southern portion of the river system, levees isolate the river from large portions of the floodplain (fig. 1). These structural modifications to the river floodplain template influence the spatial and temporal variability of water movement and a whole host of related ecosystem functions, habitats, and biotic communities. Given that the ecology of floodplain-river ecosystems is largely determined by hydrologic and geomorphic patterns, many restoration efforts have focused on attempting to restore various aspects of the UMRS river floodplain hydrogeomorphic template (Theiling and others, 2015).

The primary ecosystem management and restoration program on the UMRS is the Upper Mississippi River Restoration (UMRR) Program. Formerly known as the Environmental Management Program, the UMRR was first authorized by Section 1103 of the Water Resources Development Act (WRDA) of 1986 and later reauthorized in WRDA 1999. The program is a partnership among the five States that border the UMRS (Illinois, Iowa, Minnesota, Missouri, and Wisconsin) and five primary Federal agencies (U.S. Army Corps of Engineers [USACE], U.S. Department of Agriculture, U.S. Environmental Protection Agency, U.S. Fish and Wildlife Service, and U.S. Geological Survey). The UMRR Program consists of two major elements: Long Term Resource Monitoring (LTRM), which leads monitoring and science in support of river restoration and management; and Habitat Rehabilitation and Enhancement Projects, which restore critical habitat on the river and floodplain. The UMRR Program utilizes information gained from monitoring and research efforts to adaptively inform rehabilitation and enhancement projects. HNAs are done periodically by the UMRR Program as a requirement of its reauthorization in WRDA 1999 and as a way to determine how the program can best address UMRS environmental issues. This report was developed to support the UMRR's second HNA (HNA-II).

\subsection{Report Objectives, Approach, and Rationale}

This report's primary objective is to document the development of a set of quantitative measures (indicators) of ecosystem structure and function for use in the UMRR's HNA-II (table 1). We assembled or otherwise developed a series of datasets that characterize fundamental aspects of the UMRS including daily river-stage data, system-wide navigation infrastructure data, land-cover data, and newly developed maps of aquatic and floodplain hydrogeomorphic areas. These datasets were developed to facilitate a wide range of future research, monitoring, and restoration activities carried out through the UMRR Program. Specific to the UMRR's HNA-II effort, we derived indicators from these datasets that quantify a series of ecosystem-management based goals and objectives adopted by the program in 2011 (USACE, 2011). This report provides the information needed for the UMRR Program to develop a quantitative report card for stated restoration goals and objectives. 


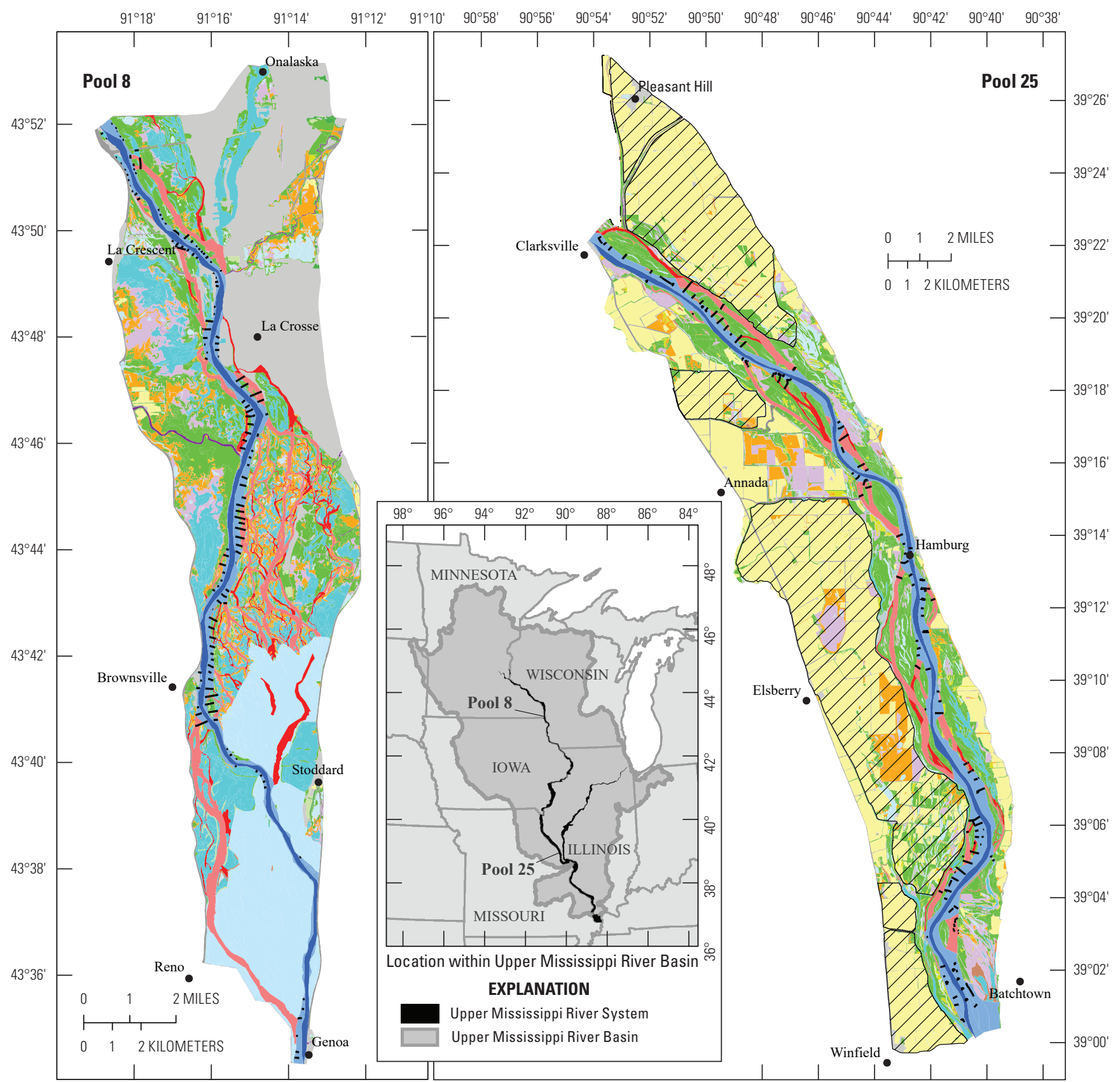

Base from U.S. Geological Survey digital data, 1:1,000,000, 2014, Universal Transverse Mercator projection, zone 15, North American Datum of 1983

\section{EXPLANATION}

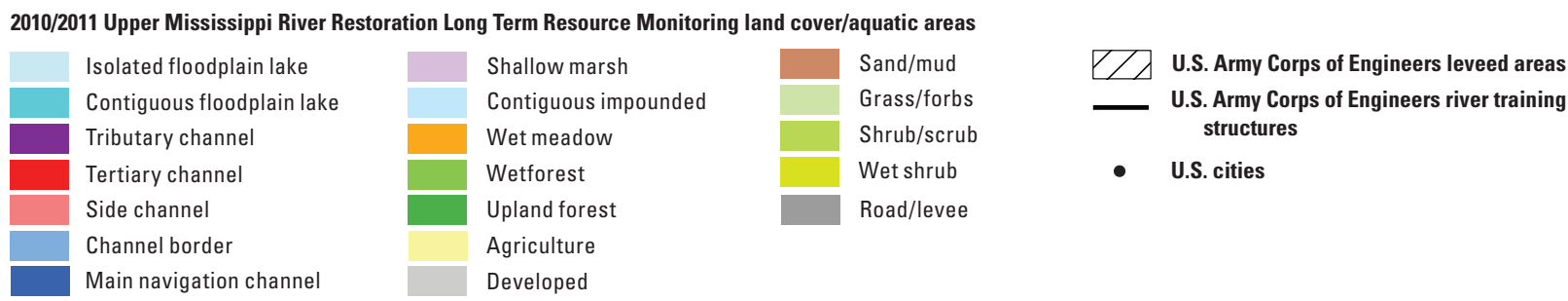

Figure 1. The information contained within this report covers the entire Upper Mississippi River System (inset). Data were developed to characterize the diversity of broad-scale hydrogeomorphic areas, including navigation infrastructure, for the year 2010 in a manner consistent with data developed for previous assessments. Navigation pools 8 and 25 are shown as examples of the mosaic of hydrogeomorphic areas, but also the impacts of navigation infrastructure (river-training structures and impounded areas in pool 8 and levees in pool 25). 
Table 1. The main objectives of this report reflect past and ongoing conceptual frameworks adopted by the Upper Mississippi River Restoration Program, recommendations from a previous habitat needs assessment, and the need for a broad-scale and quantitative approach to ecosystem management on the Upper Mississippi River System.

1. Provide a rationale for a Upper Mississippi River Restoration Program - based Habitat Needs Assessment that incorporates:

a. Goals and objectives for ecosystem-management.

b. Recommendations for improved hydrogeomorphic modelling and mapping from Habitat Needs Assessment-I.

c. Rules of thumb for maintaining or improving general ecosystem resilience such as

i. Managing connectivity.

ii. Maintaining diversity and redundancy.

iii. Managing controlling variables, slow processes, and feedbacks.

2. Document the methods and report the results of quantitative measures (indicators) that represent stated management goals and objectives for the Upper Mississippi River System.

a. Provide the information necessary for Upper Mississippu River Restoration to develop an ecosystem-integrity report card.

3. Investigate relations among individual indicators to better understand how management actions aimed at some indicators might impact other indicators.

4. Identify potential future trajectories of important lentic and floodplain habitats.

5. Synthesize results across multiple indicators to quantify the basic structure of the Upper Mississippi River System and identify similarities and differences across the river system.

a. Use inductive methods to identify potential management units within the river system.

6. Provided a general- and broad-scale (system or reach-wide) context for more specific management decisions made at finer scales (navigation pool or project site).

In addition to providing information about individual indicators, we investigated relations among various indicators using existing literature or new data analyses. These investigations were aimed at helping the UMRR Program better understand how management actions focused on some indicators could impact other indicators. We also performed two modelling studies to identify (1) potential future changes in water depth conditions in lentic areas resulting from sedimentation and (2) long-term responses of floodplain forests to variability in flooding and an exotic wood boring insect Agrilus planipennis (emerald ash borer). These studies provide a longer-term (50 and 100 year) context for decisions aimed at important lentic and floodplain habitats within the UMRS. Finally, we used inductive methods to synthesize results across multiple indicators. These analyses characterize the basic structure of the UMRS and identify areas that share similar ecosystem characteristics. In the remainder of this section, we outline the approach and rationale for the information contained within this report. Our approach included incorporating (1) recommendations from the UMRR's first HNA I (HNA-I), (2) ecosystemmanagement based goals and objectives adopted by the UMRR Program, (3) results and concepts from an ongoing ecosystem resilience assessment, and (4) hierarchy theory.

\subsection{Habitat Needs Assessment I}

HNA-I (Theiling and others, 2000) reflected the state of information, expertise, technology, and the prevailing concepts that informed restoration and management decisions within the UMRR Program at the time (species-focused management). HNA-I was based on the idea that habitat is defined by collections of structural, physical, and chemical conditions that often covary across the surface of river floodplains. The assessment relied on photo-interpreted delineations of broad hydrogeomorphic classes (such as main and side channels, backwater lakes, impounded areas, vegetation types, etc.; see fig. 1 for example). Such areas characterize differences in important components of riverine habitat including flow velocity, water exchange rates, substrate type, and vegetation composition and structure at relatively coarse scales (Wilcox, 1993). HNA-I assigned each hydrogeomorphic and vegetation class a rank score for potential occurrence of 289 bird species, 107 fish species, 30 species of freshwater mussels, 97 species of reptiles and amphibians, and 5 invertebrate guilds. As little empirical data existed for most of these taxa, HNA-I relied on expert opinion to rank each combination of hydrogeomorphic area and vegetation type for each species in order to map the 
potential habitat for a wide range of taxonomic groups. In addition, expert opinion was used to develop conceptual models to identify some potential future habitat distributions. The results of HNA-I demonstrated the challenges associated with trying to quantify habitat distributions in a species-rich system that contains a diverse array of hydraulic and geomorphic conditions, which covers such a broad geographic extent, and for which limited species-level empirical data are available. In response to these challenges, several recommendations were made for quantifying and modelling the broad range of physical, chemical, and structural attributes of the UMRS that define habitat (table 2).

In developing information for use in HNA-II, many of the recommendations in table 2 were accounted for, as was achieving some degree of comparability with data and results from HNA-I. For example, similar to HNA-I, this report utilizes information about the entire UMRS (fig. 1). Further, this report is also based on the idea that habitat is defined by collections of structural, physical, and chemical conditions that often covary across the UMRS surface. Also similar to methods used in HNA-I, this report utilizes photo-interpreted distribution maps of broad hydrogeomorphic classes (such as main and side channels, backwater lakes, impounded areas, and vegetation types). However, since HNA-I, the UMRR has developed additional information, expertise, and technology; and these advances were used to generate a more contemporary (2010) and more quantitative characterization of hydrogeomorphic conditions across the UMRS for HNA-II. Topobathy data (combined terrestrial elevation and bathymetry), gage data, river-training structure data, and GIS-derived connectivity indices were used to further characterize differences among and within the broad hydrogeomorphic classes described in the previous section (table 3). Metrics from these data were used to further identify hydrophysical differences among and within lotic and lentic areas. Enhancements to nonpermanently aquatic area coverages were also made using a floodplain surface-water connectivity model that quantified patterns of floodplain inundation (table 3), a key process related to the distribution of vegetation types and other biophysical patterns in the UMRS. Output from the model was used to develop a hydrogeomorphic classification for nonaquatic areas that captured important physical gradients believed to structure the floodplain. These enhanced lotic, lentic, and floodplain data layers provide a higher resolution hydrogeomorphic classification and a way to examine the relative quality of lentic, lotic, and floodplain habitats across the UMRS for a single period (2010).

In addition to developing information to represent the current (2010) structure and composition of the UMRS, two modeling studies were done to approximate future conditions in lentic and floodplain areas. In lentic areas, rates of sedimentation observed in UMRS backwater areas were used to project changes in lentic area depth during a 50-year period. On the floodplain, a forest succession model was developed to simulate the process of forest change in response to inundation and an invasive insect pest (emerald ash borer) through 50 and 100 years. Though these efforts do not capture the full range of habitats within the UMRS, they provide an approximation of how significant portions of the UMRS might change in the future.

Table 2. Information needs identified in Habitat Needs Assessment-I. In most cases, data were developed to improve understanding and characterization of the river and floodplain hydrogeomorphic template. Information pertaining to improved species-habitat models was not pursued given a general shift in the focus of the Upper Mississippi River Restoration Program away from species-focused management and towards ecosystem management as well as the lack of data appropriate for developing species-habitat models.

[HNA, Habitat Needs Assessment; *, data acquired or developed for the current assessment]

\begin{tabular}{ll}
\hline \multicolumn{1}{c}{ Information needs identified in HNA-I } & \multicolumn{1}{c}{ Examples } \\
\hline More detailed information to characterize river habitats & $\begin{array}{l}\text { System-wide topographic data.* } \\
\text { System-wide bathymetric data.* }\end{array}$ \\
& $\begin{array}{l}\text { System-wide numerical hydraulic model. } \\
\text { Substrate type characterization. }\end{array}$ \\
& $\begin{array}{l}\text { Floodplain inundation models.* } \\
\text { Floodplain geomorphic classification. }{ }^{*}\end{array}$ \\
Improved species-habitat models & $\begin{array}{l}\text { Data on presence and/or absence for species. } \\
\text { Development of refined life-history information. } \\
\text { Analysis of seasonal habitat availability and use. }\end{array}$ \\
More information and (or) better approach to representing & Habitat spatial structure metrics. \\
forest communities and model succession & Surveys of existing floodplain plant communities. ${ }^{*}$ \\
\hline
\end{tabular}


Table 3. Datasets, indicators derived from datasets, and descriptions and sources for each dataset used in this report.

[UMRS, Upper Mississippi River System; UMRR, Upper Mississippi River Restoration; LTRM, Long Term Resource Monitoring; HNA, Habitat Needs Assessment; GIS, geographic information system; USACE, U.S. Army Corps of Engineers]

\begin{tabular}{|c|c|c|c|c|}
\hline Dataset & Use/indicator & Description & Citation & Location (if available) \\
\hline \multirow[t]{6}{*}{$\begin{array}{l}\text { UMRS land cover/ } \\
\text { land use (1989, } \\
2000,2010)\end{array}$} & $\begin{array}{l}\text { Longitudinal flood- } \\
\text { plain connectivity }\end{array}$ & $\begin{array}{l}\text { Photo interpreted maps used } \\
\text { to measure area in natural } \\
\text { vegetation classes. }\end{array}$ & \multirow{2}{*}{$\begin{array}{l}\text { U.S. Army Corps of Engineers' Upper Mississippi River Restora- } \\
\text { tion (UMRR) Program Long Term Resource Monitoring (LTRM) } \\
\text { element. 1994, } 1989 \text { Land Cover/Use Data for the Upper Mis- } \\
\text { sissippi River System: La Crosse, Wis., https://doi.org/10.5066/ } \\
\text { F77M0771 }\end{array}$} & \multirow{2}{*}{$\begin{array}{l}\text { https://doi.org/10.5066/ } \\
\text { F77M0771 } \\
\text { https://doi.org/10.5066/ } \\
\text { F73X85X2 }\end{array}$} \\
\hline & $\begin{array}{l}\text { Lateral river flood- } \\
\text { plain connectivity }\end{array}$ & $\begin{array}{l}\text { Photo interpreted maps used to } \\
\text { measure open water area. }\end{array}$ & & \\
\hline & $\begin{array}{l}\text { Aquatic vegetation } \\
\text { diversity }\end{array}$ & $\begin{array}{l}\text { Photo interpreted maps used to } \\
\text { measure area within different } \\
\text { aquatic vegetation classes. }\end{array}$ & \multirow{2}{*}{$\begin{array}{l}\text { U.S. Army Corps of Engineers' Upper Mississippi River Restora- } \\
\text { tion (UMRR) Program Long Term Resource Monitoring (LTRM) } \\
\text { element. 2013, } 2000 \text { Land Cover/Use Data for the Upper Mis- } \\
\text { sissippi River System: La Crosse, Wis., https://doi.org/10.5066/ } \\
\text { F73X85X2 }\end{array}$} & \multirow[t]{4}{*}{$\begin{array}{l}\text { https://doi.org/10.5066/ } \\
\text { F77942QN }\end{array}$} \\
\hline & $\begin{array}{l}\text { Floodplain vegetation } \\
\text { diversity }\end{array}$ & $\begin{array}{l}\text { Photo interpreted maps used to } \\
\text { measure area within different }\end{array}$ & & \\
\hline & & floodplain vegetation classes. & \multirow{2}{*}{$\begin{array}{l}\text { U.S. Army Corps of Engineers' Upper Mississippi River Restoration } \\
\text { (UMRR) Program Long Term Resource Monitoring (LTRM) } \\
\text { element. 2014, UMRS LTRMP 2010/11 LCU Mapping: } \\
\text { La Crosse, Wis., https://doi.org/10.5066/F77942QN }\end{array}$} & \\
\hline & $\begin{array}{l}\text { Floodplain forest } \\
\text { succession model }\end{array}$ & $\begin{array}{l}\text { Photo interpreted maps used to } \\
\text { delineate the current distribu- } \\
\text { tion of primary forest types. }\end{array}$ & & \\
\hline \multirow[t]{7}{*}{$\begin{array}{l}\text { UMRS aquatic } \\
\text { areas }(1989, \\
\text { 2010) }\end{array}$} & \multirow[t]{5}{*}{ Aquatic area diversity } & \multirow[t]{5}{*}{$\begin{array}{l}\text { Photo interpreted maps used to } \\
\text { measure the area of different } \\
\text { general aquatic classes. }\end{array}$} & \multirow{3}{*}{$\begin{array}{l}\text { U.S. Army Corps of Engineers' Upper Mississippi River Restoration } \\
\text { (UMRR) Program Long Term Resource Monitoring (LTRM) ele- } \\
\text { ment. 1995, 1989-91 Aquatic Habitats - Upper Mississippi River } \\
\text { System : La Crosse, Wis., https://doi.org/10.5066/F7057F7H } \\
\text { U.S. Army Corps of Engineers' Upper Mississippi River Restora- } \\
\text { tion (UMRR) Program Long Term Resource Monitoring (LTRM) } \\
\text { element. 2016, UMRR HNA - II Aquatic Areas: La Crosse, Wis., } \\
\text { https://doi.org/10.5066/F7VD6WH8 }\end{array}$} & $\begin{array}{l}\text { https://doi.org/10.5066/ } \\
\text { F7057F7H } \\
\text { https://doi.org/10.5066/ } \\
\text { F7VD6WH8 }\end{array}$ \\
\hline & & & & $\begin{array}{l}\text { https://doi.org/10.5066/F7B- } \\
\text { K1BKQ }\end{array}$ \\
\hline & & & & \multirow{3}{*}{$\begin{array}{l}\text { https://doi.org/10.5066/F7Z- } \\
\text { 89BMP }\end{array}$} \\
\hline & & & $\begin{array}{l}\text { Program Long Term Resource Monitoring (LTRM) element. 2018, } \\
\text { 2010/11 Level } 2 \text { Aquatic Areas-Upper Mississippi River System: } \\
\text { U.S. Army Corps of Engineers' Upper Mississippi River Restora- } \\
\text { tion (UMRR) La Crosse, Wis., https://doi.org/10.5066/F7BK1BKQ }\end{array}$ & \\
\hline & & & $\begin{array}{l}\text { U.S. Army Corps of Engineers' Upper Mississippi River Restora- } \\
\text { tion (UMRR) Program Long Term Resource Monitoring (LTRM) } \\
\text { element. 2018, 2010/11 Level } 3 \text { Aquatic Areas-Upper Mississippi } \\
\text { River System: La Crosse, Wis., https://doi.org/10.5066/F7Z89BMP }\end{array}$ & \\
\hline & $\begin{array}{l}\text { Lentic functional } \\
\text { classes }\end{array}$ & $\begin{array}{l}\text { Attributes of depth and connec- } \\
\text { tivity used to delineate differ- } \\
\text { ent lentic areas in a GIS. }\end{array}$ & \multirow[t]{2}{*}{ Appendix 1} & \\
\hline & $\begin{array}{l}\text { Lotic functional } \\
\text { classes }\end{array}$ & $\begin{array}{l}\text { Attributes of depth and structure } \\
\text { used to delineate different lotic } \\
\text { areas in a GIS. }\end{array}$ & & \\
\hline
\end{tabular}


Table 3. Datasets, indicators derived from datasets, and descriptions and sources for each dataset used in this report.-Continued

[UMRS, Upper Mississippi River System; UMRR, Upper Mississippi River Restoration; LTRM, Long Term Resource Monitoring; HNA, Habitat Needs Assessment; GIS, geographic information system; USACE, U.S. Army Corps of Engineers]

\begin{tabular}{|c|c|c|c|c|}
\hline Dataset & Use/indicator & Description & Citation & Location (if available) \\
\hline \multirow[t]{2}{*}{$\begin{array}{l}\text { UMRS } \\
\text { surface-water } \\
\text { connectivity } \\
\text { model }\end{array}$} & $\begin{array}{l}\text { Floodplain functional } \\
\text { classes }\end{array}$ & $\begin{array}{l}\text { Integration of topo-bathymetric } \\
\text { data with river stage data to } \\
\text { map multiple attributes of } \\
\text { flood regime }\end{array}$ & $\begin{array}{l}\text { U.S. Army Corps of Engineers' Upper Mississippi River Restora- } \\
\text { tion (UMRR) Program Long Term Resource Monitoring (LTRM) } \\
\text { element. 2018, UMRS Floodplain Inundation Attributes: } \\
\text { La Crosse, Wis., https://doi.org/10.5066/F7VD6XRT }\end{array}$ & $\begin{array}{l}\text { https://doi.org/10.5066/ } \\
\text { F7VD6XRT }\end{array}$ \\
\hline & $\begin{array}{l}\text { Floodplain forest } \\
\text { succession model }\end{array}$ & $\begin{array}{l}\text { Annual maps of growing season } \\
\text { inundation duration }\end{array}$ & Appendix 3 & \\
\hline $\begin{array}{l}\text { UMRS topobathy } \\
\text { data }\end{array}$ & $\begin{array}{l}\text { Floodplain functional } \\
\text { classes }\end{array}$ & $\begin{array}{l}\text { Land surface elevation used to } \\
\text { estimate inundation statistics }\end{array}$ & $\begin{array}{l}\text { U.S. Army Corps of Engineers' Upper Mississippi River Restora- } \\
\text { tion (UMRR) Program Long Term Resource Monitoring (LTRM) } \\
\text { element. 2016, UMRR Topobathy: La Crosse, Wis., https://doi. } \\
\text { org/10.5066/F7057CZ3 }\end{array}$ & $\begin{array}{l}\text { https://doi.org/10.5066/ } \\
\text { F7057CZ3 }\end{array}$ \\
\hline $\begin{array}{l}\text { USACE forest } \\
\text { inventory data }\end{array}$ & $\begin{array}{l}\text { Floodplain forest } \\
\text { succession model }\end{array}$ & $\begin{array}{l}\text { Development of tree size-age } \\
\text { relationships, growth param- } \\
\text { eters, and age distributions for } \\
\text { primary tree species }\end{array}$ & Appendix 3 & \\
\hline $\begin{array}{l}\text { Post } 1993 \text { flood tree } \\
\text { mortality data }\end{array}$ & $\begin{array}{l}\text { Floodplain forest } \\
\text { succession model }\end{array}$ & $\begin{array}{l}\text { Development of flood inundation- } \\
\text { mortality relationships for } \\
\text { primary tree species. }\end{array}$ & Appendix 3 & \\
\hline $\begin{array}{l}\text { Total suspended } \\
\text { solids data }\end{array}$ & $\begin{array}{l}\text { Total suspended } \\
\text { solids concentrations }\end{array}$ & $\begin{array}{l}\text { Data used to estimate total sus- } \\
\text { pended solids concentrations at } \\
\text { locks and dams }\end{array}$ & $\begin{array}{l}\text { Lock and dam data provided by James Noren and Nicole Manasco } \\
\text { (USACE). LTRM data downloaded from LTRM online data- } \\
\text { browser }\end{array}$ & $\begin{array}{l}\text { https://www.umesc.usgs. } \\
\text { gov/ltrmp.html\#ltrmpdata }\end{array}$ \\
\hline \multirow[t]{3}{*}{ Gage data } & $\begin{array}{l}\text { Longitudinal aquatic } \\
\text { connectivity }\end{array}$ & $\begin{array}{l}\text { Daily riverstage data used to cal- } \\
\text { culate the percentage of annual } \\
\text { days that river stage exceeds } \\
\text { 'open river conditions' }\end{array}$ & $\begin{array}{l}\text { Additional data from Illinois River provided by M. Montenero, } \\
\text { M. Brey, B. Knights, T. Knox) } \\
\text { Michael Montenero, Marybeth Brey, Brent Knights, and Thomas }\end{array}$ & \multirow[t]{3}{*}{$\begin{array}{l}\text { rivergages.com } \\
\text { https://doi.org/10.5066/ } \\
\text { F7833R62 }\end{array}$} \\
\hline & $\begin{array}{l}\text { Water surface eleva- } \\
\text { tion fluctuations }\end{array}$ & $\begin{array}{l}\text { Daily river stage data used to cal- } \\
\text { culate mean annual maximum } \\
\text { growing season water surface } \\
\text { elevation fluctuations }\end{array}$ & $\begin{array}{l}\text { Nock, 2018, Assessing Techniques to Enhance Barrier Charac- } \\
\text { teristics of High-head Navigation Dams on the Upper Illinois } \\
\text { River: Data: U.S. Geological Survey data release, https://doi. } \\
\text { org/10.5066/F7833R62. }\end{array}$ & \\
\hline & $\begin{array}{l}\text { Floodplain functional } \\
\text { classes }\end{array}$ & $\begin{array}{l}\text { Daily river stage data used to } \\
\text { estimate inundation statistics }\end{array}$ & $\begin{array}{l}\text { Special thanks to Farley R. Haase (USACE, St Paul), Scott R. Pettis } \\
\text { (USACE, Rock Island), Donald L. Duncan (USACE, St Louis), } \\
\text { and Elizabeth A. Norrenberns (USACE, St Louis) for assistance } \\
\text { obtaining data from their respective districts }\end{array}$ & \\
\hline
\end{tabular}


Table 3. Datasets, indicators derived from datasets, and descriptions and sources for each dataset used in this report.-Continued

[UMRS, Upper Mississippi River System; UMRR, Upper Mississippi River Restoration; LTRM, Long Term Resource Monitoring; HNA, Habitat Needs Assessment; GIS, geographic information system; USACE, U.S. Army Corps of Engineers]

\begin{tabular}{|c|c|c|c|c|}
\hline Dataset & Use/indicator & Description & Citation & Location (if available) \\
\hline $\begin{array}{l}\text { Sedimentation } \\
\text { rates }\end{array}$ & $\begin{array}{l}\text { Sedimentation in } \\
\text { off-channel areas }\end{array}$ & $\begin{array}{l}\text { Repeated surveys of bed eleva- } \\
\text { tion along backwater transects } \\
\text { in Navigation Pools } 4 \text { and } 8\end{array}$ & Appendix 3 & \\
\hline $\begin{array}{l}\text { National levee } \\
\text { database }\end{array}$ & $\begin{array}{l}\text { Lateral river-flood- } \\
\text { plain connectivity }\end{array}$ & $\begin{array}{l}\text { Database of levees on the UMRS } \\
\text { used to measure area behind } \\
\text { levees }\end{array}$ & $\begin{array}{l}\text { National Levee Database, United States. Army. Corps of Engineers, } \\
\text { EP 1110-1-16, 2012-05 }\end{array}$ & $\begin{array}{l}\text { http://www.usace.army.mil/ } \\
\text { Missions/Civil-Works/ } \\
\text { Levee-Safety-Program/ } \\
\text { National-Levee-Database/ }\end{array}$ \\
\hline $\begin{array}{l}\text { River training } \\
\text { structures }\end{array}$ & $\begin{array}{l}\text { Lotic functional } \\
\text { classes }\end{array}$ & $\begin{array}{l}\text { Database of river training struc- } \\
\text { tures including groins, training } \\
\text { walls, revetments, and rip-rap } \\
\text { used to measure structure } \\
\text { within aquatic areas }\end{array}$ & $\begin{array}{l}\text { United States Army Corps of Engineers-Army Geospatial Center, } \\
\text { Inland Electronic Navigation Charts }\end{array}$ & $\begin{array}{l}\text { http://www.agc.army.mil// } \\
\text { Missions/Echarts/Prod- } \\
\text { uct-Downloads/ }\end{array}$ \\
\hline
\end{tabular}




\subsection{Ecosystem Management}

Large floodplain-river ecosystems have been described as endangered ecosystems (Ward and others, 1999) in need of ecosystem management (Sparks, 1995). These systems are large, complex, species-rich, and cross jurisdictional boundaries. The UMRS traverses five States and supports approximately 485 vertebrate species (USACE, 1992). Thus, restoration efforts require cooperation among agencies and across borders. No single management agency has the ability, authority, or funding to effectively manage the natural resources of the entire ecosystem. Other ecosystems share many of these features, and as a result, the concept of ecosystem management began to emerge in the United States during the 1970s and 1980s (Skillen, 2016).

Ecosystem management departs from species-focused management in that multiple aspects of ecosystem structure and function are considered valuable (Skillen, 2016). This conceptual framework recognizes that the functioning of the broader ecosystem is a prerequisite for sustaining any individual element or species within the ecosystem. Particular emphasis is placed on the ability of a system to maintain stability and persistence of several ecosystem components (such as species, communities, and habitats) as well as ecosystem functions (such as transfers of matter and energy) (Grumbine, 1994). Hence, individual elements of an ecosystem take on meaning in the ecosystem management concept not only because of their specific utility to any given stakeholder group, but also because of their role in supporting the stability and functioning of the system as a whole. Management actions typically need to occur at scales much broader than actions focused on a single species, and typically cross the jurisdictional boundaries of multiple management agencies. Thus ecosystem management often necessitates decision-making strategies that involve several agencies and stakeholders working together. The size, complexity, and sheer number of species moving across large floodplain-river ecosystems like the UMRS necessitates an ecosystem management approach (Sparks, 1995).

In 2011, the UMRR Program adopted a series of ecosystem-management based goals and objectives (USACE, 2011). We therefore developed information to address these stated goals and objectives. A consequence of taking an ecosystembased approach is that, unlike HNA-I, this report does not take a species-by-species approach to mapping habitat, but rather quantifies a series of essential ecosystem characteristics (EECs) that represent the goals and objectives for the UMRS. These goals and objectives were developed for the UMRS following a generic approach outlined by Harwell and others (1999). The approach outlined by Harwell and others (1999) is conceptually driven from the top-down by the societal goals for the integrity of multiple EECs and from the bottom-up by datasets and indicators developed to quantify stated goals and objectives (fig. 2). The EECs provide an interface between the scientists, who are developing datasets and quantitative measures (indicators) to diagnose the integrity of an ecosystem, and the key stakeholder groups and agencies, who are developing restoration and management goals and objectives. Ultimately, the approach can yield an ecosystem integrity report card. USACE (2011) identified five EECs that captured important river and floodplain components for the UMRS: hydraulics and hydrology, biogeochemistry, geomorphology, habitat, and biota. Management objectives were subsequently developed that pertain to each of these EECs (USACE, 2011). At the time however, quantitative datasets and indicators were not developed to support this previous effort, so quantitative assessment of the UMRS ecosystem has not yet been possible.

HNA-II builds on this previous effort by developing datasets and indicators for as many UMRS objectives as possible (table 4). Hence, this report is a quantification of the stated objectives of the UMRR Program (fig. 2). It is intended that future efforts will use the quantitative information provided here to help the UMRR Program more strategically implement restoration and management actions where they can be most impactful. In the following paragraphs, each EEC and the related management objectives are briefly explained.

Hydrology is the study of water distribution and amount, and hydraulics is the study of the energetics of water movement, including through a river network. For this EEC, data (table 3) and indicator (table 4) development focused on representing water-surface elevation fluctuations and the transfer of water, materials, and energy across the river floodplain transition zone (lateral connectivity). These indicators help quantify a general UMRS goal to manage a more natural hydrologic regime.

Biogeochemistry includes the biological, physical, and chemical processes that affect the cycling of chemical elements (such as carbon and nitrogen) and how they interact with living and nonliving things to impact ecosystems. For the UMRS, the broad biogeochemistry goal is to manage for processes that input, transform, assimilate, and output material within the UMR Basin, with emphasis on water quality, sediments, and nutrients. For the biogeochemistry EEC in this report, data (table 3 ) and indicator (table 4) development were focused on the fundamental role of TSS and how TSS influence a suite of other biotic and abiotic UMRS components.

Geomorphology is the collection of physical features, including topography and bathymetry, created by processes operating across the surface of the earth. For the UMRS, the general geomorphology goal developed is to manage for processes that shape a physically diverse and dynamic river floodplain system. Examples of data and indicators developed for geomorphic patterns include sedimentation in off-channel areas and the diversity of floodplain hydrogeomorphic areas. In addition, many of the indicators developed to understand geomorphic patterns play a large role in altering biogeochemical processes (De Jager and Houser, 2012). 


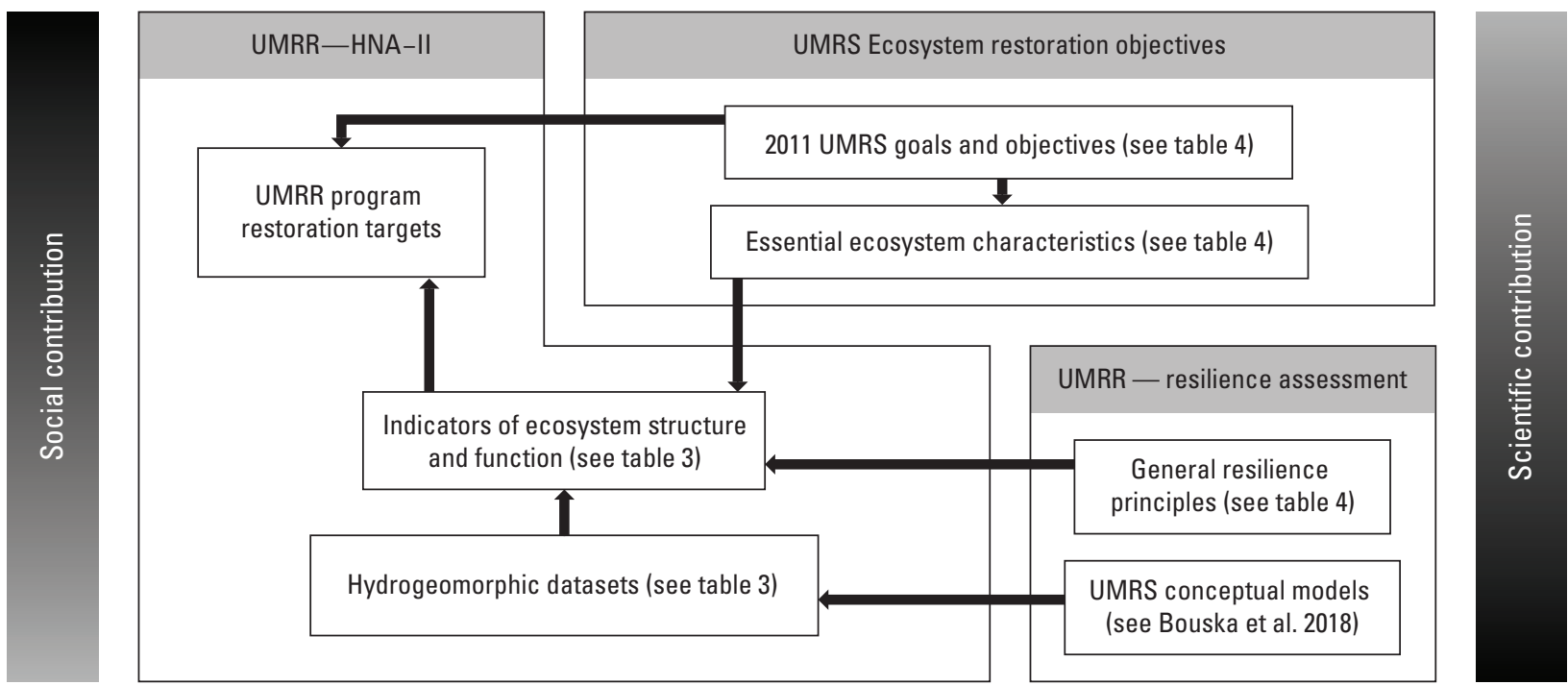

Figure 2. For the Upper Mississippi River Restoration Habitat Needs Assessment II (UMRR-HNA-II), datasets and indicators derived from those datasets were developed to quantify existing Upper Mississippi River System (UMRS) goals and objectives and related essential ecosystem characteristics. In addition, information from an ongoing resilience assessment was considered when developing data and indicators. The diagram is adapted from Harwell and others (1999) to illustrate the increasing contribution of society and stakeholders in the development of goals, objectives, and targets and the increasing contribution of scientific information in the development of data and indicators. This report summarizes efforts aimed at developing hydrogeomorphic datasets and indicators of ecosystem structure and function in support of Habitat Needs Assessment II.

Habitat is the suite of physical, chemical, and biological conditions that support a given organism, species, or community. As such, habitat can be thought of on a continuum from generic to specific. At a generic level, a river may be considered a habitat that supports riverine species. Within large floodplain-river ecosystems, lotic, lentic, and floodplain areas may each be considered separate habitats because each may correspond with different assemblages of organisms. Further variability within lotic, lentic, and floodplain areas may contribute to additional, local differences in species and community distributions. The broad habitat EEC goal established for the UMRS is to manage for a diverse and dynamic pattern of habitats to support native biota. Data (table 3 ) and indicator (table 4) development for this EEC therefore focused on distributions of hydrogeomorphic areas and vegetation types considered important to a broad range of species and communities that use the UMRS.

Finally, an identified biota goal for the UMRS was managing for viable populations of native species within diverse plant and animal communities. However, little system-wide data exist to quantify status or trends in population sizes for species that use the UMRS. Therefore, we focused attention on quantifying goals and objectives for which data allow a relatively accurate assessment, which did not include this EEC (table 4). Future efforts could be aimed at improving the availability and standardization of biotic data to better quantify this EEC for the UMRS.

\subsection{Ecosystem Resilience}

With the completion of the 2015-25 UMRR Strategic Plan (UMRR, 2015), the UMRR Program adopted an emphasis on the health and resilience of the UMRS. The concept of system health provides a useful metaphor for understanding the condition of large ecosystems and has been incorporated into previous assessments of the UMRS (Johnson and Hagerty, 2008). Concepts of ecological resilience have been developed during the last 30 years (Holling, 1973; Folke and others, 2004) and, within the last 10 years, have been increasingly emphasized within natural resource management practices. The UMRR is currently leading a resilience assessment of the UMRS (Bouska et al. 2018), and the concepts developed in the initial stages of that assessment have informed the structure of this report.

Resilience is the capacity of a system to absorb disturbance and reorganize so as to retain essentially the same function, structure, and feedbacks-to have the same identity (Walker and Salt 2012). A resilience perspective is based on the basic idea that ecosystems are self-organizing (Walker and Salt, 2012) and will respond and adapt to disturbances and management actions. Within limits, such systems can absorb shocks and disturbances (such as invasive species, large wind or flood events, and pest outbreaks) and maintain their basic functions and identity. Those functions and that identity are sustained by internal interactions and feedbacks 
Table 4. Essential ecosystem characteristics and related management and restoration objectives from the 2011 UMRS Ecosystem Restoration Objectives report. Indicators (quantification of specific objectives) and categories that address each objective within the context of resilience principles (see Section 2.5) are also listed.

[NA, does not apply]

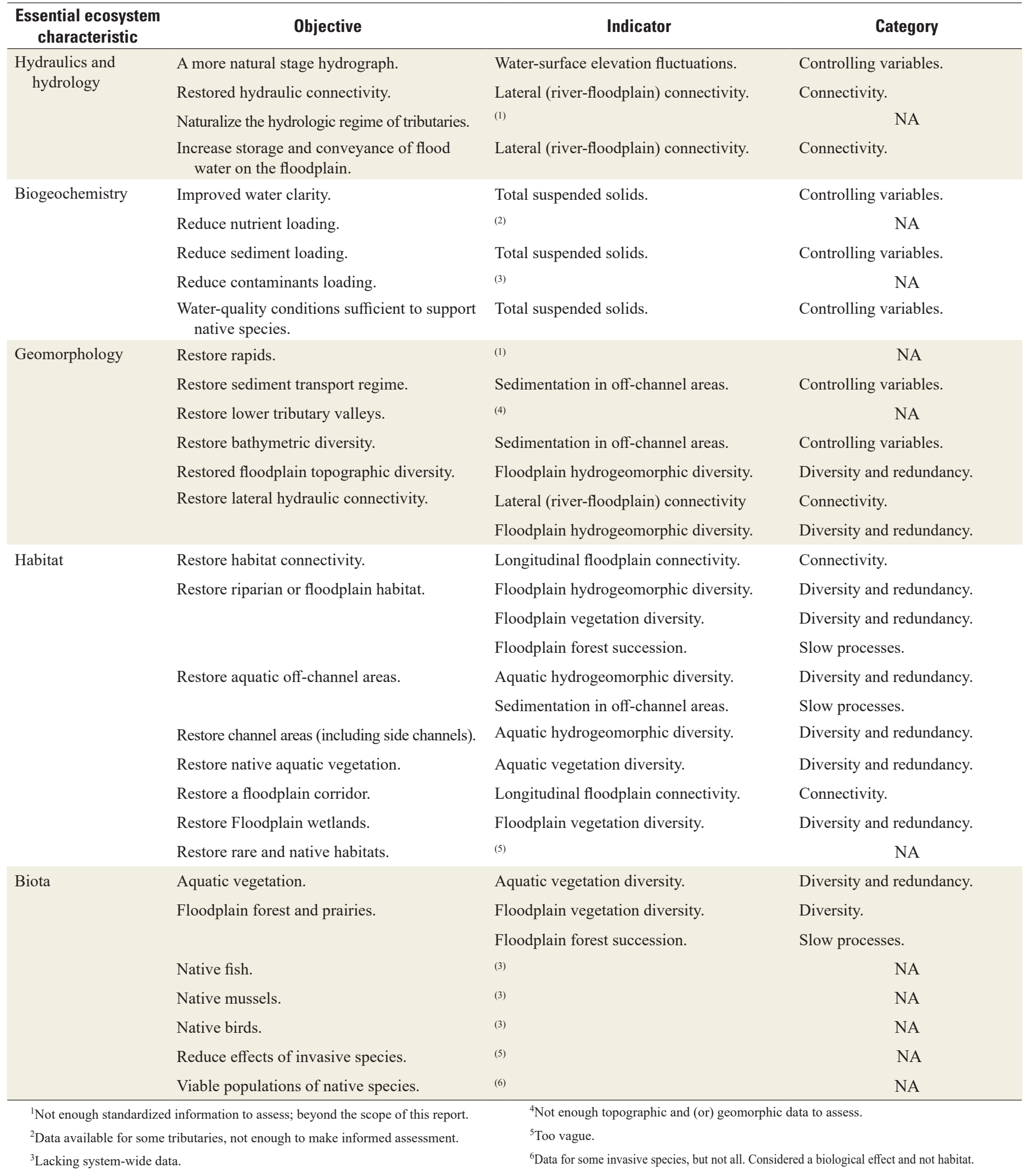


among various components of the system. However, when a disturbance pushes an ecosystem past a threshold, it may change rapidly and transition into a new state. A system's resilience is essentially how likely it is to move to a new state as the result of disturbance (or management action). Resilience has been described as having two aspects: general resilience and specified resilience. General resilience emphasizes how much a system is likely to be changed by disturbances both expected (things that have happened before) and novel (new disturbances). Specified resilience emphasizes understanding where important thresholds are for major system controlling variables and where the current values of those controlling variables are relative to those thresholds. Thus, a system's likelihood of being pushed to a new state is a function of both specified resilience (where the thresholds are relative to where the system is) and general resilience (how far the system is likely to move in response to a disturbance or management action).

The first step of the resilience assessment of the UMRS was to assemble a description of the ecosystem. An important objective of the system description was to develop conceptual models of the structure and function of the river that identified "the minimum but sufficient information needed to effectively manage the system for the values held important" (Walker and Salt, 2012). The conceptual models developed as part of that effort described the UMRS as being composed of three interacting subsystems (lotic channels, lentic off-channel areas, and floodplains) and identified key controlling variables, interactions, and feedbacks that influence the resilience of each subsystem and the UMRS as a whole (Bouska and others, 2018). Data development for HNA-II utilized these conceptual models by identifying important variables to model and map lentic, lotic, and floodplain functional areas (fig. 2).

The resilience assessment has also developed indicators of general resilience of the UMRS (Bouska et al. written commun., 2018). Rather than a single quantitative entity, general resilience is currently viewed as a collection of rules of thumb, or principles, regarding factors that contribute to the ability of an ecosystem to adapt and respond to disturbance (O'Connell and others, 2015; Biggs and others, 2012. The most relevant of those rules of thumb for this assessment include (1) managing connectivity, (2) maintaining diversity and redundancy, (3) managing controlling variables, and (4) doing these activities within the context of long-term successional processes (Biggs and others, 2012). Connectivity describes the interactions between different ecosystem components (such as populations or hydrogeomorphic patches) and the ability of the system to exchange materials and energy resources within its boundaries. Connectivity among different life-stage habitats is often critical to maintain viable and productive populations. However, too much connectivity in a system can facilitate the spread of disturbances (such as disease, invasive species, or pollutants) or erosive forces (such as wind fetch), but excessive fragmentation can limit recolonization following a disturbance. Diversity and redundancy of biological communities and the physical environment provide a wide range of options for responding to disturbances and adapting to slow successional changes. Controlling variables that are coupled with processes that change slowly (such as succession) can strongly influence the underlying structure of a system (Biggs and others, 2012). Discharge and sediment regimes are examples of controlling variables in river systems that strongly interact with vegetation to influence channel morphology, hydraulics, and related habitat distributions. For this report, indicators that quantify stated ecosystem goals and objectives were placed into categories reflecting four components of general resilience: connectivity, diversity and redundancy, controlling variables, and slow processes (fig. 2; table 4). Beyond these principles of general resilience that directly apply to the river floodplain ecosystem itself, larger social-ecological system characteristics also contribute system resilience. These characteristics include understanding the larger social-ecological system as a complex adaptive system, encouraging learning and experimentation, broadening stakeholder and public participation, and promoting polycentric governance systems (Biggs and others, 2012). These aspects of social-ecological systems are beyond the scope of the current resilience and HNAs.

\subsection{Merging Previous Efforts and Concepts to Form an Approach}

The datasets and indicators developed in support of HNA-II integrate existing UMRS goals and objectives, EECs, conceptual models from the resilience assessment system description, and general resilience principles (fig. 2). Figure 2 is modified from Harwell and others (1999) but is consistent with the basic approach of developing an ecosystem integrity report card. From the top-down, the goals and objectives for the UMRS describe a broad vision of what is important about the UMRS. The EECs step this information down and provide an interface between the public and scientists who are developing data and indicators that quantify the ecosystem's overall integrity (this report; fig. 2). With the addition of resiliencebased conceptual models and general resilience principles, the data and indicators further allow for an evaluation of the general resilience of the UMRS. This information could later be used in combination with the goals and objectives of the UMRR Program to prioritize areas for management actions (not included in this report).

Finally, information was compiled for this document at the maximum spatial extent of the UMRS river and floodplain and at the resolution of individual navigation pools (the area between two dams), plus two geomorphically distinct river reaches in the open river (undammed part of the UMR). In the UMR, the navigation pools are numbered in increasing sequence from north (upriver) to south (downriver). Our analysis extended from navigation pool 3 (p03) as its most upriver navigation pool through the two open river reaches (or1 and or2) to the Mississippi River's junction with the Ohio River at Cairo, Illinois (fig. 1). For the Illinois River, we assembled data for the following named navigation pools: Dresden (dre), 
Marseilles (mar), Starved Rock (sta), Peoria (peo), La Grange (lag), and Alton (alt). For all geospatial analyses, the spatial extent of the river and floodplain were standardized to facilitate comparison through time. For most datasets, we were able to attain information for at least two time periods (c. 1989 and 2010), but for others we were able to also attain information for the year 2000. The navigation-pool scale tends to correspond with the ecosystem and landscape levels of biological organization (fig. 3). At these scales and levels of organization, the goal of our assessment was to quantify aspects of the river floodplain landscape mosaic, important processes impacting it, and the consequences for ecosystem and landscape-level habitat availability, diversity, and resilience. One reason for focusing on broader spatio-temporal scales is the lack of speciesand community-level data for organisms that use or travel through the UMRS. With the exception of fisheries and aquatic vegetation data collected by the UMRR-LTRM in select pools, it is simply not possible to quantify the abundance and distribution of different biota identified by the goals and objectives of the UMRS (table 4). Instead, this report considers the broad-scale distribution of different physical, hydrological, and biological conditions and how they shape the UMRS landscape mosaic. The indicators developed quantify as many existing UMRS goals and objectives as possible given the availability of data and focus on three different components of general resilience within the UMRS (table 4).

Thus, this report builds on (1) lessons learned through the HNA-I, including the focus on habitat for specific species that was part of HNA-I; (2) UMRS management objectives derived from the application of an ecosystem-management perspective to the condition of and expectations for the UMRS; and (3) the initial results of an ongoing resilience assessment of the UMRS.
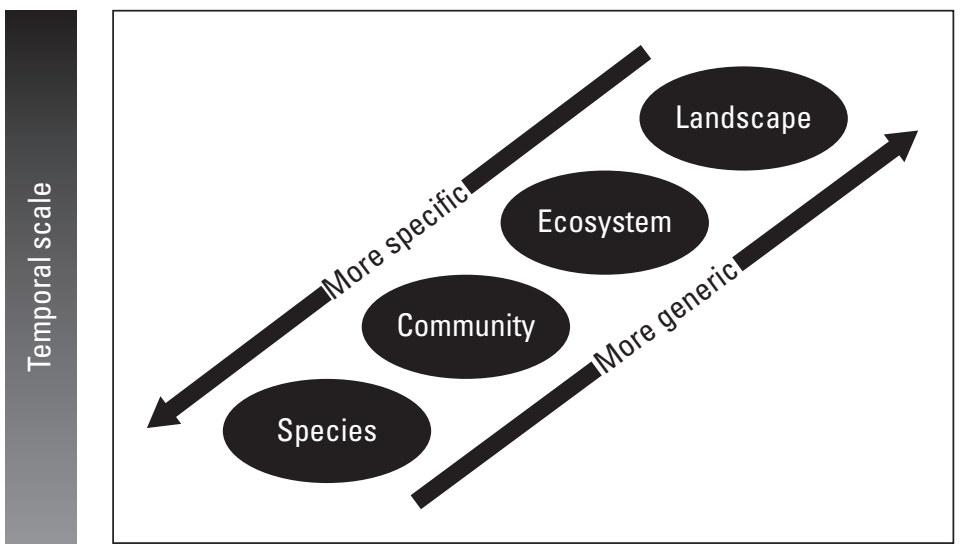

Spatial scale

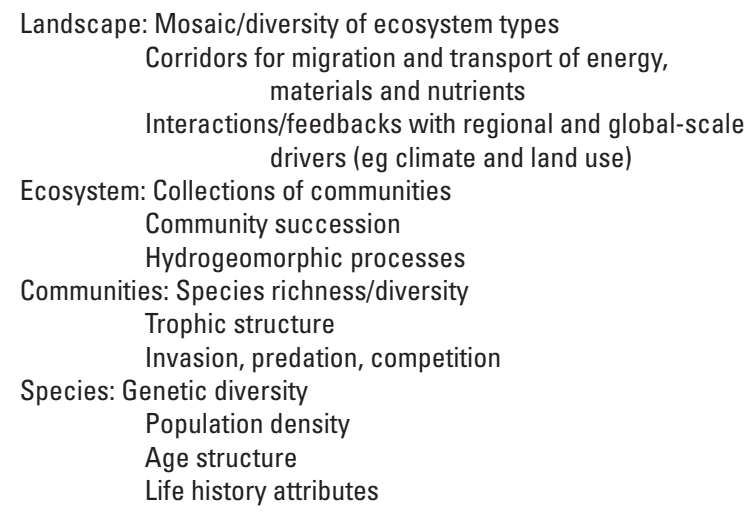
materials and nutrients

Figure 3. A generalization of the relations among spatial and temporal scales and different levels of biological organization (adapted from Harwell and others, 1999). At fine spatial and temporal scales, very specific information can be collected to quantify the density, age structure, life-history attributes, and genetic diversity of individual species. At a broader scale, data can be collected to evaluate the diversity and trophic structure of communities (made up of different species), along with processes such as invasion, predation, and competition among species. At even broader and more generalizable scales, data can be collected to characterize collections of communities and processes that operate on communities and species (such as succession and hydrogeomorphic change). Finally, at the broadest scales, landscape are collections of species, communities, and ecosystem types. For this report, data and indicators were developed to assess the Upper Mississippi River System at the ecosystem and landscape levels of biological organization. 


\section{Indicators of Ecosystem Structure and Function}

In this section we briefly describe the methods, results, and discuss some of the implications of our findings for a series of indicators of ecosystem structure and function for the UMRS. The indicators are grouped into four categories, relating to principles of promoting general ecosystem resilience (1) managing connectivity, (2) maintaining diversity and redundancy, (3) managing controlling variables, and (4) doing these activities within the context of long-term successional processes (Biggs and others, 2012).

\subsection{Connectivity}

Connectivity indicators quantify how organisms moving through the UMRS can access a wide range of conditions. Connectivity indicators also quantify the transport of materials and energy moving downriver and across the river floodplain transition zone via water movement. We quantified three indicators of connectivity relevant to the UMRS. The first two indicators characterize aspects of longitudinal connectivity, or the upriver-downriver exchange of organisms and resources (Ward, 1989), and the third indicator characterizes the potential for lateral movement of water across the river floodplain transition zone.

\subsubsection{Longitudinal Aquatic Connectivity}

\section{Brief Methods}

Longitudinal aquatic connectivity was quantified as the average percentage of days that dams were in open river conditions annually for each UMRS navigation pool. Open river conditions happen when all dam gates either are lifted out of the water or lowered to the bottom, allowing for potentially unobstructed water flow and the movement of long-distance migratory fish species both upriver and downriver. We calculated the annual number of days in which the gage discharge or stage at each lock and dam exceeded open river conditions identified in USACE lock and dam operating manuals for the periods 1985-94 and 2006-15. The periods covered in these manuals match the 1989 and 2010 datasets developed for other indicators. We expressed these values as percent annual days for each year and calculated averages within each period. If no downriver lock and dam was present (such as downriver from St. Louis), longitudinal connectivity was assumed to be 100 percent.

\section{Brief Results and Discussion}

The percentage of annual days that the downriver dams of the UMRS were in open river conditions ranged from 100 percent in the open river (undammed) reaches to near 0 percent at important pinch-points where longitudinal migration may be inhibited (such as navigation pools 2, 5, 14, and 19 in the UMR and pools dre, mar, and sta of the Illinois River; fig. 4). The longitudinal pattern in open river days reflects the construction of locks and dams on the UMRS and how particular dams are operated. Lock and dam 19 is a hydropower dam with relatively high head even in open river conditions and serves as an important pinch-point in the UMRS. In the undammed reaches of the river, where absence of locks and dams suggest high longitudinal connectivity, there is interest in understanding whether wing dikes obstruct fish movement along channel margins. In a few pools, the percentage of annual days in open river conditions was slightly higher during 2006-15 than during 1985-94, likely reflecting increased peak discharge conditions during the $2006-15$ period (fig. 4). Locks and dams with fewer open days represent more significant barriers to upriver migration. Recent evidence suggests that upriver fish movement is reduced when the gates on the UMRS are regulating flow (Tripp and others, 2014), and such regulation may limit access to life stage-specific habitat requirements. Finally, mussels that rely on migratory host fish have experienced declines in their spatial distribution as a result of limited longitudinal connectivity (Kelner and Sietman, 2000). On the other hand, longitudinal connectivity may increase the likelihood that invasive species will establish a presence in an area. For example, reproducing Asian carp (Hypophthalmichthys spp.) have been documented as far upriver as pool 16 (Larson and others, 2017).

\subsubsection{Longitudinal Floodplain Connectivity}

\section{Brief Methods}

Longitudinal floodplain connectivity was quantified as the area (hectare) per linear river mile of the floodplain within each UMRS navigation pool that was in natural vegetation (for example, undeveloped and not in agricultural production) for the years 1989, 2000, and 2010. Natural vegetation provides habitat and a migratory corridor for many floodplain species, such as migrant birds and mobile animals, as well as insects, reptiles and amphibian species. Excessive fragmentation of natural vegetation by anthropogenic land-cover types (such as agriculture and development) may inhibit the movement of migratory species across the UMRS, as suggested by patch dynamics theory (Pickett and White, 1985). Land cover and land use datasets for the years 1989, 2000, and 2010 (table 3 ) were used to quantify longitudinal floodplain connectivity by dividing the total natural vegetation area by the length of each navigation pool. The index provides a first approximation of broad-scale constraints on many riverine functions and restoration options. 


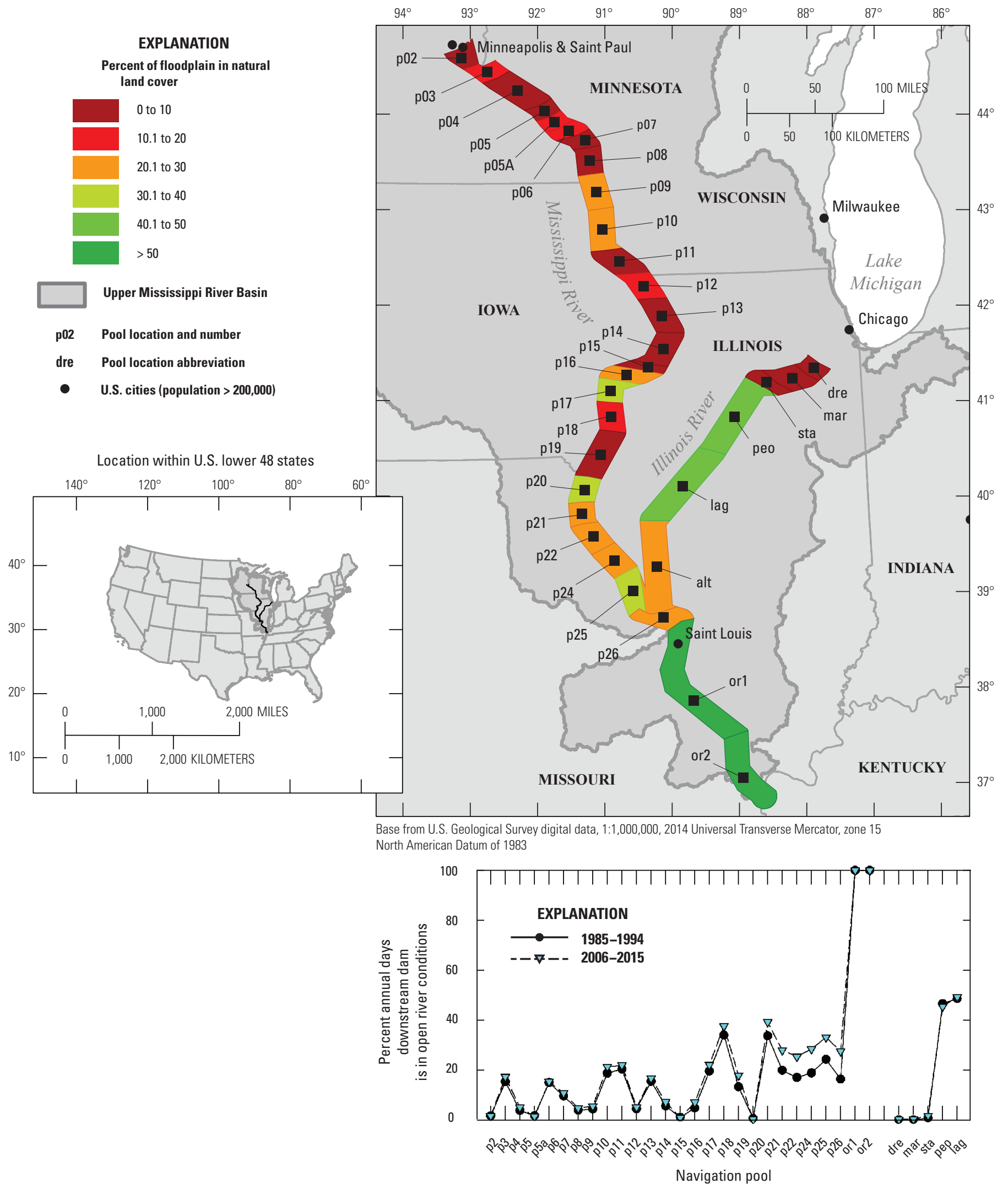

Figure 4. The percentage of annual days that downriver dams on the Upper Mississippi River System were in open river conditions from 1985-94 and from 2006-15 was used to quantify longitudinal aquatic connectivity (for example, the ability of some organisms to longitudinally traverse the Upper Mississippi River System). 


\section{Brief Results and Discussion}

The floodplain area within UMRS navigation pools in natural vegetation (for example, nondeveloped, nonagricultural areas) ranged from 25 to 75 hectare per linear river mile in heavily developed pools (such as pool 15 and pool dre) to nearly 400 hectare per linear river mile in pools with more natural land cover (such as pool 13) (fig. 5). Across the river system, most navigation pools support more than 200 hectare per linear river mile of natural land cover, despite large differences in total floodplain area (fig. 5). In the lower UMR and Illinois River, the total floodplain (including anthropogenic land-cover classes) increases substantially. Hence, natural vegetation makes up a much larger proportion of the floodplain in the northern pools of the UMRS relative to the lower pools, despite similar estimates of the total area of natural land cover. This longitudinal pattern in the relative abundance of natural vegetation reflects a complex history of policies and actions related to land use and commercial navigation on the UMRS. In the lower portion of the river system, a broad floodplain has been largely disconnected from the Mississippi River due an extensive system of levees (see section 3.1.3 Lateral River Floodplain Connectivity), allowing for additional agricultural and urban development in areas that would otherwise be prone to flood inundation and hence more likely to be in natural land cover. In contrast, the upper portions of the Mississippi River are largely in Federal ownership and managed for fish and wildlife habitat, lack significant levee development, and continue to support a higher proportion of natural land cover.

Only minor differences were observed among the 1989, 2000, and 2010 datasets, and these differences may reflect a previously reported reduction in agricultural land cover in 2010 and increase in natural vegetation cover for some navigation pools in the lower portion of the UMRS (De Jager and Rohweder, 2017). However, such changes through time were minor relative to the stronger spatial differences across the river system.

\subsubsection{Lateral River Floodplain Connectivity}

\section{Brief Methods}

The third indicator of connectivity described the potential for lateral movement of water across the floodplain by calculating the area of navigation pools in open water area and the area behind levees (disconnected floodplain). Land cover and land use datasets for the years 1989 and 2010, along with levee areas from the National Inventory of Dams (table 3), were used to quantify the effects of floodplain infrastructure on lateral river floodplain connectivity. The proportion of open water and disconnected floodplain areas provide indices of potentially overconnected conditions resulting from lock and dam construction. Levee datasets were used to quantify how much of the floodplain is potentially isolated from the river by levees.

\section{Brief Results and Discussion}

The area of navigation pools in permanently open water ranged from approximately 431 hectare per linear river mile in pools with large expanses of open water (for example impounded areas) in the northern UMRS to approximately 76 hectare per linear river mile in the highly constricted open river reaches of the UMRS (fig. 6). Higher values may reflect overconnected conditions resulting from the impoundment by locks and dams. Lower values may reflect underconnected conditions resulting from river-training structures, such as wing dams and closing structures. Large expanses of open water contribute to the long distances across which waves can build (wind fetch) in the impounded reaches of the UMRS. Wind fetch, in turn, contributes to higher levels of turbidity and reduced water clarity (Owens and Crumpton, 1995). Wind fetch also increases erosion of small islands and shallow water areas (West Consultants Inc., 2000), leading to an overall homogenization of UMRS topography. On the other hand, large open-water areas that support aquatic vegetation may be the preferred habitat for some migratory waterfowl (such as Aythya valisineria [canvasback ducks]; Korschgen, 1989).

The area of navigation pools behind levees ranged from 0 hectare per linear river mile in many of the northern UMRS pools to 1000 hectare per linear river mile in some of the lower UMRS reaches (fig. 6). The strong increase in leveed areas in the lower UMRS and lower Illinois River can help explain the reduced amount of natural land cover in those reaches relative to total floodplain area (see section 3.1.2 Longitudinal Floodplain Connectivity). Some consequences of reduced river floodplain connectivity include: reduced capture of sediments and nutrients by the floodplain and a concomitant increase in the delivery of sediments and nutrients to downriver areas (such as the Gulf of Mexico); reduced access to critical spawning, nursery, foraging, and refuge habitats for some fish species; and loss of floodplain habitat to agricultural land cover and urban development behind levees (Opperman and others, 2010; Galat and others, 1998). 



Figure 5. The hectares per river mile within the navigation pools of the Upper Mississippi River System that are in vegetation classes not associated with direct anthropogenic impacts (for example, nondeveloped and nonagricultural areas) for the years 1989, 2000, and 2010 is shown in the lower panel. Also shown in the lower panel is the total floodplain area (including all cover types) for Upper Mississippi River System navigation pools. The map displays the proportion of total floodplain area in natural land-cover types for each navigation pool (pool widths not to scale). These data were used to quantify longitudinal floodplain connectivity (the ability of organisms to longitudinally traverse the Upper Mississippi River System floodplain). 


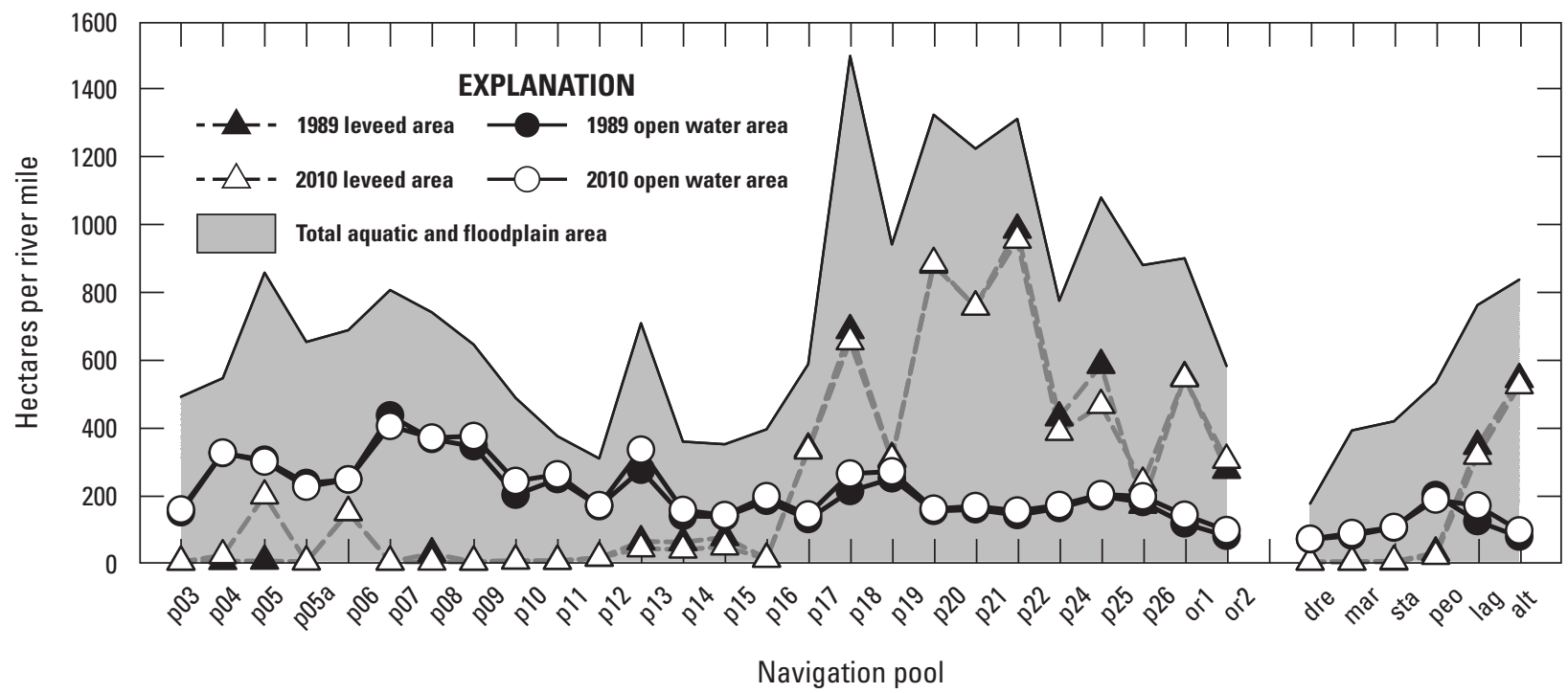

Figure 6. The hectares per river mile for navigation pools of the Upper Mississippi River System in open water and behind Federal levees for the years 1989 and 2010. Also shown is the hectares per river mile for the total navigation pool area. These data were used to quantify patterns of lateral river floodplain connectivity (for example, ability of water, energy, nutrients, and organisms to mover laterally across the river floodplain template).

\subsection{Diversity and Redundancy}

Diversity and redundancy in a system provides options and insurance for responding and adapting to change and disturbances. In rivers, the diversity of hydrogeomorphic features provides asynchronous conditions (McCluney and others, 2014) that in turn promotes diversity and redundancy in associated biological populations and functional attributes. Such diversity further supports persistent delivery of ecosystem services, such as harvestable fish communities and recreational opportunities (Oliver and others, 2010; Schindler and others, 2010). Vegetation diversity is also important in river floodplain systems as many communities rely on different vegetation types for food and cover. Indicator development for this report therefore focused on measures of diversity relevant to habitat conditions along the UMRS including aquatic and floodplain hydrogeomorphic areas and aquatic and floodplain vegetation types.

\subsubsection{Aquatic Areas and Functional Classes}

\section{Brief Method}

The importance of resource diversity across time and space for supporting and maintaining species diversity has long been recognized (Hutchinson, 1961; Cardinale and others, 2012). In the same way, habitat heterogeneity and asynchrony across space and time can provide species with a portfolio of options to buffer against local-scale shifts in habitat availability or conditions (Schindler and others, 2015). Floodplain-river ecosystems are especially well known for their shifting habitat mosaic (Stanford and others, 2005). Local scale variation in habitat availability in floodplain-river ecosystems such as the UMRS is often buffered by the availability of habitat at broader scales (Whited and others, 2007), which can confer stability to mobile organisms as long as those habitats are accessible. Given the dynamic nature of floodplain-river ecosystems, however, habitats can be challenging to classify in a way that is robust to management and conservation needs but accounts for this inherent variability.

The diverse habitat mosaic of the UMRS has long been appreciated, and there have been a series of efforts to classify and map aquatic patches (Sternberg, 1971, Wilcox, 1993). This report classifies the diverse UMRS habitats in a more quantitative way than was previously possible (see Wilcox, 1993) and in a way that recognizes the importance of how hydrogeomorphic features control habitat dynamics across space and time. For this assessment, a hierarchical classification of aquatic hydrogeomorphic areas and functional classes was developed based on large-to-fine scale physical characteristics known to influence species distributions in rivers.

First, at the large-scale level, primary river features were delineated. This first level of classification was primarily based on visually delineating land-water boundaries from 2010 system-wide aerial photography and following rules to delineate the primary river features using methods that were consistent with UMRS aquatic areas developed in 1989 (Wilcox, 1993; appendix 1). This classification included broadly defined aquatic area types such as main channel, side channel, etc. (fig. 7). Second, newly available bathymetric and landcover data were used to more quantitatively distinguish these broad scale aquatic areas. For example, this second classification level included redefining the continuous impounded area 

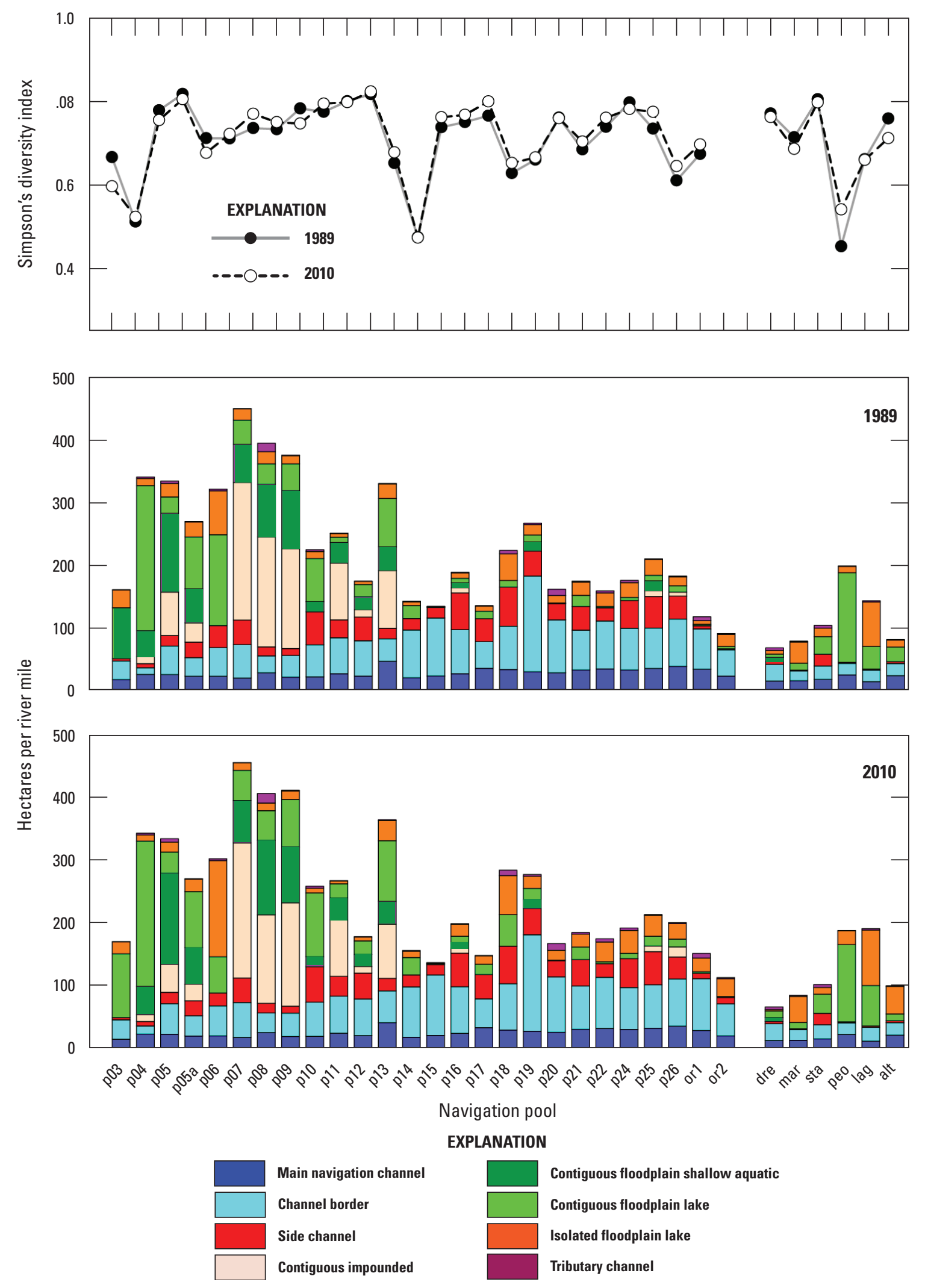

Figure 7. The hectares per river mile of each general aquatic area within each navigation pool of the Upper Mississippi River System for 1989 (middle panel) and 2010 (lower panel), along with Simpson's diversity index derived from the data (top panel). 
class from the first level into side channel and contiguous floodplain lake habitat based on bathymetric and aquatic vegetation features. This second classification level was only used to generate the third level of classification; no patterns in the second level are reported here.

Third, finer-scale functional classes were developed within the previous broad categories using metrics of depth and connectivity. Depth and connectivity are fundamental physical features of habitat and influence important smallerscale habitat characteristics as current velocity, vegetation growth, and water quality that shape how and if species use various areas of the larger river system. In this instance, we define connectivity as the ability of water to move among different hydrogeomorphic patches.

The aquatic functional classes were defined primarily by depth and connectivity attributes associated with each individual aquatic area region (for example, polygon; classes shown in table 5 and described more fully in appendix 1). More than 50 metrics were derived from data on bathymetry, surrogates for water exchange rates, river training structures, wind fetch, and adjacent terrestrial vegetation (table 3 ; appendix 1). Some, but not all, metrics were shared among lotic and lentic classes. The three depth-related metrics were the same between lentic and lotic classes, but given the distinct nature of lentic and lotic areas, different metrics were used to describe their connectivity. For example, metrics that describe connectivity in lentic areas included the effective number of connections and percent perimeter as channel, which do not apply easily to lotic areas. Lotic area metrics included measuring for the presence of artificial river training structures such as wing dams, which do not occur in off-channel areas. See appendix 1 for a full description of each metric and how they were calculated.

Although more than 50 metrics were derived, only 11 of these metrics, which mainly describe features of depth and connectivity, were used to develop 13 functional classes. The set of functional classes was developed to capture relevant characteristics that might best represent a wide range of general habitat types within a limited number of classes. Eight of the classes applied to lentic areas and five applied to lotic areas of the UMR (table 5). In addition, because the criteria for some of the classes overlap, each class is not mutually exclusive of other classes (polygons can be in multiple classes and when summed, the areas of all classes will exceed the total aquatic area). For example, a backwater may be deep, have a depression, and have a borrow pit and, therefore, would be classified as being in all three classes.

Table 5. Criteria used to assign regions (polygons) to aquatic functional classes based on geographic information system-calculated metrics (metric definitions below). Area thresholds (those not a percentage) for depth, size, sill, and TPI are in hectares; fetch is in kilometers; econ is dimensionless (0-100; high values are more connected); and Str is the count of wingdams and closing dams. A full description of all metrics developed for the 2010 aquatic areas data set are provided in appendix 1.

[Econ, effective connections, a measure of flow through a water body; Sill, measure of morphometric depression; PPC, percent perimeter that is channel; TPI, topographic position index using TPI1 measure of canyon bottom; Str, structures, both wingdams and closing dams; Fetch, weighted mean fetch; Size, areal extent of region; forest, percent of perimeter that is forested; depth, depth at the 75 percent exceeded discharge condition; <, less than; \%, percent; >, greater than]

\begin{tabular}{|c|c|c|c|c|c|c|c|c|c|c|c|}
\hline \multirow{3}{*}{ Class name } & \multicolumn{11}{|c|}{ Metric } \\
\hline & \multicolumn{5}{|c|}{ Connectivity } & \multirow{2}{*}{ Fetch } & \multirow{2}{*}{ Size } & \multirow{2}{*}{ Forest } & \multicolumn{3}{|c|}{ Depth (meter) } \\
\hline & Econ & Sill & PPC & TPI & Str & & & & $>0.5$ & $>1$ & $>3$ \\
\hline Shallow & -- & -- & $<30 \%$ & -- & -- & -- & -- & -- & $<20 \%$ & -- & -- \\
\hline Deep & -- & -- & $<30 \%$ & -- & -- & -- & -- & -- & -- & $>1$ & -- \\
\hline Borrow pit & -- & $>0.1$ & -- & -- & -- & $<1$ & -- & -- & -- & -- & $>1$ \\
\hline Wooded shoreline & -- & -- & $<50 \%$ & -- & -- & -- & -- & $>50 \%$ & -- & -- & -- \\
\hline Low connectivity & $<5$ & -- & $<10 \%$ & -- & -- & -- & -- & -- & -- & -- & -- \\
\hline Shallow w/flow & $>5$ & -- & $>10 \%$ & -- & -- & -- & -- & -- & $<50 \%$ & $<10$ & -- \\
\hline Structured w/scour & -- & -- & -- & $>1$ & $>0$ & -- & -- & -- & -- & -- & -- \\
\hline Structured & -- & -- & -- & -- & $>0$ & -- & -- & -- & -- & -- & -- \\
\hline Wooded shoreline & -- & -- & -- & -- & -- & -- & -- & $>50 \%$ & -- & -- & -- \\
\hline Deep & -- & -- & -- & -- & -- & -- & -- & -- & -- & -- & $>80 \%$ \\
\hline
\end{tabular}


After compiling these new classifications, the area of each aquatic area class (for example, the first level of classification) per river mile within each navigation pool was measured and used to calculate Simpson's diversity index. This index is intended to capture broad-scale differences in aquatic hydrogeomorphic composition and diversity across the river system. Functional classes (for example, the third level of classification), defined using a multivariate clustering analysis, were then used to group navigation pools that share similar functional habitat characteristics across the UMR. This section first describes the frequency, spatial distribution, and diversity of aquatic areas in the UMRS based on the general classes and then describes the distribution of functional classes. More specifics of the methods and metrics used for classification are detailed in appendix 1.

\section{Brief Results and Discussion}

There was not a strong longitudinal trend in Simpson's diversity in aquatic hydrogeomorphic areas, but the diversity ranged from high values in navigation pools with a relatively even mix of aquatic area classes (such as most of the navigation pools north of pool 14) to lower values in pools that were dominated by a few classes (such as pools 4, 15, and the open river reaches; fig. 7). In some cases, pools with a very different composition of aquatic area classes had similar estimates of diversity. For example, in the lower UMR, most pools have a relatively high proportion of aquatic area in channel borders and lack impounded areas compared to the upper UMR, whereas the pools in the upper UMR tend to support higher quantity of impounded area and off-channel habitat but a lower amount of channel border habitat as compared to the lower UMR. Minor differences were observed in aquatic area diversity between 1989 and 2010. In some cases, these differences reflect subtle changes in water levels at the time of photography (such as isolated versus contiguous floodplain lakes), but in other cases, these differences represent effects of longerlasting hydrogeomorphic changes. For example, restoration of islands in some navigation pools (such as Pool 8; fig. 8) has converted some impounded areas into shallow aquatic areas (for example, channel and floodplain lake complexes).

Clear spatial patterns in the finer-scale classification using functional classes were also observed across the UMR in both lentic and lotic classes (fig. 9). In most cases, the area of lentic functional classes is greater in northern navigation pools upriver of pool 15. Some lentic classes, however, tended to group more strongly across space. For example, longitudinal trends for lentic shallow and lentic with wooded shoreline areas were similar, with high abundances in the northern UMR navigation pools and southern Illinois River navigation pools (fig. 10). Comparatively lower abundances of these classes were found in the southern UMR pools and northern Illinois River pools.
Shallow lentic areas can provide benefits to species that associate with aquatic vegetation and macroinvertebrates, such as dabbling ducks (Stafford and others, 2007) and wading birds (Custer and others, 2004). Emergent vegetation is a common feature of lentic shallow areas (Peck and Smart, 1986) that can also provide food sources or cover from predation for some species. However, lentic shallow areas provide only marginal habitat conditions (for example, low dissolved oxygen and temperature) for species that depend on deep water during critical periods (such as overwintering fish habitat; Sheehan and others, 1994). Lentic areas with wooded shoreline provide a diversity of benefits, such as potential habitat for some terrestrial species (such as Megaceryle alcyon [kingfishers]). Wooded shorelines have indirect effects on aquatic habitat as well, such as the increased probability of woody debris from fallen trees (mast deposited in aquatic areas; Angradi and others, 2004), lower water temperatures through shading (Rounds, 2007; Julian and others, 2008) and alter the abundance of submersed vegetation (Köhler and others, 2010). Loss of forest cover because of invasion by herbaceous species (such as Phalaris arundinacea L. [reed canarygrass]) may impact the amount of wooded shoreline in some pools.

The lentic deep and deep-depression classes displayed similar longitudinal distributions across the UMRS, with highest abundances in the northern portion of the UMRS (pools 5, 7, 8, 9, 10, and 13; fig. 11). Few navigation pools in the lower UMR or Illinois River supported high abundances of any deep areas. Borrow pits were generally less abundant than other deep lentic areas, but such pits can be found in the pools in the northern UMRS. The borrow pit class includes areas that were not dredged, but the predominant origin of areas deeper than 3 meters $(\mathrm{m})$ are from dredging.

Within backwaters, deeper areas are often considered to be critically important habitat areas because sedimentation continues to fill in backwaters (See Section 3.4.1 Sedimentation in Off-Channel areas). Deep lentic areas and depressions often have lower water-exchange rates, and these deep areas provide refuge from cold main-channel water during the winter. Deep lentic areas with low velocity provide critical habitat conditions (for example, oxygen and temperature) for some fish species during winter (Knights and others, 1995; Sheehan and others, 1994). However, in some cases flow velocities are so low that they limit winter survival because of low oxygen levels (Gent and others, 1995). Borrow pits are anthropogenic, very deep depressions that also provide unique habitats, although hypoxic conditions can cause these areas to be unsuitable for overwintering fish in some cases. 


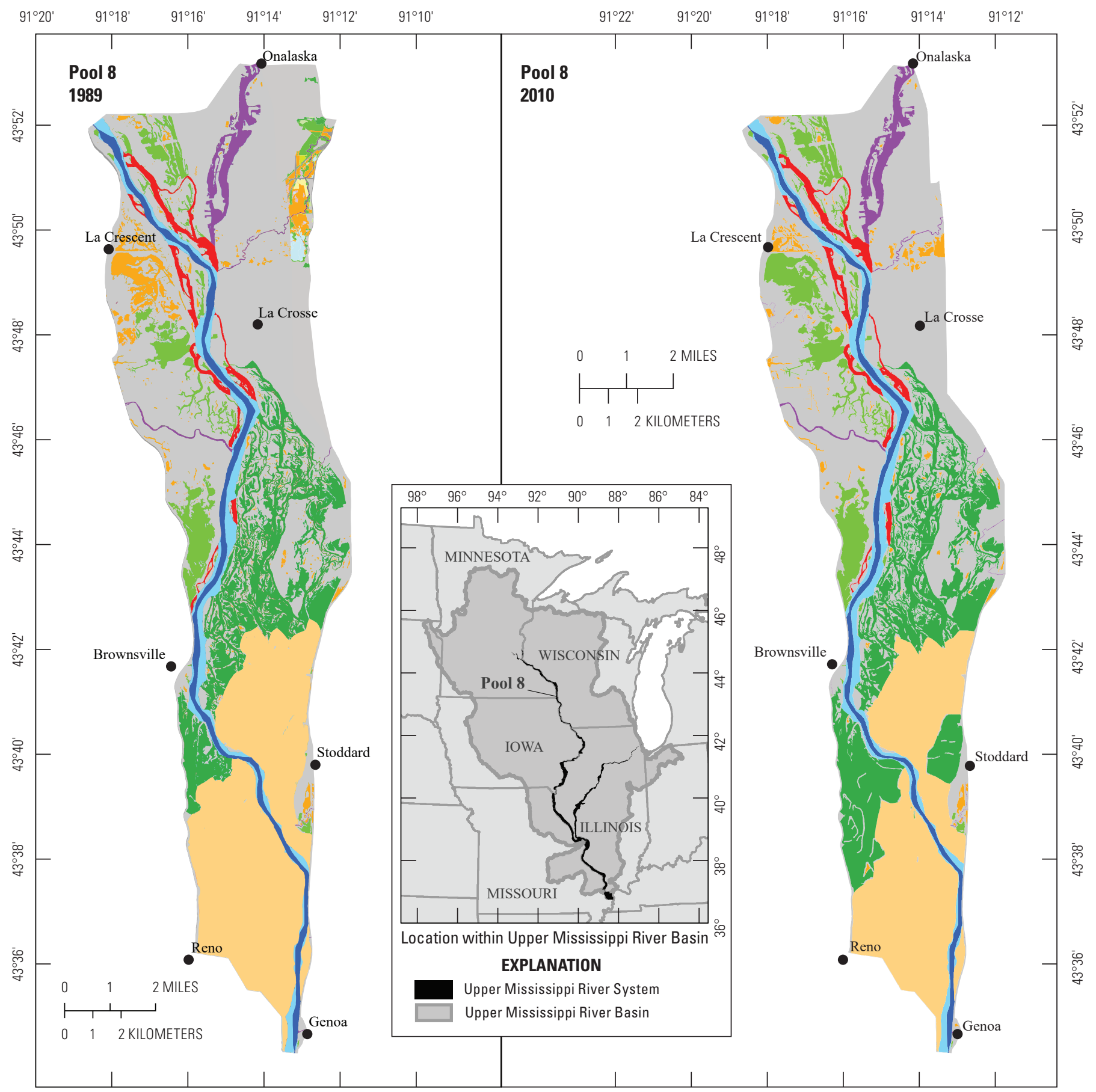

Base from U.S. Geological Survey digital data, 1:1,000,000, 2014, Universal Transverse Mercator projection, zone 15, North American Datum of 1983

\section{EXPLANATION}

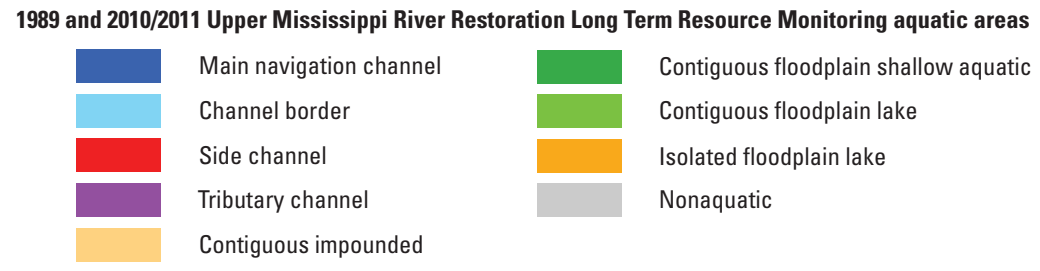

Figure 8. Navigation pool 8 of the Upper Mississippi River System showing the distribution of aquatic areas in 1989 (left) and 2010 (right). Note the increase in the contiguous floodplain shallow-aquatic class in the lower portion of the pool, reflecting island construction during the 1990s and early 2000s. 


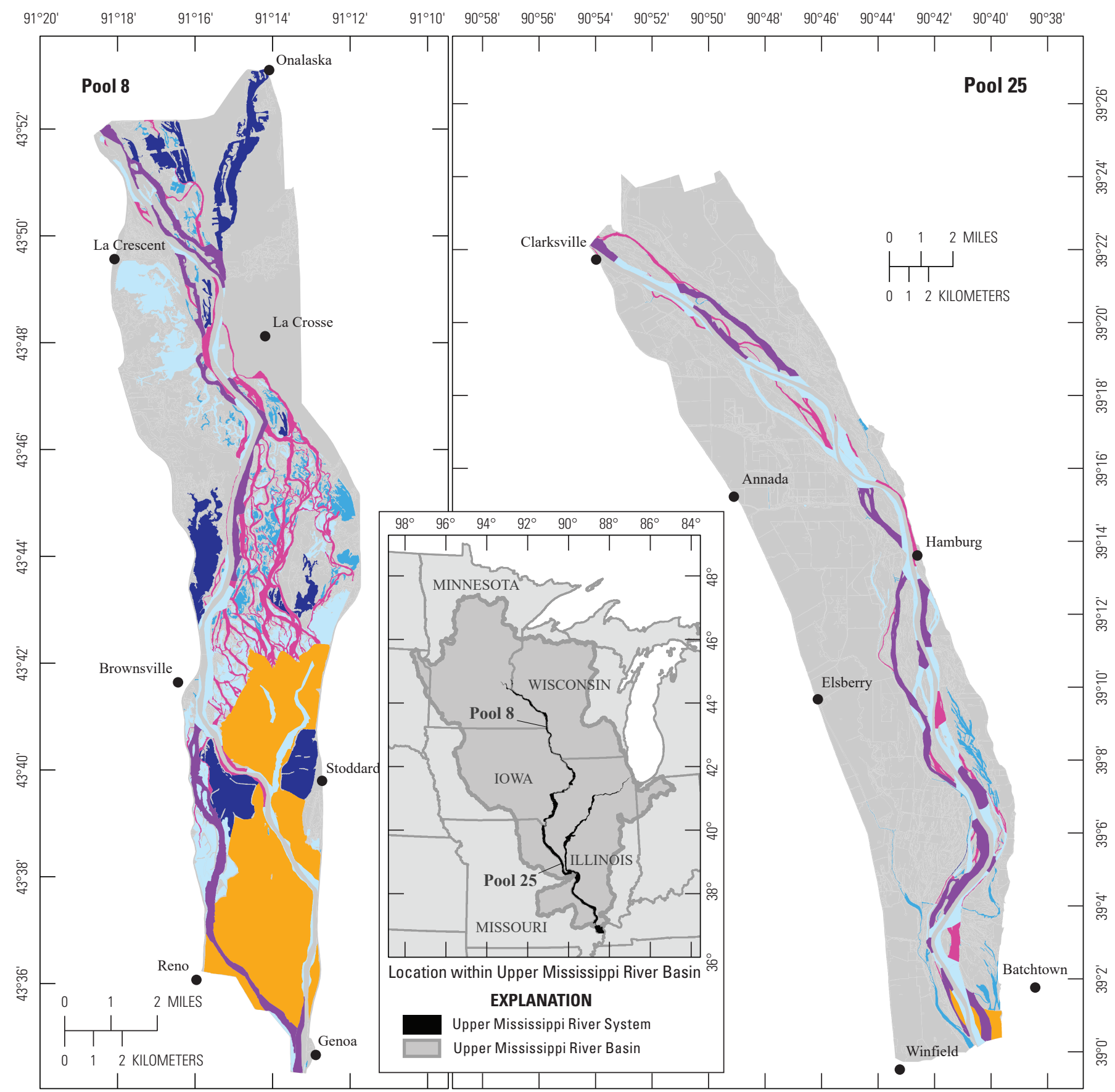

Base from U.S. Geological Survey digital data, 1:1,000,000, 2014 Universal Transverse Mercator projection, zone 15 North American Datum of 1983

\section{EXPLANATION}

2010/2011 Upper Mississippi River Restoration Long Term Resource Monitoring aquatic functional classes
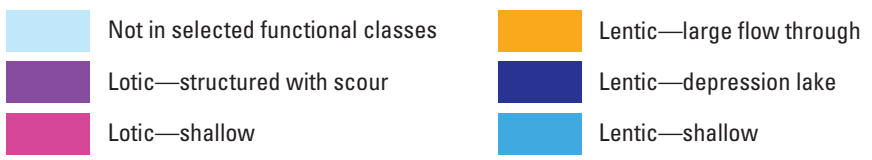

Terrestrial

U.S. cities

Figure 9. Examples of selected aquatic functional classes in navigation pools 8 and 25. Aquatic functional classes are not mutually exclusive (regions within the maps can belong to multiple classes). Therefore, only a few classes are mapped here and some backwaters are not in any of the mapped classes (denoted as "Not in selected functional classes"). 


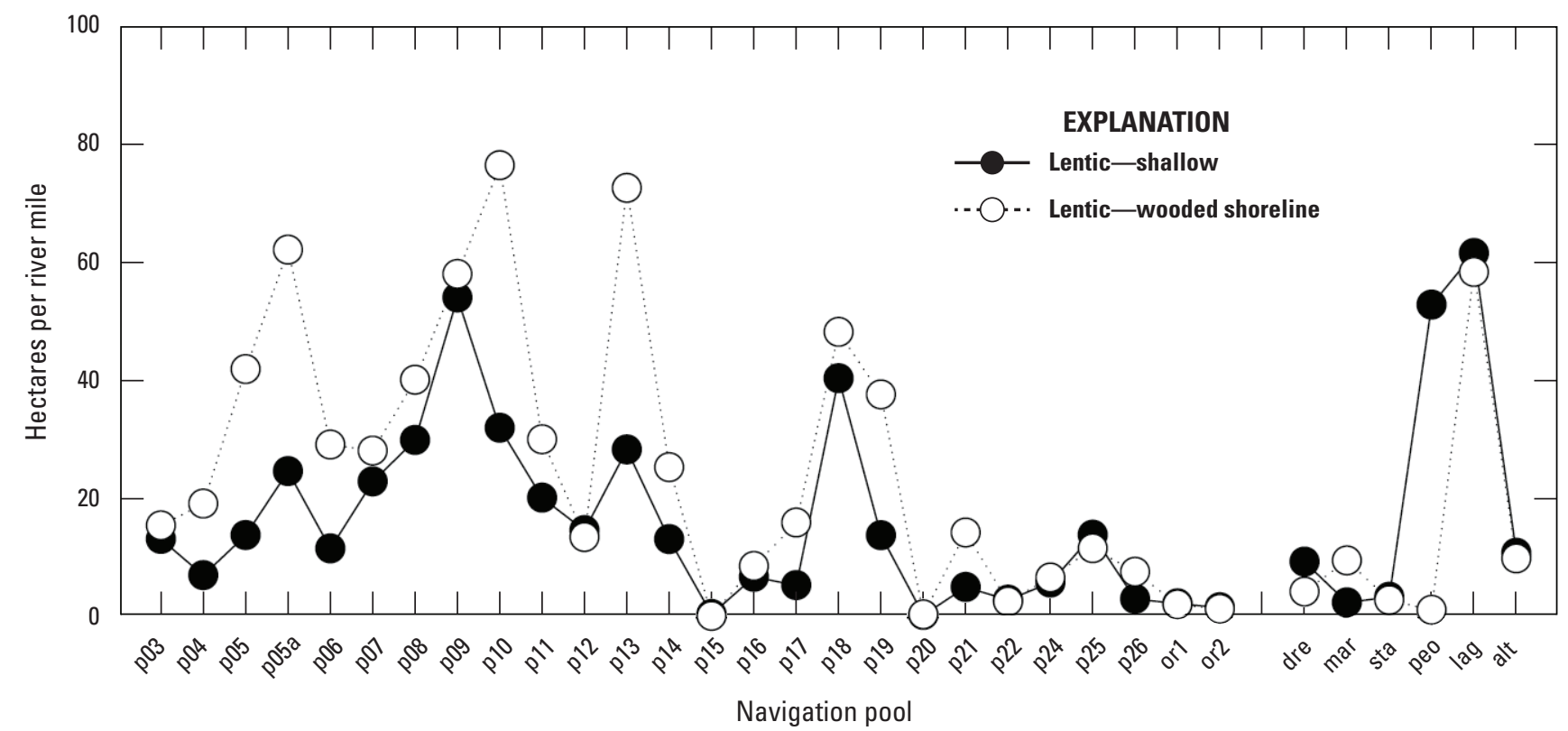

Figure 10. The hectares per river mile of lentic shallow areas and lentic areas with wooded shorelines. See table 5 for criteria for shallow and wooded shoreline.

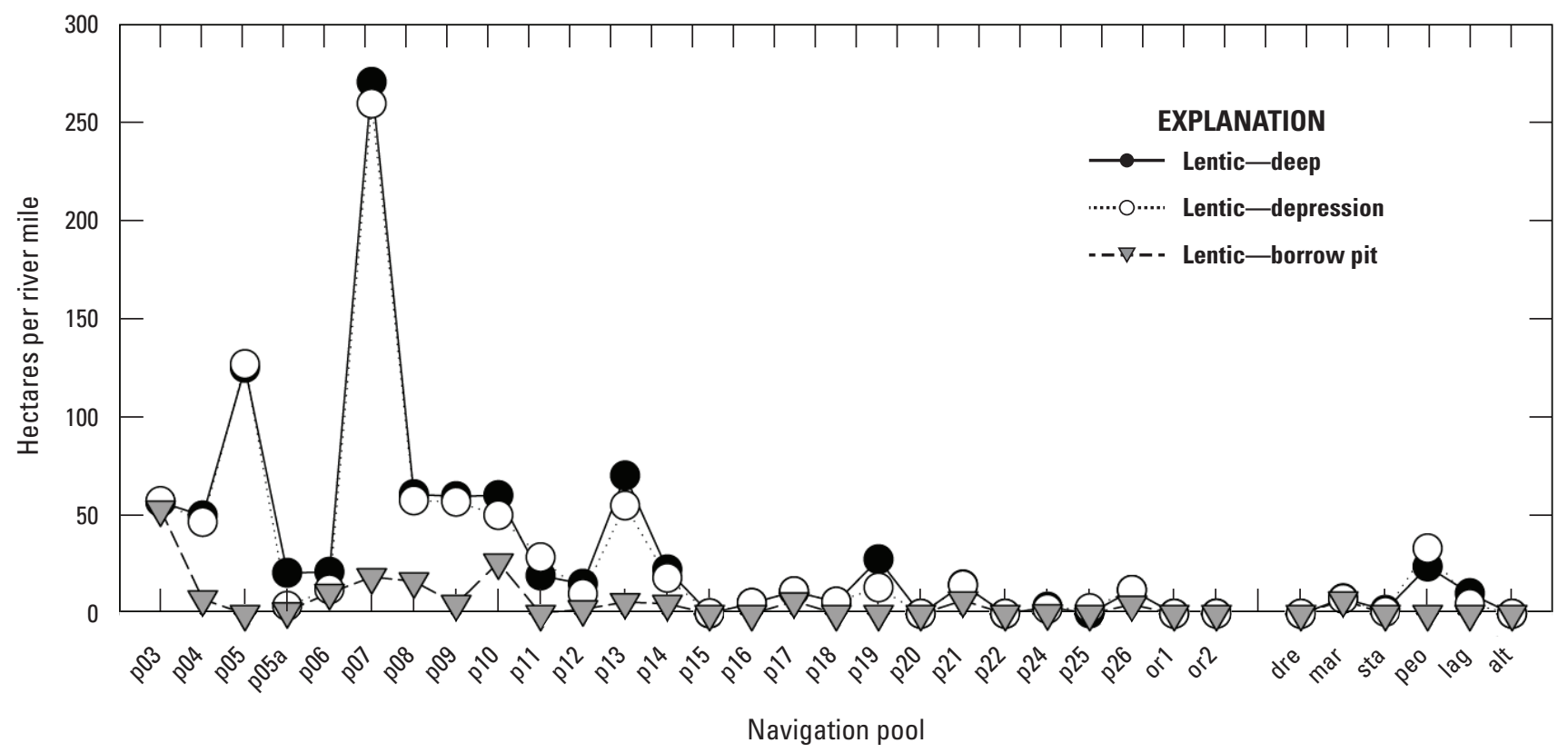

Figure 11. The hectares per river mile of lentic deep areas. See table 5 for criteria for deep, depression and borrow pit. 
All lentic areas defined by their connectivity to the main channel (such as low connectivity, shallow with flow, deep with flow) tended to be more abundant in the northern navigation pools of the UMR and the southern navigation pools of the Illinois River (fig. 12). This was especially true for the class defined as low connectivity. Lentic large and lentic shallow with high exchange rates classes (for example, large with flow and shallow with flow, respectively) are similar to the Impounded Area in the Wilcox classification (Wilcox, 1993), so this high abundance partially reflects the prevalence of impounded habitat in northern navigation pools. For these two classes, there were important pool-by-pool differences. For example, navigation pools with large impounded areas often, but not always, also had large areas defined as shallow with flow. However, in many cases pools with abundant lentic shallow areas with flow had no area defined as large with flow (for example, pools with no impounded area).

Water exchange rates in off-channel areas define many of the physical, chemical, and structural criteria of lentic species' habitat. For example, low flow conditions common to many off-channel areas are important in providing many fish species refuge from high flows in main channel areas. Low flow conditions can negatively influence water quality; however low water exchange can result in declines in dissolved oxygen levels in off-channel areas that harm species survival (James and others, 1995). Some species, such as lentic mussel communities, thrive in off-channel areas with greater water exchange (Tucker and others, 1996). Large lentic areas of higher exchange rates also provide unique habitat for diving ducks during fall migration (Korschgen, 1989). At intermediate rates of water exchange, these off-channel habitats provide relatively high levels of nutrient retention and removal important to water quality in the larger river landscape (James and others, 2008).

There were interesting patterns in the functional characteristics of lotic areas across UMRS navigation pools as well. Shallow channel areas were most abundant in navigation pools $7-13,18$, the open river reaches, and most of the pools of the Illinois River (fig. 13). Channels with wooded shorelines were generally most abundant in the southern UMR pools, where there is an abundance of both channel area and forested area (see section 3.2.4 Floodplain Vegetation Diversity).

Shallow lotic-channel areas provide different habitat than deeper channels, and are more often associated with islands and sandbars. Shallow-channel areas may be particularly important in the unimpounded portion of the UMR where the predominant aquatic environments have deep and high velocity conditions (such as the main channel). Wooded shoreline provides habitat for some terrestrial species (such as kingfisher), and has some indirect effects on aquatic habitat (such as increased probability of woody debris from fallen trees; Angradi and others, 2004). Wooded shorelines also affect some aquatic conditions because of overstory shading, such as water temperature (Rounds, 2007; Julian and others, 2008) and abundance of submersed vegetation (Köhler and others, 2010). Deep channel areas provide habitat for many large river fish species (Dettmers and others, 2001) and function somewhat differently with regard to primary production, as a small fraction of the volume is in the photic zone (Sobotka and Phelps, 2016).

The lotic-structured class was relatively abundant throughout the UMR, but nonexistent in the Illinois River (fig. 14). For most navigation pools, a subset of the loticstructured area contains scours, hence a similar longitudinal pattern was observed for lotic-structured class types with and without scours. Deep lotic areas were relatively rare in the northern UMR but increased substantially in the lower UMR. There were no deep lotic areas in the Illinois River. Areas of all regions that fit the criteria were summed by pool for the lotic deep and lotic with structure classes. Areas consisting of only the structure scour were summed for the lotic with structure scour class. Areas of regions containing a structure score were not included. Channels with structures often have rock substrates and morphometric variation, which provide interstitial habitats for macroinvertebrates and larval fishes (Sandheinrich and Atchison, 1986). Further, low velocity conditions directly downriver from wing dikes often have a high concentration of larval fishes and may provide nursery conditions (Barko and others, 2004). Those channels with scours associated with structures provide diversity in morphometry and area of lower water exchange rates. Lotic fishes often associate with wing dike scour holes, presumably because of lower velocities and the capture of invertebrate drift in eddy pools formed behind wing dikes (Koch and others, 2012; Calkins and others, 2012; Barko and others, 2004).

\section{Synthesis of Aquatic Functional Class Distribution}

We performed a hierarchical cluster analysis to identify the navigation pools within the UMRS that share similar distributions of aquatic functional classes. All functional classes identified in table 5 were included in the analysis. We evaluated the cluster analysis results by examining the distribution of navigation pools and their cluster membership with a metric dimensional scaling (MDS) ordination. MDS ordination is a way to obtain a 2-dimensional spatial representation of similarities among the navigational pools that comprise unique distributions of multiple aquatic functional classes. In our MDS, the $\mathrm{x}$ - and y-axes represent combinations of aquatic functional classes, with the $\mathrm{x}$ - and $\mathrm{y}$-coordinates of each navigational pool reflecting a given pool's combination of aquatic functional classes. Navigation pools appearing close together in MDS plots are interpreted as being more compositionally similar to each other than to navigational pools plotted farther away. The first MDS axis (MDS 1; fig. 15) was positively correlated (R) with all lentic classes $(R>0.27)$ and negatively correlated with four of the five lotic classes $(\mathrm{R}<-0.27)$. The only lotic class positively correlated with MDS 1 was the shallow lotic class $(\mathrm{R}=$ 0.27). Hence, navigation pools located to the right of MDS 1 (positive values) tend to have large areas in lentic functional classes, but navigation pools located to the left of MDS 1 


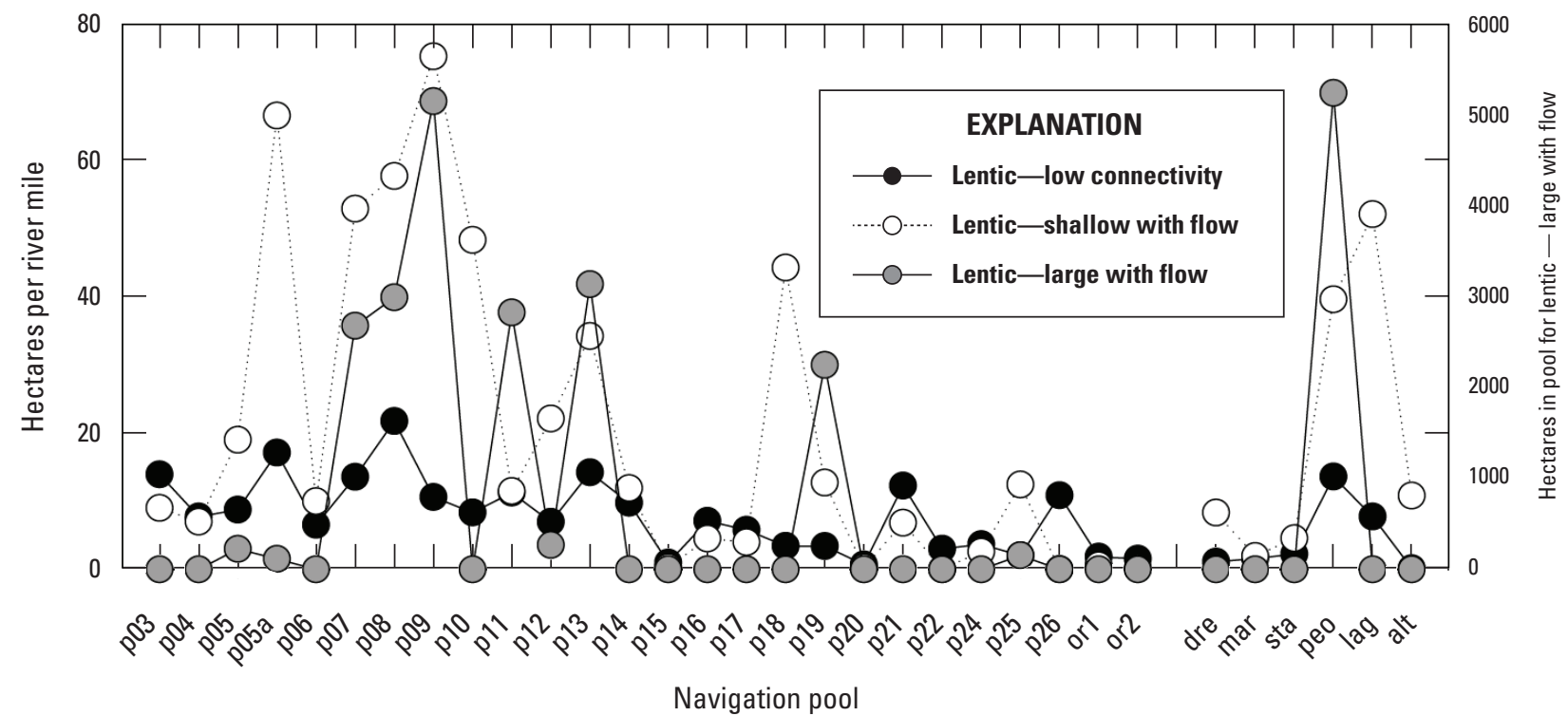

Figure 12. The area of lentic functional classes primarily defined by connectivity measures that reflect water exchange rates. The low connectivity and shallow with flow (higher connectivity) classes are measured in hectares per river mile, but the large with flow (higher connectivity, for example, impounded areas) is measured in hectares per navigation pool. See table 5 for criteria for each class.

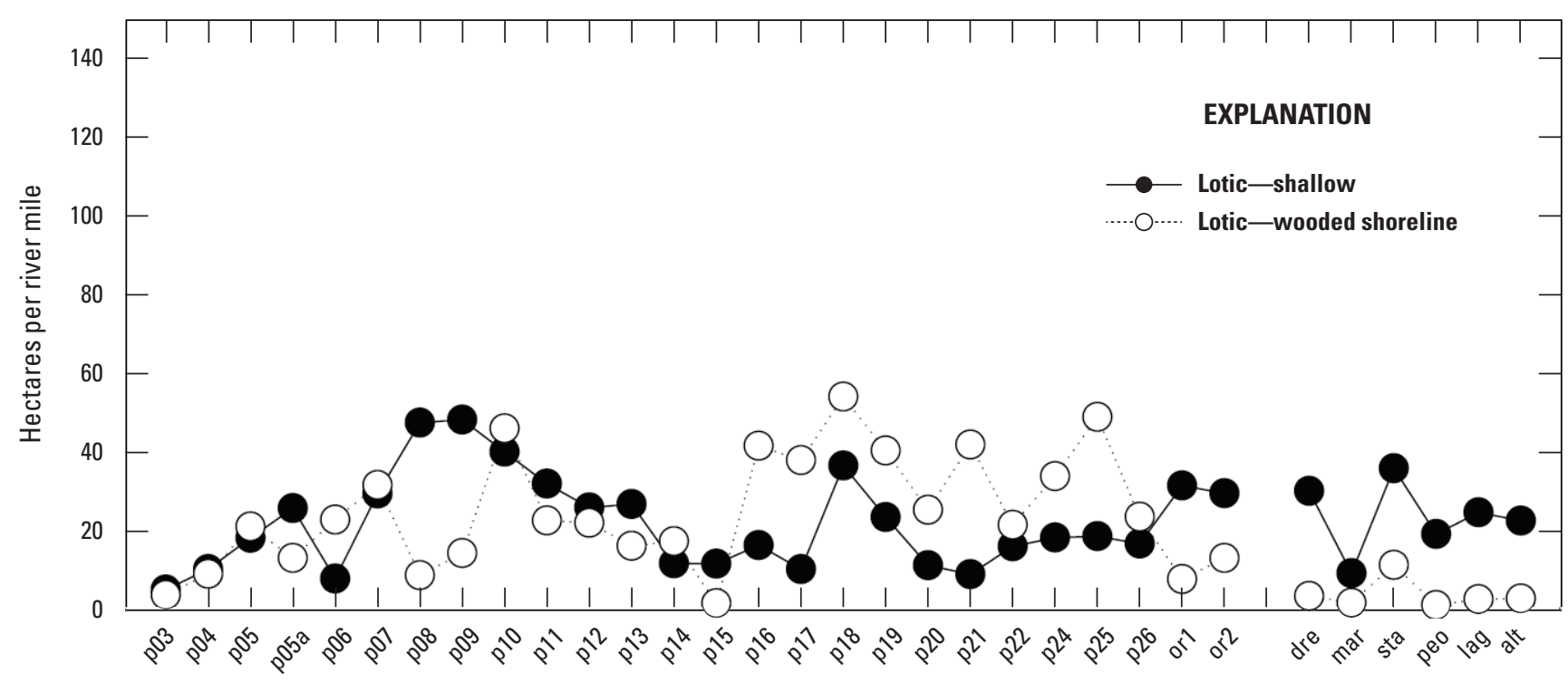

Navigation pool

Figure 13. The area in hectares per river mile of lotic functional classes characterized as shallow and containing wooded shoreline. See table 5 for the criteria for each class. 


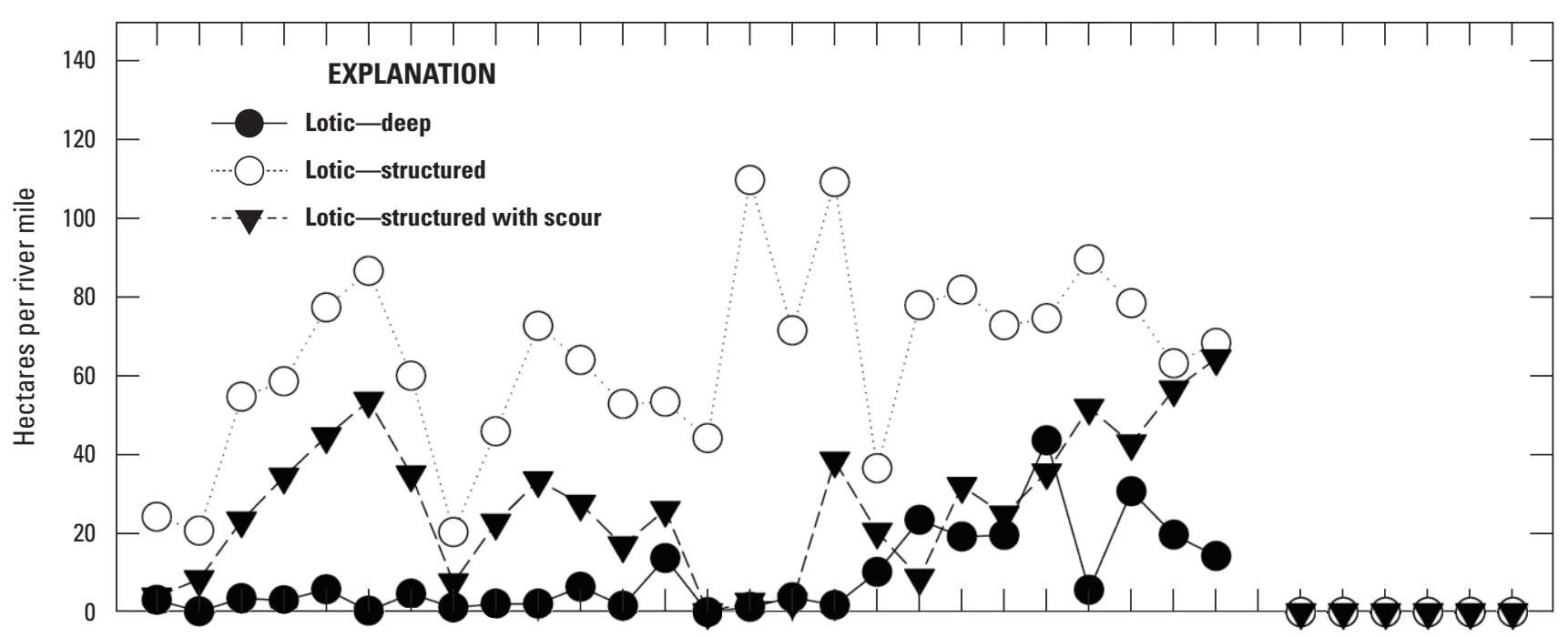

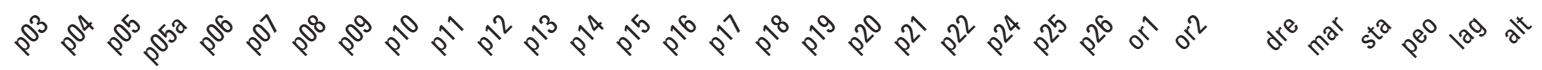

Navigation pool

Figure 14. The hectares per river mile of lotic functional classes primarily defined by deep depths or structures. Classes include deep lotic, lotic with structure, and lotic with structure scours. Structures include wing dams and closing dams. See table 5 for criteria for each class.

(negative values) tend to have large areas in lotic functional classes. The second (vertical) axis of the biplot (MDS 2; fig. 15) was positively correlated with three primary lentic functional classes (lentic burrow pit [ $\mathrm{R}=0.51]$, lentic deep [ $\mathrm{R}$ $=0.54]$, and lentic depression $[\mathrm{R}=0.55]$ ) and was negatively correlated with the lotic shallow functional class $(\mathrm{R}=-0.23)$. Hence, navigation pools located to the top of MDS 2 tend to have large amounts of area in deep lentic classes, but pools located to the bottom of MDS 2 tend to have large amounts of area in the shallow lotic class. Later, in section 3.4 (CrossIndicators Synthesis) we use the pool-specific values for MDS 1 and 2 (referred to as aquatic functional class score [AFCS] 1 and 2, respectively) to quantify differences among pools in aquatic functional class distributions.

The hierarchical cluster analysis identified eight groups of navigation pools (fig. 15). Unique navigation pools included mar (group b) in the Illinois River, which had very little aquatic area meeting any of the functional class criteria, and pool 15 (group e) in the UMR, which also tended to have very little aquatic area meeting any of the functional class criteria, with the exception of the lotic-structured class. The two open river reaches (or1 and or2) grouped together (group f) and were characterized by a lack of lentic area and high abundance of lotic-structured areas and lotic-structured with scour areas. Group g (pools 20, 22, and 24 of the UMR) were similarly characterized by an abundance of structured channel area. Nine navigation pools were contained within group $h$ (pools $6,12,14,16,17,18,21,25$, and 26), which was somewhat similar to the channel-dominated groups (f and g) but included more lentic area. Eight navigation pools were found in group $\mathrm{d}$ (UMR pools 5A, 8, 9, 10,11,13, 19, and peo of the Illinois River), which was characterized by having both large shallow lentic areas with flow and lentic areas that were deep and with wooded shorelines. Navigation pools 3, 4, 5, and 7 fell within group c, which differed from the other highly lentic group (group d) in that it contained a much higher abundance of deep lentic areas. Finally, four navigation pools from the Illinois River (lag, alt, dre, and sta) were found in group a. This group was restricted to the Illinois River and exhibited a combination of lentic areas with wooded shorelines, lentic-shallow areas with flow, and lotic shallow areas, without much area in any other aquatic functional class. 


\section{EXPLANATION}

Cluster groupings for navigation pools based on hierarchical cluster analysis

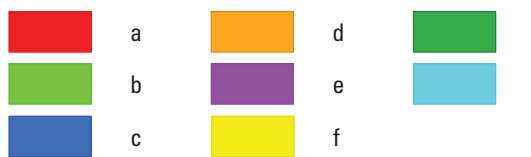

Upper Mississippi River Basin

p02 Pool location and number

dre Pool location abbreviation

- U.S. cities (population $>\mathbf{2 0 0 , 0 0 0}$ )

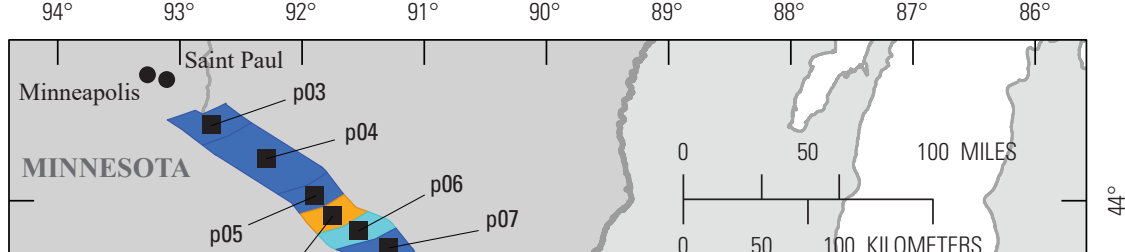

IOWA
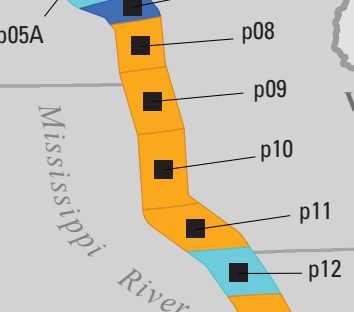

WISCONSIN



(1)
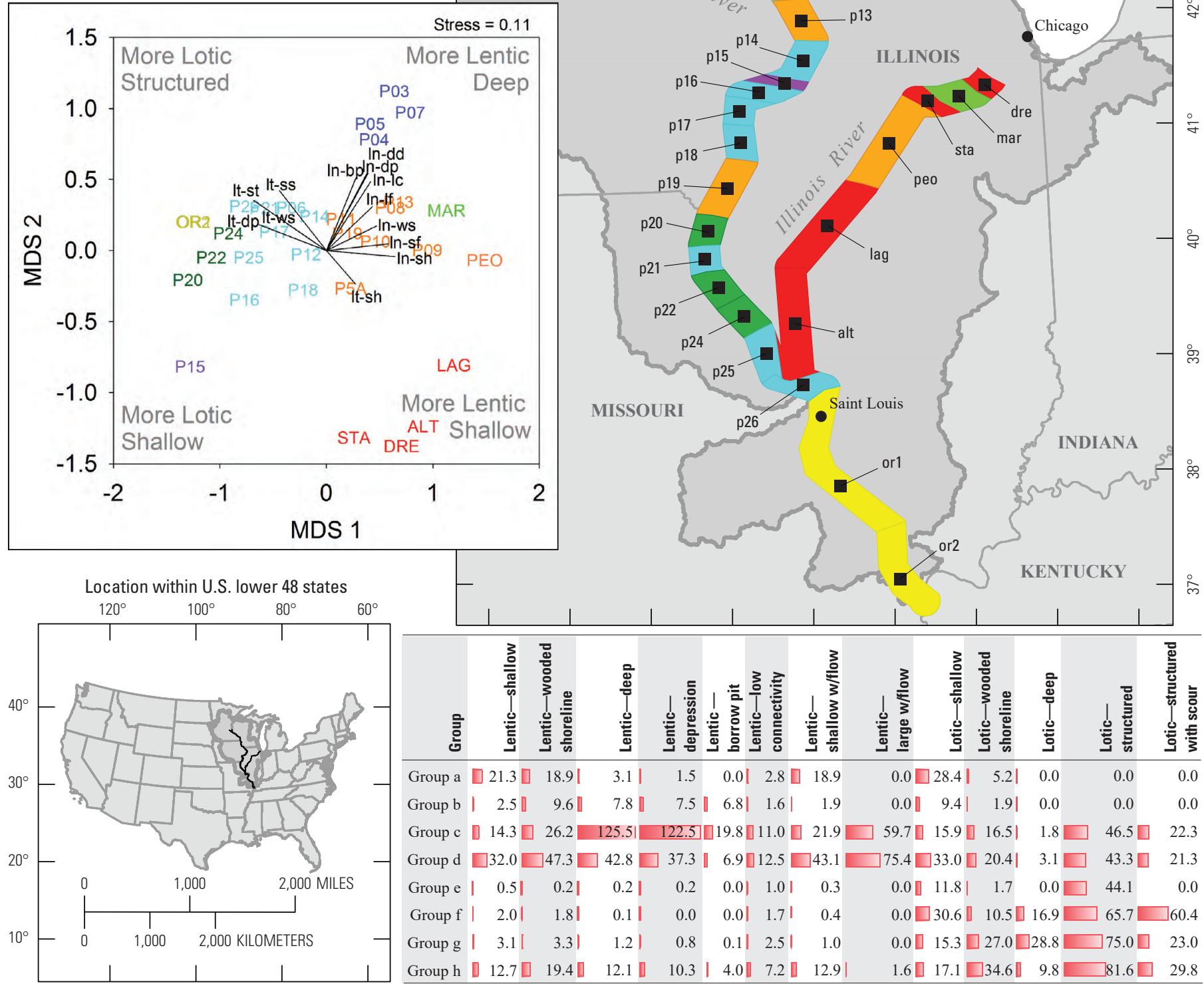

Figure 15. Results from a multivariate cluster analysis based on the area of each aquatic functional class (table in lower panel) for Upper Mississippi River System navigation pools. Pools that clustered together $(P=0.05)$ have the same color. The table provides the mean area (hectare per linear river mile) for the navigation pools in each aquatic functional class. 


\subsubsection{Aquatic Vegetation Diversity}

\section{Brief Methods}

To represent the abundance and diversity of aquatic vegetation, land cover and land use data (fig. 16) were used for the years 1989, 2000, and 2010. These datasets were used to quantify the area of navigation pools where no vegetation was detected (open water), along with the area in five aquatic vegetation types: deep marsh annual (annual wild rice, Zizania aquatica); deep marsh perennial (arrowhead, Sagittaria spp.; cattail, Typha spp.; bur-reed, Sparganium eurycarpum; and pickerel weed, Pontederia cordata); deep marsh shrub (buttonbush, Cephalanthus occidentalis and swamp loosestrife, Decodon verticillatus); rooted floating aquatic (American lotus, Nelumbo lutea; and water and pond lilies, Nymphaea spp. and Nuphar spp); and submersed aquatic vegetation (wild celery, Vallisneria americana; Elodea canadensis, Potamogeton spp.; and coontail, Ceratophyllum demersum) (Dieck and others, 2014). Simpson's diversity index was used to quantify vegetation diversity based on these vegetation classes (including no vegetation as one of the classes).

\section{Brief Results and Discussion}

The diversity of aquatic vegetation classes was highest in the upper navigation pools of the UMR and in pool dre of the Illinois River (fig. 17). In these pools, submersed aquatic vegetation and rooted floating aquatics were the most abundant vegetation classes, followed by deep marsh perennial and deep marsh annual classes. The longitudinal pattern in aquatic vegetation reflects spatial differences in a combination of variables known to limit aquatic vegetation in the UMRS. Downriver of Pool 13, the relative abundance of side channel and channel border habitats increases substantially, but the abundance of shallow water aquatic areas, floodplain lakes, and impounded areas decreases (see section 3.2.1 Aquatic Areas and Functional Classes). Such changes suggest that there are fewer areas that support shallow and slow-moving water required for aquatic plant growth. In addition, aquatic plants tend to establish and preform best under stable water level conditions. In the lower UMRS, water-surface elevations fluctuate more than in the upper UMRS (see section 3.3.1 Water-surface Elevation Fluctuations). TSS concentrations increase from upriver to downriver in the UMRS (see section 3.3.2 Total Suspended Solids Concentrations), which reduces water clarity. Finally, additional factors not evaluated in this report that could limit aquatic vegetation are substrate stability and grazing. In combination with each other, the geomorphic conditions, water levels, and water clarity in the lower UMRS help to explain the low-levels of aquatic vegetation found in the lower UMRS.

Differences in aquatic vegetation class diversity through time have been observed in some reaches of the UMR and Illinois River. For example, drought conditions during the late 1980 s are thought to have contributed to a widespread decline in submersed vegetation throughout the UMRS during the early 1990s (Tyser and others, 2001; Fischer and Claflin 1995). Since then, submersed vegetation has increased throughout the northern portions of the UMRS (upriver of navigation pool 14), but has not increased as much in the lower UMRS (De Jager and Yin, 2011; De Jager and Rohweder, 2017). These results can be seen in figure 18, as the diversity of aquatic vegetation in 2010 either was similar to or greater than in 1989 for northern pools of the UMR and the dre and lag pools of the Illinois River, but navigation pools downriver from Pool 13 tended to have a lower abundance and diversity of aquatic vegetation in 2010 .

\subsubsection{Floodplain Functional Classes}

\section{Brief Methods}

In the UMRS, inundation is the dominant physical driver of an array of ecosystem patterns and processes including vegetation dynamics and biogeochemical cycling (De Jager and others, 2012; 2015b). In general, four aspects of hydrologic regimes are thought to drive river floodplain ecosystem form and function: event frequency, duration, depth, and timing (Poff and others, 1997). The responses of many ecological processes (such as plant establishment and survival or biogeochemical cycling) to individual flood events can vary depending on frequency of occurrence, how long the flood event lasts (duration), how deep the water becomes on the land surface (depth), or the event's seasonality (timing) (Junk and others, 1989; Merritt and others, 2010). For example, the frequency of flooding may mediate assemblage composition of microbial (Argiroff and others, 2017) and vegetation communities (Stokes and others, 2010). Prolonged flood events can result in soil hypoxia that affects nutrient cycling rates (Pinay and others, 2002) and metabolic processes in plants (Blom and Voesenek, 1996; Kozlowski, 1984). Flooding depth can impact the establishment and growth of both understory and overstory plant species (Karrenberg and others, 2003; Robertson and others, 1984). The timing of floods can interact with plant life-history strategies to affect patterns of colonization, competition, and succession (Braatne and others, 2007; Lytle and Merritt, 2004; Merritt and others, 2010) and other ecosystem attributes such as productivity, nutrient cycling, and riverine species diversity (Junk and others, 1989; Jardine and others, 2015; Kreiling and others, 2015). Over longer time spans, annual summaries of total duration help describe spatial differences in ecological properties that may emerge through decades to centuries (such as plant community composition and structure or soil texture) (De Jager and others, 2012; 2015a Marks and others, 2014).

Despite the important role of inundation, system-wide characterizations of flood frequency, duration, depth, and timing have been limited for the UMRS. There are a few existing spatially explicit characterizations summarizing only annual total duration in the northernmost portion of the 


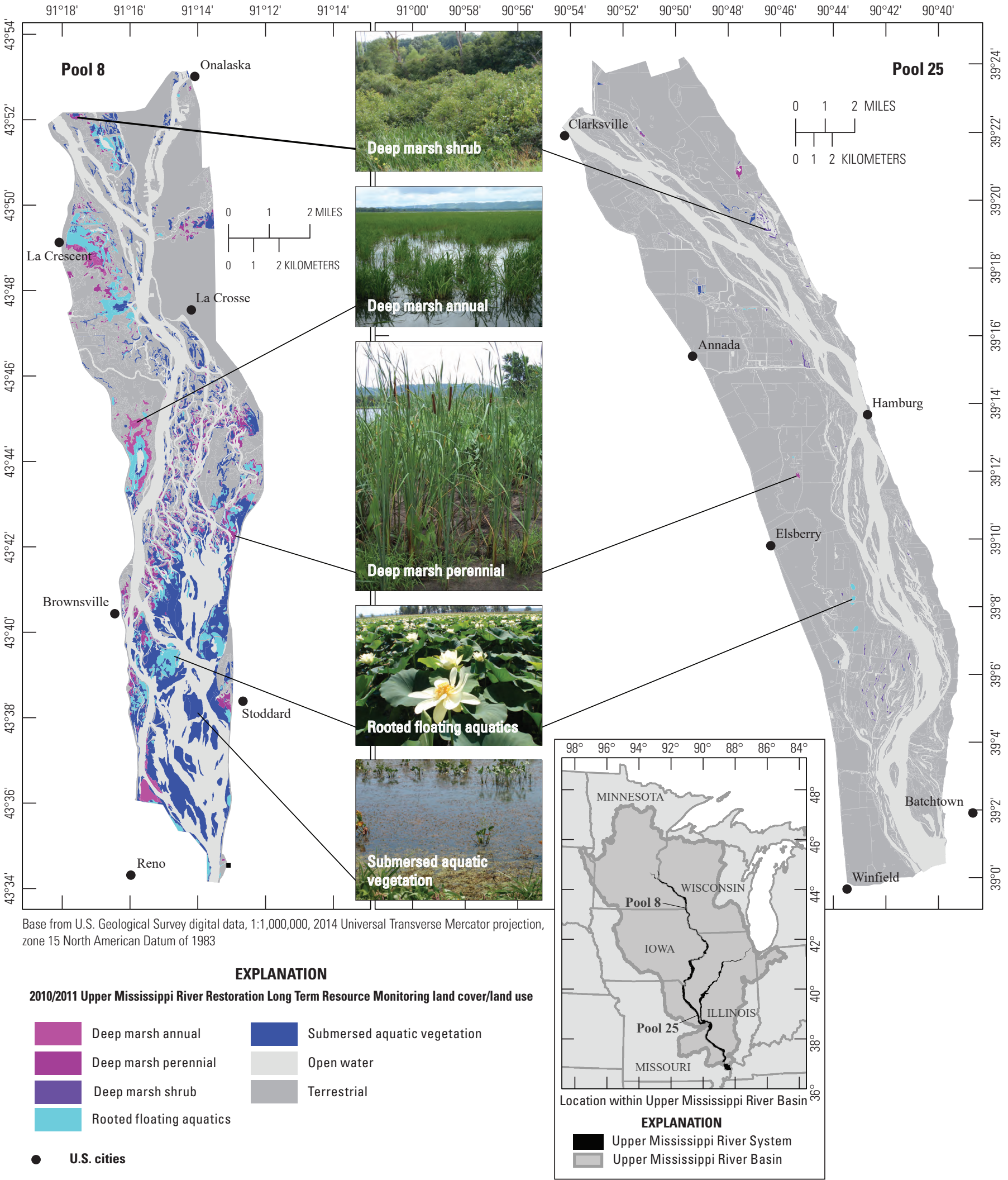

Figure 16. Navigation pools 8 and 25 of the Upper Mississippi River System, illustrating the widespread distribution of aquatic vegetation in the spatially extensive lentic areas of the northern Upper Mississippi River System (pool 8) and the lack of vegetation in the relatively more lotic conditions found in the southern Upper Mississippi River System (pool 25). 

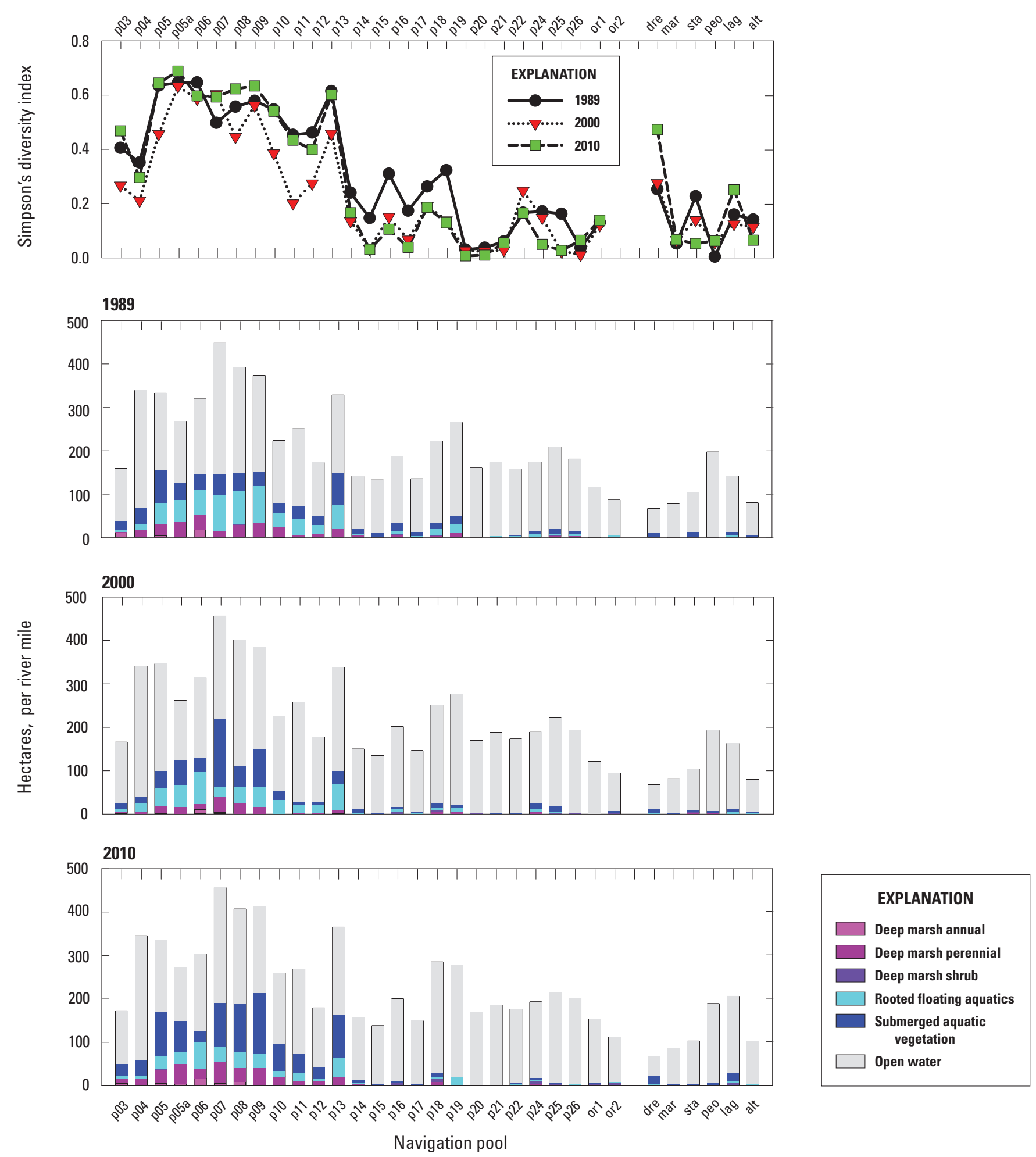

Figure 17. Simpson's diversity index (top panel) and the area (hectare per linear river mile) of vegetated and unvegetated aquatic areas within navigation pools of the Upper Mississippi River System for 1989, 2000, and 2010 (progressively lower panels). 


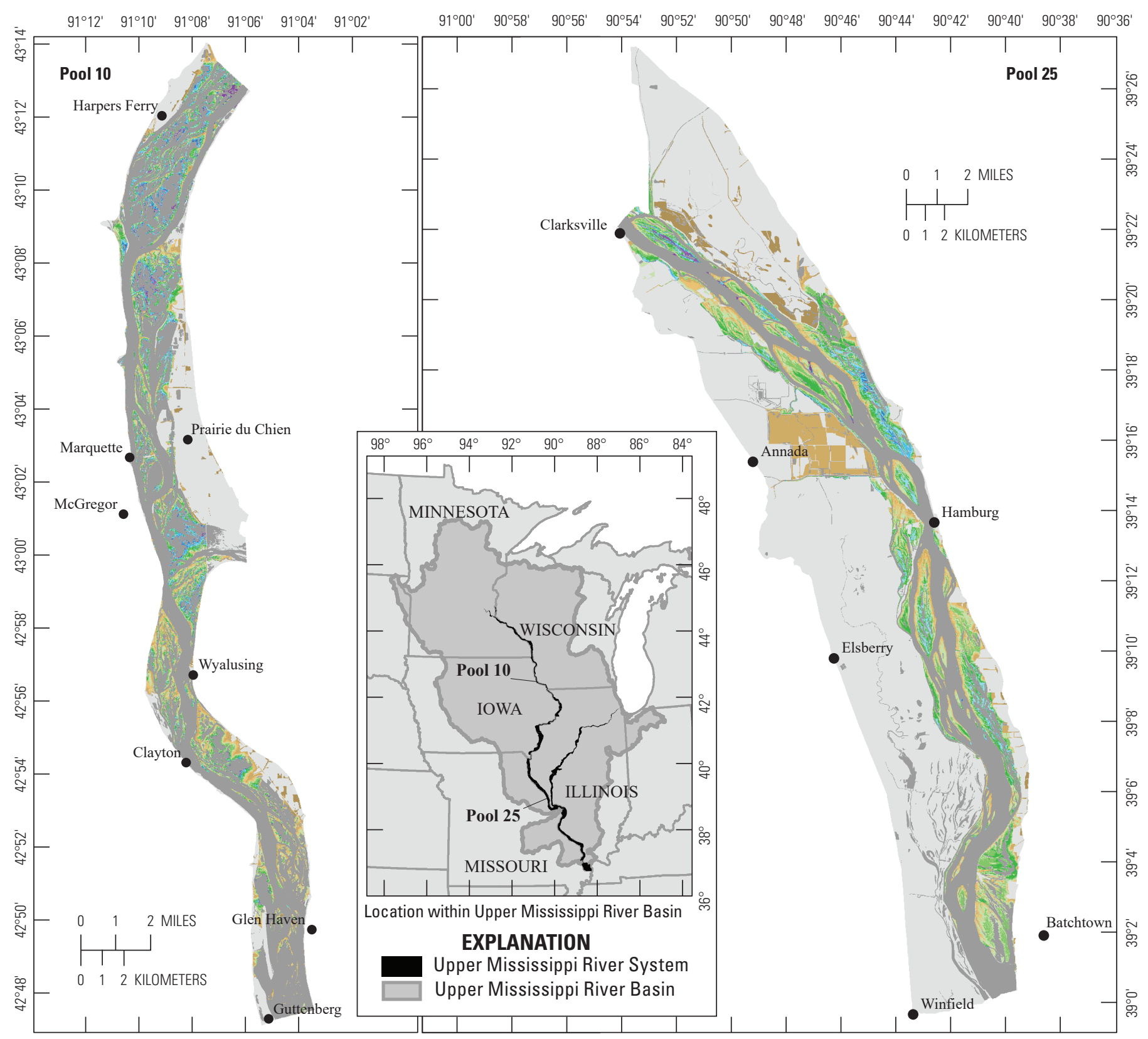

Base from U.S. Geological Survey digital data, 1:1,000,000, 2014 Universal Transverse Mercator projection, zone 15 North American Datum of 1983

\section{EXPLANATION}

Upper Mississippi River Restoration Long Term Resource Monitoring mean growing season flood duration, in days

\begin{tabular}{|l|l|l|}
\hline 0 & $30.01-40$ \\
\hline $0.01-10$ & $40.01-50$ \\
$10.01-20$ & $50.01-60$ \\
\hline $20.01-30$ & $60.01-70$ \\
\hline
\end{tabular}

$70.01-80$

$80.01-90$

90.01-100

Greater than 100

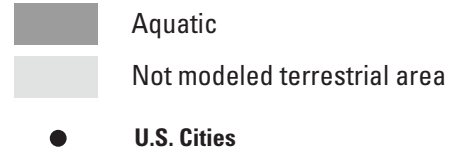

Figure 18. Floodplain functional classes, defined by the mean total duration of inundation during the growing season and for the past 40 years, shown here for navigation pools 10 and 25 in the Upper Mississippi River System. 
UMRS (pools 3-10; De Jager and others, 2016), and no efforts have focused on characterizing flood event frequency, depth or timing for any portion of the UMRS. It is important to more fully describe inundation dynamics across the UMRS because no single aspect of the hydrologic regime is uniformly useful for understanding all ecological phenomena in floodplain ecosystems (Merritt and others, 2010). We therefore developed a surface-water connectivity modelling framework to support investigations of a wide range of ecological properties and processes that may respond to different aspects of the UMRS hydrological regime across different spatial and temporal scales (see appendix 2 for details on methods).

The goal of the analysis presented here was to develop floodplain functional classes that systematically describe and map ecologically relevant gradients of surface-water inundation. Briefly, we began by interpolating 40 years (1972-2011) of daily water-surface elevations between pairs of gages along the UMRS. We limited the analysis to the growing season days between April 1 and September 30 to approximate the season in which most of biophysical processes, such as vegetative metabolism and biogeochemical cycling, are likely to be most active across the URMS longitudinal gradient. We compared these water-surface elevations to topo-bathymetric data that had been modified to account for slopes and hydrologic routing. The comparisons resulted in spatially explicit distributions of inundation depth through time across the entire UMRS.

The inundation model can be used to characterize flooding patterns across the UMRS by summarizing the inundation depth time series in several ways. First, unique inundation events in the depth time series can be calculated as sets of sequential days during which the water surface exceeded the terrestrial elevation (for example, discrete periods of land submergence). Using the 40-year period of record for all UMRS floodplain terrestrial areas, these events can be summarized in terms of their frequency (average number of events per year of record), duration (median event length), depth (maximum depth observed during an event, summarized as a median across all events), and timing of inundation events (day of the year peak depth was achieved, summarized as a median of all events and as circular variance of all events) (appendix 2). These event-based metrics and combinations thereof may be useful in understanding various ecological patterns and processes in the UMRS floodplain.

For this assessment, we calculated the 40 -year mean total growing season inundation duration (the average number of days a surface is inundated in a given year) (fig. 18). Given the importance of long-term inundation durations on floodplain vegetation and soil distributions and dynamics in this system (De Jager and others, 2012; 2015a), we used this value as a basis for classifying all floodplain areas. After masking out all nonnatural areas of the floodplain (for example, areas in agricultural production or developed) we summarized the distribution of floodplain functional classes as the area per river mile (calculated as total area of each class in each pool divided by the length of the pool) in each navigation pool in 10-day duration bins. The end result was floodplain functional classes that represented areas expected to experience different growing season inundation durations based on average hydrologic conditions from 1972 to 2011. We calculated Simpson's diversity index for each navigation pool based on the abundance of these floodplain functional classes.

\section{Brief Results}

The diversity of floodplain functional classes was lowest in the three upper pools of the Illinois River (dre, mar, and sta) because they generally lacked area that flooded for more than 30 days during the growing season (fig. 19). Other pools with relatively low estimates of Simpson's diversity included pools 5, 6, 14, 15, 20, 26, and the open river reaches. These pools tended to have a more uneven distribution of floodplain functional classes as compared to the rest of the navigation pools, with a relatively lower abundance of areas that flood for more than 60 days during the growing season. The remaining navigation pools tended to support Simpson's diversity indices $>0.80$ and had a relatively even mix of floodplain functional classes. However, the pools in the northern portion of the UMR (approximately upriver of Pool 12), along with pools 18 and 19 in the middle UMR and the peo and lag pools in the Illinois River, tended to have more area in classes with long inundation durations ( $>60$ days during the growing season). In contrast, the pools in the lower portion of the UMR (downriver from pool 15) tended to have greater area in classes that flood between 30 and 60 days during the growing season.

Given that previous research has indicated nonrandom associations between the vegetation communities of the UMR and similar indices of flood inundation duration, the longitudinal patterns in the abundance and diversity of floodplain functional classes help to explain patterns in floodplain vegetation across the UMRS (see section 3.2.4 Floodplain Vegetation Diversity). Specifically, in the northern portion of the UMR upriver of Pool 11, De Jager and others (2015a) determined that forest communities that support less flood-tolerant oak and hickory species, as well as dry grassland species, were positively associated with floodplain areas that flooded for less than 30 days during the growing season. Areas that flooded between 30 and 70 days during the growing season may support a wide range of plant communities, including wet meadows, maple dominated floodplain forests, willow, and cottonwood communities. Finally, areas that flooded for longer than 70 days showed a positive association with shallow marsh communities, with progressively more flood-tolerant herbaceous species occurring in areas with even longer durations. These results are further supported by correlations between the area (hectare per linear river mile) in different floodplain functional classes and the area (hectare per linear river mile) in different floodplain vegetation communities (See section 3.2.4 Floodplain Vegetation Diversity), suggesting that modifications to the abundance and distribution of floodplain functional classes could play a strong role in modifying the abundance and distribution of specific plant communities. 

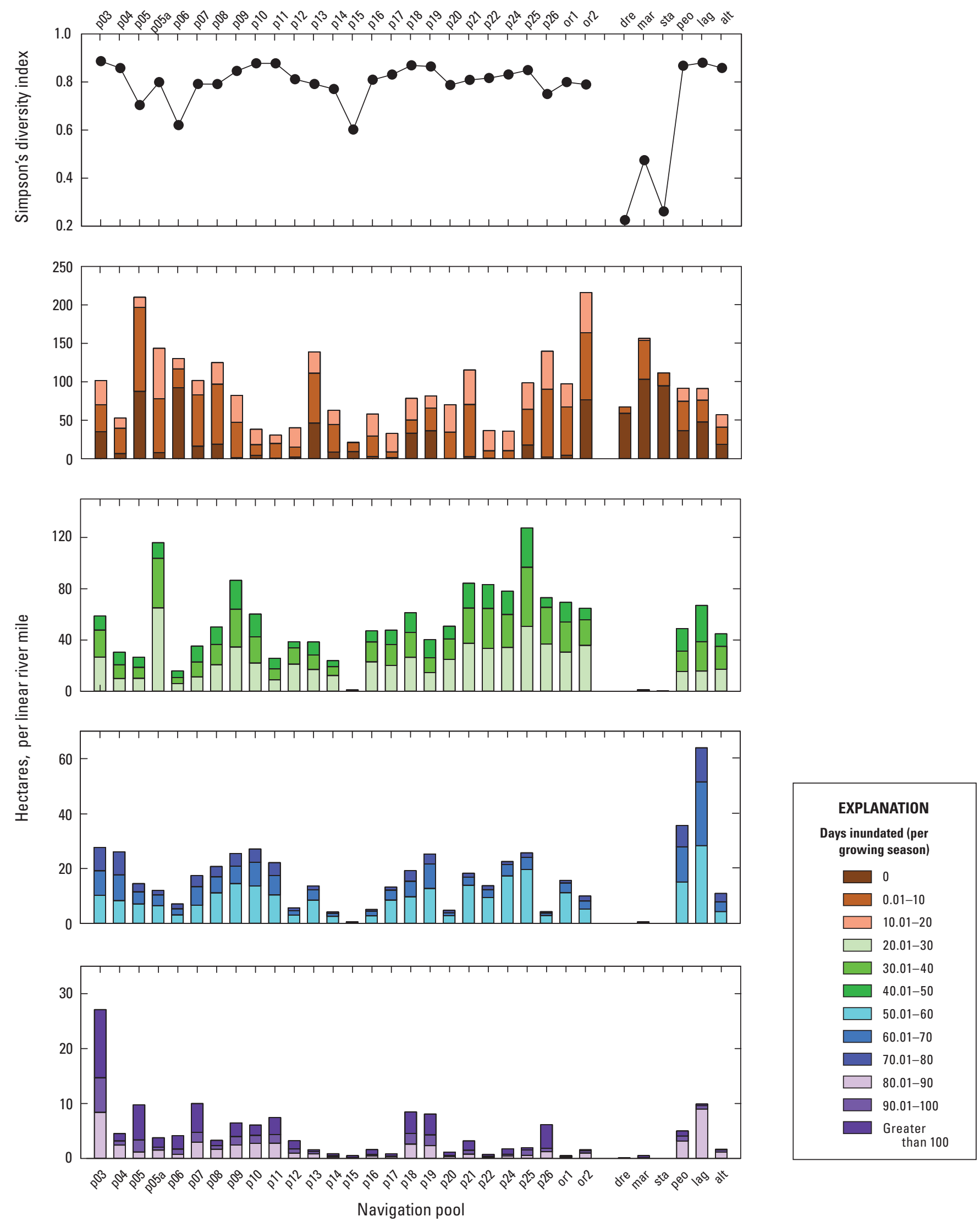

Figure 19. The area (hectare per linear river mile) of different 40-year mean growing season flood inundation zones (for example, floodplain functional classes) and Simpson's diversity index (top panel) applied to all inundation zones for each navigation pool within the Upper Mississippi River System. Note different y-axis scales among different panels. 
The floodplain functional classes represent different flood-inundation duration zones that have known relations with UMRS floodplain vegetation communities. For this reason, the diversity of classes represents the hydrogeomorphic variability of nonaquatic areas. Identifying places with relatively high or low hydrogeomorphic variability can be useful for understanding how restoration projects that modify surface topography or manipulate water-surface elevations may affect pool-scale hydrogeomorphic variability in ways that support diverse and resilient floodplain plant communities. However, there are other aspects of the flood regime that may be useful in parsing out variability in vegetation communities and (or) other important ecological attributes such as nutrient cycling. Future research could illuminate how multiple aspects of flooding (such as frequency, duration, depth, and timing) might drive patterns of vegetation, biogeochemical cycling, soil development, and sediment dynamics in the UMRS.

\subsubsection{Floodplain Vegetation Diversity}

\section{Brief Method}

To represent the composition and diversity of floodplain vegetation communities, land cover and land use data were used for the years 1989, 2000, and 2010 (fig. 20). Briefly, the land-cover data provides an approximation of the amount and distribution of standard land-cover classes (such as agriculture, development, roads, sand, etc.) as well as important vegetation communities (table 6; Dieck and others, 2014). We focused on 10 vegetation classes considered to be natural vegetation in section 3.1.2 in addition to sand and (or) mud to further characterize differences among navigation pools and through time in the composition and diversity of the UMRS floodplain. .

\section{Brief Results and Discussion}

As noted in section 3.1.2 (Longitudinal Floodplain Connectivity), floodplain vegetation makes up a much greater proportion of the total UMRS floodplain in the northern portion of the river system than in the southern portion of the system where the floodplain is much wider, protected by levees, and dominated by agriculture. Within the areas of the UMRS floodplain in natural land-cover types, a diversity of vegetation types exists. The high degree of interspersion among vegetation types results from the complex interplay between temporal patterns in water levels on the UMRS and the topographic structure of the floodplain (see section 3.2.4 Floodplain Functional Classes). For example, the abundance of upland forest, grassland, lowland forest, shrub-scrub, and sedge meadow communities was generally greatest in navigation pools that had more area that flooded for less than 10 days during the growing season (table 7). As the amount of area in navigation pools that exceeded 10 days inundation per growing season increased, the area in these less flood-tolerant plant communities declined. In contrast, the area of navigation pools in floodplain forest, wet meadow shrub, wet meadow, Salix, Populus, and shallow marsh communities was positively correlated with the area of navigation pools that flooded for longer than 10 days per growing season (table 7). The most highly flood-tolerant vegetation types appeared to be wet meadow, Salix, and shallow marsh communities, as their abundances were often highly correlated with the area of navigation pools that flooded for longer than 50-60 days during the growing season (table 7).

The associations between flood inundation and vegetation communities can help explain the longitudinal patterns in floodplain vegetation diversity and composition shown in fig. 21. For example, in the northern portion of the UMR, the diversity of vegetation types fluctuated between lows near 0.5 in navigation pools 4 and $5 \mathrm{a}$ to higher values (near 0.7 ) in navigation pools 5, 6, 7, and 8 . However, diversity declined from navigation pool 6 to 12 . This decline occurred in relation to the decline in floodplain functional classes that flood for fewer than 20 days during the growing season (fig. 19) and an associated decline in the abundance of the lowland forest community type (fig. 21). In addition, two more flood-tolerant plant communities (wet meadow and shallow marsh) also tended to decline in abundance from pools 6 to 12. The longitudinal shift in the abundance of wet meadow communities is notable because a recent study showed that approximately 70 percent of the wet meadows in pools $3-10$ were dominated by single invasive species, Phalaris arundinacea [reed canarygrass]) (De Jager and others, 2017).

Downriver of Navigation Pool 12 and throughout the Illinois River, the diversity of vegetation types varied, but generally increased to reach similar levels to those observed in the far north of the UMR for the years 2000 and 2010 (fig. 21). This spatial increase in diversity was primarily driven by an increase in the relative abundance of three forest types: lowland forest, Populus, and Salix communities. In the open river reaches (or1 and or2), these community types were relatively abundant during all years $(1989,2000$, and 2010), but for pools 17-26, these community types were much less abundant in 1989, and the floodplain forest community type was dominant in 1989. One explanation for these changes is that the flood of 1993, in which river levels exceeded bank-full conditions for approximately the entire growing season in the lower river (Yin and others, 1994), may have created new sandbars and more open-canopied conditions that supported the establishment of early successional cottonwood and willow communities. It is also possible that agricultural lands in the lower river were abandoned following the flood of 1993 and have since recruited to early successional cottonwood communities. However, another explanation is that young oak, willow, and cottonwood communities were difficult to identify in 1989 photos; in 2000 and 2010, when the communities were older, oak, willow, and cottonwoods became easier to distinguish from other species. In addition, the relative abundance of wet meadow and other herbaceous communities that tend to be associated with longer flood durations decreased downriver from pool 12 (fig. 21) along with the area of the floodplain in long duration flood inundation zones ( $>80$ days; fig. 19). These lower-river navigation pools had a higher abundance of lowland forest and Populus communities, likely reflecting a greater abundance of areas that flood for less than 30 days during the growing season (fig. 19). 


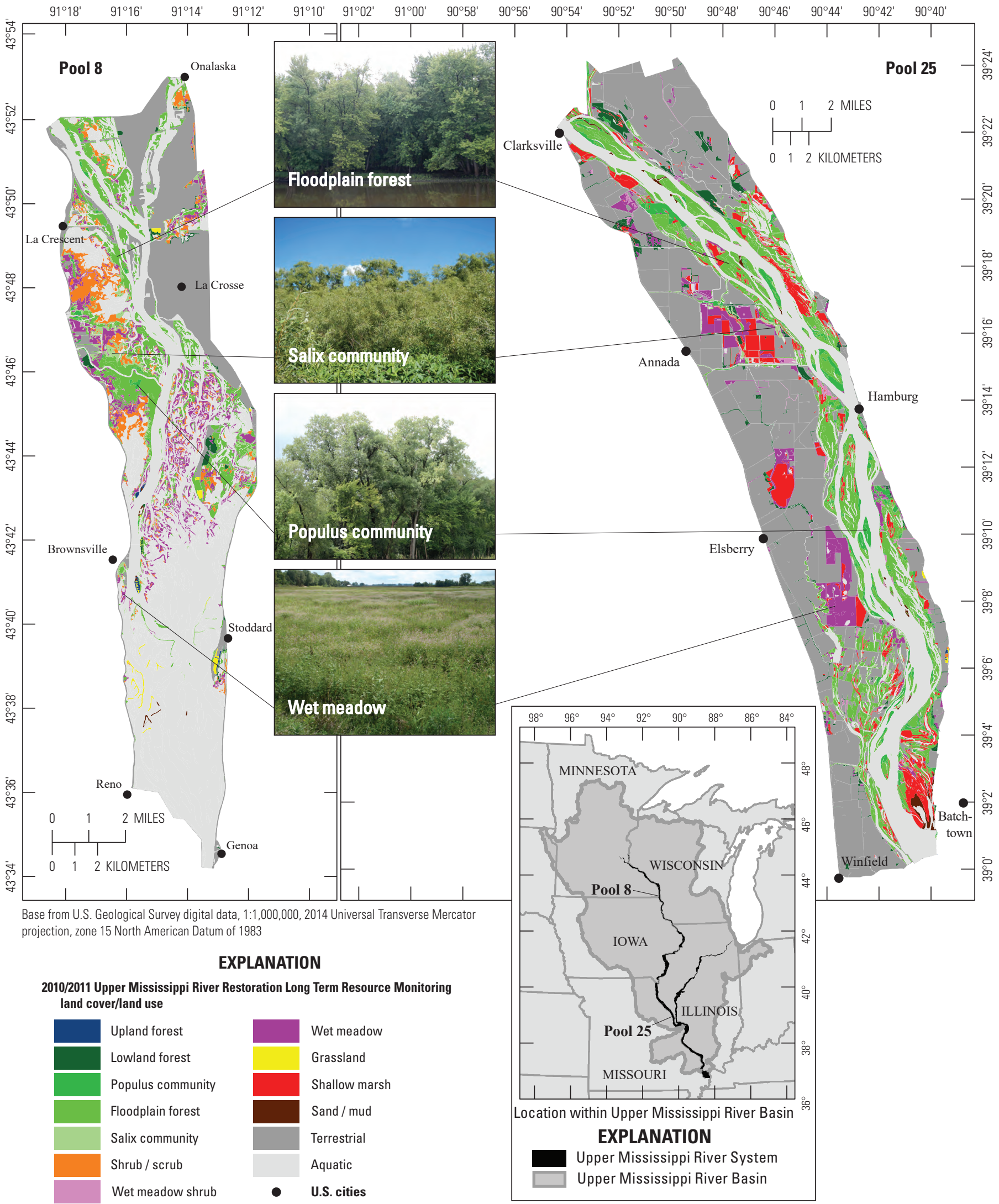

Figure 20. Maps illustrating the distribution of different floodplain vegetation types in navigation pool 8 in the northern portion of the Upper Mississippi River System and pool 25 in the south. 
Table 6. The floodplain vegetation community types used in the analysis of floodplain vegetation diversity, along with the plant species commonly found within each community type.

Community type

\section{Species present in community type}

Quercus rubra L., Quercus alba L., Carya ovate (Mill.) K. Koch, Populus tremuloides Michx., Betula papyrifera Marshall, Ulmus Americana L.

Quercus bicolor Willd., Quercus rubra L., Quercus macrocarpa Michx., Betula nigra L., Acer negundo, Populus deltoides W. Bartram ex Marshall, Carya cordiformis (Wangenh.) K. Koch.

Populus community Populus deltoides W. Bartram ex Marshall $>50 \%$ (other species listed in FF category at $<50 \%$ ).

Floodplain forest

Acer saccharinum L., Populus deltoides W. Bartram ex Marshall, Salix nigra Marshall, Betula nigra L., Ulmus americana L.

Salix community

Salix nigra Marshall, Salix interior Rowlee.

Amorpha fruticosa L., Rhus hirta L. (Sudworth), Rhus glabra L., Lonicera tatarica L., Lonicera morrowii A. Gray, Elaeagnus umbellata Thunb.

Salix interior Rowlee, Amorpha fruticosa L., Cornus amomum Mill., Cornus sericea L., S. nigra L, Sambucus racemosa L.

Phalaris arundinacea L., Leersia oryzoides (L.) Sw., Spartina pectinata Bosc ex Link, Panicum virgatum L., Lycopus americanus Muhl. ex W.P.C. Barton, Vernonia fasciculate Michx., Solidago canadensis L., Solidago gigantean Aiton, Asclepias incarnate L.

Grassland

Bromus inermis Leyss., Phleum prantense L., Poa pratensis L., Andropogon gerardii Vitman, Panicum virgatum L., Schizachyrium scoparium (Michx.) Nash, Sorghastrum nutans (L.) Nash.

Cephalanthus occidentalis L., Decodon verticillatus (L.) Elliott, Salix interior Rowlee, Cornus amomum Mill., Scirpus fluviatilis , Phragmites australis (Cav.) Trin. ex Steud., Polygonum amphibium L., Lythrum salicaria L., Echinochloa crus-galli (L.) P. Beauv., Echinochloa muricata (P. Beauv.) Fernald, Bidens frondosa L., Bidens cernua L., Cyperus odoratus L., Xanthium strumarium L., Polygonum pensylvanicum L., Eleocharis obtusa (Willd.) Schult.

Table 7. Correlation coefficients quantifying associations between the area (hectare per river mile) in different floodplain functional classes in navigation pools of the Upper Mississippi River System and the area (hectare per river mile) in different floodplain vegetation types in navigation pools of the Upper Mississippi River System.

$[>$, greater than $]$

\begin{tabular}{|c|c|c|c|c|c|c|c|c|c|c|c|c|c|}
\hline $\begin{array}{l}\text { Floodplain } \\
\text { functional } \\
\text { class }\end{array}$ & $\begin{array}{l}\text { Upland } \\
\text { forest }\end{array}$ & Conifers & $\begin{array}{c}\text { Lowland } \\
\text { forest }\end{array}$ & Grassland & $\begin{array}{l}\text { Shrub/ } \\
\text { scrub }\end{array}$ & $\begin{array}{c}\text { Sedge } \\
\text { meadow }\end{array}$ & $\begin{array}{l}\text { Populus } \\
\text { community }\end{array}$ & $\begin{array}{l}\text { Flood- } \\
\text { plain } \\
\text { forest }\end{array}$ & $\begin{array}{c}\text { Wet } \\
\text { meadow } \\
\text { shrub }\end{array}$ & $\begin{array}{c}\text { Wet } \\
\text { meadow }\end{array}$ & $\begin{array}{c}\text { Salix } \\
\text { community }\end{array}$ & $\begin{array}{c}\text { Shallow } \\
\text { marsh }\end{array}$ & $\begin{array}{l}\text { Sand/ } \\
\text { mud }\end{array}$ \\
\hline 0 & 0.41 & 0.25 & 0.48 & 0.40 & 0.38 & 0.34 & -0.27 & -0.36 & 0.07 & 0.09 & 0.02 & 0.13 & $\llcorner 0.04$ \\
\hline 20 & $\square-0.11$ & 0.01 & $\mathbb{L}_{-0.05}$ & $\square-0.11$ & $\square-0.13$ & 口-0.11 & 0.37 & 0.75 & 0.18 & 0.14 & 0.13 & 0.34 & [0.15 \\
\hline 30 & $\square-0.18$ & $\vdash 0.01$ & $\vdash 0.02$ & \begin{tabular}{|l}
-0.21 \\
\end{tabular} & $\square-0.22$ & - 0.11 & 0.56 & 0.78 & 0.35 & 0.23 & 0.14 & 0.47 & D.21 \\
\hline 60 & $\square-0.12$ & 【-0.04 & $\square-0.27$ & П-0.10 & 『-0.08 & $\mathbb{-}-0.04$ & 0.40 & 0.48 & 0.31 & 0.32 & 0.64 & 0.45 & 0.59 \\
\hline 70 & $\mathbb{\sharp} 0.02$ & $\llcorner 0.01$ & -0.38 & 口-0.08 & 【-0.06 & $\llcorner 0.02$ & $\mathbb{\square}-0.07$ & 0.25 & $\| 0.02$ & 0.20 & 0.73 & 0.27 & 0.57 \\
\hline 80 & 『0.05 & 0.01 & -0.42 & D-0.07 & 』-0.08 & 0.01 & $\square-0.12$ & 0.22 & $\mathbb{L}-0.03$ & 0.21 & 0.62 & 0.27 & 0.45 \\
\hline 90 & 0.12 & 0.01 & -0.38 & $\mathbb{-}-0.04$ & $\vdash 0.03$ & $\llbracket 0.04$ & $\square-0.12$ & 0.28 & $\llbracket-0.04$ & 0.15 & 0.29 & 0.21 & 0.40 \\
\hline 100 & 0.20 & 0.01 & 0.01 & 0.01 & $\mid 0.03$ & 0.01 & 0.01 & 0.35 & 0.05 & 0.25 & 0.08 & 0.29 & $\llbracket 0.08$ \\
\hline
\end{tabular}



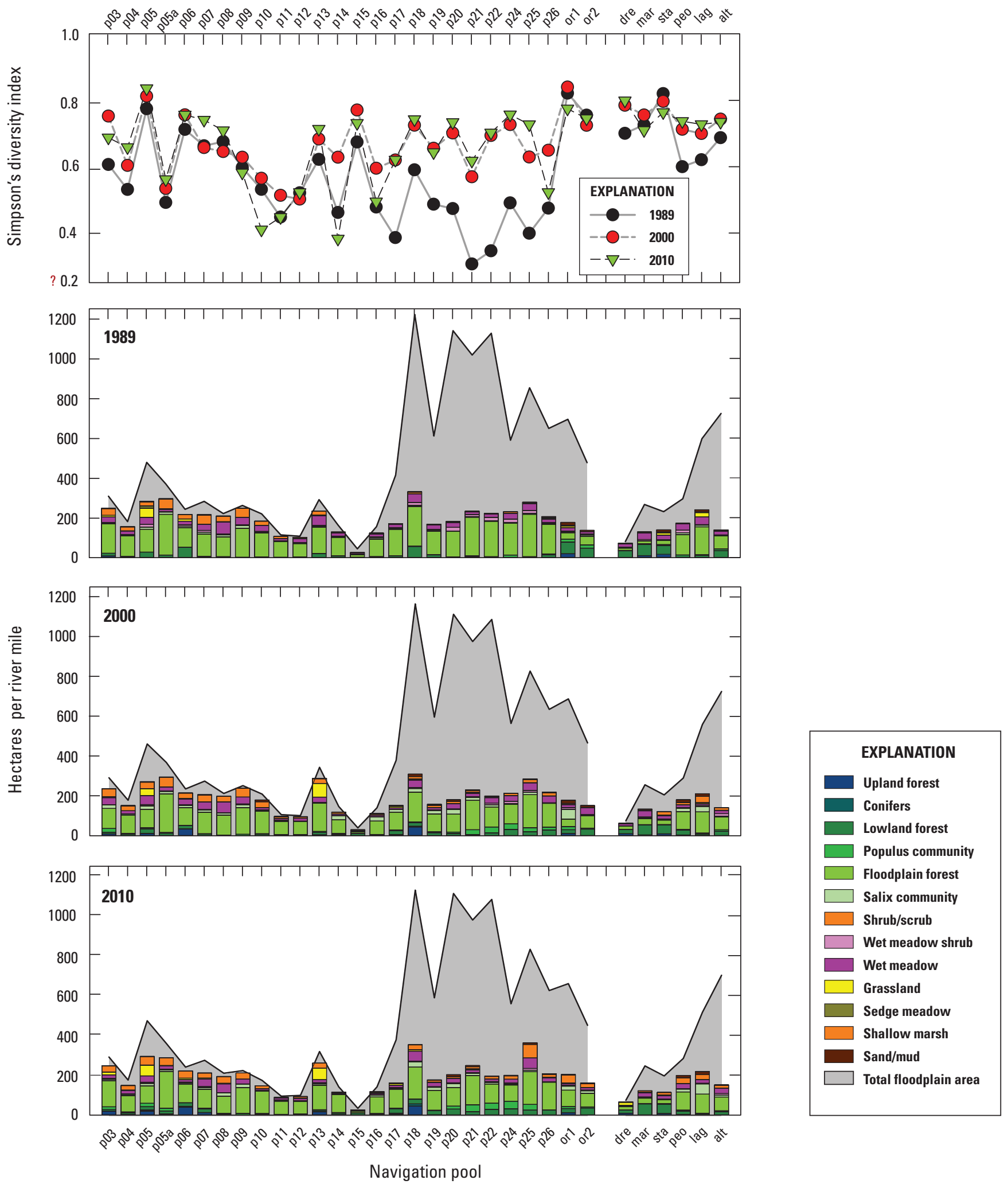

Figure 21. Simpson's diversity (top panel) and the area (hectare per linear river mile) of different floodplain vegetation classes within the navigation pools of the UMRS for 1989, 2000, and 2010 (progressively lower panels). Also shown is the total floodplain area in the background of the lower three panels. 


\subsection{Controlling Variables}

Strong controlling variables help maintain the underlying structure of a system; however, the system may change rapidly if controlling variables cross critical thresholds or approach close enough to critical thresholds that an environmental or anthropogenic disturbance moves the system over the threshold (Biggs and others, 2012). Flow and sediment regimes are examples of controlling variables in river systems that strongly interact with vegetation to influence channel morphology, hydraulics, and related habitat features. We included watersurface elevation fluctuations as an indicator of flow regime and TSS concentrations as an indicator of sediment regimes and water clarity because TSS and water level fluctuations are important in feedback loops with aquatic vegetation, as described in sections 3.3.1 and 3.3.2.

\subsubsection{Water-Surface Elevation Fluctuations}

\section{Brief Methods}

Water-surface elevation fluctuations characterize the effects of locks and dams on the UMRS flow regime and how locks and dams impact processes and communities that respond to water-level variability (such as denitrification in the near-shore environment and emergent and submersed plant communities). Daily water-surface elevation data were compiled from USACE (http://rivergages.mvr.usace.army.mil/WaterControl/ new/layout.cfm) for all tailwater and pool gages within the navigation pools of the UMR and from U.S. Geological Survey gages (https://waterdata.usgs.gov/nwis/) with both contemporary and prelock and dam stage data. For each year between 1985 and 2015, the minimum water-surface elevation was subtracted from the maximum water-surface elevation during the growing season (April 1 through September 30). Annual calculations of maximum water-surface elevation change during the growing season were averaged across the period. Maximum growing season water-surface elevation change was also calculated and averaged for U.S. Geological Survey gages with prelock and dam water-surface elevation data for years 1900-1930 (except the Winona, Minnesota, gage, which was calculated for years 1878-1902 and 1928-1935 because of lack of data between 1902 and 1928). Between gages with historical data, the mean annual maximum growing season water-surface elevation change was linearly interpolated using data from the two closest gages. The difference between prelock and dam and current watersurface elevation fluctuations represents increased $(+)$ or decreased (-) seasonal fluctuations because of river management changes (fig. 22).

\section{Brief Results and Discussion}

Mean annual maximum growing season water-surface elevation fluctuations for the pool gages on the UMRS tended to increase from upriver to downriver on the UMR, indicating the navigation pools in the lower portion of the UMR exhibit water-level variability more similar to prelock and dam conditions (fig. 22). However, all pool gages on the UMR display less variability than prelock and dam conditions. Minor differences were observed between the early period of record ( 1989 period) and the later period ( 2010 period), with higher variability in water-surface elevation fluctuations observed more recently. Limited data were available for the gages on the Illinois River, but for those where data were available, the gages on the lag and peo navigation pools showed higher variability in water-level fluctuations than observed for the prelock and dam condition (fig. 22).

Some tailwater dams in the far northern portion of the UMRS (navigation pools 5-8 and 15) also show less variability in water-surface elevation than prelock and dam conditions (fig. 23). For the remaining navigation pools on the UMR, water levels were similar to prelock and dam conditions, with levels slightly more ( $\sim 2010$ period) or less ( $\sim 1989$ period) variable. Overall, most tailwater gages exhibit a similar degree of variability in water-surface elevation fluctuations as occurred prelock and dam. For these navigation pools, the effects of the downriver dams on water-surface elevation fluctuations do not appear to extend to the length of the navigation pool to the upriver dam. In the Illinois River and the open river reaches (or1 and or2) on the UMR, water-surface elevation fluctuations have increased greatly from prelock and dam conditions (fig. 23), reflecting a combination of increased magnitude and variability in river discharge due to watershed land use and the effects of levees and river training structures on river stage (Sparks and others, 1998; Huizinga, 2009; Watson and others, 2013).

Seasonal water-level patterns have been altered by permanently inundating and, thereby, reducing the range of waterlevel variation directly upriver of lock and dam structures (Sparks and others, 1998). Inundation duration and frequency strongly influences the composition and age structure of floodplain plant communities (De Jager, 2012; De Jager and others, 2015a) and strongly influences the establishment of emergent vegetation and moist-soil plants (Sparks and others, 1998). On the other hand, stable water levels tend to support submersed aquatic vegetation, helping to explain the correspondence between reduced water-level variability and high amounts of submersed vegetation in the upper portions of the UMR (see section 3.2.2 Aquatic Vegetation Diversity). In areas adversely affected by reduced water-level variations, management 
actions such as water level drawdowns or restoration projects that alter floodplain elevation may influence vegetation communities. In the unimpounded (open river) reaches, growing season water-level variations have greatly increased, likely a result of changes in channel morphology and basin-wide runoff patterns. Though management actions likely will not influence stage variation in this reach, water-level fluctuations may influence the effectiveness of restoration actions.

The change in seasonal water-level fluctuations owing to the completion of the locks and dams was a relatively rapid step-change in seasonal ranges of river stage as well as shortterm variation in water-level elevation. Many decades later, the system continues to adapt to the change in water level, as exemplified by the long-term accumulation of sediment in offchannel areas and ongoing erosion of islands in the impounded areas of some pools. In addition, the short-term variation in water levels associated with maintaining adequate depth in the navigation channel likely affects the distribution and abundance of aquatic and floodplain vegetation.

\subsubsection{Total Suspended Solids Concentrations}

\section{Brief Methods}

TSS concentrations provide important information regarding water clarity and feedbacks that occur between TSS and a suite of biological and biogeochemical processes. TSS concentrations also show the important link between the combined effects of watershed land use and climate (which ultimately determine TSS inputs) and in-river conditions of water clarity and vegetation distribution and abundance (Madsen and others, 2001). Variation in TSS concentrations occur at a wide range of temporal scales from hours or days (in response to short-term storm-run off events); years (in response to fluctuations in aquatic vegetation); and decades or centuries (in response to changes in land use). USACE transparency data collected at lock and dams were converted to TSS concentrations (using equations from Giblin and others [2010] established in pools 8 and 13) and combined with LTRM fixed sites that collect TSS to visualize longitudinal TSS patterns. In addition, TSS data from LTRM stratified random sampling was used to illustrate broad-scale changes in TSS between 1994-2001 and 2007-14. The LTRM TSS data are available online (see table 3 for link) and Soballe and Fischer (2004) describe the sampling design, data collection methods, and laboratory analysis. For navigation pools with overlapping data (both LTRM and USACE) the two datasets were highly correlated with each other $(\mathrm{R}=0.96)$.

\section{Brief Results and Discussion}

TSS concentrations were highest upriver from Lake Pepin in the northern UMRS (upriver of pool 4). Lowest concentrations were observed immediately downriver from Lake Pepin because the lake acts as a natural settling basin and retains much of the sediment input from upriver sources (Maurer and others, 1995). Downriver of Lake Pepin, TSS increases steadily (Houser and others, 2010; fig. 24). TSS concentrations tend to be highest in the open river reaches of the UMR. However, differences in TSS have been observed in some navigation pools through time. The early period (1994 2001) of LTRM sampling showed higher TSS concentrations in the main channel of the northern navigation pools (4 and 8 ) and for the open river reach (lower panel in fig. 24) than the later period (2007-2014). Although minor in comparison to the large longitudinal differences in TSS across the system, the improvements in water clarity may be important for the distribution of vegetation in some of these reaches (see section 3.2.2 Aquatic Vegetation Diversity).

TSS affect water clarity, which is an important driver of the distribution and abundance of aquatic vegetation that provide habitat and food for fish and waterfowl (Korschgen and others, 1988). Increased TSS (and associated increased rates of sedimentation) can also directly affect macroinvertebrate and fish communities (Wood and Armitage, 1997). Changes in aquatic vegetation abundance and fish community in pools 4 and 8 have been attributed to long-term declines in TSS concentrations (Popp and others, 2014; Giblin, 2017). In aquatic ecosystems, short-term variability of TSS concentrations is generally driven by precipitation patterns across the basin and, in off-channel areas (impoundments and backwater lakes), by wind and wave resuspension (Forsberg and others, 2017). Long-term TSS trends are likely driven by watershed derived changes in inputs (Allan and others, 1997). Over shorter temporal and spatial scales, the interaction between TSS and vegetation is likely important (Madsen and others, 2001). Because TSS variability is caused by multiple drivers at different scales, management of TSS can take numerous forms. At the basin scale, best management practices across the landscape can be used to reduce suspended sediment inputs. Within the UMRR Program, management actions have included island construction in impounded areas to reduce wind-induced turbidity. Water-level management has also been used to reduce water levels to support sediment compaction and vegetation growth. Once vegetation is established, it encourages the deposition of sediment by locally reducing flow and allowing suspended materials to settle, subsequently improving water clarity and promoting further aquatic vegetation establishment and persistence. 
EXPLANATION

Difference in range of growing season water surface elevations, in meter, from pre-lock and dam conditions at pool gages

\begin{tabular}{|c|c|}
\hline $\begin{array}{l}\text { Less than or equal } \\
\text { to }-2.00\end{array}$ & 0.01 to 0.50 \\
\hline-1.99 to -1.00 & 0.51 to 1.00 \\
\hline-0.99 to -0.50 & 1.01 to 2.00 \\
\hline-0.49 to 0.00 & Greater than 2.00 \\
\hline
\end{tabular}

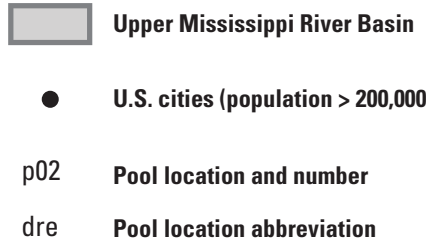

Location within U.S. lower 48 states

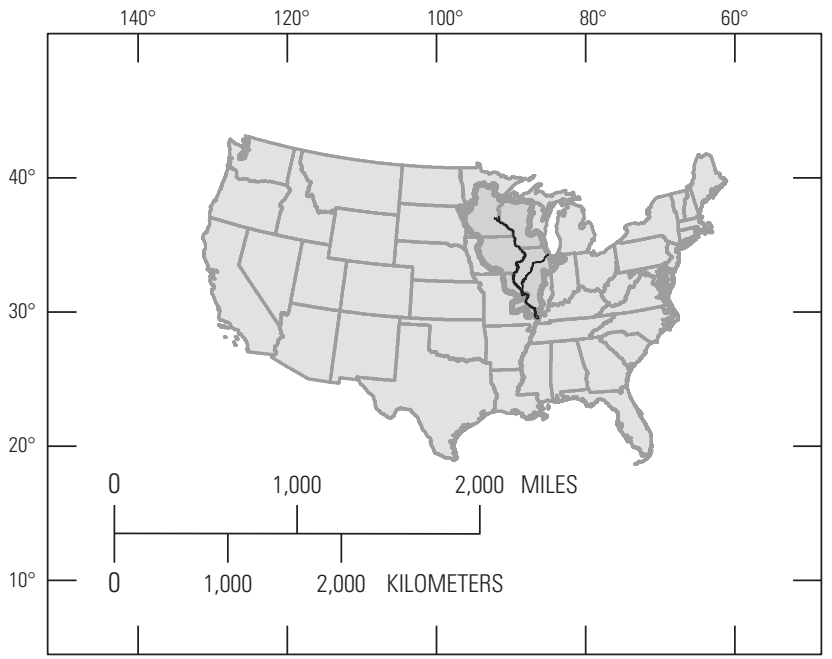

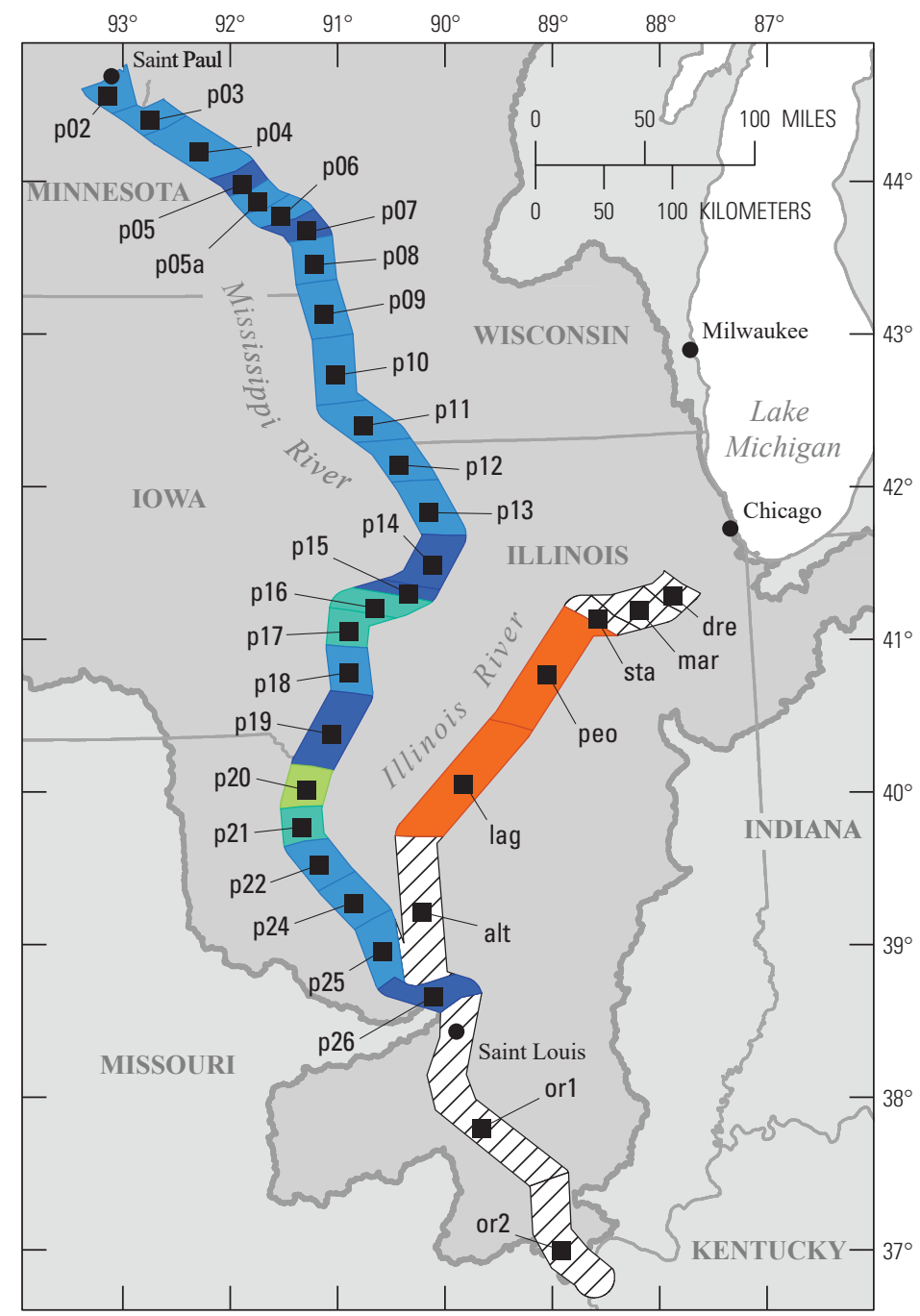

Base from U.S. Geological Survey digital data, 1:1,000,000, 2014 Universal Transverse Mercator, zone 15 North American Datum of 1983



Figure 22. Mean annual maximum growing season water-surface elevation fluctuations for pool gages on the Upper Mississippi River System for two periods (1985-94 and 2006-15) to match the other 1989 and 2010 datasets included in this report, along with estimated prelock and dam fluctuations (red line in lower panel). The map and colors represent the departure from prelock and dam conditions, with the dammed navigation pools typically having less variability (negative values) in water-surface elevation fluctuations than during prelock and dam conditions. Navigation pools referred to as "Unlm" are gages located within the unimpounded reach of the river south of St. Louis. The number following "Unlm" is the river mile at which the gage is located. 


\section{EXPLANATION}

Difference in range of growing season water surface elevations, in meter, from pre-lock and dam conditions at tailwater gages

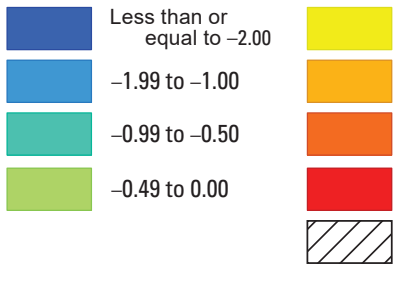

0.01 to 0.50

0.51 to 1.00

1.01 to 2.00

Greater than 2.00

No / limited data)

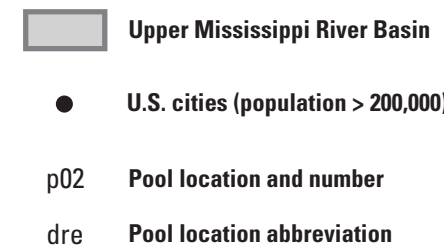

Location within U.S. lower 48 states



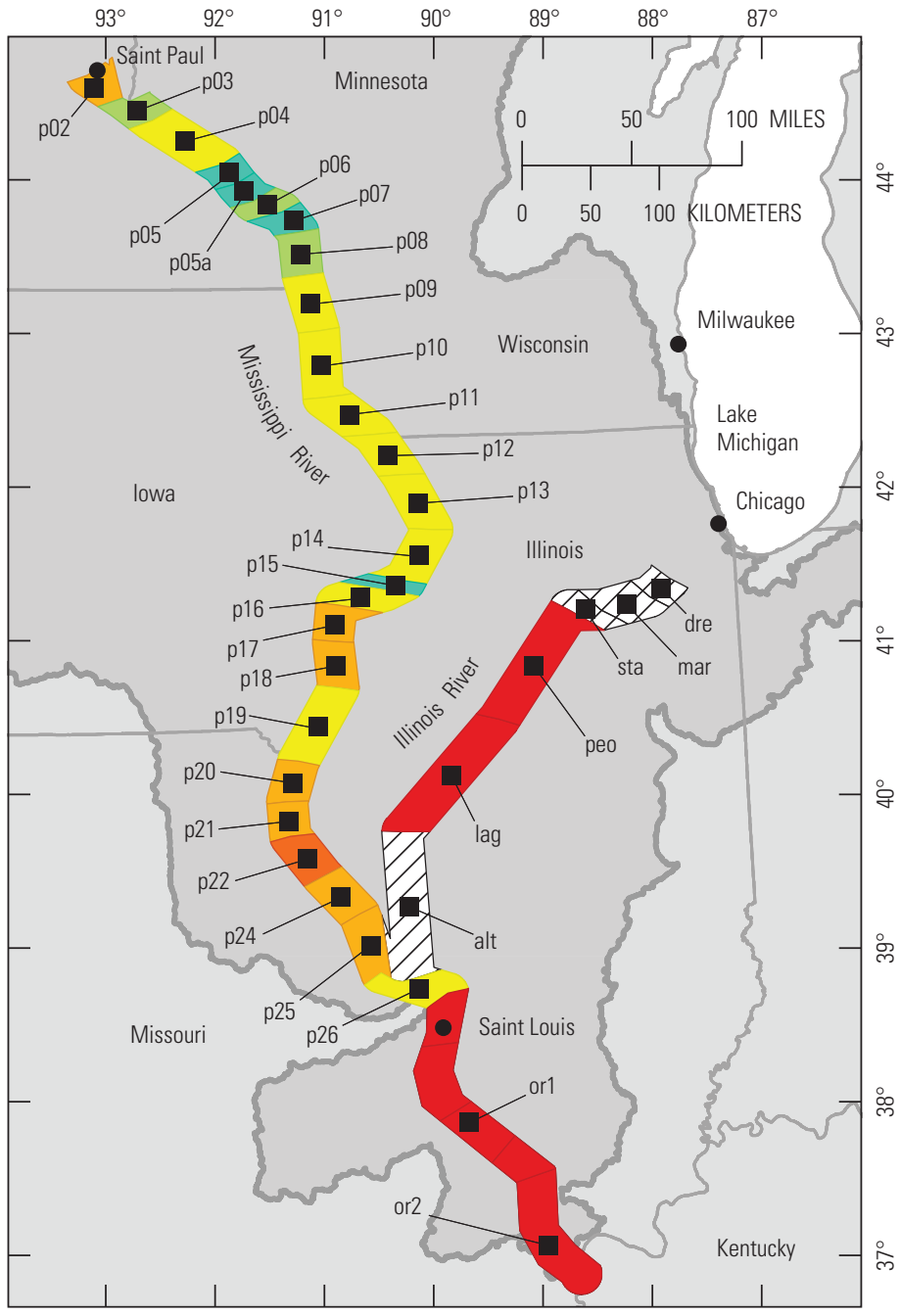

Base from U.S. Geological Survey digital data, 1:1,000,000, 2014 Universal Transverse Mercator, zone 15 North American datum of 1983

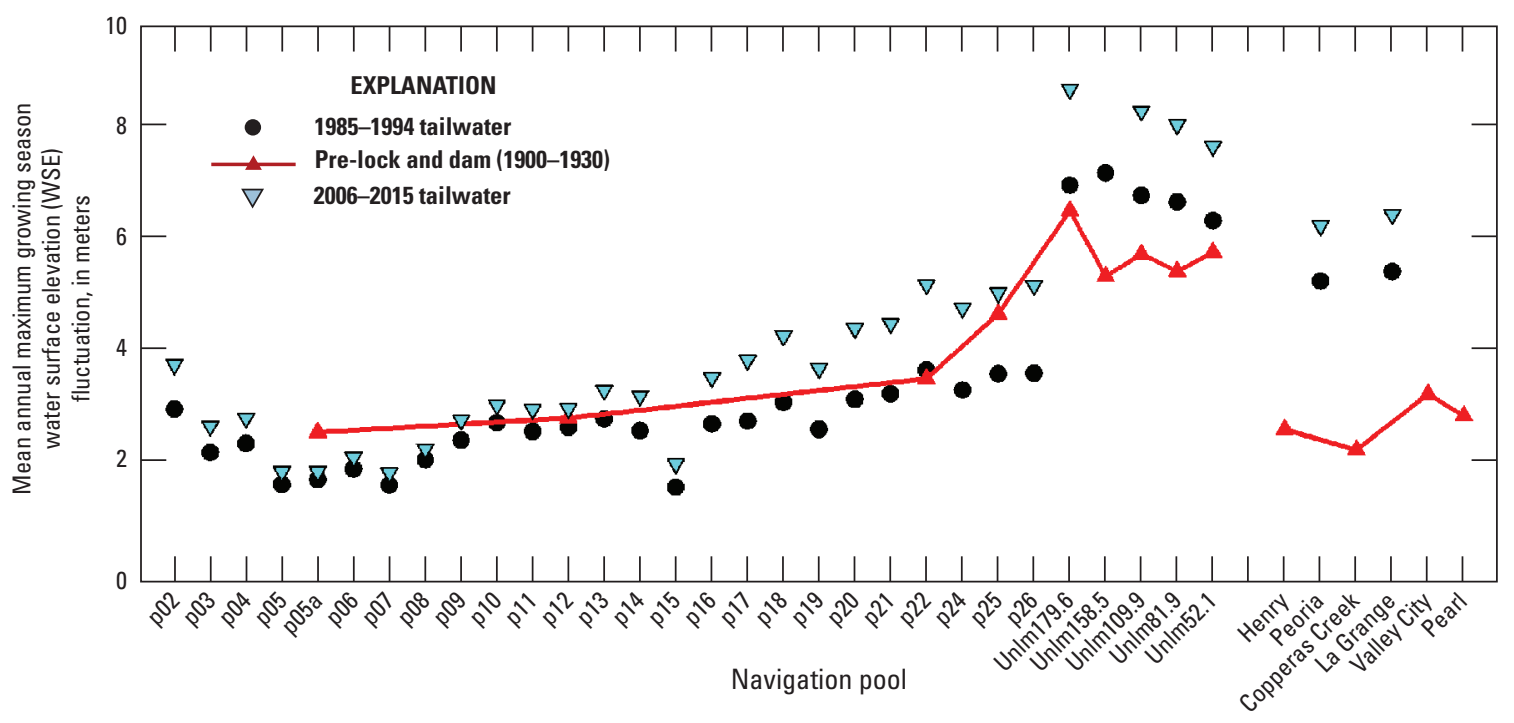

Figure 23. Mean annual maximum growing season water-surface elevation fluctuations for tailwater gages on the Upper Mississippi River System during 1985-94 and during 2006-15, along with estimated prelock and dam fluctuations (red line in the lower panel). The map and colors represent the departure from prelock and dam conditions, with the lower river reaches typically having more variability (positive values) in water-surface elevation fluctuations than during prelock and dam conditions and values closer to prelock and dam conditions. Navigation pools referred to as "Unlm" are gages located within the unimpounded reach of the river south of St. Louis. The number following "Unlm" is the river mile at which the gage is located. 


\section{EXPLANATION}

Total suspended solids, in milligrams per liter, in main channel (May to September)

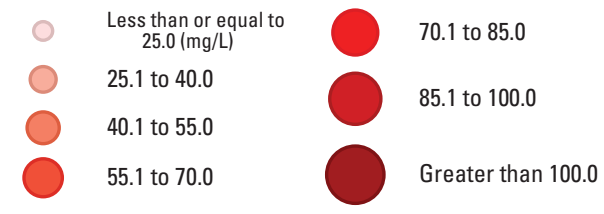

Upper Mississippi River basin

- U.S. cities (population greater than 200,000)

p02 Pool location and number

dre Pool location abbreviation

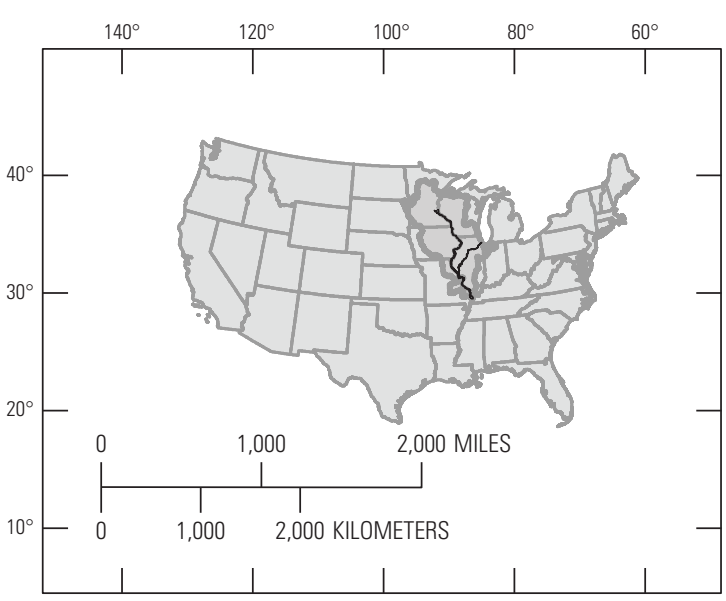

Base from U.S. Geological Survey digital data, 1:1,000,000, 2014 Universal Transverse Mercator, zone 15 North American Datum of 1983

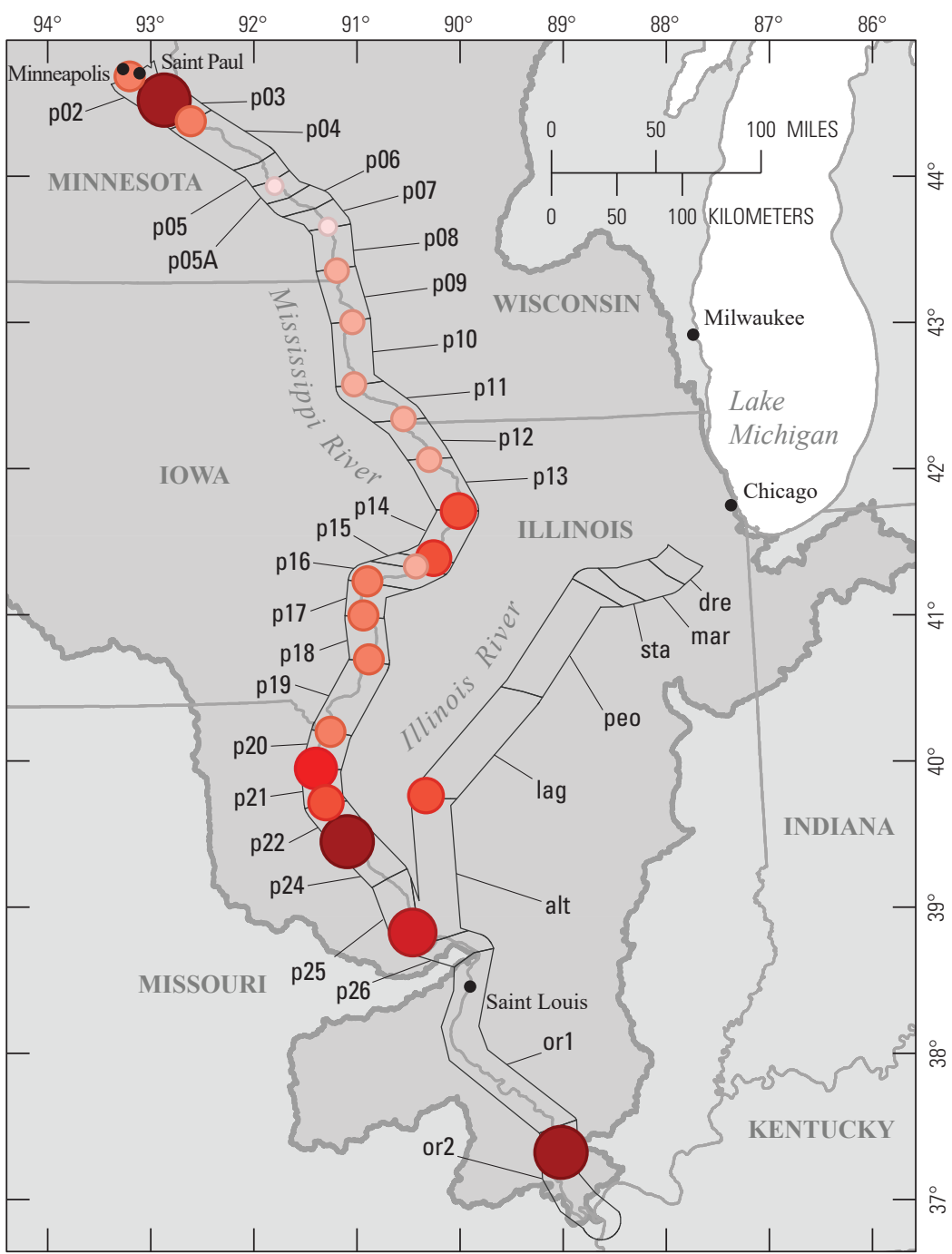

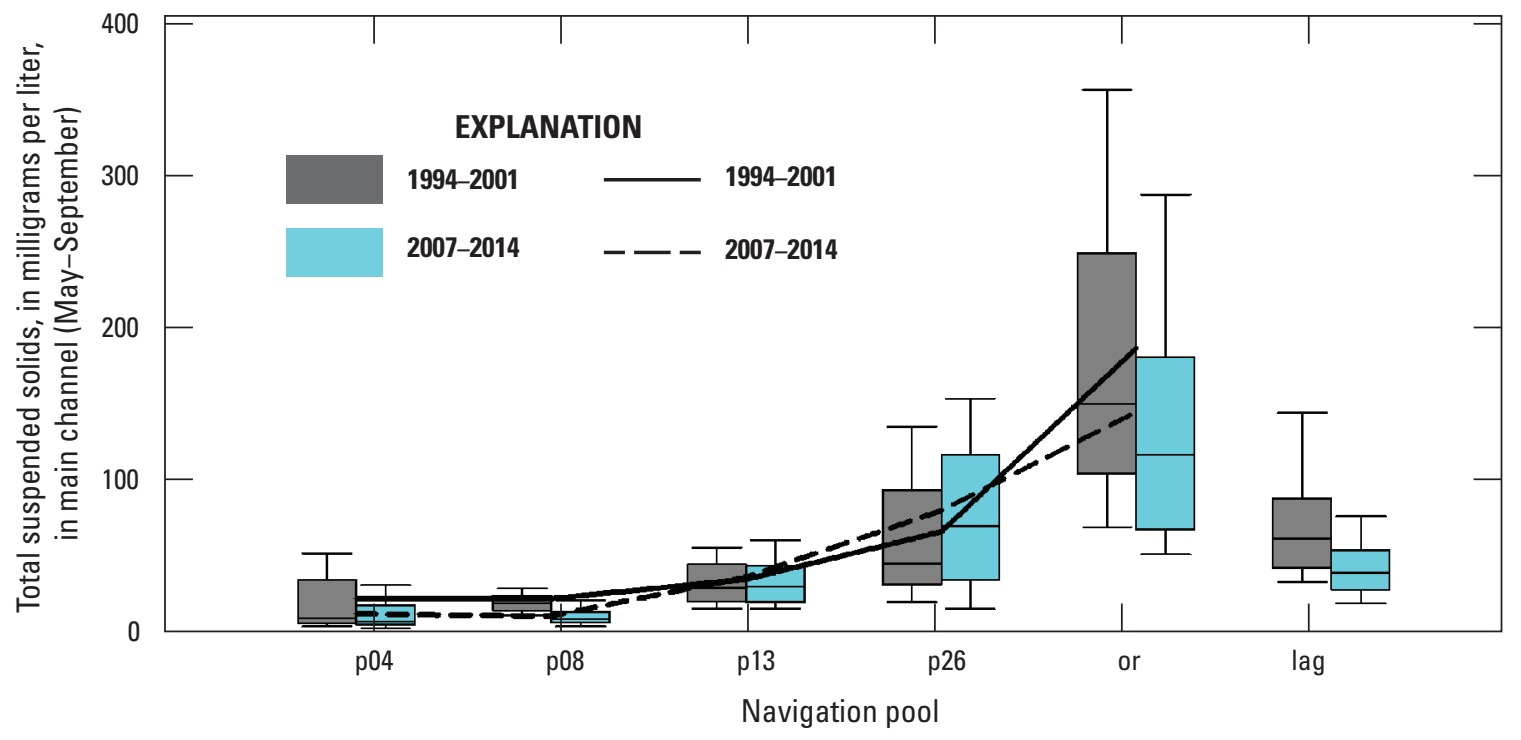

Figure 24. Total suspended solids concentrations collected at select dams on the Upper Mississippi River System (top panel) and in the main channel in select navigation pools of the Upper Mississippi River System sampled by the Upper Mississippi River Restoration Long Term Resource Monitoring (bottom panel). Shown on the lower panel are five reaches of the Upper Mississippi River (pool 4 [p04] through the open river reach [or]) and one reach of the Illinois River (lag). 


\subsection{Slow Processes}

We included two indicators that reflect processes that occur across broad spatial and long temporal scales: sedimentation in off-channel areas and floodplain forest succession. In both cases, observed slow changes during a few decades may underestimate potential future changes if critical thresholds exist that have not yet been reached. For example, though sedimentation may result in the loss of depth in off-channel areas, the observed accumulation of sediments may have not yet resulted in a fundamental shift in the lentic area distribution (such as from deep lentic areas supporting fish habitat to shallow lentic areas supporting waterfowl habitat). However, if projected into the future, observed accumulation rates may cross such critical thresholds and result in large-scale shifts in lentic functional classes abundance. Similarly, observed changes in floodplain forests may appear relatively minor if most tree cohorts have yet to reach their longevity. If the current species-age distributions are projected into the future, along with successional dynamics (such as species establishment, recruitment, and competition among new species), it is possible for large-scale changes to take place in the area, composition, and structure of floodplain forests.

\subsubsection{Sedimentation in Off-Channel Areas}

\section{Brief Methods}

Sedimentation in off-channel habitats of the UMRS was forecasted using a model (appendix 3) based on general sedimentation rates patterns derived from data attained by repeated surveys of bed elevation between 1997 and 2017 along lentic area transects in navigation pools 4 and 8 (Rogala and others, 2003; James T. Rogala written comm., 2017) The modeling objective was to forecast loss of deeper $(>0.5 \mathrm{~m})$ lentic habitats as they were converted to shallow lentic habitats (as defined in table 5) by the accumulation of sediment. Other lentic classes defined by depth (such as lentic depression lakes) were omitted from this assessment because sediment accumulation and erosion within such lakes vary greatly in time and space and cannot be reasonably predicted with the mean rates of accumulation we use in this report. We also estimated the expected future total area with depth greater than 0.5 and $1.0 \mathrm{~m}$ for each pool. Such forecasts of potential changes in functional classes can be used to inform management and restoration decisions for maintaining off-channel deep water habitats.

There were no strong relations between examined backwater characteristics (such as size high/low connectivity) or sampling site characteristics (such as depth) and measured sedimentation rates. This precluded developing a model for backwater and site-specific sedimentation rates that could be used to extrapolate measurements to larger scales. Instead, the model was based on mean sedimentation rates for each of 24 transects found in the 20-year period from 1997 through 2017.
The model selected sedimentation rates for each deep backwater lake randomly from this set of 24 transects to forecast conditions in 50 years. Results of this method can only appropriately be applied at the pool scale because forecasts of change in individual lakes is random. More details on the model, and how it was derived and deployed, are included in appendix 3.

\section{Brief Results and Discussion}

The results of the model yielded 50-year forecasts of the total area in each pool of two lentic functional classes (shallow lentic and deep lentic; fig. 25). The shallow lentic class is defined as lakes with less than 30 percent of the lake's perimeter being channel and less than 20 percent of its total area being less than $0.5 \mathrm{~m}$ deep. The deep lentic class is defined as lakes with less than 30 percent of the lake's perimeter being channel and greater than 1.0 hectares of area greater than $1.0 \mathrm{~m}$ deep. Similar forecasts were made for two depth classes $(>0.5 \mathrm{~m}$ and $>1.0 \mathrm{~m}$; fig. 26). These functional class and depth class criteria were based on expert opinion from a team of UMRR Program resource managers. Figures 25 and 26 illustrate forecasts of loss or gain in the selected classes during the next 50 years. Note that present conditions differ from those in the diversity and redundancy section of this report, because the large lentic with flow class (impounded areas) was not included in the results shown in figures 25 and 26. For functional classes in figure 26, the increase in the shallow lentic class is much larger than the decrease in the deep lentic class. Most of the functional class differences are because of how classes are defined whereby lakes, although accreting sediment, still maintained enough deep area to meet the criteria for that class. The changes in the area of deep water $(>1 \mathrm{~m})$ in figure 26 (lower panel) captures the raw change in water depths that is not reflected in the functional classes. The loss of area in both depth classes ( $>0.5 \mathrm{~m}$ and $>1.0 \mathrm{~m}$ ) is often large during the 50-year period, and the loss nears or exceeds 50 percent in some pools (fig. 26).

The survey data used to estimate the distribution of sedimentation rates across the UMRS was collected only in pools 4 and 8 in the uppermost reach of the UMRS. Data from past surveys in pool 13 suggest higher rates than those in pools 4 and 8 during a 1997-2001 study period (Rogala and others, 2003), and higher rates were also found in lag during a 19912001 study period (James T. Rogala and others, written communication). Whether that spatial pattern exists in the recent 20 -year sedimentation rates is unknown. The historical pattern suggests that actual losses of depth in the lower reaches may be greater than what is presented in this report. In addition to sedimentation rates, the assumption of limited transitions from aquatic to terrestrial may also not apply across the entire system. Also of note is that we are only looking at the loss of backwater habitats from the existing conditions. Many of the deeper backwaters habitats that existed after impoundment have already been lost. See appendix 3 for additional discussion of model assumptions, limitations, and interpretation. 

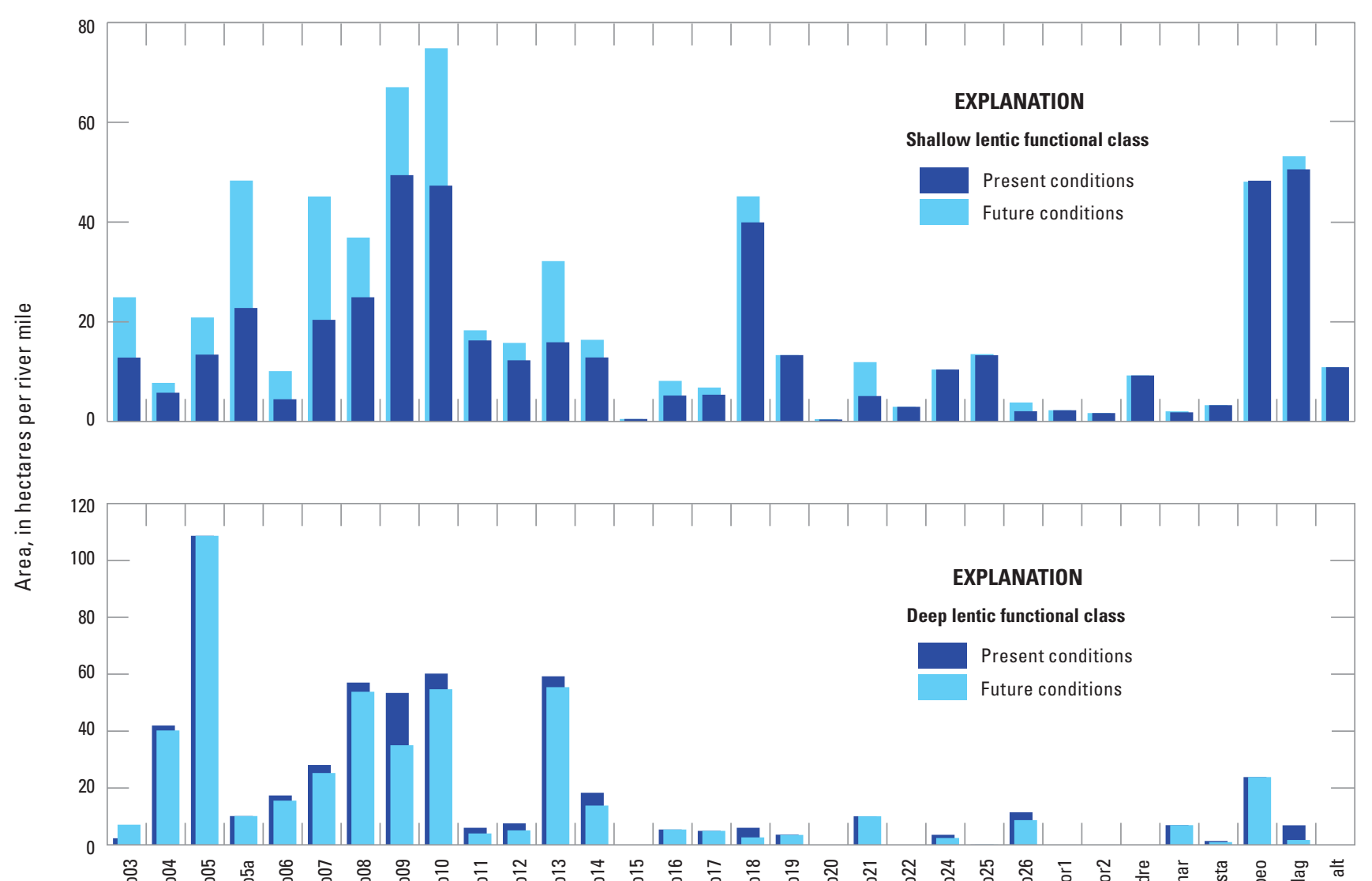

Navigation pool

Figure 25. Present (dark blue) and simulated future (light blue) area per linear river mile of lentic area in the shallow (upper panel) and deep (lower panel) functional classes. Note that these area estimates exclude large lentic areas with flow (for example, impounded areas). 


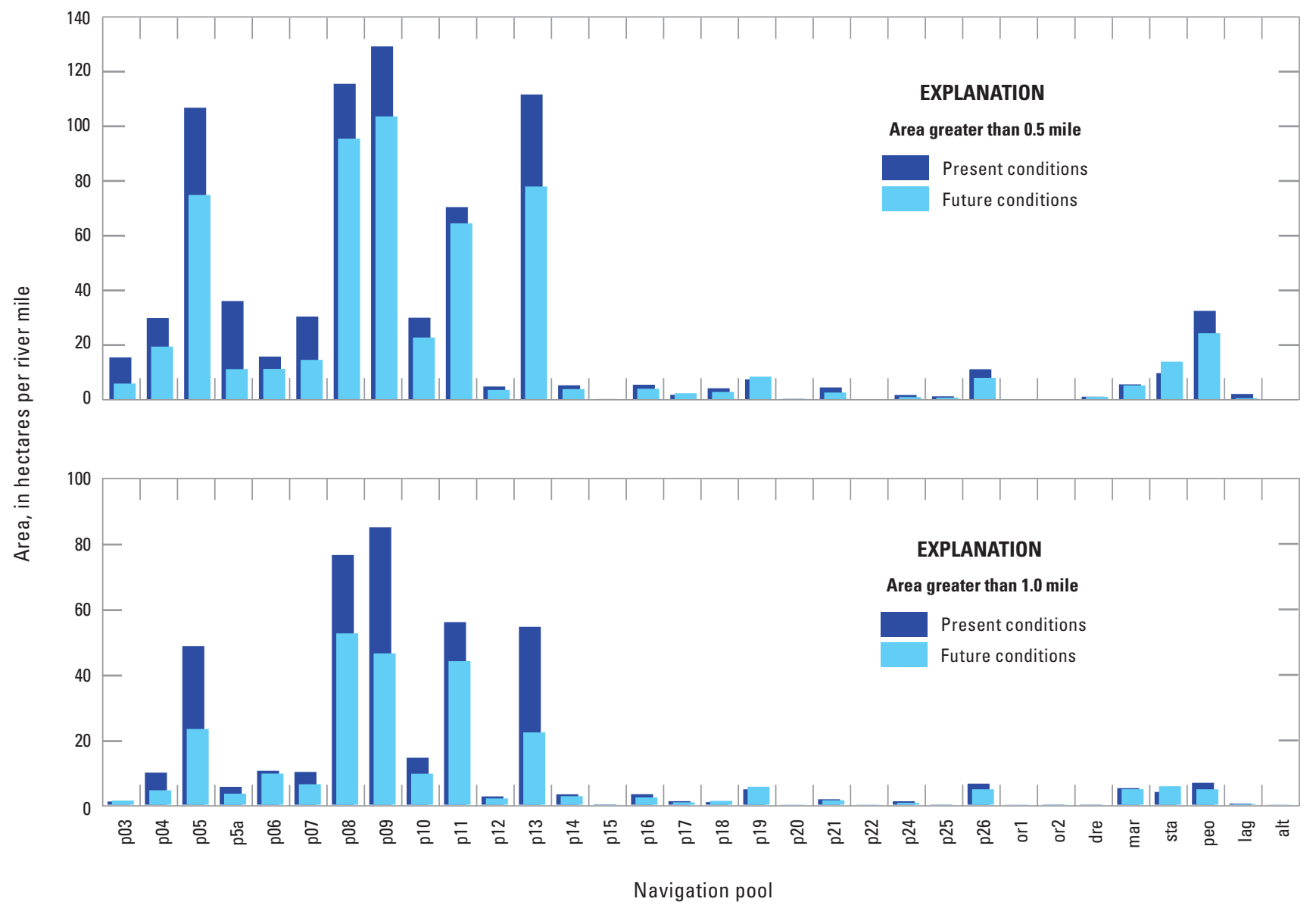

Figure 26. Present (dark blue) and simulated future (light blue) area per linear river mile of lentic area greater than 0.5 mile (upper panel) and greater than 1.0 mile (lower panel). Note that these area estimates exclude large lentic areas with flow (for example, impounded areas). 


\subsubsection{Floodplain Forest Succession}

\section{Brief Methods}

Patterns of forest succession in floodplains are difficult to predict given the stochastic nature of flooding and its importance in shaping different aspects of plant community dynamics (such as germination, recruitment, competition, and survival). Consequently, many research efforts are aimed at improving our empirical understanding of the various ways flooding impacts plant communities. Though such studies provide valuable information about which species may perform better than others during flooded conditions (flood tolerance), it is often unclear how empirical relations between flood inundation and tree survival ultimately impact succession across large landscapes subject to spatial and temporal variability in flooding, especially in ecosystems that have undergone changes to their hydrological regime. One way to evaluate long-term and large-scale patterns of forest succession in such spatially and temporally dynamic landscapes is to use spatially explicit simulation models (Xi and others, 2009).

We adapted a widely used forest landscape model (LANDIS-II) to simulate forest succession in the UMRS in the context of annual spatial variability in flood inundation and the effects of an exotic invasive wood-boring insect (Agrilus planipennis [emerald ash borer; EAB]). LANDIS-II is a process-based, spatially explicit model that represents forest generative processes (such as dispersal, growth, and competition) as well as forest degenerative processes (such as senescence and disturbance) at broad spatial scales ( $>1,000$ hectare) and long temporal scales (centuries) (Mladenoff and others, 1993; Mladenoff and He, 1999). In particular, we used the Biomass Succession LANDIS-II extension (Scheller and Mladenoff, 2004) to represent the processes of establishment, growth, competition, and senescence as they affect and are affected by the biomass of tree-species cohorts (See appendix 4 for details).

The initial forest landscape consisted of four forest types delineated by aerial photo interpretation: floodplain forest, lowland forest, Populus community, and Salix community. These forest types were represented in section 3.2.4 (Floodplain Vegetation Diversity). For modelling purposes, the floodplain forest-community type included silver maple (Acer saccharinum L.); American elm (Ulmus americana L.); green ash (Fraxinus pennsylvanica Marshall); river birch (Betula nigra L.); boxelder (A. negundo L.); American sycamore (Platanus occidentalis L.); and swamp white oak (Quercus bicolor Willd.). The lowland forest community type included northern red oak (Q. rubra L.); bur oak (Q. macrocarpa Michx.); swamp white oak (Q. bicolor Willd.); common hackberry (Celtis occidentalis L.); bitternut hickory (Carya cordiformis [Wangenh.] K. Koch); and shellbark hickory (C. laciniosa [Michx. f.] G. Don). Swamp white oak is often a component of both floodplain and lowland forest communities in the UMR and is therefore included in both forest types. The Populus community consisted of eastern cottonwood ( $P$. deltoides
W. Bartram ex Marshall). Finally, the Salix community primarily consisted of sandbar willow ( $S$. interior Rowlee) and (or) black willow (S. nigra Marshall) but may also contain other Salix species. To estimate the species composition and age structure of these forest types, we randomly imputed plot-level forestry data collected by the USACE for plots that had a species composition that matched those found within the four forest types. We further developed regression equations to derive age from the diameter of measured trees. Finally, we empirically developed species-specific growth equations to simulate changes in the biomass of species-age cohorts within the Biomass Succession extension (see appendix 4 for complete details for these methods). These methods were used to assemble datasets for the current distribution of species-age cohorts on the landscape, as well as species-specific growth parameters, for all navigation pools of the UMRS, except for the four uppermost pools of the Illinois River where no forestry data were collected.

In addition to simulating changes in forests due to processes such as establishment, growth, competition, and senescence within the Biomass Succession extension, we also simulated the effects of two disturbances on species-age cohort survival. We simulated spatial and temporal patterns in flooding using a newly developed surface-water connectivity model (see appendix 2 for details). We simulated a 100-year business-as-usual scenario by utilizing annual maps of total flood inundation duration during the growing season for each of the past 40 years (1972-2011). These maps were then recycled for years $41-80$, and the first 20 years were again recycled for years $81-100$ to simulate a possible 100-year scenario. These maps were used to represent spatial variability in flooding at the scale of $30 \mathrm{~m}$ pixels (approximately the size of forest plot data used to generate initial forest conditions) and temporal variability in flooding at an annual time step. Within the model, species-age cohort mortality was probabilistic. Mortality depended on both the annual duration of flooding that occurred within a pixel and the flood tolerance of the species-age cohorts present within that pixel. We used empirical data to parameterize species-age cohort flood tolerance using methods outlined in appendix 4 . We also simulated effects of an introduced insect, EAB, on the survival of ash species (see appendix 4 for details) because green ash is among the most abundant tree species in the UMRS (De Jager and others, 2012). Previous research indicates that all size classes of ash are hosts for EAB and infested trees are killed within a decade (Siegert and others, 2014). Across the Midwestern United States, EAB outbreaks have been responsible for the deaths of millions of ash trees since its arrival in 2002, and it is anticipated that $\mathrm{EAB}$ will persist in UMRS forests into the future, limiting the recruitment of ash species.

Because it is not possible to fully validate results from simulation models for future periods, such models are most appropriately used to project most-likely future changes under different scenarios. However, to support decision making within the UMRR Program, we focused attention on a single most probable future scenario to help management agencies 
better understand potential pathways of forest succession in this system. This scenario included EAB outbreaks and spatial and temporal flooding patterns similar to those observed during the past 40 years. We specifically addressed the following two questions: (1) how might the abundance and spatial distribution of the four forest types change during the next 50 and 100 years, and (2) are there specific floodplain functional classes (for example, long-term average inundation duration zones; see section 3.2.3 Floodplain Functional Classes) where forests of a given type fail to regenerate under simulated future conditions?

\section{Brief Results and Discussion}

The area classified as Salix community increased in some navigation pools (such as 3, 4, 10-14, 17-19, 21-26) stayed relatively similar in others (5A-7, 15, and lag), and declined in others navigation pools (such as $5,8,9,16,20$, or 1 , or 2 , and alt) through a 100-year period (fig. 27). Across all navigation pools, decreases in Salix communities occurred in areas subjected to short flood durations (floodplain functional classes 0-20; fig. 28). These same floodplain functional classes showed no net change in total forest area, suggesting that the loss of Salix communities in these areas resulted from transitions to other community types (such as lowland or floodplain forests). In contrast, increases in Salix communities occurred in areas subject to longer flood durations (floodplain functional classes 30-70; fig. 28) and between the years 50 and 100.

Given the relatively short lifespan of Salix species ( $\sim 70$ years), these dynamics indicate that the increase in the area in Salix communities resulted from the establishment of new cohorts in areas formerly classified as other forest types. These new Salix communities could have resulted from the loss of Populus communities or floodplain forests in areas subject to long flood durations, given that Salix has a greater flood tolerance (see appendix 4) than the species in these other classes. Or, the increase in Salix communities could have resulted from the loss of floodplain forests because of the $\mathrm{EAB}$ and green ash loss. However, for a given site to undergo transition from one forest type to a Salix community, nearly all cohorts at a site would need to be absent as Salix species are shade intolerant (See appendix 4). Hence, the observed transitions toward Salix communities are dependent on other herbaceous invasive species (such as P. arundinacea [reed canarygrass] or Humulus japonicas [Japanese hops]), which were not modeled in this study, not first colonizing sites where forest was lost due to flooding or EAB. Nevertheless, the pool-by-pool differences suggest that there may be complex interactions among flood duration, existing forest stand conditions, and the shade and flood tolerance of Salix species that drive local differences in Salix community dynamics.

Similar to Salix communities, Populus communities are considered to be an early successional shade-intolerant floodplain community. However, in contrast to Salix communities, Populus communities exhibited a strong decline in forest area in most navigation pools (fig. 27), with navigation pools 14, 17, 18, and 26 the exceptions. The loss of Populus communities was most pronounced in floodplain functional classes $0-30$, where these communities were initially the most abundant. As for Salix communities, these changes were likely driven by transition to lowland or floodplain forests as no net loss of forest cover was observed in these areas.

In contrast to the early successional forest types, lowland forests include a range of species that have long lifespans (often $>200$ years; see appendix 4). Lowland forests distributions are projected to expand in every UMRS navigation pool during the next 50 and 100 years (fig. 27), with the largest expansions occurring in areas typically experiencing shorter flood durations (for example, in floodplain functional classes with long-term average inundation durations $<30$ days per growing season; fig. 28). These changes can help explain the loss of the other three community types in higher elevation areas, where shorter-lived Salix, Populus, and floodplain forest communities may include longer-lived and shade-tolerant species from the lowland forest community in the midstory and understory. Consequently, these other three forest types are projected to transition toward the longer-lived lowland forest community type in areas with suitable flooding conditions through time. The loss of green ash as a component of the floodplain forest community because of EAB may also have aided the expansion of the lowland forest type. However, these transitions were generally restricted to higher elevation areas, given that the species found within lowland forests are generally less tolerant of flooding than the species in the other community types (See appendix 4 for flood tolerance equations).

Though the previously outlined changes in Salix, Populus, and lowland forest types may be important for the animal species that utilize them, the forest types largely represent the process of natural forest succession. Furthermore, the area occupied by these forest types is very small relative to changes in the floodplain forest community, which is the most abundant forest type found in the UMRS by about an order of magnitude (fig. 27). During the first 50 years of model simulations, many navigation pools showed an increase in the area classified as floodplain forest (such as 3-5a, 9, 21-25, OR1, OR2, lag and alt) (fig. 27), and these increases tended to occur across all floodplain functional classes (fig. 28). The 50-year increase in floodplain forest cover in these pools may help explain the loss of the early successional Salix and Populus communities, and suggests that other species within the floodplain forest community replaced green ash as it was lost from the forest canopy of existing floodplain forest stands. Silver maple has a relatively high tolerance to inundation (see appendix 4) and often cooccurs with Salix and Populus species. It is likely that as willow and cottonwood stands reached their longevity, silver maple became the dominant overstory species by year 50 . However, other navigation pools showed moderate losses of floodplain forest cover during the next 50 years, which may help explain the increases in the lowland forest type in the model, as some floodplain forest stands transitioned toward the longer-lived lowland forest species. In these cases, the loss of green ash, due to EAB outbreaks, may have aided 

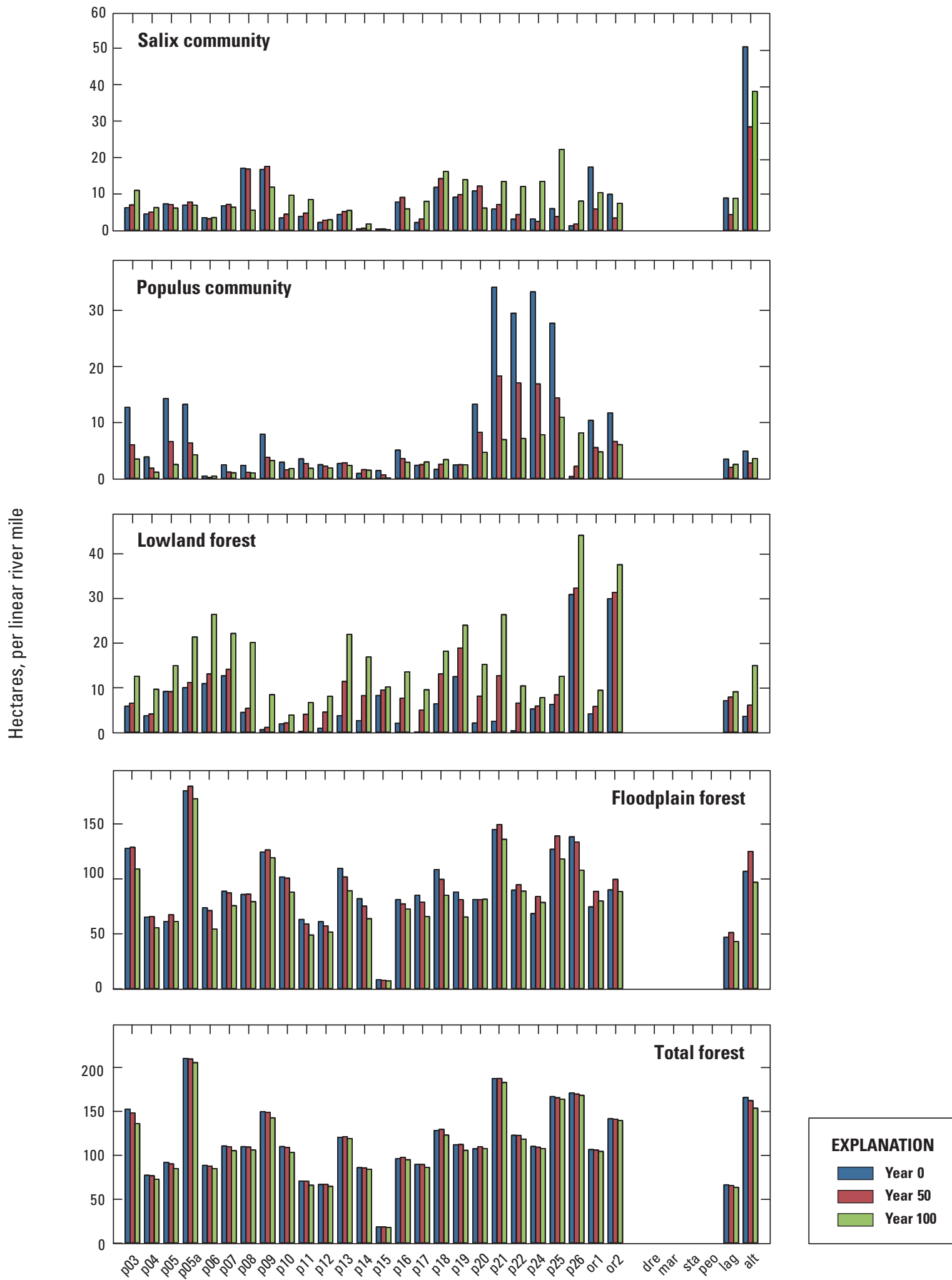

Navigation pool

Figure 27. The area (hectare per linear river mile) of four forest types, along with the area in total forest cover (across all four types) for year 0 (initial conditions for year 2010; see 3.2.5 Floodplain Vegetation Diversity) and years 50 and 100 resulting from model simulations for the navigation pools of the Upper Mississippi River System. 

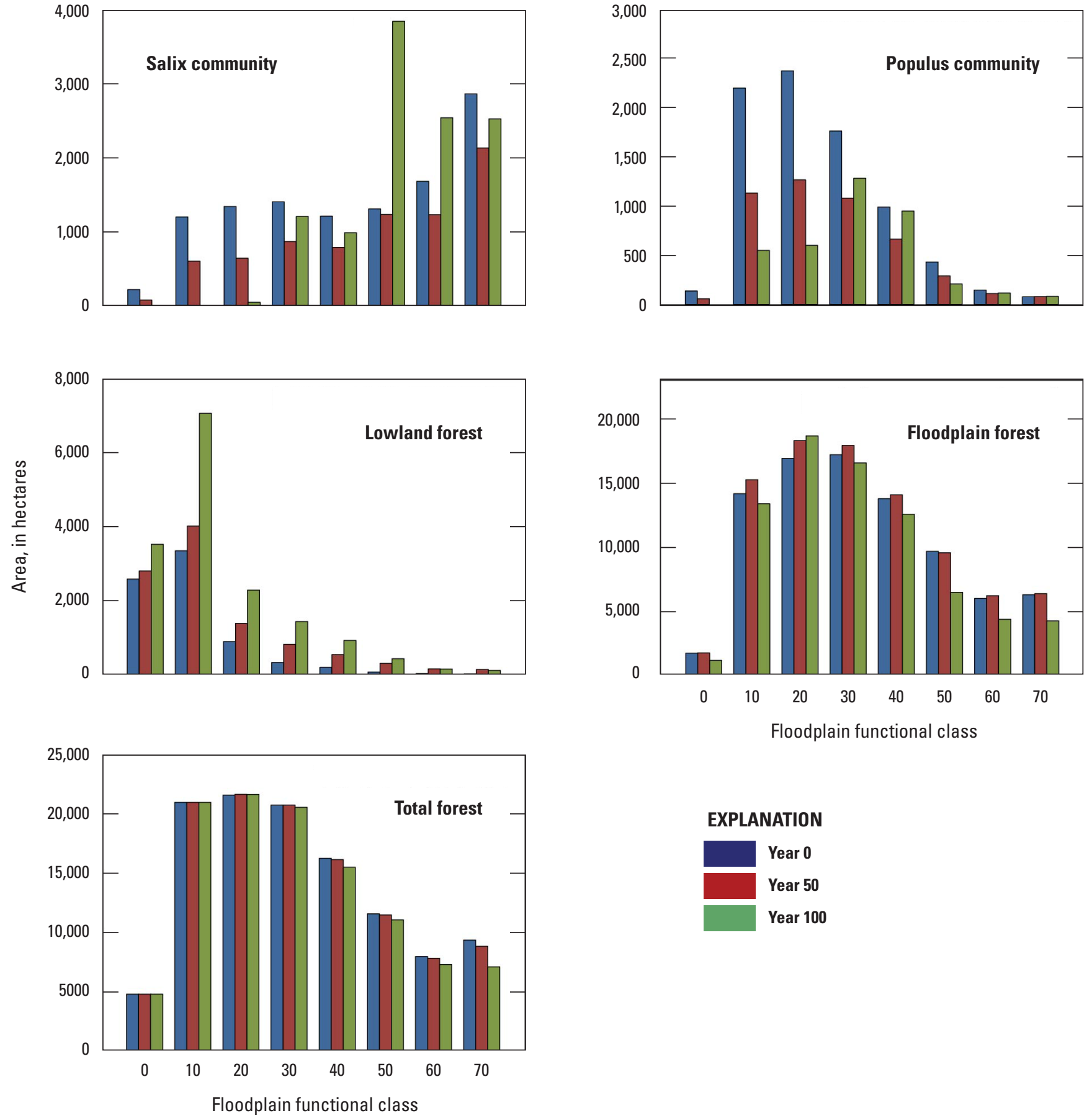

EXPLANATION

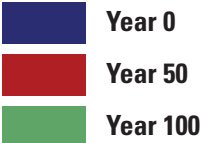

Figure 28. The area (hectares) of four forest types, along with the area in total forest cover (across all four types) for year 0 (initial conditions for year 2010; see 3.2.5 Floodplain Vegetation Diversity) and years 50 and 100 resulting from model simulations for 7 floodplain functional classes (see section 3.2.4 Floodplain Functional Classes). Class 0 experienced no flooding during model simulations, class 10 experienced an average of 0.1 to 10 days of flooding annually, with similar ranges of durations for all other classes, except for class 70, which experienced an average between 60.1 and 180 days of flooding annually. 
this forest type transition. As we pointed out earlier, the expansion of lowland forests was largely restricted to floodplain functional classes with short flood durations; thus, the loss of floodplain forest from low-lying areas likely reflects the loss of total forest cover. Over 100 years, the loss of floodplain forest cover appeared to account for a large proportion of the loss of total forest cover (fig. 27).

Nearly all navigation pools showed small losses in total forest cover during the next 50 years. These losses ranged between 0 and 2.8 percent of existing forest cover within navigation pools. Over 100 years, the range of forest loss was between 1 and 10 percent of exiting forest cover within navigation pools. The larger losses through 100 years indicates a lack of forest regeneration in stands that currently have overstory species that are between 50 and 100 years of their maximum lifespan. Forest loss was restricted to floodplain functional classes with long flood durations (for example, in floodplain functional classes with long-term average inundation durations $>30$ days per growing season; fig. 28). These losses ranged from 4.5 percent of existing forest cover in the 30-40 day floodplain functional class to 24.2 percent of existing forest cover in the $>60.1$ day floodplain functional class. Hence, in areas subject to short inundation durations, the decline in one forest type was compensated for by an increase in another forest type, reflecting species replacement and forest succession. In areas with longer flood durations, the loss of Salix, Populus, and floodplain forest cover was not compensated for with an increase in any of the other forest types, reflecting the likely transition to more flood-tolerant herbaceous communities (such as wet meadow or shallow marsh). The circumstances surrounding the lack of recruitment to forest cover in these areas warrants additional investigation. However, our results suggest that total forest cover in the UMRS and the distribution of other competing vegetation types (see 3.2.4 Floodplain Vegetation Diversity) are likely not at equilibrium with the hydrological regime of the UMRS, and specific floodplain functional classes may be more likely to experience conversion from forest to nonforest area during the next 50 to 100 years.

Overall, our results reflect multiple complex pathways of forest succession in the UMRS, including transition to nonforest communities. These transitions depend on the current species and age-structure of forest stands, along with the tolerance of individual species-age cohorts to flood inundation, and the local flooding regime experienced by forest stands. Further examination of model outputs is needed to more fully identify how landscape positioning and forest stand conditions (species and age structure) interact to make one successional pathway more likely than others, especially in the context of EAB outbreaks. In addition, other factors, such as competition from invasive species (such as $P$. arundinacea [reed canarygrass, H. japonicus [Japanese hops], Sorghum halepense [L.] [Johnson grass]), were not included in our model simulations. Thus, our estimates of forest loss due to EAB and flood inundation in the UMRS may be conservative.

\subsection{Cross-Indicator Synthesis of Results}

\section{Brief Methods}

To synthesize the results of the individual indicators described in the previous section, we performed a hierarchical cluster analysis based on indicators describing different aspects of connectivity, diversity and redundancy, and controlling variables for the year 2010. To characterize connectivity, we used the percentage of time gates were open, the area (hectare per linear river mile) in natural land cover, the area (hectare per linear river mile) in leveed area, and the area (hectare per linear river mile) in open water (see section 3.1 Connectivity for additional details).

To characterize diversity and redundancy, we used two variables describing the composition of aquatic functional classes (AFC1 and AFC2), the diversity of floodplain functional classes, the diversity of aquatic vegetation, and the diversity of floodplain vegetation. The two variables describing aquatic functional classes were derived from the same multivariate analysis performed in section 3.2.1 (Aquatic Areas and Functional Classes). We visualized the results of the hierarchical cluster analysis using MDS ordination. On the first axis of the multivariate biplot (MDS 1), AFC1 was positively correlated with all lentic functional classes (therefore, higher values of AFC1 indicate more lentic functional class area) and negatively correlated with the lotic functional classes (therefore, lower values of AFC1 indicate more lotic functional class area). On the second axis of the biplot (MDS 2), AFC2 was positively correlated with deep lentic areas (borrow pits, deep, and deep depression areas) as well as lentic low-connectivity areas and lotic structured and lotic structured with scour classes. Hence, higher values of AFC2 indicate the presence of deep lentic areas with low connectivity and structured channels. AFC2 was negatively associated with lentic and lotic shallow areas (therefore, low values of $\mathrm{AFC} 2$ indicate the presence of shallow areas). For more details on diversity and redundancy metrics, see section 2.2 (Diversity and Redundancy).

To characterize controlling variables, we used watersurface elevation fluctuations at both pool and tailwater gages (in meters) and TSS concentrations (milligrams per liter). For more information on the indicators used to characterize slow variables and feedbacks, see section 3.3 (Controlling Variables). We rescaled all values so that they ranged between 0 and 100 to facilitate comparison across indicators with different values. For all indicators with nonnegative values, we divided the value for each navigation pool by the value for the pool with the maximum value for a particular indicator. For indicators with both positive and negative values we first added the most negative value and then divided each value by the maximum. Given the data for all indicators identified previously, hierarchical cluster analysis was done to identify navigation pools that resemble each other and those pools which were significantly different from other groups of pools $(p=0.05)$. 


\section{Brief Results and Discussion}

Hierarchical cluster analysis identified seven different groupings of navigation pools (fig. 29). The navigation pools within each group share similar characteristics with each other, and significantly differ from the navigation pools within other groups $(\mathrm{P}=0.05)$. In the following sections, we identify some of the similarities and differences among the different groups and discuss how some of these characteristics may change during the next 50 to 100 years based on simulation modelling results.

\section{Upper Impounded Pools (P3-9, 13)}

Navigation pools 3-9 and 13 (upper impounded pools) grouped together and, thus, shared similar characteristics (figs. 29 and 30). The hydrology of the upper impounded pools is such that the dam gates are rarely open, creating a high degree of fragmentation in upriver-downriver connectivity, and watersurface elevations at both pool and tailwater gages fluctuate much less than they did historically. These stable water conditions, along with very low concentrations of TSS (clear water), and a very high abundance of lentic aquatic area make the upper impounded pools an ideal section of the UMRS for aquatic plant growth. These pools also contain the highest abundance of deep lentic functional classes. However, sedimentation in off-channel areas is projected to have the largest impact on aquatic functional class distributions in the upper and middle impounded pools during the next 50 years. These changes include a loss of deep lentic area and an increase in shallow lentic area.

The upper impounded pools support an abundance of unleveed natural floodplain land cover (for example, high degrees of longitudinal floodplain and lateral river floodplain connectivity). In addition, these pools contain a diversity of floodplain functional classes and vegetation types. However, these pools also tend to support a relatively high abundance of long-duration floodplain functional classes (those that flood for more than 80 days). The presence of these longer-duration classes may explain the higher abundance of wet meadow and other nonforest communities in these pools as compared to the rest of the UMRS. The relatively higher abundance of wet meadows in these pools is a concern, because most of these meadows are dominated by a single invasive species known to suppress forest regeneration (reed canarygrass; De Jager and others, 2017). In addition, the longer-duration floodplain functional classes were most susceptible to forest loss in our forest succession model, and this model did not include effects of invasive species. Thus, the upper impounded pools currently offer a diversity of aquatic and floodplain hydrogeomorphic areas but may also undergo a large degree of change during the next 50 to 100 years.

\section{Middle Impounded Pools (P10-12, 14, 16, 19)}

Navigation pools 10-12, 14, 16, and 19 (middle impounded pools) grouped together (fig. 29). Like the upper impounded pools, the dam gates of the middle impounded pools are rarely open and water-surface elevations at both pool and tailwater gages fluctuate less than they did historically. However, unlike the upper impounded pools, aquatic functional class distributions and aquatic vegetation abundance in the middle impounded pools tended to be more highly variable from one pool to the next (fig. 30). Nevertheless, the middle impounded pools are more similar to the upper impounded pools in these features than any other section of the UMRS. Furthermore, these pools showed future loss of deep and gain of shallow lentic classes during the next 50 years similar to the upper impounded pools. This indicates that sedimentation is likely to cause a shift toward shallower lentic areas.

The middle impounded pools support less unleveed natural floodplain land cover than the upper impounded pools, but more than the other groups. The middle impounded pools contain a high diversity of floodplain functional classes (inundation zones), but the diversity of floodplain vegetation types was much lower than for the upper impounded pools. This result was largely driven by a reduction in the amount of lowland (oak-hickory) forest cover. In fact, these pools had the lowest abundance of lowland forest cover in the entire UMRS. Over the next 50 to 100 years, forecasted net changes in the abundance of forest types and total forest cover were similar to those of the rest of the system. Thus, the middle impounded pools offer a similar mix of ecological characteristics as the upper impounded pools and may also undergo similar changes in lentic and floodplain areas as the upper impounded pools during the next 50 to 100 years. However, the middle impounded pools also share similarities with the lower impounded pools (see discussion in following sections).

\section{Pool 15}

Navigation pool 15 did not group with any other navigation pools. The characteristics of pool 15 that make it unique from all other pool groups include a very small amount of natural land cover in the floodplain. Pool 15 includes a large urban area and is, therefore, the most heavily developed of all navigation pools. In addition, the aquatic functional classes offered by pool 15 differed from all other pool groups as it lacks nearly all aquatic functional classes, except for the loticstructured and lotic-shallow classes.

\section{Lower Impounded Pools (P17, 18, 20-26)}

Navigation pools 17, 18 and 20-26 (lower impounded pools) grouped together (fig. 29) and contain much less lentic area, much more lotic area (negative AFCS 1), and much less deep lentic area than the upper and middle impounded pools. In addition, water-surface elevations fluctuate more in these pools than in the upper or middle impounded pools, TSS concentrations increase significantly downriver from pool 19, and these 


\section{EXPLANATION}

Cluster groupings for navigation pools based on hierarchical cluster analysis

\begin{tabular}{|l|l|}
\hline & Upper impounded pools \\
\hline Middle impounded pools \\
\hline Pool 15 \\
\hline Lower impounded pools \\
\hline Open river reaches \\
\hline Upper Illinois pools \\
\hline Lower Illinois pools \\
\hline
\end{tabular}

Upper Mississippi River Basin

p05 Pool location and number

dre Pool location abbreviation

- U.S. cities (population > 200,000)



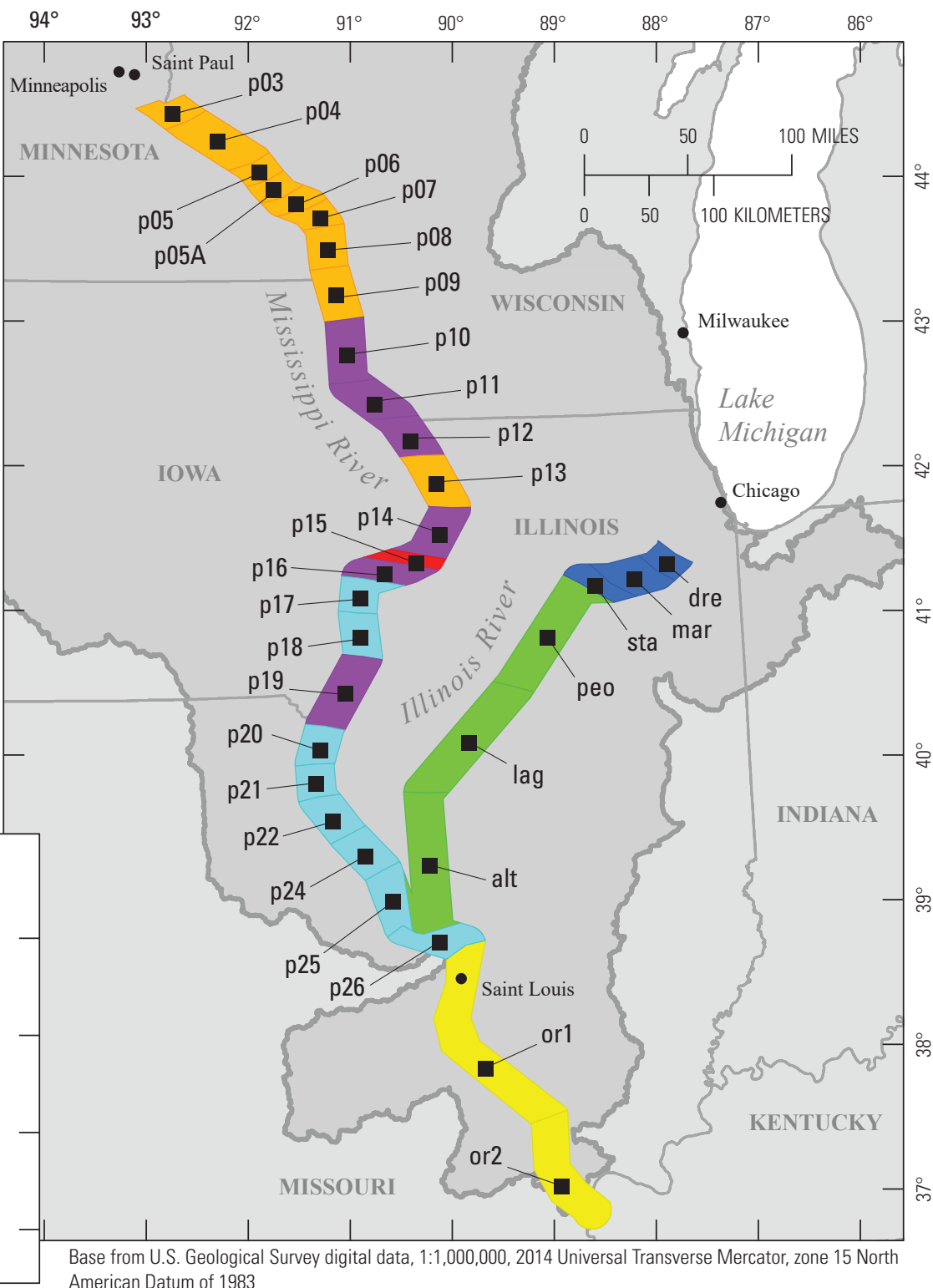

American Datum of 1983

\begin{tabular}{|c|c|c|c|c|c|c|c|c|c|c|c|c|}
\hline \multirow{2}{*}{ Label } & \multicolumn{4}{|c|}{ Connectivity } & \multicolumn{5}{|c|}{ Diversity } & \multicolumn{3}{|c|}{ Slow variables and feedbacks } \\
\hline & $\begin{array}{c}\begin{array}{c}\text { Longitudinal } \\
\text { aquatic } \\
\text { connectivity }\end{array} \\
\begin{array}{c}\text { Percent of } \\
\text { time } \\
\text { gates open }\end{array}\end{array}$ & $\begin{array}{c}\begin{array}{c}\text { Longitudinal } \\
\text { floodplain } \\
\text { connectivity }\end{array} \\
\begin{array}{c}\text { Natural area } \\
\text { (hectare per } \\
\text { river mile) }\end{array}\end{array}$ & $\begin{array}{c}\text { Leveed area } \\
\text { (hectare per } \\
\text { river mile) }\end{array}$ & $\begin{array}{c}\text { Open water } \\
\text { (hectare per } \\
\text { river mile) }\end{array}$ & $\begin{array}{c}\text { AFCS2 } \\
\text { (unitless) }\end{array}$ & $\begin{array}{c}\text { AFCS2 } \\
\text { (unitless) }\end{array}$ & $\begin{array}{c}\begin{array}{c}\text { Aquatic } \\
\text { vegetation } \\
\text { diversity }\end{array} \\
\begin{array}{c}\text { Simpson's } \\
\text { diversity index } \\
\text { (unitless) }\end{array}\end{array}$ & $\begin{array}{c}\begin{array}{c}\text { Floodplain } \\
\text { vegetation } \\
\text { diversity }\end{array} \\
\begin{array}{c}\text { Simpson's } \\
\text { diversity index } \\
\text { (unitless) }\end{array}\end{array}$ & \begin{tabular}{|c|}
$\begin{array}{c}\text { Floodplain } \\
\text { functional } \\
\text { class } \\
\text { diversity }\end{array}$ \\
$\begin{array}{c}\text { Simpson's } \\
\text { diversity index } \\
\text { (unitless) }\end{array}$ \\
\end{tabular} & $\begin{array}{c}\text { Tailwater } \\
\text { fluctuations } \\
\text { (meter) }\end{array}$ & $\begin{array}{c}\text { Pool } \\
\text { fluctuations } \\
\text { (meter) }\end{array}$ & \begin{tabular}{|c}
$\begin{array}{c}\text { Total } \\
\text { suspended } \\
\text { solids }\end{array}$ \\
$\begin{array}{c}\text { Average TSS } \\
\text { (milligram } \\
\text { per liter) }\end{array}$ \\
\end{tabular} \\
\hline Upper impounded pools & 9.91 & 234.32 & 44.32 & 300.40 & 0.49 & 0.49 & 0.57 & 0.69 & 0.79 & -0.24 & 1.71 & 32.93 \\
\hline Pool 15 & 7.15 & 26.57 & 44.74 & 137.32 & -1.28 & -0.82 & 0.03 & 0.73 & 0.60 & -0.95 & 2.17 & 38.26 \\
\hline Lower impounded pools & 29.70 & 247.93 & 579.88 & 178.63 & -0.76 & 0.03 & 0.07 & 0.68 & 0.82 & 0.84 & 1.22 & 76.92 \\
\hline Open river reaches & 100.00 & 189.40 & 420.60 & 115.63 & -1.25 & 0.20 & 0.10 & 0.76 & 0.79 & 4.83 & & 209.97 \\
\hline Upper Illinois pools & 0.79 & 102.66 & 0.65 & 84.55 & 0.70 & -0.81 & 0.20 & 0.76 & 0.32 & & & \\
\hline Lower Illinois pools & 40.81 & 193.73 & 283.23 & 146.86 & 1.20 & -0.71 & 0.13 & 0.73 & 0.87 & 3.27 & 1.03 & 64.24 \\
\hline
\end{tabular}

Figure 29. Results of multivariate cluster analysis based on indicators describing different aspects of connectivity, diversity and redundancy, and slow variables and feedbacks (see text for details). Navigation pools are colored according to significant $(P=0.05)$ differences among pool groupings. Mean values of the indicators used in the analysis are provided in the table (lower panel) and characterize each group of pools. 

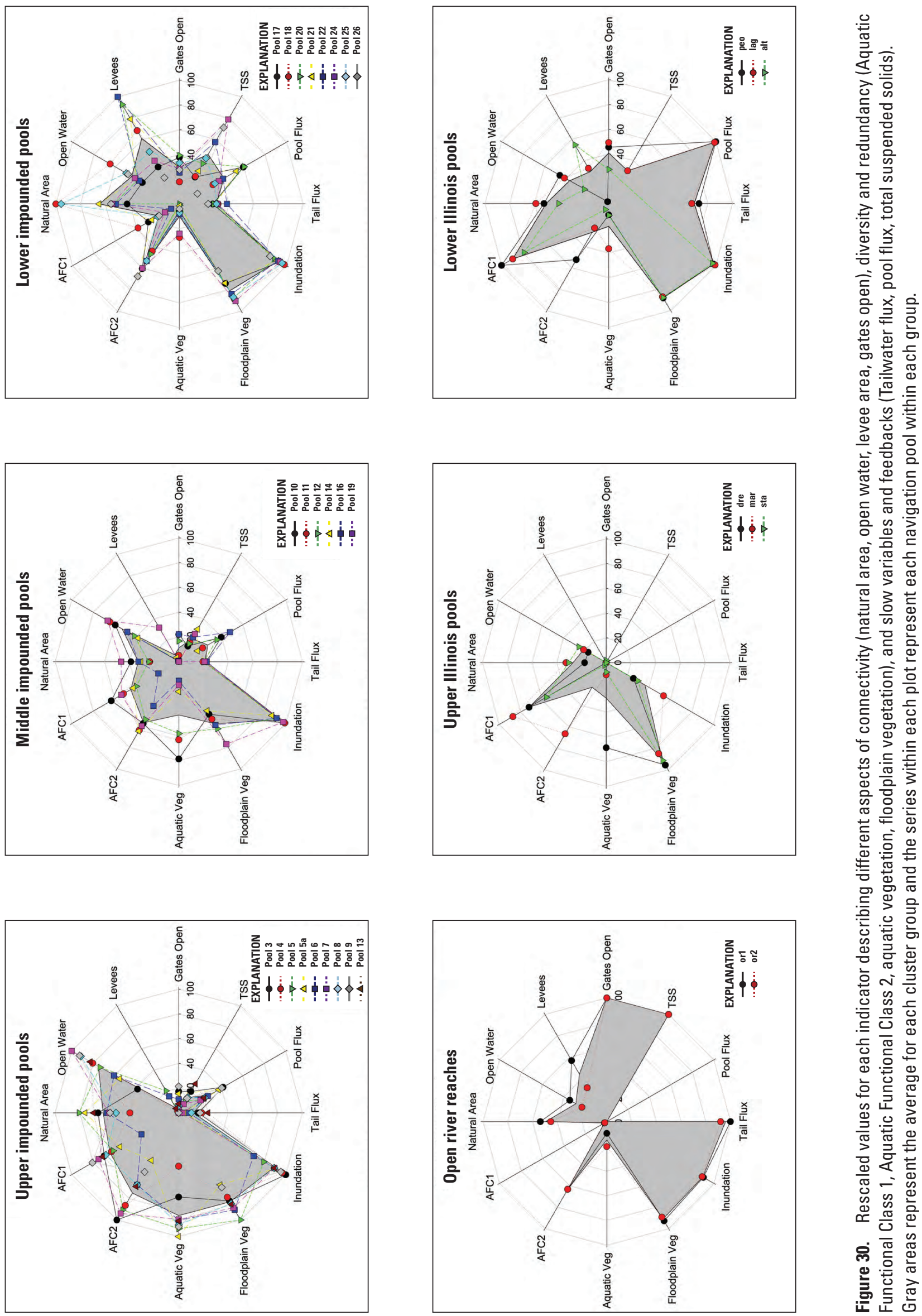
pools contain little aquatic vegetation. Aquatic habitat conditions in these pools were projected to change very little during the next 50 years given the general lack of lentic area near critical depth thresholds. Finally, this group was less fragmented in terms of upriver-downriver connectivity as compared with the upper and middle impounded pools upriver (for example, the gates are open more often), although there is much variability from one pool to the next, reflecting important pinchpoints within the reach (fig. 30).

The relatively wide floodplain found in this area of the river system supports large areas of natural land cover but also has large areas behind levees. Hence, the degree of longitudinal floodplain connectivity and lateral river floodplain connectivity found in this section of the UMRS is significantly less than would have been found under historical conditions, although results vary substantially among pools (fig. 30). In the areas that are currently in unleveed, natural land cover, a diversity of floodplain functional classes and vegetation types are found in these pools. In fact, these pools currently contain the greatest amount of forest cover in early successional Populus communities; forest successional modelling indicated that many of these forest stands are projected to succeed to silver-maple dominated floodplain forests and (or) oak-hickory dominated lowland forests during the next 50 to 100 years.

\section{Open River Reaches (OR1 and OR2)}

The open river reaches of the UMRS (OR1 and OR2) are unique in that they had the highest degree of longitudinal aquatic connectivity (they are undammed). These reaches complete a transition from more lentic hydrogeomorphic areas in the northern UMR to dominance by lotic conditions in the south. These reaches had the greatest abundance of structured channel area and had virtually no area meeting any of the lentic functional class criteria. Consequently, the aquatic areas within this reach are projected to change little during the next 50 years. Also, unlike the reaches to the north, the open river reaches exhibited an increase, not decrease, in water-surface elevation fluctuations relative to prelock and dam conditions. This section of river also has TSS concentrations that were at least three times greater than anywhere else in the UMR, reflecting a much larger agricultural watershed contributing sediment.

Similar to the lower impounded pools, the open river has a wide floodplain that supports both a large amount of natural area and a large amount of area behind levees. Thus, though it continues to support longitudinal floodplain connectivity in the form of natural vegetation cover, the amount of available natural land cover is just a fraction of what it was historically. Furthermore, the floodplain is laterally isolated from the river in these reaches because of levees. However, in the areas currently in natural land cover, the open river still supports a diversity of floodplain functional classes and vegetation types and tends to have a smaller area of long-duration floodplain functional classes prone to future forest loss than the dammed sections of the UMR.

\section{Upper Illinois Pools (Dresden (dre), Marseilles (mar), Starved Rock (sta))}

The three uppermost navigation pools on the Illinois River (dre, mar, sta) shared similar characteristics and grouped together (fig. 29). These pools were characterized as having low longitudinal aquatic connectivity (dam gates are rarely open). The aquatic habitats of the upper Illinois pools were similar to those found in the lower Illinois pools (see following section) and differed from the rest of the UMRS. These pools were characterized as having an abundance of shallow lentic area. The upper Illinois pools tended to support more diverse aquatic vegetation than the lower pools, but not as much diversity as found in the upper and middle impounded pools of the UMR. Finally, the upper Illinois pools were dominated by high-elevation floodplain functional classes and, therefore, had the lowest estimates of floodplain functional class diversity. In the areas that continue to support natural vegetation, these pools do have a diverse mix of floodplain vegetation types.

Controlling variables and feedbacks were not quantified for current conditions in the upper Illinois River pools because of a lack of data. However, model projections for lentic deep and shallow areas showed no projected change during the next 50 years because most lentic area in these pools is already shallow.

\section{Lower Illinois Pools (Peoria (peo), La Grange (laf), Alton (alt))}

The three pools in the lower Illinois River (peo, lag, alt) grouped together (fig. 29). In these pools, both pool and tailwater gages showed an increase in water-surface elevation fluctuations as compared to prelock and dam conditions. These pools were very similar to the lower impounded pools in terms of connectivity. These pools support a moderate degree of longitudinal aquatic connectivity (gates are open about 30-50 percent of the time). As mentioned in the previous section, the aquatic areas of the lower Illinois pools were similar to the upper Illinois pools and different from the rest of the UMRS in that the Illinois River supports a large amount of shallow lentic area. Although the Illinois River pools contain geomorphic conditions that should be suitable for aquatic vegetation, aquatic vegetation is scarce. A likely explanation is the high TSS concentrations from the watershed, comparable to those found in the lower impounded pools of the UMR, which results in a poor light environment for vegetation growth. Relative to the upper impounded and middle impounded navigation pools, the abundance of deep and shallow lentic area in the lower Illinois River were projected to change little during the next 50 years because most lentic area is already shallow.

Unlike the three upper pools of the Illinois River, the lower three pools maintain moderate amounts of natural floodplain land cover and support relatively high estimates of floodplain functional class and vegetation diversity within these areas (fig. 29). Finally, changes in forest communities 
of the Illinois River were projected to be somewhat similar to other areas within the UMRS. Although, the initial amount of Salix communities tended to be much higher in the Peoria (peo) pool than any other UMRS navigation pool, and these communities either were projected to be lost to nonwoody communities or to other forest types.

\section{Implications}

In this report we have introduced new geospatial datasets and used them to develop a series of indicators that quantify general aspects of the structure and function of the Upper Mississippi River System (UMRS). These indicators reflect a history of navigation and other anthropogenic impacts to the river system and provide important contextual information about the distribution of potential habitat conditions for a wide range of species. Each indicator was developed to represent previously stated management objectives for the UMRS (U.S Army Corps of Engineers, 2011). As a result, the Upper Mississippi River Restoration (UMRR) Program now has an opportunity to use system-wide quantitative information to set management and restoration goals at multiple scales. To help the UMRR Program most effectively use the information contained in the newly developed datasets and in this report, we highlight a few of the implications of our approach in the remainder of this section.

First, the datasets that we developed or otherwise assembled contain much more information than could be summarized for this report. For example, the new aquatic areas GIS coverage contains at least 50 different patch-level attributes that could be used in subsequent species- and community-level habitat modelling efforts or in developing a better understanding of spatial and temporal patterns in various ecosystem functions (such as nutrient cycling or trophic interactions). Our efforts to develop the first system-wide flood inundation model for the UMRS provides researchers and managers the ability to export flood-depth maps for any day during the past 40 years and to export maps that summarize additional flood metrics (such as frequency, duration, and timing) through any time interval (weeks to decades). Such efforts should greatly improve our ability to understand and predict patterns of floodplain sedimentation, nutrient cycling, and plant community dynamics, as well as how different aquatic communities use the UMRS floodplain during inundation events.

However, these datasets also have some limitations, particularly when used at increasingly finer spatial scales. Both the aquatic and floodplain areas datasets rely on the same nondynamic topo-bathymetric dataset. This means that any changes in land surface elevation occurring after these datasets were developed will not be captured by our mapping efforts and could result in differences at local scales. In addition, the different bathymetric surveys and lidar data collection efforts have varying levels of vertical accuracy, which also creates the possibility for local differences between our maps and observed conditions. For this reason, our datasets are probably best suited for use at large to intermediate scales of restoration planning and to provide only a first approximation of local conditions.

Secondly, the indicators that we developed for this report are generic in that they represent physical and ecological conditions that should broadly apply to a wide range of organisms and ecological processes but may not accurately reflect the specific habitat requirements of any given species or community. Likewise, these indicators generally reflect navigation and anthropogenic impacts to the UMRS but do not attempt to isolate how specific management actions might impact the river system.

As we pointed out in the introduction, the UMRS is utilized by so many species (and little empirical information exists for many of them) that developing functional indicators for specific species or communities would be challenging. Furthermore, the currently stated management objectives for the UMRS do not identify specific species, communities, or management actions. For example, we developed a single generic indicator to represent flood inundation dynamics across the UMRS (annual duration), which proved useful for understanding general differences among navigation pools and with respect to the diversity of plant communities found across the river system. However, it is also possible to isolate other aspects of the UMRS flood regime (frequency, depth, and timing) that may have specific impacts on select organisms or processes. Similarly, we calculated a single generic index of hydrological alteration to represent water-surface elevation fluctuations. However, there are hundreds of other indices of hydrological alteration that could have been included in this report. We deemed such efforts to be beyond the scope of this document. However, the datasets that we developed for this effort offer the opportunity to further elaborate on any individual indicator introduced in this study.

The generic nature of the indicators developed in this study has important implications for how the UMRR Program uses them in restoration planning. For example, these indicators are best used as a first approximation of the structure and function of the UMRS and the general differences found across the river system. It would, therefore, not be advisable to use these indicators to isolate the specific habitat conditions for specific species or communities. Nor would it be advisable to use these indicators to isolate effects of a specific management action. In the future, if the UMRR Program develops more specific restoration objectives, targeted to specific species, communities, ecological processes, and (or) management actions, then more specific indicators could be developed and used to monitor the effects of restoration projects.

Thirdly, we chose to develop indicators at the navigationpool scale, a common planning unit in the UMRS, and we synthesized information across indicators at the maximum extent of the entire UMRS. Consequently, spatial and temporal variability occurring within navigation pools was not accounted for in our indicators. Many of the navigation pools 
have significant within-pool structural differences resulting from the lock and dam system or because of natural variation (such as Lake Pepin in navigation pool 4). In some cases, within-pool variability may be larger than the variability found among pools. Further, by examining the data across the entire UMRS, the very large degree of variability found across the river system may obscure subtle but important differences found among nearby navigation pools. The implication of these differences is that the information provided in this report is best suited to making broad-scale restoration planning decisions, not for isolating specific places within navigation pools for restoration projects or for attempting to compare relatively minor differences among pools. However, future planning efforts could use the datasets we have developed to zoom into each cluster group identified in this report with more specific analyses at finer scales.

Finally, our modelling efforts focused on significant portions of the UMRS (lentic areas and floodplain forests), but not the entire river floodplain ecosystem. In addition, we examined potential future conditions associated with flooding scenarios that we considered to be most likely. For example, in modelling sedimentation rates and floodplain inundation dynamics, we assumed that future rates and patterns would match those observed through the past few decades and simply projected these rates and patterns into the future. However, changes in land use, navigation infrastructure, and (or) precipitation patterns could alter these rates into the future. Hence, future efforts could consider extending modelling efforts to other portions of the river (for example, channels) and floodplain (such as, other herbaceous communities or developed areas) and could consider other alternative hydrological or management scenarios.

\section{References Cited}

Allan, J.D., Erickson, D.L., and Fay, J., 1997, The influence of catchment land use on stream integrity across multiple spatial scales: Freshwater Biology, v. 37, no. 1, p. 149-161.

Angradi, T.R., Schweiger, E.W., Bolgrien, D.W., Ismert, P., and Selle, T., 2004, Bank stabilization, riparian land use and the distribution of large woody debris in a regulated reach of the upper Missouri River, North Dakota, USA: River Research and Applications, v. 20, no. 7, p. 829-846.

Argiroff, W.A., Zak, D.R., Lanser, C.M., and Wiley, M.J., 2017, Microbial community functional potential and composition are shaped by hydrologic connectivity in riverine floodplain soils: Microbial Ecology, v. 73, no. 3, p. 630-644.
Beatty, W.S., Webb, E.B., Kesler, D.C., Naylor, L.W., Raedeke, A.H., Humburg, D.D., Coluccy, J.M., and Soulliere, G.J., 2015, An empirical evaluation of landscape energetic models-Mallard and American black duck space use during the non-breeding season: The Journal of Wildlife Management, v. 79 , no. 7, p. 1141-1151.

Blom, C.W.P.M., and Voesenek, L.A.C.J., 1996, FloodingThe survival strategies of plants: Trends in Ecology \& Evolution, v. 11, no. 7, p. 290-295.

Bouska, K.L., Houser, J., De Jager, N.R., and Hendrickson, J., (2018) Developing a shared understanding of the Upper Mississippi River-The foundation of a resilience assessment: Ecology and Society: 23 (2) 6. doi.org/10.5751/ ES-10014-230206

Barko, V.A., Herzog, D.P., Hrabik, R.A., and Scheibe, J.S., 2004, Relationship among fish assemblages and mainchannel-border physical habitats in the unimpounded Upper Mississippi River: Transactions of the American Fisheries Society, v. 133, no. 2, p. 371-384.

Biggs, R., Schlüter, M., Biggs, D., Bohensky, E.L., BurnSilver, S., Cundill, G., Dakos, V., Daw, T.M., Evans, L.S., Kotschy, K., Leitch, A.M., Meek, C., Quinlan, A., Raudsepp-Hearne, C., Robards, M.D., Schoon, M.L., Schultz, L., and West, P.C., 2012, Toward principles for enhancing the resilience of ecosystem services: Annual Review of Environment and Resources, v. 37, no. 1, p. 421-448.

Braatne, J.H., Jamieson, R., Gill, K.M., and Rood, S.B., 2007, Instream flows and the decline of riparian cottonwoods along the Yakima River, Washington, USA: River Research and Applications, v. 23, no. 3, p. 247-267.

Calkins, H.A., Tripp, S.J., and Garvey, J.E., 2012, Linking silver carp habitat selection to flow and phytoplankton in the Mississippi River: Biological Invasions, v. 14, no. 5, p. 949-958.

Cardinale, B.J., Hillebrand, H., Harpole, W.S., Gross, K., and Ptacnik, R., 2009, Separating the influence of resource 'availability' from resource 'imbalance' on productivitydiversity relationships: Ecology Letters, v. 12, no. 6, p. 475-487.

Chen, Y.H., and Simmons, D.B., 1986, Hydrology, hydraulics, and geomorphology of the Upper Mississippi River System: Hydrobiologia, v. 136, no. 1, p. 5-19.

Custer, C.M., Suarez, S.A., and Olsen, D.A., 2004, Feeding habitat characteristics of the Great Blue Heron and Great Egret nesting along the Upper Mississippi River, 1995-1998 - Waterbirds: The International Journal of Waterbird Biology, v. 27, no. 4, p. 454-468. 
De Jager, N.R., and Yin, Y., 2011, Temporal changes in spatial patterns of submersed macrophytes in two impounded reaches of the Upper Mississippi River, USA, 1998-2009: River Systems, v. 19, no. 2, p. 129-141.

De Jager, N.R., and Houser, J.N., 2012, Variation in watermediated connectivity influences patch distributions of total N, total P, and TN:TP ratios in the Upper Mississippi River, USA: Freshwater Science, v. 31, no. 4, p. 1254-1272.

De Jager, N.R., 2012, Effects of flood frequency and duration on the allometry of community-level stem size-density distributions in a floodplain forest: American Journal of Botany, v. 99, no. 9, p. 1572-1576.

De Jager, N.R., Thomsen, M.T., and Yin, Y., 2012, Threshold effects of flood duration on the vegetation and soils of the Upper Mississippi River floodplain, USA: Forest Ecology and Management, v. 270, p. 135-146.

De Jager, N.R., Rohweder, J.J., Yin, Y., and Hoy, E., 2015a, The Upper Mississippi River floodscape-Spatial patterns in flood inundation and associated plant community distributions: Applied Vegetation Science, v. 19, no. 1, p. 164-172.

De Jager, N.R., Swanson, W., Strauss, E.A., Thomsen, M., and Yin, Y., 2015b, Flood pulse effects on nitrification in a floodplain forest impacted by herbivory, invasion, and restoration: Wetlands Ecology and Management, v. 23, no. 6, p. $1067-1081$.

De Jager, N.R., and Rohweder, J.J., 2017, Changes in aquatic vegetation and floodplain land cover in the Upper Mississippi and Illinois Rivers (1989-2000-2010): Environmental Monitoring and Assessment, v. 189, no. 77, 14 p.

De Jager, N. R., Rohweder, J. J., Hoy, E. E., 2017, Mapping areas invaded by Phalaris arundinacea in navigation pools 2-13 of the Upper Mississippi River: Completion Report to the U.S. Army Corps of Engineers Upper Mississippi River Restoration Program 2017L2.

Dettmers, J.M., Gutreuter, S., Wahl, D.H., and Soluk, D.A., 2001, Patterns in abundance of fishes in main channels of the Upper Mississippi River system: Canadian Journal of Fisheries and Aquatic Sciences, v. 58, no. 5, p. 933-942.

Dieck, J.J., Ruhser, J., Hoy, E., and Robinson, L.R., 2014, General classification handbook for floodplain vegetation in large river systems (ver. 2.0, November 2015): U.S. Geological Survey Techniques and Methods, book 2, chap. A1, 51 p., accessed May 23, 2018, at https://doi. org $/ 10.3133 / \mathrm{tm} 2 \mathrm{~A} 1$.
Fink, D., Hochachka, W.M., Zuckerberg, B., Winkler, D.W., Shaby, B., Munson, M.A., Hooker, G., Riedewald, M., Sheldon, D., and Kelling, S., 2010, Spatiotemporal exploratory models for broad-scale survey data: Ecological Applications, v. 20, no. 8, p. 2131-2147.

Fischer, J.R., and Claflin, T.O., 1995, Declines in aquatic vegetation in Navigation Pool No. 8, Upper Mississippi River between 1975 and 1991: River Research and Applications, v. 11, p. $157-165$.

Fremling, C.R., Rasmussen, J.L., Sparks, R.E., Cobb, S.P., Bryan, C.F., and Claflin, T.O., 1989, Mississippi River fisheries: a case history, in Proceedings of the International Large River Symposium, edited by D.P. Dodge: Canadian Special Publications in Fisheries and Aquatic Sciences v. 106, p. 309-351.

Folke, C., Carpenter, S., Walker, B., Scheffer, M., Elmqvist, T., Gunderson, L., and Holling, C.S., 2004, Regime shifts, resilience, and biodiversity in ecosystem management: Annual Review of Ecology Evolution and Systematics, v. 35 , no. 1 , p. $557-581$.

Forsberg, B.R., Melack, J.M., Richey, J.E., and Pimentel, T.P., 2017, Regional and seasonal variability in planktonic photosynthesis and planktonic community respiration in Amazon floodplain lakes: Hydrobiologia, v. 800, no. 1, p. 187-206.

Galat, D.L., Fredrickson, L.H., Humburg, D.D., Bataille, K.J., Bodie, J.R., Dohrenwend, J., Gelwicks, G.T., Havel, J.E., Helmers, D.L., Hooker, J.B., Jones, J.R., Knowlton, M.F., Kubisiak, J., Mazourek, J., McColpin, A.C., Renken, R.B., and Semlitsch, R.D., 1998, Flooding to restore connectivity of regulated, large-river wetlands - Natural and controlled flooding as complementary processes along the lower Missouri River: Bioscience, v. 48, no. 9, p. 721-733.

Garvey, J., Ickes, B., and Zigler, S., 2010, Challenges in merging fisheries research and management-The Upper Mississippi River experience: Hydrobiologia, v. 640, no. 1, p. $125-144$.

Gent, R.; Pitlo, J., Jr.; and Boland, T., 1995, Largemouth bass response to habitat and water quality rehabilitation in a backwater of the Upper Mississippi River: North American Journal of Fisheries Management, v. 15, no. 4, p. 784-793.

Giblin, S., Hoff, K., Fischer, J., and Dukerschein, T., 2010, Evaluation of light penetration on Navigation pools 8 and 13 of the Upper Mississippi River: U.S. Geological Survey Long Term Resource Monitoring Program Technical Report 2010-T001, 16 p., accessed May 23, 2018, at https://pubs. usgs.gov/mis/LTRMP2010-T001/. 
Giblin, S.M., 2017, Identifying and quantifying environmental thresholds for ecological shifts in a large semiregulated river: Journal of Freshwater Ecology, v. 32, no. 1, p. 433-453.

Grumbine, R.E., 1994, What is ecosystem management?: Conservation Biology, v. 8, no. 1, p. 27-38.

Harwell, M.A., Myers, V., Young, T., Bartuska, A., Gassman, N., Gentile, J.H., Harwell', C.C., Appelbaum, S., Barko, J., Causey, B., Johnson, C., McLean, A., Smola, R., Templet, P., and Tosini, S., 1999, A Framework for an ecosystem integrity report card: Bioscience, v. 49, no. 7, p. 543-556.

Holling, C.S., 1973, Resilience and stability of ecological systems: Annual Review of Ecology and Systematics, v. 4, no. 1, p. 1-23.

Houser, J.N., Bierman, D.W., Burdis, R.M., and Soeken-Gittinger, L.A., 2010, Longitudinal trends and discontinuities in nutrients, chlorophyll, and suspended solids in the Upper Mississippi River-Implications for transport, processing, and export by large rivers: Hydrobiologia, v. 651, no. 1, p. $127-144$.

Hutchinson, G.E., 1961, The paradox of the plankton: American Naturalist, v. 95, no. 882, p. 137-145.

Huizinga, R.J., 2009, Examination of direct discharge measurement data and historic daily data for selected gages on the Middle Mississippi River, 1861-2008: U.S. Geological Survey Scientific Investigations Report 2009-5232, 60 p.

James, W.F., Barko, J.W., and Eakin, H.L., 1995, Internal phosphorus loading in Lake Pepin, Upper Mississippi River: Journal of Freshwater Ecology, v. 10, no. 3, p. 269-276.

James, W.F., Richardson, W.B., and Soballe, D.M., 2008, Contribution of sediment fluxes and transformations to the summer nitrogen budget of an Upper Mississippi River backwater system: Hydrobiologia, v. 598, no. 1, p. 95-107.

Jardine, T.D., Bond, N.R., Burford, M.A., Kennard, M.J., Ward, D.P., Bayliss, P., Davies, P.M., Douglas, M.M., Hamilton, S.K., Melack, J.M., Naiman, R.J., Pettit, N.E., Pusey, B.J., Warfe, D.M., and Bunn, S.E., 2015, Does flood rhythm drive ecosystem responses in tropical riverscapes?: Ecology, v. 96 , no. 3, p. 684-692.

Johnson, B.L., and Hagerty, K.H., eds., 2008, Status and trends of selected resources of the Upper Mississippi River System: U.S. Geological Survey, Upper Midwest Environmental Science Center Technical Report LTRMP 2008T002, 102 p., 3 app., accessed May 23, 2018, at https:// pubs.usgs.gov/mis/LTRMP2008-T002/.

Julian, J.P., Doyle, M.W., and Stanley, E.H., 2008, Empirical modeling of light availability in rivers: Journal of Geophysical Research, v. 113, G3, 16 p.
Junk, W., Bayley, P.B., and Sparks, R.E., 1989, The flood pulse concept in river-floodplain systems: Pages $110-127$ D. P. Dodge [ed.] Proceedings of the International Large River Symposium.

Karrenberg, S., Blaser, S., Kollmann, J., Speck, T., and Edwards, P.J., 2003, Root anchorage of saplings and cuttings of woody pioneer species in a riparian environment: Functional Ecology, v. 17, no. 2, p. 170-177.

Kelner, D.E., and Sietman, B.E., 2000, Relic populations of the Ebony shell, Fusconaia ebena (Bivalvia-Unionidae), in the Upper Mississippi River Drainage: Journal of Freshwater Ecology, v. 15, no. 3, p. 371-377.

Knights, B.C., Johnson, B.L., and Sandheinrich, M.B., 1995, Responses of bluegills and black crappies to dissolved oxygen, temperature, and current in backwater lakes of the Upper Mississippi River during winter: North American Journal of Fisheries Management, v. 15, no. 2, p. 390-399.

Koch, B., Brooks, R.C., Oliver, A., Herzog, D.P., Garvey, J.E., Hrabik, R.A., Colombo, R., Phelps, Q.E., and Spier, T., 2012, Habitat selection and movement of naturally occurring pallid sturgeon in the Mississippi River: Transactions of the American Fisheries Society, v. 141, no. 1, p. 112-120.

Köhler, J., Hachoł, J., and Hilt, S., 2010, Regulation of submersed macrophyte biomass in a temperate lowland river-Interactions between shading by bank vegetation, epiphyton and water turbidity: Aquatic Botany, v. 92, no. 2, p. 129-136.

Korschgen, C.E., George, L.S., and Green, W.L., 1988, Feeding ecology of canvasbacks staging on pool 7 of the Upper Mississippi River, in Weller, M.W., ed., Waterfowl in winter: Minneapolis, Minnesota, USA, University of Minnesota Press.

Korschgen, C.E., 1989, Riverine and deepwater habitats for diving ducks, in Smith, L.M., Pederson, R.L., and Kaminski, R.M., eds., Habitat management for migrating and wintering waterfowl in North America: Lubbock, Texas, USA, Texas Tech University Press.

Kozlowski, T.T., 1984, Plant Responses to Flooding of Soil: Bioscience, v. 34, no. 3, p. 162-167.

Kreiling, R.M., De Jager, N.R., Swanson, W., Strauss, E.A., and Thomsen, M., 2015, Effects of flooding on ion exchange rates in an Upper Mississippi River floodplain forest impacted by herbivory, invasion, and restoration: Wetlands, v. 35, no. 5, p. 1005-1012.

Larson, J.H., Knights, B.C., Mccalla, G.S., Monroe, E., Tuttle-Lau, M., Chapman, D.C., George, A., Vallazza, J.M., and Amberg, J., 2017, Evidence of Asian carp spawning upriver of a key choke point in the Mississippi River: North American Journal of Fisheries Management, v. 37, no. 4, p. 903-919. 
Littlejohn, S.L., Holland, L.E., Jacobson, R., Huston, M., and Hornung, T., 1985, Habits and habitats of fish in the Upper Mississippi River: U.S. Fish and Wildlife Recourse Publication, $25 \mathrm{p}$.

Lytle, D.A., and Merritt, D.M., 2004, Hydrologic regimes and riparian forests - A structured population model for cottonwood: Ecology, v. 85, no. 9, p. 2493-2503.

Marks, C.O., Nislow, K.H., and Magilligan, F.J., 2014, Quantifying flooding regime in floodplain forests to guide river restoration: Elementa, Science of the Anthropocene, v. $2,15 \mathrm{p}$.

Maurer, W.R., Claflin, T.O., Rada, R.G., and Rogala, J.T., 1995, Volume loss and mass-balance for selected physicochemical constituents in Lake Pepin, Upper Mississippi River, USA: Regul River, v. 11, no. 2, p. 175-184.

Merritt, D.M., Scott, M.L., Poff, N.L., Auble, G.T., and Lytle, D.A., 2010, Theory, methods and tools for determining environmental flows for riparian vegetation: riparian vegetation-flow response guilds: Freshwater Biology, v. 55, no. 1, p. 206-225.

Madsen, J.D., Chambers, P.A., James, W.F., Koch, E.W., and Westlake, D.F., 2001, The interaction between water movement, sediment dynamics and submersed macrophytes: Hydrobiologia, v. 444, no. 1/3, p. 71-84.

McCluney, K.E., Poff, N.L., Palmer, M.A., Thorp, J.H., Poole, G.C., Williams, B.S., Williams, M.R., and Baron, J.S., 2014, Riverine macrosystems ecology-Sensitivity, resistance, and resilience of whole river basins with human alterations: Frontiers in Ecology and the Environment, v. 12, no. 1, p. $48-58$.

Mladenoff, D.J., Host, G.E., Boeder, J., and Crow, T.R., 1993, LANDIS-A spatial model of forest landscape disturbance, succession, and management, in Goodchild, M.F., Steyaert, L.T., Parks, B.O., Johnston, C., Maidment, D., Crane, M., and Glendining, S., eds., GIS and environmental modeling: Fort Collins, Colo., USA, GIS World Books, p. 175-179.

Mladenoff, D.J., and He, H.S., 1999, Design, behavior and applications of LANDIS, an object-oriented model of forest landscape disturbance and succession, chap. 6 of Mladenoff, D.J., and Baker, W.L., eds., Spatial modeling of forest landscape change-Approaches and applications: Cambridge, UK, Cambridge University Press.

O'Connell, D., Walker, B., Abel, N., and Grigg, N., 2015, The resilience, adaptation and transformation assessment framework-From theory to application: Dickson, ACT, Australia, CSIRO.

Oliver, T., Roy, D.B., Hill, J.K., Brereton, T., and Thomas, C.D., 2010, Heterogeneous landscapes promote population stability: Ecology Letters, v. 13, no. 4, p. 473-484.
Opperman, J.J., Luster, R., McKenney, B.A., Roberts, M., and Meadows, A.W., 2010, Ecologically Functional Floodplains - Connectivity, Flow Regime, and Scale: Journal of the American Water Resources Association, v. 46, no. 2, p. 211-226.

Owens, J.L., and Crumpton, W.G., 1995, Primary production and light dynamics in an Upper Mississippi River backwater: Regul River, v. 11, no. 2, p. 185-192.

Peck, J.H., and Smart, M.M., 1986, An assessment of the aquatic and wetland vegetation of the Upper Mississippi River: Hydrobiologia, v. 136, no. 1, p. 57-75.

Pickett, S.T.A., and White, P.S., 1985, The ecology of natural disturbance and patch dynamics: New York, Academic Press.

Pinay, G., Clément, J.C., and Naiman, R.J., 2002, Basic principles and ecological consequences of changing water regimes on nitrogen cycling in fluvial systems: Environmental Management, v. 30, no. 4, p. 481-491.

Poff, N.L., Allan, J.D., Bain, M.B., Karr, J.R., Prestegaard, K.L., Richter, B.D., Sparks, R.E., and Stromberg, J.C., 1997, The natural flow regime: Bioscience, v. 47, no. 11, p. $769-784$.

Popp, W.A., Burdis, R.M., DeLain, S.A., and Moore, M.J., 2014, Temporal trends in water quality and biota in segments of Pool 4 above and below Lake Pepin, Upper Mississippi River-Indications of a recent ecological shift Upper Mississippi River Restoration Long Term Resource Monitoring Program: Completion Report 2010D6 submitted to the U.S. Army Corps of Engineers, $47 \mathrm{p}$.

Robertson, P.A., MacKenzie, M.D., and Elliott, L.F., 1984, Gradient analysis and classification of the woody vegetation for four sites in southern Illinois and adjacent Missouri: Vegetatio, v. 58, no. 2, p. 87-104.

Rogala, J.T., Boma, P.J., and Gray, B.R., 2003, Rates and patterns of net sedimentation in backwaters of pools 4,8 , and 13 of the Upper Mississippi River: U.S. Geological Survey, Upper Midwest Environmental Sciences Center web page report, accessed May 23, 2018, at http://www.umesc.usgs. gov/data_library/sedimentation/documents/rates_patterns/ page1.html.

Rounds, S.A., 2007, Temperature effects of point sources, riparian shading, and dam operations on the Willamette River, Oregon: U.S. Geological Survey Scientific Investigations Report 2007-5185, 34 p.

Sandheinrich, M.B., and Atchison, G.J., 1986, Environmental effects of dikes and revetments on large riverine systems Environmental and Water Quality Operational Studies: Washington, D.C., Department of the Army, p. 54. 
Scheller, R.M., and Mladenoff, D.M., 2004, A forest growth and biomass module for a landscape simulation model, LANDIS-Design, validation, and application: Ecological Modelling, v. 180, no. 1, p. 211-229.

Schindler, D.E., Hilborn, R., Chasco, B., Boatright, C.P., Quinn, T.P., Rogers, L.A., and Webster, M.S., 2010, Population diversity and the portfolio effect in an exploited species: Nature, v. 465, no. 7298, p. 609-612.

Schindler, D.E., Armstrong, J.B., and Reed, T.E., 2015, The portfolio concept in ecology and evolution: Frontiers in Ecology and Evolution, v. 13, no. 5, p. 257-263.

Schramm, H.L., and Ickes, B.S., 2016. The Mississippi River-A Place for Fish, in Fishery Resources, Environment, and Conservation in the Mississippi and Yangtze (Changjiang) River Basins. Edited by Yushun Chen, Duane Chapman, John Jackson, Daqing Chen, Zhongjie Li, Jack Kilgore, Quinton Phelps, and Michael Eggleton. American Fisheries Society Symposium v. 84, p. 3-34.

Sheehan, R.J., Lewis, W.M., and Bodensteiner, L.R., 1994, Winter habitat requirements and overwintering of riverine fishes: Southern Illinois University, Final Performance Report F-79-R-6, accessed May 23, 2018, at https://opensiuc.lib.siu.edu/fiaq_reports/8/.

Siegert, N.W., McCullough, D.G., Liebhold, A.M., and Telewski, F.W., 2014, Dendrochronological reconstruction of the epicentre and early spread of emerald ash borer in North America: Diversity \& Distributions, v. 20, no. 7, p. $847-858$.

Skillen, J.R., 2016, Federal ecosystem management-Its rise, fall, and afterlife: Lawrence, Kans., University Press of Kansas.

Soballe, D. M. and Fischer, J. R., 2004, Long Term Resource Monitoring Program Procedures: Water quality monitoring. LTRMP 2004-T002-1, La Crosse, Wis., U.S. Geological Survey, Upper Midwest Environmental Sciences Center, 73 p., 10 app., accessed June 6, 2018 at https://www.umesc. usgs.gov/documents/reports/2004/04t00201.pdf.

Sobotka, M.J., and Phelps, Q.E., 2016, A comparison of main and side channel physical and water quality metrics and habitat complexity in the Middle Mississippi River: River Research and Applications, v. 33, no. 6, p. 879-888.

Sparks, R.E., 1995, Need for ecosystem management of large rivers and their floodplains: Bioscience, v. 45 , no. 3 , p. $168-182$.

Sparks, R.E., Nelson, J.C., and Yin, T., 1998, Naturalization of the flood regime in regulated rivers: Bioscience, v. 48, no. 9, p. 706-720.
Stafford, J.D., Horath, M.M., Yetter, A.P., Hine, C.S., and Havera, S.P., 2007, Wetland use by Mallards during spring and fall in the Illinois and central Mississippi river valleys: Waterbirds, v. 30, no. 3, p. 394-402.

Stanford, J.A., Lorang, M.S., and Hauer, F.R., 2005. The shifting habitat mosaic of river ecosystems. SIL Proceedings, 1922-2010, 29:1, 123-136, DOI:10.1080/03680770.2005.1 1901979.

Sternberg, R.B., 1971. Upper Mississippi River habitat classification survey, Hastings, Minnesota, to Alton, Illinois. Upper Mississippi River Conservation Committee, Fish Technical Section.

Stokes, K., Ward, K., and Colloff, M., 2010, Alterations in flood frequency increase exotic and native species richness of understory vegetation in a temperate floodplain eucalypt forest: Plant Ecology, v. 211, no. 2, p. 219-233.

Theiling, C.H., Korschgen, C., De Haan, H., Fox, T., Rohweder, J., and Robinson, L., 2000, Habitat needs assessment for the Upper Mississippi River System-Technical Report: La Crosse, Wis., U.S. Geological Survey, Upper Midwest Environmental Sciences Center, 248 p., plus appendixes, accessed May 23, 2018, at https://www.umesc.usgs. gov/data_library/related_study_efforts/hna/hna_report.pdf.

Theiling, C.H., Janvrin, J.A., and Hendrickson, J., 2015, Upper Mississippi River restoration-Implementation, monitoring, and learning since 1986: Restoration Ecology, v. 23 , no. 2 , p. $157-166$.

Tripp, S., Brooks, R., Herzog, D., and Garvey, J., 2014, Patterns of fish passage in the Upper Mississippi River: River Research and Applications, v. 30, no. 8, p. 1056-1064.

Tucker, J.L., Theiling, C.H., and Camerer, J.B., 1996, Utilization of backwater habitats by Unionid mussles (BivalviaUnionidae) on the Lower Illinois River and in Pool 26 of the Upper Mississippi River: Transactions of the American Fisheries Society, v. 89, p. 113-122.

Tyser, R.W., Rogers, S.J., Owens, T.W., and Robinson, L.R., 2001, Changes in backwater plant communities from 1975 to 1995 in Navigation Pool 8, Upper Mississippi River: Regulated Rivers, Research and Management, v. 17, no. 2, p. 117-129.

Upper Mississippi River Restoration Program, 2015, A Strategic Plan for the Upper Mississippi River Restoration Program, 2015 - 2025: Rock Island, Ill., U.S. Army Corps of Engineers, Rock Island District, 20 p., accessed June 6, 2018 at http://www.mvr.usace.army.mil/Portals/48/ docs/Environmental/EMP/Key\%20Docs/umrr-strategicplan-fy15-25-jan2015.pdf. 
U.S. Army Corps of Engineers [USACE], 1992, Upper Mississippi River-Illinois Waterway System Navigation Study. Initial project management plan. St. Paul District, Rock Island District, and St. Louis District, North Central Division, U.S. Army Corps of Engineers, Chicago, Ill.

U.S. Army Corps of Engineers [USACE], 2011, Upper Mississippi River System Ecosystem Restoration Objectives 2009: accessed May 23, 2018, at http:/www.mvr.usace.army.mil/ Portals/48/docs/Environmental/EMP/UMRR_Ecosystem_ Restoration_Objectives_2009.pdf.

Walker, B., and Salt, D., 2012, Resilience practice-Building capacity to absorb disturbances and maintain function: Washington, D.C., USA, Island Press.

Ward, J.V., 1989, The four-dimensional nature of lotic ecosystems: Journal of the North American Benthological Society, v. 8 , no. 1 , p. $2-8$.

Ward, J.V., Tockner, K., and Schiemer, F., 1999, Biodiversity of floodplain river ecosystems-Ecotones and connectivity: River Research and Applications, v. 15, p. 125-139.

Watson, C.C., Biedenharn, D.S., and Thorne, C.R., 2013, Analysis of the impacts of dikes on flood stages in the Middle Mississippi River: Journal of Hydraulic Engineering, v. 139 , no. 10 , p. 1071-1078.

WEST Consultants, Inc., 2000, Final report-Upper Mississippi River and Illinois Waterway cumulative effects study, volume 1: Geomorphic assessment, ENV Report 40-1 [also available at http://www.mvs.usace.army.mil/Portals/54/ docs/navigation/SEIS/Library/Other_Documents/Nav Study_Cumulative_Effects_Vol_1_Geomorphic_Assessment.pdf]
Whited, D.C., Lorang, M.S., Harner, M.J., Hauer, F.R., Kimball, J.S., and Stanford, J.A., 2007, Climate, hydrologic disturbance, and succession-Drivers of floodplain pattern: Ecology, v. 88, no. 4, p. 940-953.

Wilcox, D.B., 1993. An aquatic habitat classification system for the Upper Mississippi River System: U.S. Fish and Wildlife Service, Environmental Management Technical Center, Long Term Monitoring Program, Technical Report 93-T003, 9 p., 1 app., accessed May 23, 2018, at http:// www.mvr.usace.army.mil/Portals/48/docs/Environmental/ EMP/UMRR_Ecosystem_Restoration_Objectives_2009. pdf.

Wood, P. J. and Armitage, P. D., 1997, Biological effects of fine sediment in the lotic environment: Environmental Management v. 21, no. 2, p. 203-217.

Xi, W., Coulson, R.N., Birt, A.G., Shang, Z.B., Waldron, J.D., Lafon, C.W., Cairns, D.M., Tchakerian, M.D., and Klepzig, K.D., 2009, Review of forest landscape models-Types, methods, development, and applications: Acta Ecologica Sinica, v. 29, no. 1, p. 69-78.

Yin, Y., J.C. Nelson, G.V. Swenson, H.A. Langrehr, and T.A. Blackburn. 1994. Tree mortality in the Upper Mississippi River and floodplain following an extreme flood in 1993. LTRMP 94- S011, U.S. Department of Interior, National Biological Service, Environmental Management Technical Center, Onalaska, WI. Pp. 39-60. 



\section{Appendix 1}

\section{An Aquatic Areas Classification for the Upper Mississippi River System}

\section{Background}

Large floodplain rivers have complex internal structures that are often difficult to characterize quantitatively (Rosgen, 1994; Montgomery, 1999; Church, 2002; Benda and others, 2004; Thorp and others, 2006). On the one hand, large floodplain rivers are defined by the movement of water, which is a fluid and moves continuously. On the other hand, these systems contain a variety of complex geomorphic structures which often create abrupt discontinuities in rates and directions of water movement and associated chemical constituents (De Jager and Houser, 2012). The result is often a patch-work mosaic of waterbodies that exist along a continuum from lotic to lentic conditions (Amoros and Bornette, 2002).

The patch-work mosaic of the Upper Mississippi and Illinois Rivers, collectively referred to as the Upper Mississippi River System (UMRS), has long been appreciated, and there have been a series of efforts to classify and map aquatic patches (Sternberg, 1971; Wilcox, 1993). At the broadest level, geomorphic and navigational structures can be delineated based on aerial photography and bathymetric data (such as main and side channels, channel borders, floodplain lakes, impounded areas, etc.). Using available monitoring data, at a finer resolution the physiochemical conditions (such as flow velocity, depth, dissolved oxygen, etc.) within each class can be used to characterize differences among individual habitat patches (Wilcox, 1993). In this manner, a hierarchy can be created ranging from coarse-scale and general habitat classes to finer-scale and more specific classes.

This document provides methodological details for the development of a hierarchical classification of UMRS aquatic habitats. This classification builds off previous classifications developed for various parts of the UMRS (Sternberg, 1971; Wilcox, 1993). Manual delineation of broad-scale geomorphic features derived from land-cover data (Dieck and others, 2015) forms the basis for the coarsest and most general classification (level 1). Automated procedures using additional geospatial data (bathymetry) are then used to identify additional geomorphic features at a finer scale (level 2). Finally, landscape metrics that characterize the connectivity and depth distribution of selected geomorphic features are used to achieve the finest scale classification (level 3).

The identification of aquatic habitat patches at different hierarchical levels can help provide information useful for making management decisions at different scales. At the broadest scale, major differences in general habitat classes abundance and distribution across the UMRS can be used to assess spatial differences in, for example, geomorphic diversity (De Jager and Rohweder, 2011). In other words, differences in general habitat classes from one period to another within a given area can be used to evaluate change over time. Both approaches can help resource managers set regional priorities for the restoration of specific habitat patches. At finer levels of detail, the geomorphic features that differentiate given habitat patches can be used to evaluate their potential to support macroinvertebrate, fish, mussel, and waterfowl populations. Further, such quantification can help to establish geomorphic criteria for restoration projects that seek to improve or modify geomorphic conditions within specific habitat patches for target species or communities. 


\section{Methods}

This section describes the methods used to delineate aquatic features at three hierarchical levels. The first level (level 1) classification consists of the broadest and most generic delineation of features. The second level (level 2) classification uses additional datasets to delineate finer-scale and more specific features. Finally, the third level (level 3) classification includes a series of metrics to delineate additional finer scale features and provide attributes for each feature.

\section{Level 1 Classification}

Distinguishing among different geomorphic features for the level 1 classification was primarily based on a land-water boundary derived from land-cover data developed for the UMRS for the years 1989 and 2010 (Dieck and others, 2015). The following classes were delineated based on visual inspection (Fig. 1.1).

\section{Main Navigation Channel (MNC)}

The designated navigation corridor as determined from navigation charts.

Each navigation reach typically contains a single large MNC polygon. For 1989, the MNC polygon was copied directly from the original aquatic areas coverage and appended to the new version (U.S. Army Corps of Engineers, 2016). This polygon was originally determined using paper navigation charts depicting the sail line and wing dams and other structures. Sometimes buoys visible on the imagery were also used to determine the navigation channel. For 2010-11, the original polygon was again appended into the new coverage but then modified if it looked like there had been changes to the corridor, such as where structures crossed into it or had clearly been added. The Inland Electronic Navigation Charts (U.S. Army Corps of Engineers, 2016) were used for these determinations.

\section{Channel Border (CB)}

Areas between the navigation channel and the shorelines.

Each navigation reach typically contains two CB polygons that run adjacent to and along the entire length of the MNC polygon. However, sometimes the MNC polygon is near the shoreline on one side of the main channel, and therefore more than two polygons are possible. These polygons can contain channel-training structures.

\section{Side Channel (SC)}

Channels other than the main channel.
Navigation reaches may contain zero to many SC polygons, delineated with straight and (or) diagonal lines from the shoreline to the apex of an island polygon at upstream and downstream limits of the apparent channels.

\section{Tributary Channel (TRC)}

Tributaries entering the river.

Each navigation reach may contain zero to many TRC polygons.

\section{Contiguous Floodplain Lake (CFL)}

Lakes connected by apparent surface flow to channels.

Each navigation reach may contain zero to many CFL polygons, which are delineated with a straight line across the connection to the channel, as a continuation of the apparent shorelines. Determination of CFL vs. IFL (see below) can be highly dependent on water levels at the time of aerial photography, image resolution, and/or the minimum mapping unit used to delineate land-cover features.

\section{Contiguous Floodplain Shallow Aquatic (CFSA)}

Inundated areas that are a mosaic of open water, emergent and floating vegetation, and islands.

Navigation reaches can have zero to many CFSA polygons, although if present, most reaches have a single CFSA polygon just upstream of CIMP polygons (see following section). Straight lines between the downstream points of islands are used to construct a boundary between CFSA and CIMP. Side channels and lakes may run through the CFSA but will have unclear or complex boundaries. Where this is the case, CFSA polygons are replaced by SC or CFL polygons for level 2 classification using bathymetric data (see Level $2 \mathrm{SC}$ and CFL for details).

\section{Contiguous Impounded (CIMP)}

Large open water areas in the downstream portions of navigation pools.

Navigation reaches may have zero to a few CIMP polygons.

\section{Isolated Floodplain Lake (IFL)}

Floodplain lakes having no apparent surface water connection to channels (see section titled "Contiguous Floodplain Lake" for determination of CFL vs IFL).

\section{No Coverage (NC)}

No photo coverage 


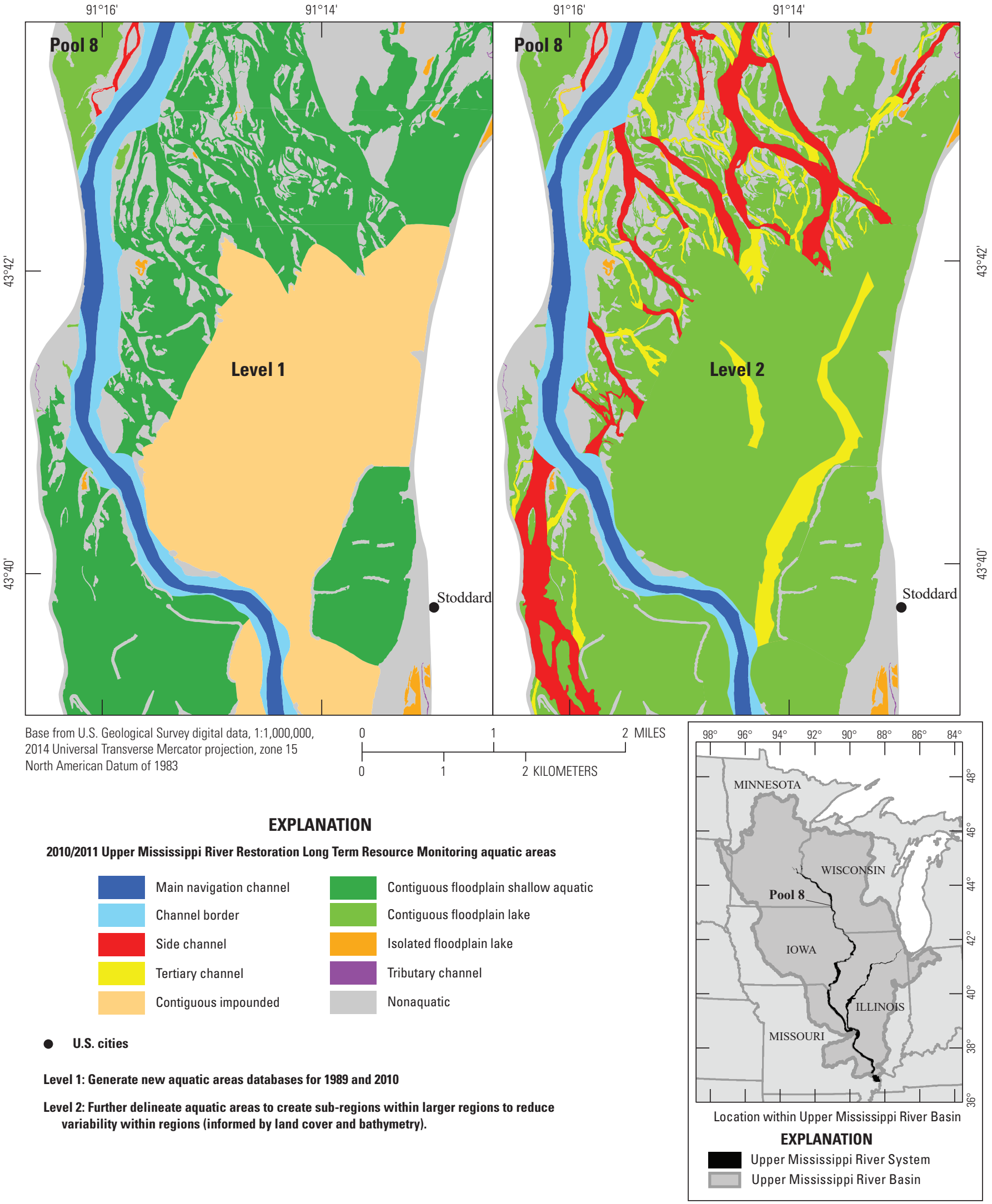

Figure 1.1 Maps depicting the development of level 1 and level 2 aquatic areas databases. 


\section{Level 2 Classification}

The purpose of level 2 classification was to further distinguish geomorphic features not easily interpreted visually. Bathymetric and land-cover data and automated approaches were used to reclassify select level 1 classes for level 2 classification. In addition, all CFSA class was reclassified to CFL or SC, and parts of the CIMP class were reclassified to CFL or SC. Also, side channels were further classified into both SC and tertiary side channels (TSC). The level 2 classification consists of all of the classes and polygons described for the level 1 classification, unless noted below. Specifically, there are no CIMP, or CFSA classes in level 2.

\section{Side Channel (SC)}

Channels other than the main channel. All side channels delineated for the level 1 are carried forward to the level 2. Other side channels are delineated for the level 2 by using bathymetry and land-cover data to derive these classes from CFSA and CIMP. Criteria for SC in CFSA are primarily open water in the 1989 land cover. However, deep areas extending outside the normal channel position into backwaters are excluded as SC. For SC in CIMP, deep areas with sharp rises to shallow that are elongated and connected to at least one side channel.

\section{Tertiary Channel (TSC)}

Side channels that are not directly connected to the main channel were generally reclassified as TSC. This level 2 classification of SC was primarily done to create natural segments that allow for adding metrics in level 3. The loose definition of TSC warrants some caution in its use as a standalone class in level 2, and collapsing TSC back into SC is recommended if using level 2 in a standalone manner (using without metrics from level 3).

\section{Contiguous Floodplain Lake (CFL)}

Lakes connected by apparent surface flow to channels. All CFL polygons are retained from the level 1. Others are newly developed for the level 2 from CIMP and (or) CFSA using bathymetry and land-cover data. Criteria for CFL in CFSA is simply the remaining area not reclassified to side channel.

\section{Tributary Delta Lake (TDL)}

This large contiguous floodplain lake feature (Lake Pepin) is formed in navigation pool 4 by the Chippewa River Delta. This contiguous-floodplain lake type is not further analyzed in level 3 .

\section{Level 3 Classification}

The purpose of level 3 classification procedure was to add metrics describing connectivity, depth, and structures to each polygon in the dataset. These metrics provide useful information for quantifying habitat for a wide range of species.

In addition, the channel border class was further reclassified for level 3 according to the presence of river-training structures. River-training structures were obtained from the U.S. Army Corps of Engineers Inland Electronic Navigation Chart (U.S. Army Corps of Engineers, 2016; fig 1.2).

\section{Structured Channel Border (SCB)}

Areas within the channel border that contain rivertraining structures. This is calculated by selecting individual channel border segments, then selecting river-training rivertraining structures that intersect that channel border segment. Next, the river-training river-training structures are buffered 400 meters, clipped by the channel border polygon and then the buffers that overlap are combined to form the structured channel border segment.

\section{Unstructured Channel Border (USCB)}

Areas within the channel border that are at least 400 meters from a river-training structure. 


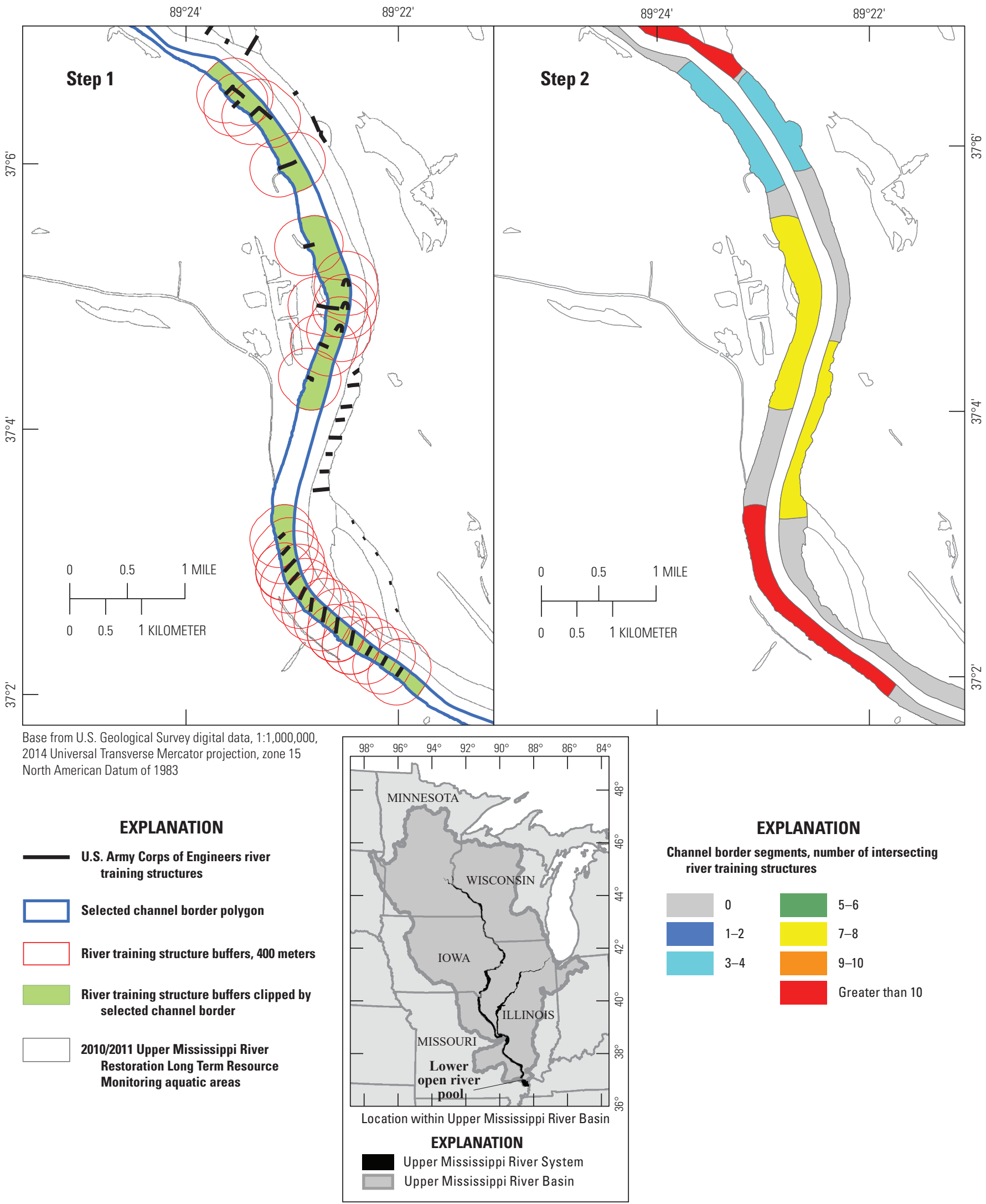

Figure 1.2 Graphical depiction of methods used to produce structured versus unstructured channel border segments. 


\section{Aquatic Area Region Polygon Metrics}

The following is a list of metrics applied to each polygon in the aquatic areas data set. Note that some metrics are only calculated for lentic aquatic areas (denoted with *), while others are only calculated for lotic aquatic areas $(* *)$.

\section{Shape and (or) Size Metrics}

- area: area of aquatic area region in meters ${ }^{2}$.

- hectares: area of aquatic area region in hectares.

- acres: area of aquatic area region in acres.

- perimeter: perimeter of aquatic area region in meters.

- min_rm: minimum river mile value of aquatic area region.

- max_rm: maximum river mile value of aquatic area region.

- len_met: distance in meters between minimum river mile and maximum river mile values of aquatic area region.

- sinuosity: polygonal sinuosity of the aquatic area region. Values approaching 1 are more sinuous, approaching 0 are less sinuous. Figure 1.3 gives an outline of how this is calculated (Tim Fox, written/oral commun., 2018).

- avg_fetch: a weighted (based on occurrence of historical wind direction) mean fetch in kilometers (Figure 1.4).*

- sdi: shoreline development index defined by the ratio of the region perimeter (including lotic connections) to the perimeter of a circle of the same area as the region.
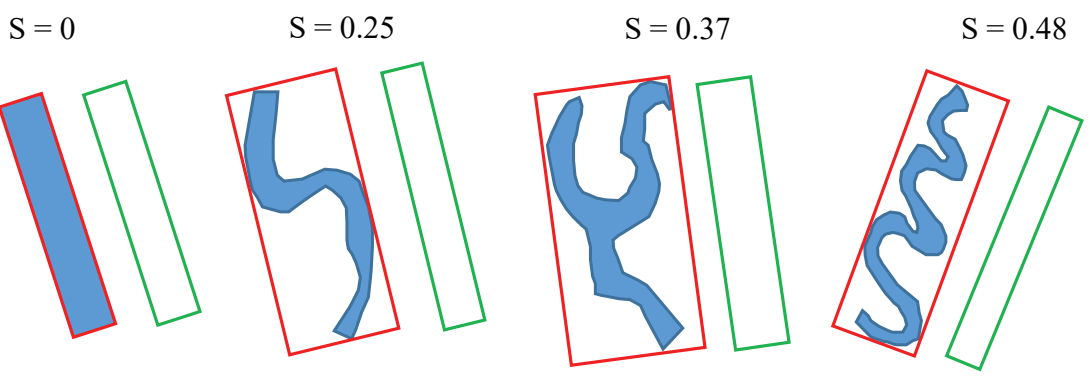

\section{EXPLANATION}

$$
\begin{aligned}
& \text { Input polygon } \\
& \text { Sinuosity }(\mathrm{S})=1-\frac{2\left(\text { Area }_{\mathrm{p}} / \text { Length }_{\mathrm{MGB}}\right)+2 \text { Length }_{\mathrm{MBG}}}{\text { Perimeter }_{\mathrm{p}}}=1-\frac{\text { Perimeter }_{\text {LSRP }_{\mathrm{P}}}}{\text { Perimeter }_{\mathrm{p}}}
\end{aligned}
$$

where

$$
\begin{aligned}
\mathrm{p}= & \text { input polygon } \\
\mathrm{MBG}= & \text { the minimum bounding geometry of input polygon } \\
\mathrm{LSRP}= & \text { least sinuous representative polygon, a rectangle where the length } \\
& \text { is equal to the MGB length and an area equal to that of the input } \\
& \text { polygon. }
\end{aligned}
$$

Interpreting $S$ values:

$\mathrm{S}<0$ : non-sinuous polygons

$\mathrm{S}=0: \quad$ rectangular input polygons (channels)

$0<\mathrm{S}<1: \quad$ as $\mathrm{S}$ values approach 1, input polygons have greater sinuosity.

$\mathrm{S}$ values are more accurate for polygons with parallel margins.

Figure 1.3 Diagram and calculations describing development of polygonal sinuosity metric (Tim Fox, written/oral commun., 2018). 


\section{Polygon metrics}

\begin{tabular}{ll}
\hline uniq_id & P08_CFL_224 \\
pool & P08 \\
AQUA_CODE & CFL \\
AQUA_DESC & Contiguous floodplain lake \\
max_depth & 5.99 \\
avg_depth & 0.54 \\
sd_depth & 0.52 \\
tot_vol & $1,155,214$ \\
avg_fetch & 0.43 \\
sdl & 3.96 \\
econ & 1.38 \\
sill & 261,183 \\
\hline
\end{tabular}


Base from U.S. Geological Survey digital data, 1:1,000,000, 2014 Universal Transverse Mercator projection, zone 15 North American Datum of 1983

\section{EXPLANATION} 2010/2011 Upper Mississippi River Restoration Long Term Resource Monitoring level 3 aquatic areas
$\square$ Example lentic aquatic area polygon

2010/2011 Upper Mississippi River Restoration Long Term Resource Monitoring level 2 aquatic areas Lotic aquatic area Lentic aquatic area Land

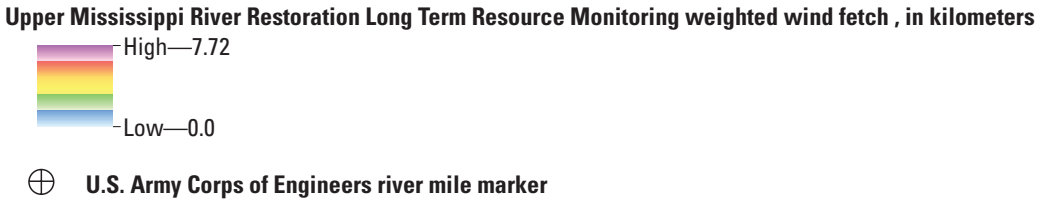

Figure 1.4 Map depicting metrics calculated specific to level 3 aquatic area polygons. 


\section{Water Depth Metrics}

- max_depth: maximum depth of 75 percent exceedance bathymetry within aquatic area region measured in meters (Figure 1.5).

- avg_depth: average depth of 75 percent exceedance bathymetry within aquatic area region measured in meters.

- sd_depth: standard deviation of depth of 75 percent exceedance bathymetry within aquatic area region measured in meters.

- tot_vol: total bathymetric volume (at 75 percent exceedance level) within aquatic area region measured in meters ${ }^{3}$.

- bath_pct: percentage of aquatic area region that is covered by $75 \%$ exceedance bathymetry raster surface.

- area_gt50: area within aquatic area region that has depth greater than 50 centimeters measured in meters ${ }^{2}$.

- area_gt100: area within aquatic area region that has depth greater than 1 meter measured in meters ${ }^{2}$.

- area_gt200: area within aquatic area region that has depth greater than 2 meters measured in meters ${ }^{2}$.

- area_gt300: area within aquatic area region that has depth greater than 3 meters measured in meters ${ }^{2}$.

- sill: total area in meters ${ }^{2}$ that meets the definition of a depression at 4 levels $(1,1.5,2$, and 3 meters deep).* 


\section{EXPLANATION}

2010 / 2011 Upper Mississippi River Restoration Long Term Resource Monitoring Level 3 aquatic Areas

Example side channel polygon

2010/2011 Upper Mississippi River Restoration Long Term Resource Monitoring Land Cover/ Land Use

Land

Upper Mississippi River Restoration Long Term Resource Monitoring 75\% Exceedence Bathymetry, in meters

\begin{tabular}{|l|l|}
\hline $0-0.5$ & $5.0-6.0$ \\
\hline $0.5-1.0$ & $6.0-7.0$ \\
\hline $1.0-1.5$ & $7.0-8.0$ \\
\hline $1.5-2.0$ & $8.0-9.0$ \\
\hline $2.0-3.0$ & $9.0-10.0$ \\
\hline $3.0-4.0$ & $>10.0$ \\
\hline $4.0-5.0$ & \\
\hline
\end{tabular}

$\bigoplus \quad$ US Army Corps of Engineers river mile marker

\section{Polygon metrics}

\begin{tabular}{|c|c|}
\hline $\begin{array}{l}\text { uniq id } \\
\text { pool }\end{array}$ & $\begin{array}{l}\text { P08_SC_17 } \\
\text { P08 }\end{array}$ \\
\hline AQUA_CODE & $\mathrm{SC}$ \\
\hline AQUA_DESC & Side channel \\
\hline LAND WATER & Water \\
\hline Perimeter & 13,783 \\
\hline Area & $1,226,171$ \\
\hline Hectares & 122.6 \\
\hline Acres & 303.0 \\
\hline len_met & 5,561 \\
\hline min_rm & 698.18 \\
\hline max_rm & 701.64 \\
\hline sinuosity & 0.1981 \\
\hline bath_pct & 93.08 \\
\hline area_gt50 & $1,065,943$ \\
\hline area_gt100 & 959,000 \\
\hline area_gt200 & 616,840 \\
\hline area_gt300 & 380,470 \\
\hline min_depth & 0.01 \\
\hline max_depth & 11.89 \\
\hline avg_depth & 2.65 \\
\hline sd_depth & 1.86 \\
\hline tot_vol & $3,027,509$ \\
\hline
\end{tabular}

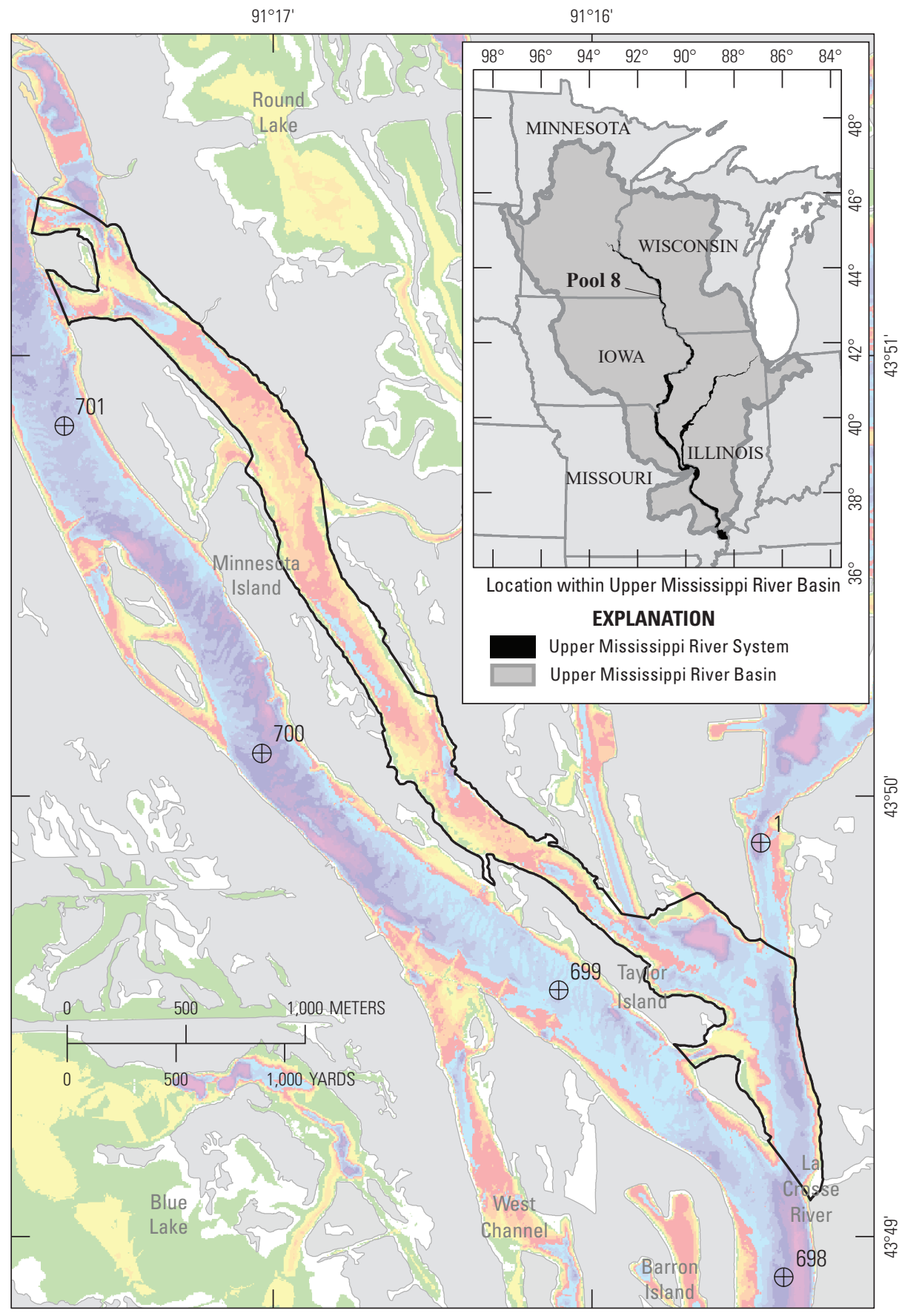

Base from U.S. Geological Survey digital data, 1:1,000,000, 2014 Universal Transverse Mercator projection, zone 15 North American Datum of 1983

Figure 1.5 Map depicting various water depth related metrics calculated for level 3 aquatic area polygons. 


\section{Shoreline Metrics}

- len_wetf: length, in meters, of aquatic area region's perimeter adjacent to wet forest. Land cover and land use developed in 2010-2011 by the Long Term Resource Monitoring element was used to determine adjacent land-cover types (Figure 1.6).

- pet1wetf: percentage of aquatic area region's perimeter adjacent to wet forest.

- pct2wetf: percentage of aquatic area region's terrestrial shoreline adjacent to wet forest.

\section{Connectivity Metrics}

- len_outl: length, in meters, of aquatic area region's perimeter adjacent to other aquatic area polygons classified as lotic (main navigation channel, channel border, tributary channel, side channel, or tertiary side channel). This metric was not calculated for channel border aquatic area polygons (Figure 1.7).

- pct_outl: percentage of aquatic area region's perimeter adjacent to other aquatic area polygons classified as lotic (main navigation channel, channel border, tributary channel, side channel, or tertiary side channel). This metric was not calculated for channel border aquatic area polygons.

- num_outl: total number of lotic outlets from aquatic area region (adjacent polygons defined as main navigation channel, channel border, tributary channel, side channel, or tertiary side channel). This metric was not calculated for channel border aquatic area polygons.

- len_oute: length, in meters, of aquatic area region's perimeter adjacent to aquatic area polygons classified as lentic (contiguous floodplain lake, isolated floodplain lake, or contiguous impounded).

- pct_oute: percentage of aquatic area region's perimeter adjacent to aquatic area polygons classified as lentic (contiguous floodplain lake, isolated floodplain lake, or contiguous impounded).

- num_oute: total number of lentic outlets from aquatic area region (adjacent polygons defined as contiguous floodplain lake, isolated floodplain lake, or contiguous impounded).

- pet_aqveg: percentage of aquatic area region classified as aquatic vegetation in 2010-2011 land cover land use.

- pct_opwat: percentage of aquatic area region classified as open water in 2010-2011 land cover land use.

- len_terr: length, in meters, of aquatic area region's perimeter adjacent to polygons defined as "terrestrial".

- pct_terr: percentage of aquatic area region's perimeter adjacent to polygons defined as "terrestrial".

- pct_chan: percentage of aquatic area region's perimeter adjacent to polygons defined as “aquatic".

- econ: effective connections defined as the ratio of the length of the longest segment of terrestrial shoreline to the total terrestrial shoreline length. * 


\section{Polygon metrics}

\begin{tabular}{ll}
\hline uniq_id & P08_SC_17 \\
pool & P08 \\
AQUA_CODE & SC \\
AQUA_DESC & Side channel \\
LAND_WATER & Water \\
len_wetf & 8,901 \\
pct1wetf & 64.6 \\
pct2wetf & 82.8 \\
\hline
\end{tabular}

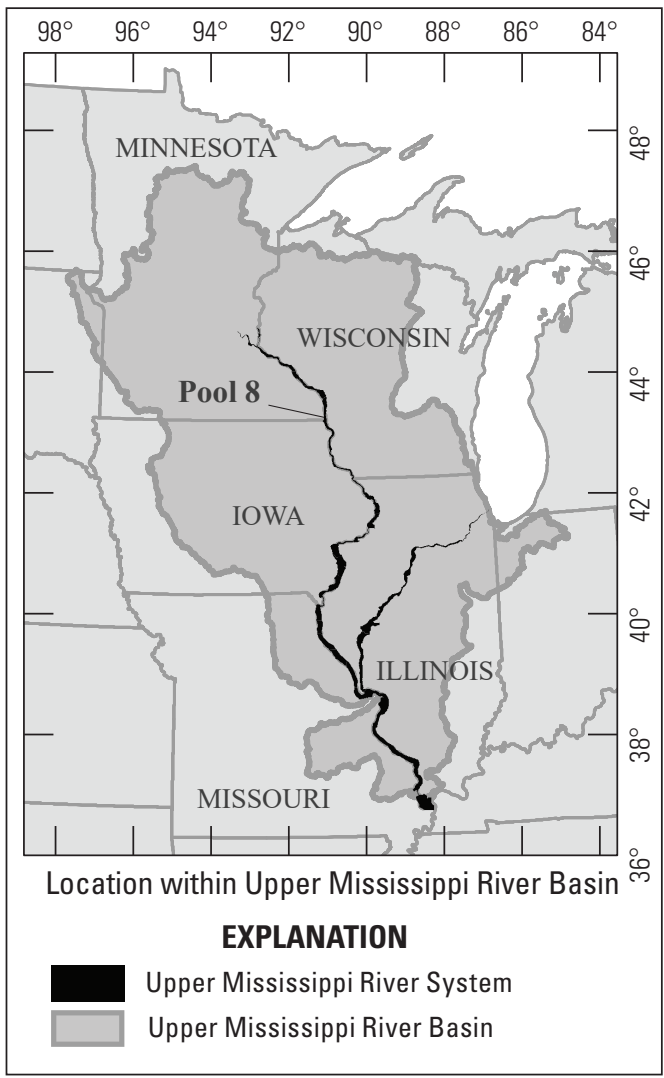

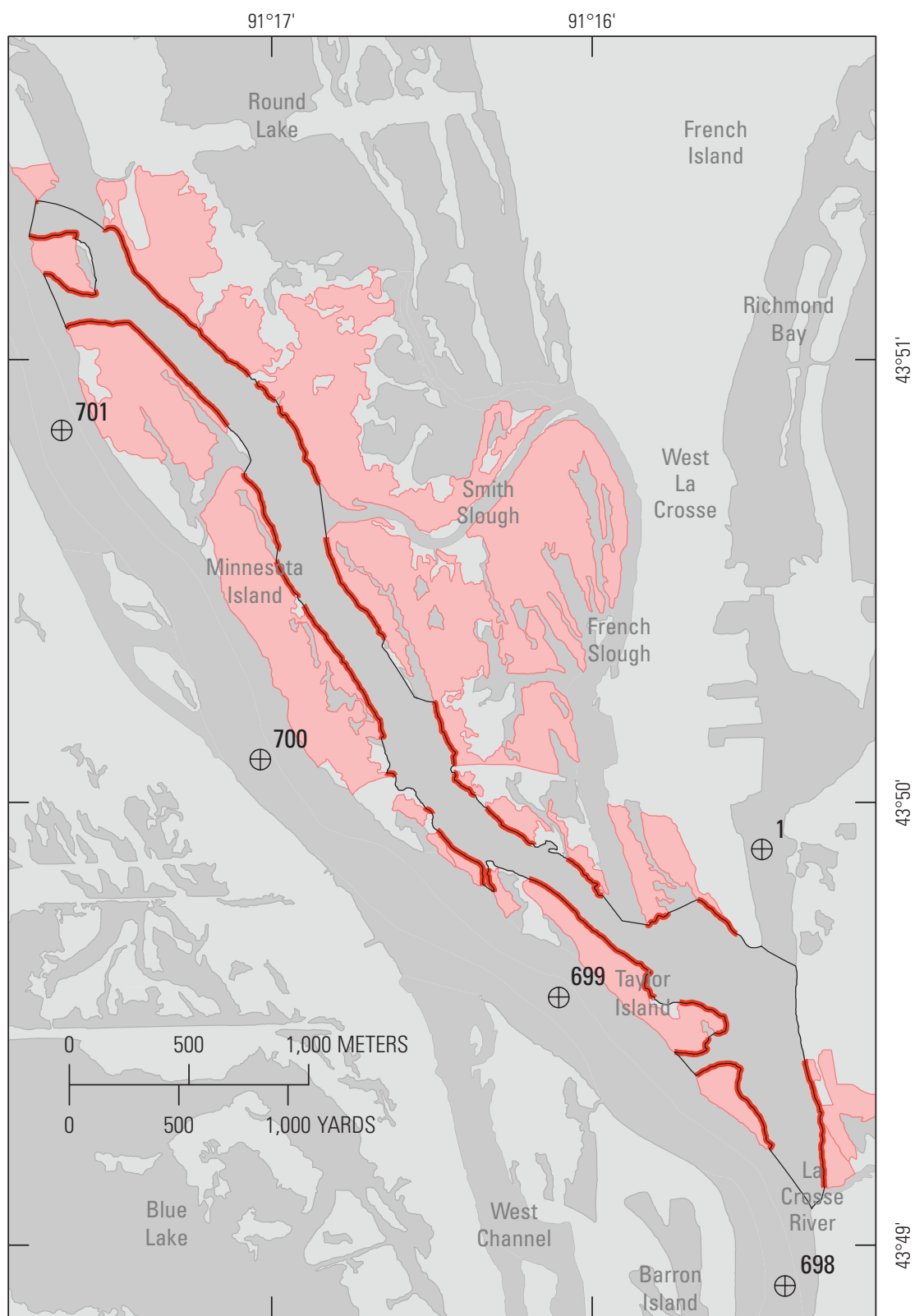

Base from U.S. Geological Survey digital data, 1:1,000,000, 2014 Universal Transverse Mercator projection, zone 15 North American datum of 1983

\section{EXPLANATION}

2010/2011 Upper Mississippi River Restoration Long Term Resource Monitoring Level 3 Aquatic Areas Example side channel polygon

2010/2011 Upper Mississippi River Restoration Long Term Resource Monitoring Land Cover / Land Use

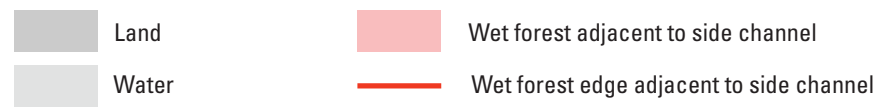

$\bigoplus$ US Army Corps of Engineers river mile marker

Figure 1.6 Map depicting wet forest adjacency metrics developed for level 3 aquatic area polygons. 
Polygon metrics

\begin{tabular}{lc}
\hline unq id & P08_SC_17 \\
pool & P08_SC_17 \\
AQUA_CODE & SC \\
AQUA_DESC & Side channel \\
LAND_WATER & Water \\
len_outl & 1,411 \\
pct_outl & 10.24 \\
num_outl & 8 \\
len_oute & 963 \\
pct_oute & 6.98 \\
num_oute & 13 \\
pct_aqveg & 2.53 \\
pct_opwat & 97.47 \\
len_terr & 11,410 \\
pct_terr & 82.78 \\
pct_chan & 17.22 \\
\hline
\end{tabular}

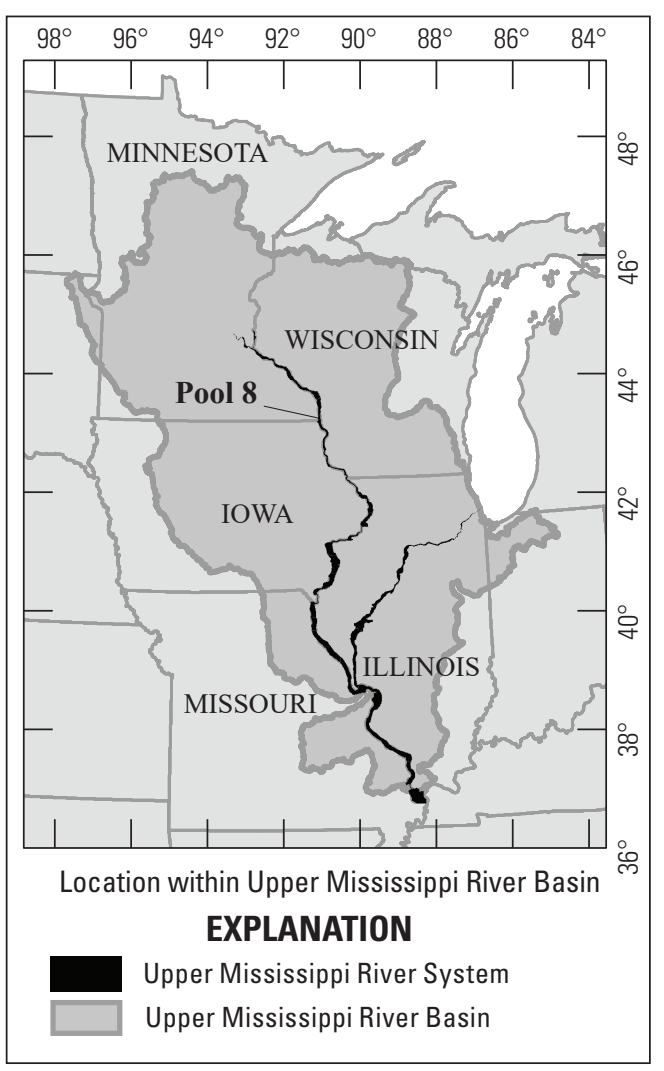

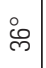

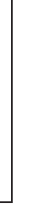

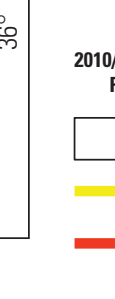

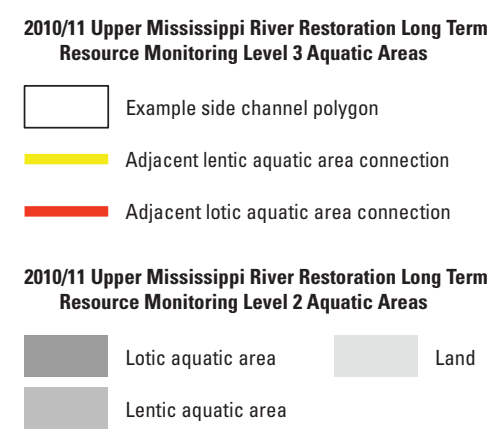

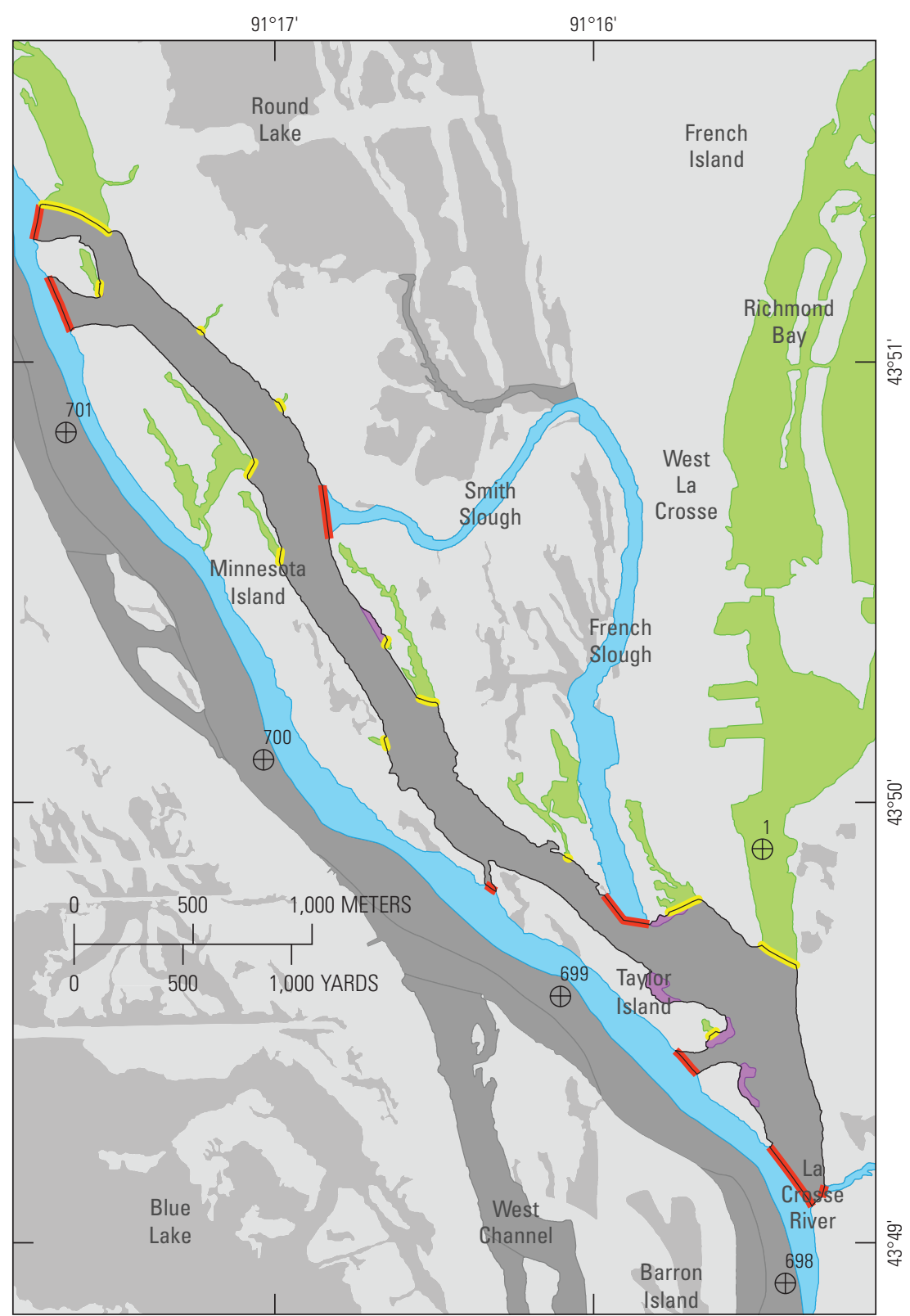

Base from U.S. Geological Survey digital data, 1:1,000,000, 2014 Universal Transverse Mercator projection, zone 15 North American Datum of 1983

\section{EXPLANATION}

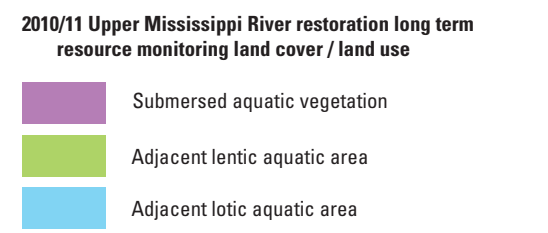

$\bigoplus \quad$ U.S. Army Corps of Engineers river mile marker

Figure 1.7 Map depicting various connectivity and aquatic vegetation metrics developed for level 3 aquatic area polygons. 


\section{River-training Structure Metrics}

- len_wd: length of river-training structures overlapping aquatic area region in meters.**

- wdl_p_m2: length of river-training structures overlapping aquatic area region in meters divided by total area of aquatic area region in meters $^{2}$ (Figure 1.8).**

- num_wd: number of river-training structures (wing dikes, bendway weirs, etc.) that overlap aquatic area region.**

- sco_wd: river-training structures with scour holes within 50 meters as defined by topographic position index classification.**

- psco_wd: percentage of river-training structures with scour holes within 50 meters.**

- area_tpil: area, in meters ${ }^{2}$, of aquatic area region classified as "canyon bottom" according to topographic position index. Topographic position index outputs developed using Land Facet Corridor Designer (Jenness Enterprise, 2013).**

- pet_tpi1: percentage of aquatic area region classified as "canyon bottom" according to topographic position index.**

- area_tpi2: area, in meters ${ }^{2}$, of aquatic area region classified as "flat/gentle" according to topographic position index.**

- pct_tpi2: percentage of aquatic area region classified as "flat/gentle" according to topographic position index.**

- area_tpi3: area, in meters ${ }^{2}$, of aquatic area region classified as "steep slope" according to topographic position index.**

- pct_tpi3: percentage of aquatic area region classified as "steep slope" according to topographic position index.**

- area_tpi4: area, in meters ${ }^{2}$, of aquatic area region classified as "ridgetop" according to topographic position index.**

- pet_tpi4: percentage of aquatic area region classified as "ridgetop" according to topographic position index.**

- len_revln: length of revetted bank (concrete or loose stone) within 20 meters of the aquatic area region in meters.**

- rev_p_m2: length of revetted bank within 20 meters of the aquatic region in meters divided by the aquatic area region's area, in meters $^{2} . * *$

- num_rev: total number of revetments within 20 meters of the aquatic region.**

- pet_rev: percentage of terrestrial shoreline that is revetted. Calculated according to the formula: (Length of revetments within 20 meters of aquatic area region divided by length of terrestrial shoreline)* $100 . * *$

- pet_rev2: percentage of aquatic area region perimeter that is resvetted. Calculated according to the formula: (Length of revetments within 20 meters of aquatic area region divided by length of aquatic area region perimeter)* $100 . * *$ 


\section{Polygon metrics}

\begin{tabular}{ll}
\hline uniq_id & P08_SCB_33 \\
pool & P08 \\
AQUA_CODE & SCB \\
AQUA_DESC & Structured channel border \\
len_wd & 1,034 \\
wdl_p_m2 & 0.00220 \\
rum_wd & 15 \\
sco_wd & 8 \\
psco_wd & 53.33 \\
len_revln & 2,362 \\
rev_p_m2 & 0.00501 \\
num_rev & 6 \\
pct_rev & 69.52 \\
pct_rev2 & 57.34 \\
area_tpi1 & 19,781 \\
pct_tpi1 & 4.20 \\
area_tpi2 & 352,814 \\
pct_tpi2 & 74.89 \\
area_tpi3 & 35,018 \\
pct_tpi3 & 7.43 \\
area_tpi4 & 43,389 \\
pct_tpi4 & 9.21 \\
\hline
\end{tabular}



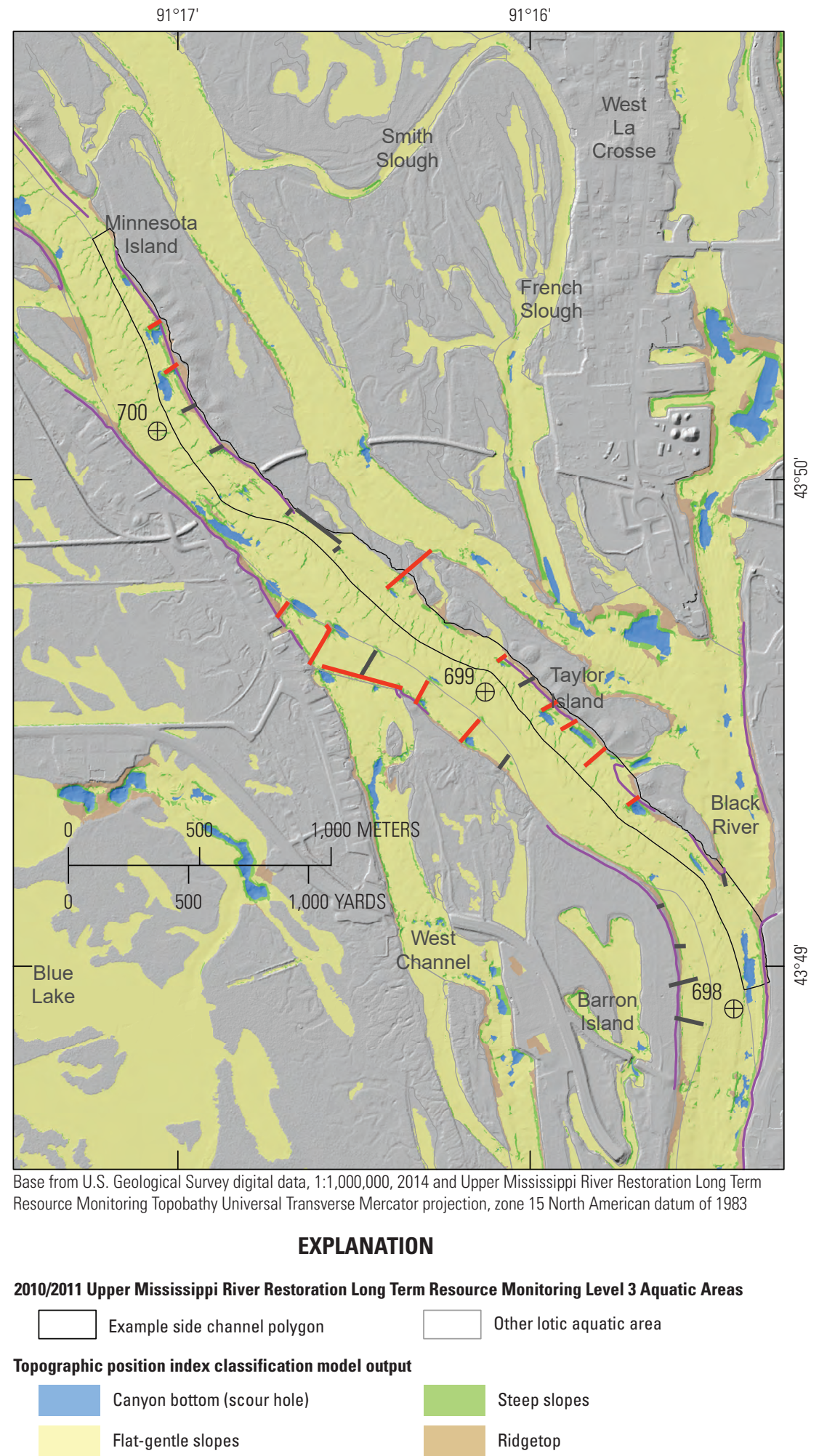

U.S. Army Corps of Engineers river training structures
No scour hole within Scour hole within 50 meters 50 meters
— US Army Corps of Engineers revetments

$\oplus$ uS Army Corps of Engineers river mile marker

Figure 1.8 Map depicting various river-training structure metrics developed for level 3 lotic aquatic area polygons. 


\section{References Cited}

Amoros, C., and Bornette, G., 2002, Connectivity and biocomplexity in waterbodies of riverine floodplains: Freshwater Biology, v. 47, no. 4, p. 761-776.

Benda, L., Poff, N.L., Miller, D., Dunne, T., Reeves, G. Pess, G., Pollock, M., 2004, The network dynamics hypothesis: How channel networks structure riverine habitats: Bioscience, v. 54, no. 5, p. 413-427.

Church, M., 2002, Geomorphic thresholds in riverine landscapes: Freshwater Biology, v. 47, no. 4, p. 541-557.

De Jager, N.R., and Houser, J.N., 2012, Variation in watermediated connectivity influences patch distributions of total $\mathrm{N}$, total P, and TN:TP ratios in the Upper Mississippi River, USA. Freshwater Science v. 31, no. 4, p. 1254-1272.

De Jager, N.R., and Rohweder, J.J., 2012, Spatial patterns of aquatic habitat richness in the Upper Mississippi River floodplain, USA: Ecological Indicators, v. 13, no. 1, p. 275-283.

Dieck, J. J., Ruhser, J., Hoy, E., and Robinson, L. R., 2015, General classification handbook for floodplain vegetation in large river systems (ver. 2.0): U.S. Geological Survey Techniques and Methods, book 2, chap. A1, p. 51, accessed June 1, 2018, at https://doi.org/10.3133/tm2A1. Jenness Enterprises, 2013. Land Facet Corridor Designer for ArcGIS 10, accessed Janurary 2018 at http://www.jennessent.com/arcgis/land_facets.htm.
Montgomery, D.R., 1999, Process domains and the river continuum: Journal of the American Water Resources Association, v. 35, no. 2, p. 397-410.

Rosgen, D.L., 1994, A classification of natural rivers: Catena, v. 22 , no. 3, p. 169-199.

Sternberg, R.B., 1971. Upper Mississippi River habitat classification survey, Hastings, Minnesota, to Alton, Illinois. Upper Mississippi River Conservation Committee, Fish Technical Section.

Thorp, J.H., Thoms, M.C., and Delong, M.D., 2006, The riverine ecosystem synthesis-Biocomplexity in river networks across space and time: River Research and Applications, v. 22, no. 2, p. 123-147.

U.S. Army Corps of Engineers' Upper Mississippi River Restoration (UMRR) Program Long Term Resource Monitoring (LTRM) element, 2016, UMRR HNA-II 1989 Aquatic Areas: La Crosse, Wisconsin, accessed June 1, 2018, at http://dx.doi.org/10.5066/F7VD6WH8.

U.S. Army Corps of Engineers, Inland Electronic Navigation Charts, Accessed August 23, 2016, at http://www.agc.army. mil/Missions/Echarts/.

Wilcox, D.B., 1993. An aquatic habitat classification system for the Upper Mississippi River System: U.S. Fish and Wildlife Service, Environmental Management Technical Report 93-T003, 9 pp. + Appendix A. 



\section{Appendix 2}

\section{Methods for Floodplain-Inundation Modeling}

\section{Background}

River-floodplain ecosystems are believed to be strongly influenced by inundation dynamics (Junk and others, 1989; Ward and others, 2002; Bornette and others, 2008). The physical template of these ecosystems is structured through vertical, lateral, and longitudinal exchanges of material and energy driven by overbank flooding (Amoros and Bornette, 2002), ultimately affecting patterns of edaphic conditions, sediment deposition and scour, biogeochemical cycling, and vegetation through space and time (Frye and Quinn, 1979; Megonigal and others, 1997; Tabacchi and others, 1998; Olde Venterink and others, 2006; Noe and Hupp, 2009; Kaase and Kupfer, 2016; De Jager and others, 2016). As a result of such interactions, river-floodplain ecosystems are characterized by pronounced spatial (Scown and others, 2015) and temporal heterogeneity (Nakamura and others, 2007), making them among the most biophysically diverse ecosystems (Tockner and Stanford, 2002). Such biophysical diversity makes these ecosystems a high conservation and restoration priority in the Upper Mississippi River System (UMRS; Guyon and others, 2012).

Ecologists have employed a diverse array of methodologies to characterize flooding dynamics based on the ecological phenomenon of interest, scale of the analysis, and available technology (Vaughan and others, 2009). For example, gradients of inundation dynamics have been approximated at relatively fine spatial scales with in-place measurements of surface water depth with piezometers (Rybicki and others, 2015; Jacinthe and others, 2015), using floodplain landforms as proxies for hydraulic and hydrologic variables (Osterkamp and Hupp, 1984; Hupp and Osterkamp, 1985), with measurements such as distance to the channel, relative elevation, or other geomorphic characterizations (Turner and others, 2004; Baker and Wiley, 2009), or by interpreting vegetation patterns (Baker and Wiley, 2004). Across relatively broad spatial scales, aspects of flooding dynamics such as inundation extent, duration, frequency, depth, and timing have been modeled for ecological purposes using combinations of satellite imagery, geographic information systems, and (or) hydraulic models (Townsend and Walsh, 1998; Townsend, 2001; Lorang and others, 2005; Heitmeyer, 2007; Martinez and Le Toan, 2007; Powell and others, 2008; De Jager and others, 2012; Theiling and Burant, 2013; Allen, 2015; De Jager and others, 2016).

System-wide characterizations of flooding dynamics across the UMRS, particularly as they may relate to ecological patterns and processes, are particularly lacking. For example, nonaquatic areas of the UMRS were described in the first Habitat Needs Assessment (HNA-I; Theiling and others, 2000) using only land cover, land use, and coarse geomorphic positioning attributes (such as island) which conveyed relatively little information about flooding. As a result, the HNA-I identified floodplain-inundation patterns as a critical information need: "[Floodplain-inundation] models should be developed to characterize the hydrologic regime of floodplains throughout the 
UMRS" (Theiling and others, 2000, p. 238). Since HNA-I, a few system-wide, spatially explicit characterizations of inundation have been produced. These studies include simple models of annual total duration for the northern portion of the UMRS (De Jager and others, 2012, 2016) and a study concerning the wetted extent for a subset of flow frequencies across the entire UMRS (Theiling and Burant, 2013). However, because no single inundation attribute is uniformly useful for understanding ecological phenomena in floodplain ecosystems (Merritt and others, 2010), there remains a need to more fully describe flooding dynamics across the UMRS.

The purpose of this modelling effort was to develop a method to simulate ecologically relevant gradients in flood frequency, duration, depth, and timing - four aspects of hydrologic regimes believed to drive river-floodplain ecosystem form and function (Poff and others, 1997; Pettit and others, 2001). To do this, we developed an inundation model to quantify multiple aspects of flooding. This modelling framework should prove useful for a wide range of future floodplain investigations. For HNA-II, we chose to map the distribution of mean total growing season flood inundation duration, given its role in shaping floodplain vegetation and soil properties in the UMRS (De Jager and others, 2012, 2016). Ten-year increments of inundation duration were used to represent "Floodplain functional classes. Finally, we mapped the floodplain functional classes across nonaquatic areas of the UMRS and describe their distributions across UMRS navigational pools. In the remainder of Appendix B, we first describe the general workflow for developing the floodplain functional classes, and then describe the approach, data inputs, methodological steps, and results in more detail. 


\section{Workflow Overview}

We used a two-part approach to describe and map floodplain functional classes in the UMRS (fig. 2.1). In Part 1, we developed a system-wide, spatially explicit inundation model to quantify flood regime for all nonaquatic areas. The model leveraged two existing datasets: daily water-surface elevations from the U.S. Army Corps of Engineers (USACE) gages and terrain data in the form of UMRS topo-bathymetric datasets. The data were analyzed by integrating geospatial processes and the statistical software $R$ (R Core Team, 2017). The final outputs from the inundation model were maps of inundation frequency, duration, depth, timing, and timing variability.

\section{Floodplain functional classes workflow}

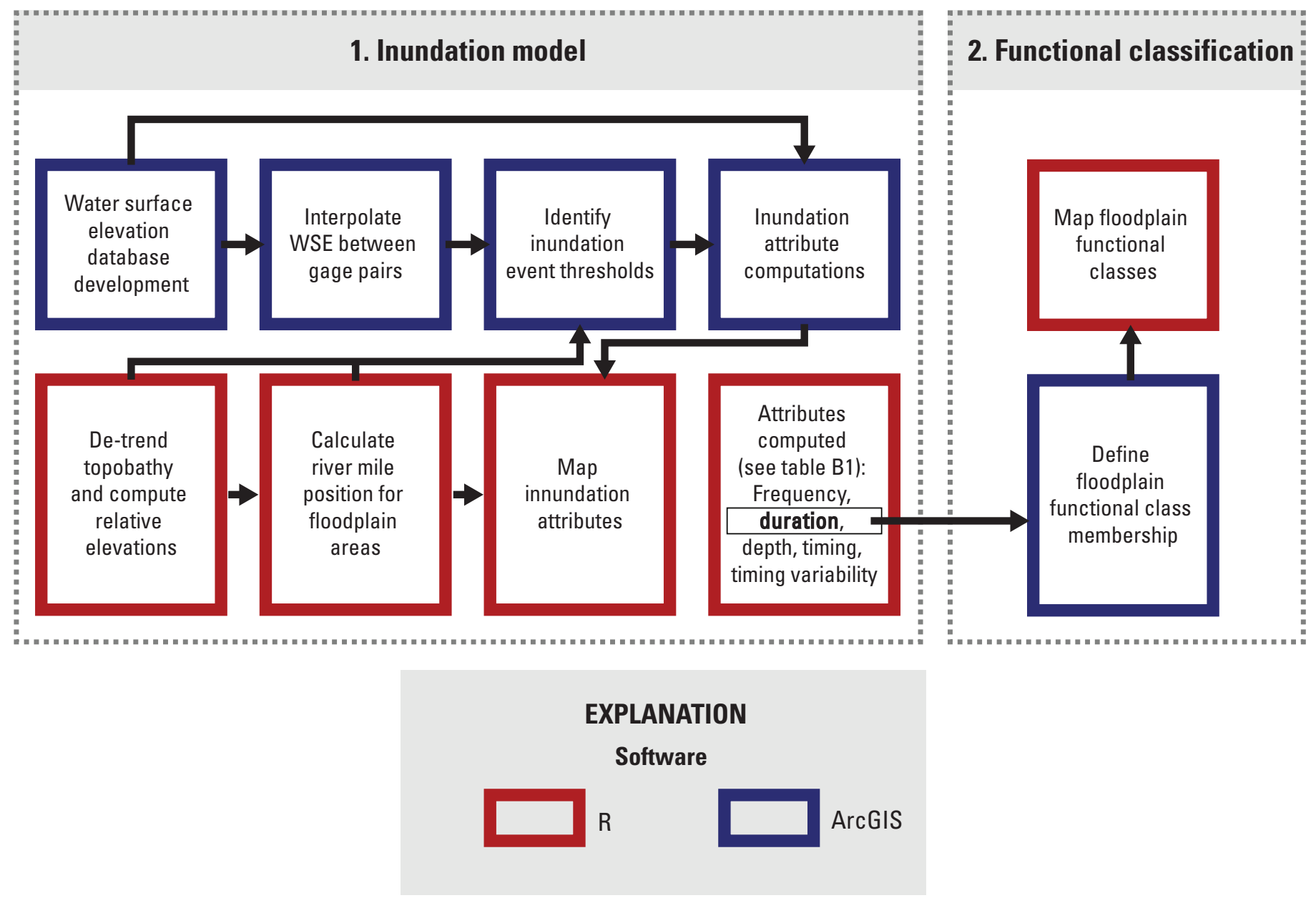

Figure 2.1 The development of floodplain functional classes was accomplished in two complimentary parts. Part 1 consisted of the development of a system-wide spatially explicit inundation model. The inundation model combined two dataset inputs (daily watersurface elevations from the U.S. Army Corps of Engineers' gages and terrain data in the form of Upper Mississippi River Systemtopobathymetry) to describe multiple attributes of inundation for all nonaquatic areas. In Part 2, we analyzed distributions of inundation duration to identify and map areas of the floodplain expected to experience similar patterns of flooding 


\section{Methods for Part 1: The UMRS Inundation Model}

Our framework for quantifying and mapping patterns of surface-water inundation throughout the UMRS is based on a planar surface model. The planar surface model, also referred to as a "bathtub" model, relies on the spatial intersection of water-surface elevations and terrain to define inundation extent and depth (fig. 2.2). Planar surface models are advantageous in large river-floodplain systems because they (1) are spatially explicit, (2) can be more computationally efficient than numerical hydraulic models, (3) can produce results at a fine grain size but over geographically broad areas, (4) can capture dynamic patterns (for example, changes through time) based on the temporal resolution of the input hydrologic data, (5) offer flexibility in how inundation patterns are summarized, and (6) rely on relatively simple assumptions.
Application of planar surface models in the UMRS is not without precedent. Inundation-duration patterns have been characterized for portions of the UMRS using spatial intersections of topo-bathymetry and spatial interpolations of watersurface elevations (De Jager and others, 2012, 2016). These efforts produced novel insights into the relationship between flood duration and vegetation patterns in the UMRS. However, the implementation relied on simplified assumptions about slope changes across the floodplain surface and summarized only flood duration patterns. Here, we build upon the approach of De Jager and others $(2012,2016)$ by employing slope detrending and flow-routing geospatial algorithms and use the model to characterize multiple aspects of flooding dynamics believed to be ecologically relevant to the UMRS.

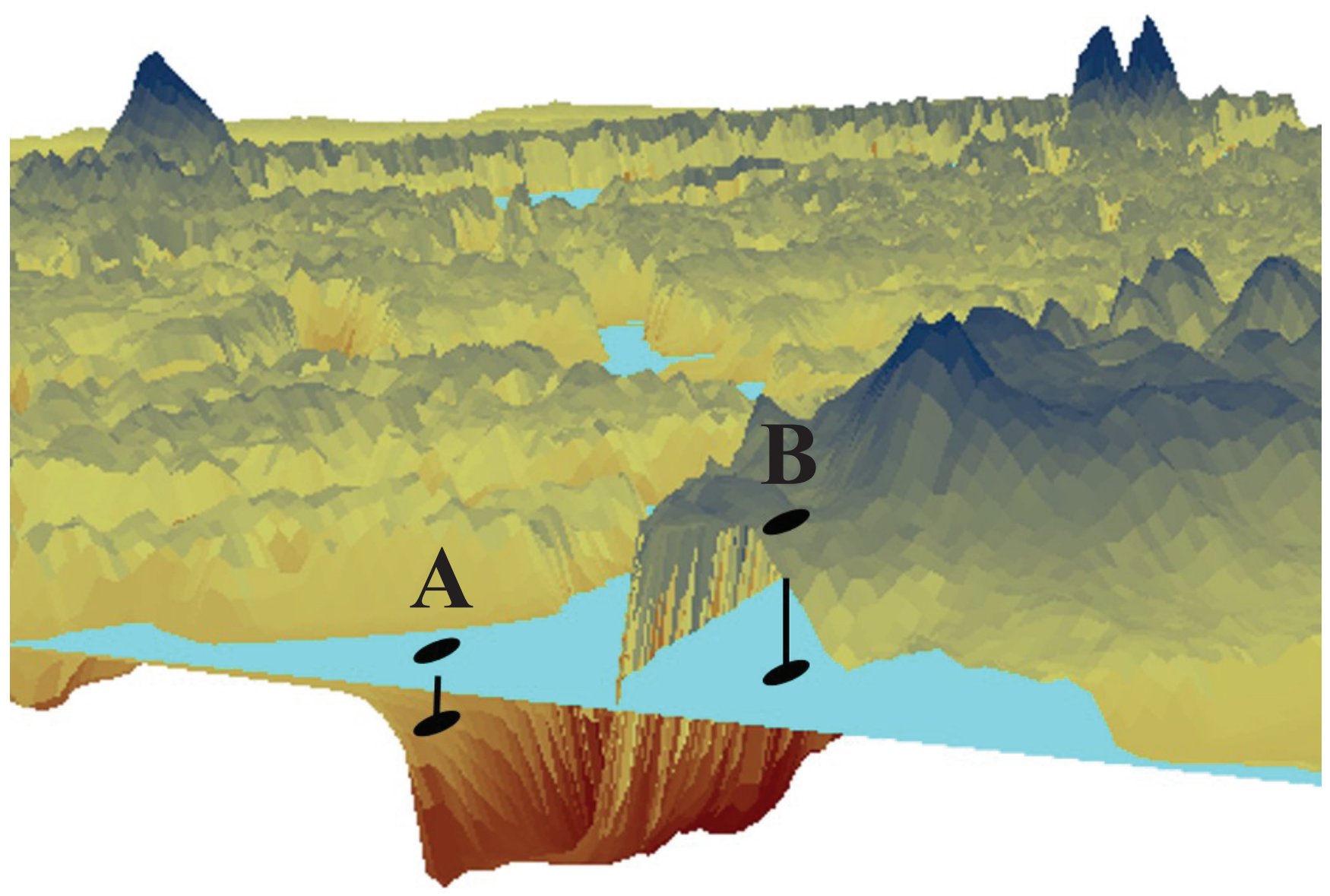

Figure 2.2 The planar surface model to mapping inundation patterns is based on the relationship between spatially-explicit water-surface elevations and topo-bathymetry. Inundation is detected at site $A$, where the water-surface elevation is greater than the terrain elevation, but not for site $B$ which has a terrain elevation that exceeds the water-surface elevation. Inundation extent and depth can therefore be measured in a spatially continuous way throughout the study domain for any time step for which water-surface elevations are known. 


\section{Data Inputs and Preprocessing}

Two types of data form the basis for the UMRS inundation model: hydrologic data and terrain data. To develop the hydrologic data input, we compiled a database of daily water-surface elevations for 128 USACE gages spanning the mainstem of the Mississippi River from Navigation Pool 3 to Cairo, Illinois and along the Illinois River from the Branden Road Lock and Dam downstream to the junction with the Mississippi River at Grafton, Illinois. Only gages with records from 1972-2011 were included. This period was chosen because it comprises relatively stationary hydrologic conditions and is long enough to provide robust characterizations of average hydrologic dynamics. The daily data were subset to comprise only days during the growing season which we defined as April 1 through September 30. These dates approximate the season in which most biophysical processes (such as vegetation metabolism or biogeochemical cycling) are likely to be strongest across the longitudinal gradient represented by the UMRS. We then linearly interpolated the water-surface elevations for the period of record between sequential pairs of gages to generate a daily time series of water-surface elevations for each river mile. Although longitudinal profiles of water-surface elevations are nonlinear (USACE, 2004), we believe our assumption of linearity to be reasonable given the elevation errors of the terrain set on which the inundation model also relies (fig. 2.3).

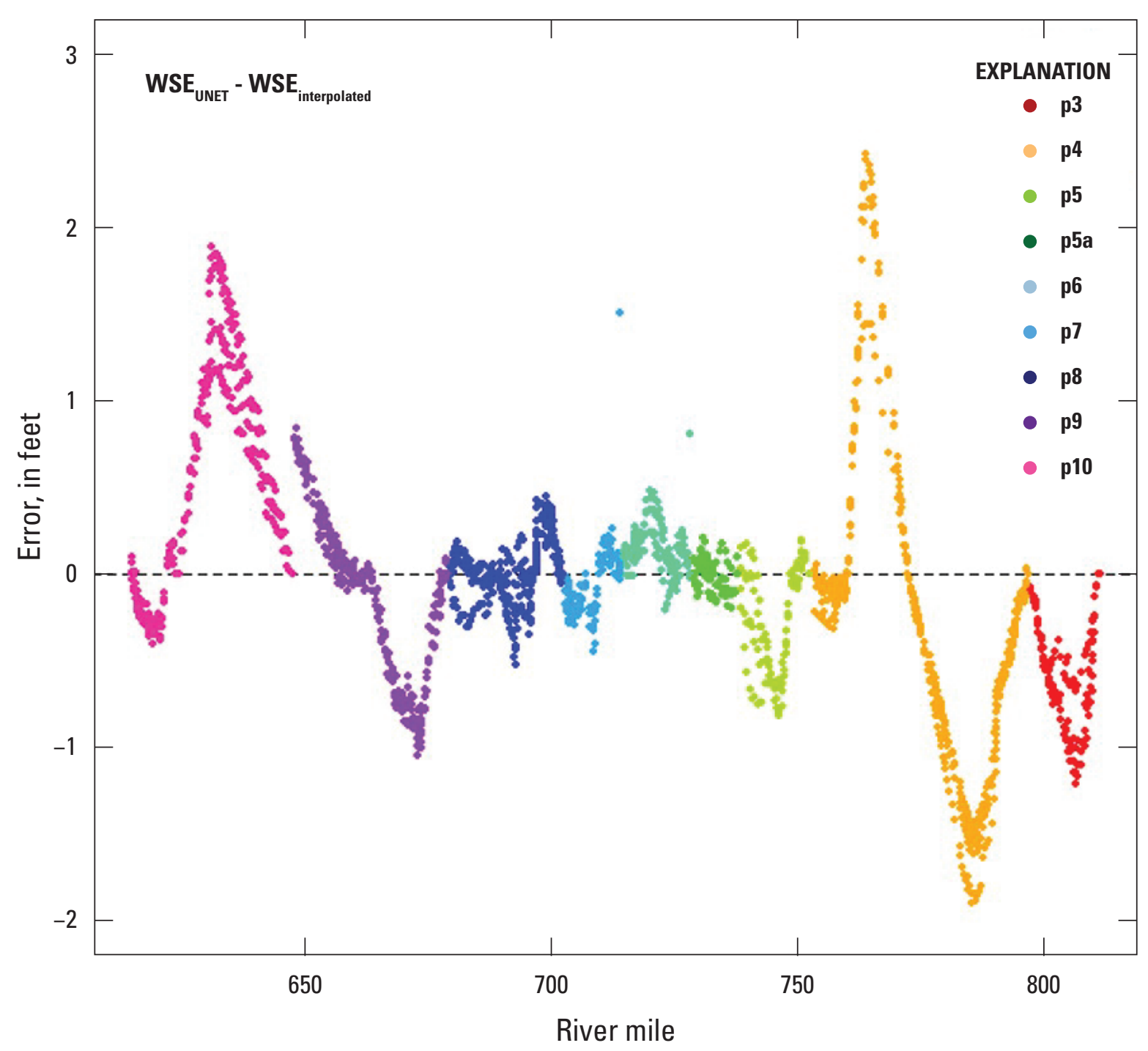

Figure 2.3 An example of differences between water-surface elevation profiles from the UNET 1-D hydraulic model (U.S. Army Corps of Engineers, 2004) and linear interpolations between gages (used in the Upper Mississippi River System Inundation Model) for 2-, 5-, 10- and 25-year flows in navigation pools 3-10. High values indicate water-surface elevations are underpredicted by linear interpolation methods; low values indicate overprediction by linear interpolation. Multiple observations at a given river mile location reflect the range of elevation differences across flow magnitudes. 
We used the pool-scale seamless topo-bathymetric datasets collected by the USACE's Upper Mississippi River Restoration Program as the terrain data input to the inundation model. The topo-bathymetric datasets are seamless digital elevation models that comprise elevations derived from LIDAR (1-meter [m] resolution) and bathymetric sampling (5-m resolution) conducted from 2000-2008 (Rogala and others, 2016).

We preprocessed the topo-bathymetric datasets to generate de-trended, hydrologically enforced terrain models similar to Height Above Nearest Drainage (HAND) terrain models described by Rodda (2005), Rennó and others (2008), and Nobre and others $(2011,2016)$. These models comprise grid cells whose values indicate the height of that cell with respect to a downstream reference point into which it drains, in our case the centerline of the navigation channel. Thus, the resulting HAND maps indicate the water height of the navigation channel centerline at which each particular cell becomes inundated.

All geospatial processing used $4 \mathrm{~m} \mathrm{X} 4 \mathrm{~m}$ grid cell resolutions and was completed via the TauDEM (Tarboton, 2016) and Geospatial Analyst Toolboxes in ArcGIS 10.3.1. First, we conditioned the topo-bathymetry by burning a single-threaded navigation channel centerline into the topo-bathymetric data, building an artificial wall around the perimeter of the study area, and removing spurious depressions following Jenson and Domingue (1988) and Jenson (1991). We then modeled hydrologic flow paths across the conditioned surface using the D-infinity algorithm (Tarboton, 1997). The D-infinity algorithm routes flow based on steepest descent while distributing flow across the facets of adjacent raster cells (Tarboton, 1997). As opposed to the standard D-8 flow direction algorithm (O'Callaghan and Mark, 1984) which only captures concentrated flow patterns, the D-infinity algorithm is well-suited for modeling hydrologic connectivity in relatively flat terrains characteristic of the UMRS floodplain. Next, we computed the elevation difference between any given cell in the study domain and the navigation channel centerline cell to which it is hydrologically connected. Because flow may have been apportioned among multiple downstream cells, we used a weighted average of flow path distances as defined in the D-infinity Distance Down algorithm (Tefsa, 2011; Tarboton, 2016). The final result was a raster dataset that identified both (1) the height of each grid cell with respect to the nearest navigation channel centerline into which it drains (for example, the water height of the navigation channel at which that cell becomes inundated), and (2) the river mile location of the connection to the navigation channel centerline. Attribute tables containing these two pieces of information - relative elevation and river mile location - were exported as text files for further analyses.

\section{Inundation Simulation and Metric Calculations}

We simulated inundation across all nonaquatic areas of the UMRS floodplain by comparing the relative elevation values to the daily water-surface elevations expected at a given river mile location (fig. 2.4). The comparison generated a time series of daily inundation depths for each $4 \mathrm{~m} \mathrm{X} 4 \mathrm{~m}$ pixel. We identified inundation events within the time series as sets of contiguous days during which the surface water elevation exceeded the relative elevation of the terrain (fig. 2.4C). Next, we summarized distributions of inundation events relative to five ecologically relevant aspects of flood regime (frequency, duration, depth, timing, and timing variability) using the statistical definitions described in table 2.1. In addition, we computed the total number of growing season days inundated each year of the analysis and exported these annual results for use in forest simulation modeling (see Appendix 4). Statistical summaries of flooding attributes were completed using the statistical software $R$ (R Core Team, 2017) and exported as comma-separated values (.csv) text files. The text files were then joined with raster attribute tables containing relative elevation and river mile locations to map the spatial patterns of inundation dynamics.

\section{Methods for Part 2: Defining and Summarizing Floodplain Functional Classes}

The goal of Part 2 was to use output from the inundation model to identify areas of the UMRS floodplain expected to experience different patterns of inundation duration based on average hydrologic conditions from 1972-2011. We defined the floodplain functional classes using only one flood regime attribute: the 40-year mean total growing season inundation duration (the average number of days a surface is inundated in any given year). Only this attribute was used because of its interpretability and ecological importance in many river-floodplain ecosystems including the UMRS (table 2.1). Similar indices of inundation duration have been related to vegetation communities in the UMRS, revealing nonrandom associations (De Jager and others, 2012, 2016).

After masking out areas of the floodplain that were leveed, were in agricultural production, or were developed, we summarized the distribution of floodplain functional classes as the area per river mile in each navigation pool in 10-day duration bins. The end result were classes representing areas expected to experience different growing season inundation durations based on average hydrologic conditions from 1972-2011. We calculated Simpson's diversity index for each navigation pool based on the abundance of floodplain functional classes. 

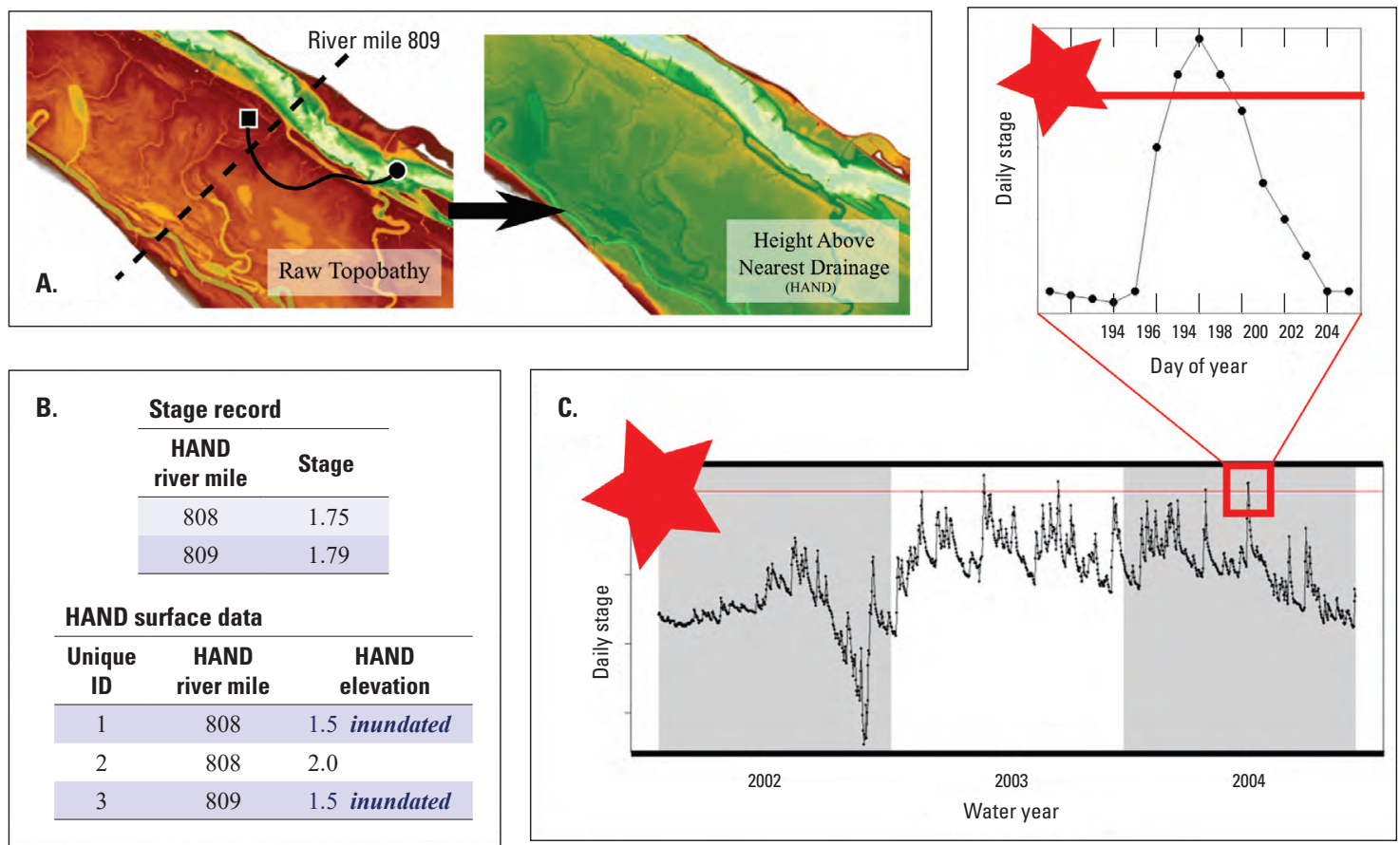

\begin{tabular}{|c|c|c|}
\hline \multirow[t]{4}{*}{ B. } & \multicolumn{2}{|l|}{ Stage record } \\
\hline & $\begin{array}{c}\text { HAND } \\
\text { river mile }\end{array}$ & Stage \\
\hline & 808 & 1.75 \\
\hline & 809 & 1.79 \\
\hline \multicolumn{3}{|c|}{ HAND surface data } \\
\hline $\begin{array}{l}\text { Unique } \\
\text { ID }\end{array}$ & $\begin{array}{c}\text { HAND } \\
\text { river mile }\end{array}$ & $\begin{array}{c}\text { HAND } \\
\text { elevation }\end{array}$ \\
\hline 1 & 808 & 1.5 inundated \\
\hline 2 & 808 & 2.0 \\
\hline 3 & 809 & 1.5 inundated \\
\hline
\end{tabular}


Figure 2.4 The Upper Mississippi River System inundation model uses a modified bathtub approach to map summary statistics of dynamic inundation patterns. First, $A$, a Height Above Nearest Drainage (HAND) map is computed for the floodplain surface. HAND is a detrended, hydrologically enforced relative elevation surface in which the values represent the elevation difference between any given point in the landscape (black square) and the elevation of the entry point to the navigation channel (black circle) into which it flows (flow path as solid line). Next, $B$, inundation is defined at the point in which a given cell's relative elevation is exceeded by the stage of the navigation channel into which that cell flows. Knowing this relationship, $C$, inundation is modeled dynamically over any period of record by referencing the stage hydrograph of the navigation channel and summarizing attributes of inundation events defined by the relative elevation at which a cell is expected to become inundated (star and red line). Many inundation attributes may be computed and expressed spatially, including, $D$, measures describing duration, timing variability, and depth distributions across inundation events. 
Table 2.1 Five flood regime attributes, the definitions used to calculate them within the Upper Mississippi River System inundation model, and select studies demonstrating their ecological importance in driving patterns of floodplain vegetation.

Flood regime attribute

\begin{tabular}{ll}
\hline Frequency & $\begin{array}{l}\text { Mean number events/year } \\
\text { Mean number events/inundation year }\end{array}$ \\
Duration & $\begin{array}{l}\text { Median number days/event } \\
\text { * Mean number total growing season days } \\
\text { inundated/year }\end{array}$
\end{tabular}

Depth

Median of maximum event depths

Timing variability
Circular variance of timing as circular median across all events
Select studies demonstrating ecological Importance

Bren and Gibbs, 1986

Pearlstine and others, 1985

Robertson and others, 2001

Stokes and others, 2010

Toner and Keddy, 1997

Blom and Voesenek, 1996

De Jager and others, 2013

De Jager and others, 2016

De Jager and others, 2012

Franz and Bazzaz, 1977

Friedman and Auble, 1999

Hook and Brown, 1973

Kozlowski, 1984

Marks and others, 2014

Toner and Keddy, 1997

Blom and Voesenek, 1996

Karrenberg and others, 2003

Kozlowski, 1984

Robertson and others, 1984

Toner and Keddy, 1997

Julian day of maximum event depth, summarized

Lytle and Merritt, 2004

Robertson and others, 2001

Stokes and others, 2010

Toner and Keddy, 1997

Jardine and others, 2015

Lytle and Merritt, 2004

* Indicates the statistical definition used to identify functional classes.

\section{Key Model Assumptions for Interpreting and Applying Results}

The development of a geospatial floodplain-inundation model and functional classes fulfilled a priority research need identified by the HNA-I (Theiling and others, 2000) by being the first systemic characterization of multiple, ecologically relevant flooding attributes in the UMRS. Although the model results and functional classes fill an important gap, our approach relied on several key assumptions that can influence interpretability and applicability. First, our model measures patterns of inundation because of surface-water connectivity to the main navigation channel and does not account for additional inputs such as direct rainfall, tributary inflows, or groundwater, which could underestimate wetted extents and depths in certain areas of the floodplain. We also did not account for direct, artificial water-level manipulations in off-channel areas (such as Rice Lake pumping stations and water control structures or beaver dams). In these places, local knowledge of inundation dynamics may supplement or even supersede the results of the inundation model in its current form. In addition, our approach uses a geospatial terrain analysis rather than a numerical hydraulic model.
Our approach allows for rapid computation of many aspects of flooding over broad areas, except for flow velocities or variation in inundation patterns affected by complex flow energetics. To more fully understand certain ecological processes such as sediment transport dynamics or propagule dispersal, it may be important to supplement our inundation model with additional information about flow velocities during inundation events from other sources (such as hydraulic models, empirical surveys). Lastly, the primary sources of error in our modeling framework are a function of vertical and horizontal accuracies of the terrain model, the quality of the gage data, and the assumption of linearity in water surface profile between pairs of gages. As such, we recommend interpreting model results within the context of these potential error sources. For example, we chose to maximize the model's interpretability by developing functional classes using long-term average hydrologic conditions and summarizing their distribution at the relatively coarse spatial scale of navigational pools. Other examples of appropriate model use may include stratifying regional sampling efforts or monitoring programs, providing context for interpreting fine-scale studies of local inundation patterns, or developing other floodplain functional classes using additional flood metrics. 


\section{References Cited}

Allen, Y., 2015, Landscape scale assessment of floodplain inundation frequency using Landsat imagery: River Research and Applications, v. 32, no. 7, p. 1609-1620.

Amoros, C., and Bornette, G., 2002, Connectivity and biocomplexity in waterbodies of riverine floodplains: Freshwater Biology, v. 47, no. 4, p. 761-776.

Baker, M.E., and Wiley, M.J., 2004, Characterization of woody species distribution in riparian forests of lower Michigan, USA using map-based models: Wetlands, v. 24, no. 3 , p. $550-561$.

Baker, M.E., and Wiley, M.J., 2009, Multiscale control of flooding and riparian-forest composition in Lower Michigan, USA: Ecology, v. 90, no. 1, p. 145-159.

Blom, C.W.P.M., and Voesenek, L.A.C.J., 1996, FloodingThe survival strategies of plants: Trends in Ecology \& Evolution, v. 11, no. 7, p. 290-295.

Bornette, G., Tabacchi, E., Hupp, C., Puijalon, S., and Rostan, J.C., 2008, A model of plant strategies in fluvial hydrosystems: Freshwater Biology, v. 53, no. 8, p. 1692-1705.

Braatne, J.H., Jamieson, R., Gill, K.M., and Rood, S.B., 2007, Instream flows and the decline of riparian cottonwoods along the Yakima River, Washington, USA: River Research and Applications, v. 23, no. 3, p. 247-267.

Bren, L.J., and Gibbs, N.L., 1986, Relationships between flood frequency, vegetation, and topography in a river red gum forest: Australian Forest Research, v. 17, p. 395-408.

De Jager, N.R., Thomsen, M., and Yin, Y., 2012, Threshold effects of flood duration on the vegetation and soils of the Upper Mississippi River floodplain, USA: Forest Ecology and Management, v. 270, p. 135-146.

De Jager, N.R., Cogger, B.J., and Thomsen, M.A., 2013, Interactive effects of flooding and deer (Odocoileus virginianus) browsing on floodplain forest recruitment: Forest Ecology and Management, v. 303, p. 11-19.

De Jager, N.R., Rohweder, J.J., Yin, Y., and Hoy, E., 2016, The Upper Mississippi River floodscape-Spatial patterns of flood inundation and associated plant community distributions: Applied Vegetation Science, v. 19, no. 1, p. 164-172.

Franz, E.H., and Bazzaz, F.A., 1977, Simulation of vegetation response to modified hydrologic regimes-A probabilistic model based on niche differentiation in a floodplain forest: Ecology, v. 58, no. 1, p. 176-183.
Friedman, J.M., and Auble, G.T., 1999, Mortality of riparian box elder from sediment mobilization and extended inundation: Regulated Rivers: Research and Management, v. 15, no. 5, p. 463-476.

Frye, R.J., and Quinn, J.A., 1979, Forest development in relation to topography and soils on a floodplain of the Raritan River, New Jersey: Bulletin of the Torrey Botanical Club, v. 106 , no. 4, p. 334-345.

Guyon, L., Deutsch, C., Lundh, J., and Urich, R., 2012, Upper Mississippi River Systemic Forest Stewardship Plan: U.S. Army Corps of Engineers. 124 p.

Heitmeyer, M.E., 2007, Feasibility Investigation, Hydrogeomorphic Modeling and Analysis, Upper Mississippi River System Floodplain: Advance, Missouri, Greenbrier Wetland Services.

Hook, D.D., 1984, Waterlogging tolerance of lowland tree species of the south: Southern Journal of Applied Forestry, v. 8 , p. $136-149$.

Hook, D.D., and Brown, C.L., 1973, Root adaptations and relative flood tolerance of five hardwood species: Forest Science, v. 19, p. 225-229.

Hupp, C.R., and Osterkamp, W.R., 1985, Bottomland vegetation distribution along Passage Creek, Virginia, in relation to fluvial landforms: Ecology, v. 66, no. 3, p. 670-681.

Jacinthe, P.A., Vidon, P., Fisher, K., Liu, X., and Baker, M.E., 2015, Soil methane and carbon dioxide fluxes from cropland and riparian buffers in different hydrogeomorphic settings: Journal of Environmental Quality, v. 44, no. 4, p. 1080-1090.

Jardine, T.D., Bond, N.R., Burford, M.A., Kennard, M.J., Ward, D.P., Bayliss, P., Davies, P.M., Douglas, M.M., Hamilton, S.K., Melack, J.M., Naiman, R.J., Pettit, N.E., Pusey, B.J., Warfe, D.M., and Bunn, S.E., 2015, Does flood rhythm drive ecosystem responses in tropical riverscapes?: Ecology, v. 96, no. 3, p. 684-692.

Jenson, S.K., and Domingue, J.O., 1988, Extracting topographic structure from digital elevation data for Geographic Information System Analysis: Photogrammetric Engineering and Remote Sensing, v. 54, p. 1593-1600.

Jenson, S.K., 1991, Applications of hydrologic information automatically extracted from digital elevation models: Hydrological Processes, v. 5, no. 1, p. 31-44.

Junk, W., Bayley, P.B., and Sparks, R.E., 1989, The flood pulse concept in river-floodplain systems. Pages 110-127 D. P. Dodge [ed.] Proceedings of the International Large River Symposium. 
Kaase, C.T., and Kupfer, J.A., 2016, Sedimentation patterns across a Coastal Plain floodplain-The importance of hydrogeomorphic influences and crossfloodplain connectivity: Geomorphology, v. 269, p. 43-55.

Karrenberg, S., Blaser, S., Kollmann, J., Speck, T., and Edwards, P.J., 2003, Root anchorage of saplings and cuttings of woody pioneer species in a riparian environment: Functional Ecology, v. 17, no. 2, p. 170-177.

Kozlowski, T.T., 1984, Plant responses to flooding of soil: Bioscience, v. 34, no. 3, p. 162-167.

Lorang, M.S., Whited, D.C., Hauer, F.R., Kimball, J.S., and Stanford, J.A., 2005, Using airborne multispectral imagery to evaluate geomorphic work across floodplains of gravel-bed rivers: Ecological Applications, v. 15, no. 4, p. 1209-1222.

Lytle, D.A., and Merritt, D.M., 2004, Hydrologic regimes and riparian forests-A structured population model for cottonwood: Ecology, v. 85, no. 9, p. 2493-2503.

Marks, C.O., Nislow, K.H., and Magilligan, F.J., 2014, Quantifying flooding regime in floodplain forests to guide river restoration-Elementa: Science of the Anthropocene, v. 2, p. 000031.

Martinez, J., and Letoan, T., 2007, Mapping of flood dynamics and spatial distribution of vegetation in the Amazon floodplain using multitemporal SAR data: Remote Sensing of Environment, v. 108, no. 3, p. 209-223.

Megonigal, J.P., Conner, W.H., Kroeger, S., and Sharitz, R.R., 1997, Aboveground production in southeastern floodplain forests - A test of the subsidy-stress hypothesis: Ecology, v. 78 , p. $370-384$.

Merritt, D.M., Scott, M.L., Poff, N.L., Auble, G.T., and Lytle, D.A., 2010, Theory, methods and tools for determining environmental flows for riparian vegetation-Riparian vegetation-flow response guilds: Freshwater Biology, v. 55, no. 1, p. 206-225.

Nakamura, F., Shin, N., and Inahara, S., 2007, Shifting mosaic in maintaining diversity of floodplain tree species in the northern temperate zone of Japan: Forest Ecology and Management, v. 241, no. 1-3, p. 28-38.

Nobre, A.D., Cuartas, L.A., Hodnett, M., Rennó, C.D., Rodrigues, G., Silveira, A., Waterloo, M., and Saleska, S., 2011, Height Above the Nearest Drainage - a hydrologically relevant new terrain model: Journal of Hydrology (Amsterdam), v. 404, no. 1-2, p. 13-29.

Nobre, A.D., Cuartas, L.A., Momo, M.R., Severo, D.L., Pinheiro, A., and Nobre, C.A., 2016, HAND contour-A new proxy predictor of inundation extent: Hydrological Processes, v. 30, no. 2, p. 320-333.
Noe, G.B., and Hupp, C.R., 2009, Retention of riverine sediment and nutrient loads by Coastal Plain floodplains: Ecosystems (New York, N.Y.), v. 12, no. 5, p. 728-746.

O'Callaghan, J.F., and Mark, D.M., 1984, The extraction of drainage networks from digital elevation data: Computer Vision Graphics and Image Processing, v. 28, no. 3, p. 323-344.

Olde Venterink, H., Vermaat, J.E., Pronk, M., Wiegman, F., van der Lee, G.E.M., van den Hoorn, M.W., Higler, L.W.G., and Verhoeven, J.T.A., 2006, Importance of sediment deposition and denitrification for nutrient retention in floodplain wetlands: Applied Vegetation Science, v. 9, no. 2, p. 163-174.

Osterkamp, W.R., and Hupp, C.R., 1984, Geomorphic and vegetative characteristics along three northern Virginia streams: Geological Society of America Bulletin, v. 95, no. 9, p. 1093-1101.

Pearlstine, L.G., McKellar, H., and Kitchens, W., 1985, Modelling the impacts of a river diversion on bottomland forest communities in the Santee River floodplain, South Carolina: Ecological Modelling, v. 29, no. 1-4, p. 283-302.

Pettit, N.E., Froend, R.H., and Davies, P.M., 2001, Identifying the natural flow regime and the relationship with riparian vegetation for two contrasting western Australian rivers: Regulated Rivers: Research and Management, v. 17, no. 3, p. 201-215.

Poff, N.L., Allan, J.D., Bain, M.B., Karr, J.R., Prestegaard, K.L., Richter, B.D., Sparks, R.E., and Stromberg, J.C., 1997, The natural flow regime: Bioscience, v. 47, no. 11, p. $769-784$.

Powell, S.J., Letcher, R.A., and Croke, B.F.W., 2008, Modelling floodplain inundation for environmental flowsGwydir wetlands, Australia: Ecological Modelling, v. 211, no. 3-4, p. 350-362.

R Core Team, 2017, R: A language and environment for statistical computing. R Foundation for Statistical Computing, Vienna, Austria. URL http://www.R-project.org/

Rennó, C.D., Nobre, A.D., Cuartas, L.A., Soares, J.V., Hodnett, M.G., Tomasella, J., and Waterloo, M.J., 2008, HAND, a new terrain descriptor using SRTM-DEMMapping terra-firme rainforest environments in Amazonia: Remote Sensing of Environment, v. 112, no. 9, p. 3469-3481.

Robertson, P.A., MacKenzie, M.D., and Elliott, L.F., 1984, Gradient analysis and classification of the woody vegetation for four sites in southern Illinois and adjacent Missouri: Vegetatio, v. 58, no. 2, p. 87-104. 
Robertson, A.I., Bacon, P., and Heagney, G., 2001, The responses of floodplain primary productivity to flood frequency and timing: Journal of Applied Ecology, v. 38, no. 1, p. 126-136.

Rodda, H.J., 2005, The development and application of a flood risk model for the Czech Republic: Natural Hazards, v. 36, no. $1-2$, p. $207-220$.

Rogala, J., Stone, J., Sattler, S., Hanson, J., and Rohweder, J., 2016, Upper Mississippi River Restoration Program Topobathy: La Crosse, WI, U.S. Geological Survey, 10.5066/F7057CZ3

Rybicki, N.B., Noe, G.B., Hupp, C.R., and Robinson, M.E., 2015, Vegetation composition, nutrient, and sediment dynamics along a floodplain landscape: River Systems, v. 21 , no. 2 , p. 109-123.

Scown, M.W., Thoms, M.C., and De Jager, N.R., 2015, Measuring floodplain spatial patterns using continuous surface metrics at multiple scales: Geomorphology, v. 245, p. $87-101$.

Stokes, K., Ward, K., and Colloff, M., 2010, Alterations in flood frequency increase exotic and native species richness of understory vegetation in a temperate floodplain eucalypt forest: Plant Ecology, v. 211, no. 2, p. 219-233.

Tabacchi, E., Correll, D.L., Hauer, R., Pinay, G., PlantyTabacchi, A.-M., and Wissmar, R.C.W., 1998, Development, maintenance and role of riparian vegetation in the river landscape: Freshwater Biology, v. 40, no. 3, p. 497-516.

Tarboton, D.G., 1997, A new method for the determination of flow directions and upslope areas in grid digital elevation models: Water Resources Research, v. 33, no. 2, p. 309-319.

Tarboton, D.G., 2016, Terrain Analysis Using Digital Elevation Models (TauDEM). Utah Water Research Laboratory. Utah State University. http://hydrology.usu.edu/taudem. Accessed January 19, 2016.

Tesfa, T.K., Tarboton, D.G., Watson, D.W., Schreuders, K.A.T., Baker, M.E., Wallace, R.M., 2011, Extraction of hydrological proximity measures from DEMs using parallel processing: Environmental Modelling and Software, v. 26, p. 1696-1709.
Theiling, C.H., Korschgen, C., De Haan, H., Fox, T., Rohweder, J.J., and Robinson, L., 2000, Habitat Needs Assessment for the Upper Mississippi River SystemTechnical Report. Contract report prepared for U.S. Army Corps of Engineers, St. Louis District: St. Louis, Missouri, Appendices A to AA, $248 \mathrm{p}$.

Theiling, C.H., and Burant, J.T., 2013, Flood inundation mapping for integrated floodplain management-Upper Mississippi River System: River Research and Applications, v. 29 , p. 961-978.

Tockner, K., and Stanford, J.A., 2002, Riverine flood plains-Present state and future trends: Environmental Conservation, v. 29, no. 03, p. 308-330.

Toner, M., and Keddy, P., 1997, River hydrology and riparian wetlands-A predictive model for ecological assembly: Ecological Applications, v. 7, no. 1, p. 236-246.

Townsend, P.A., 2001, Mapping seasonal flooding in forested wetlands using multi-temporal Radarsat SAR: Photogrammetric Engineering and Remote Sensing, v. 67, no. 7, p. $857-864$.

Townsend, P.A., and Walsh, S.J., 1998, Modeling floodplain inundation using an integrated GIS with radar and optical remote sensing: Geomorphology, v. 21, no. 3-4, p. 295-312.

Turner, M.G., Gergel, S.E., Dixon, M.D., and Miller, J.R., 2004, Distribution and abundance of trees in floodplain forests of the Wisconsin River-Environmental influences at different scales: Journal of Vegetation Science, v. 15, no. 6, p. 729-738.

U.S. Army Corps of Engineers, 2004. Upper Mississippi River System Flow Frequency Study: Final Report.. U.S. Army Corps of Engineers, 33p + Appendix A-I.

Vaughan, I.P., Diamond, M., Gurnell, A.M., Hall, K.A., Jenkins, A., Milner, N.J., Naylor, L.A., Sear, D.A., Woodward, G., and Ormerod, S.J., 2009, Integrating ecology with hydromorphology - A priority for river science and management: Aquatic Conservation, v. 19, no. 1, p. 113-125.

Ward, J.V., Tockner, K., Arscott, D.B., and Claret, C., 2002, Riverine landscape diversity: Freshwater Biology, v. 47, no. 4 , p. 517-539. 



\section{Appendix 3}

\section{Methods for Backwater Sedimentation Forecast Modeling}

\section{Background}

This study used measured rates of backwater sedimentation to forecast the loss of a deep lentic functional class and the gain of a shallow lentic functional class over a 50-year period. Such changes reduce the abundance of deep lentic habitats. The forecasts are based on the data from backwater transect surveys in Pools 4 and 8 over the period of 1997-2017 (specifically, during 1997-2002, Rogala et al. 2003; and during 2016-2017, James T. Rogala, written comm., 2017). 


\section{Methods}

\section{Data Collection}

This study used the same sampling design and survey methodology used in a 1997-2002 study. Detailed methods can be found in Rogala and others (2003). A brief summary of those methods is provided here.

Randomly selected locations were used to establish transects in backwaters in Pools 4, 8, and 13 in 1997. Impounded areas (for example, large flow through backwaters) were not surveyed. A stratified design based on backwater lake size and connectivity was used to select 25 transects in each pool. Two transects were selected in each of the 6 largest backwater lakes in each pool, and 13 transects split across low and high connectivity backwater lakes. Maps of all transects can be found in appendix A of Rogala and others (2003).

The measurement of bed elevation along established transects is split into over ice and open-water surveys. The measurements through the ice are performed at all locations except those in shallow areas where ice freezing to the bottom makes such measurements impossible. In such shallow areas, open-water surveys are performed (during ice-free periods). Predetermined distances from an endpoint are used to locate survey locations along transects. Water depth was measured during over ice surveys, and, using a level, the depth was converted to a bottom elevation relative to an established temporary vertical benchmark. Levelling was also used to measure bed elevation for open-water surveys.

For the 2016-2017 study, transects were reestablished in the same locations used in Rogala and others (2003) by recovering previously established benchmarks. Only a subset of the original 25 transects per pool could be recovered: 13 transects in Pool 4 and 19 transects in Pool 8. Transects surveyed are listed in table 3.1. Because of high water and poor ice formation, no surveys were completed in Pool 13. Open-water nearshore surveys were completed in the fall of 2016, and over ice surveys were completed in the winter of 2016-17.

Table 3.1 Names of transects surveyed in 2016 or 2017.

\begin{tabular}{|c|c|c|c|c|}
\hline \multicolumn{5}{|c|}{ Surveyed transects } \\
\hline \multicolumn{2}{|c|}{ Pool 4} & \multicolumn{3}{|c|}{ Pool 8} \\
\hline $1 \mathrm{R}$ & $3 \mathrm{~B}$ & $1 \mathrm{R}$ & $1 \mathrm{~B}$ & FLN \\
\hline $5 \mathrm{R}$ & $4 \mathrm{~B}$ & $2 \mathrm{R}$ & 3B & FLS \\
\hline $7 \mathrm{R}$ & BLN & $3 \mathrm{R}$ & $4 \mathrm{~B}$ & LLN \\
\hline 9R & GLN & $4 \mathrm{R}$ & $5 \mathrm{~B}$ & LLS \\
\hline $11 \mathrm{R}$ & GLS & $5 \mathrm{R}$ & BYN & RLN \\
\hline 1B & RLE & $6 \mathrm{R}$ & BYS & RLS \\
\hline 2B & & & & TLE \\
\hline
\end{tabular}

\section{Sediment Rate Calculations}

Average annual sedimentation rates at each measurement location along the transects were determined by the simple difference between bed elevations of the first survey (earliest year surveyed in 1997-2002; Rogala and others, 2003) and the resurvey in 2017 , divided by number of years between surveys. Mean rates for each transect for various areas of interest (specific subareas such as area $>0.5$ meters [m]) were estimated using designed-based statistics.

\section{Estimating Changes in Deep and Shallow Lentic Functional Classes}

There are two depth thresholds from the functional classes that we addressed with the sedimentation predictions. A $0.5 \mathrm{~m}$ threshold was used for the shallow lentic class and a $1.0 \mathrm{~m}$ threshold was used for deep lentic habitats (table 5 in main text). For the shallow lentic class, sedimentation rates were applied to areas $>0.5 \mathrm{~m}$ deep to determine which of those areas became $<0.5 \mathrm{~m}$ deep in 50 years. Similarly, sedimentation rates were applied to areas $>1.0 \mathrm{~m}$ to determine loss of deep lentic habitats in 50 years. Mean rates for transects were found to not differ greatly for areas $>0.5 \mathrm{~m}$ and areas $>1.0 \mathrm{~m}$ (fig. 3.1). Therefore, rates from areas $>0.5 \mathrm{~m}$ were used for all predictions to simplify the model. Only if accounting for sediment focusing (see following discussion) would the $>1.0 \mathrm{~m}$ areas need to be treated differently.

Variation in sedimentation rates along transects (for example, within-lake variation) was large for some transects (fig. 3.2). The variation was sometimes because of sediment focusing (deep areas having higher sedimentation rates than shallow areas), but some transects were scoured in the deepest areas. We characterized the differences in within-lake variance among lakes using the following connectivity measures: fetch, size, sill, shoreline development index, effective connections, and percentage of the perimeter that is channel (see table 4 in main report for variable definitions). Correlations between any of these metrics and within-lake variance were poor, so we could not effectively model the within-lake variation.

However, for our purposes of predicting change only in deeper areas, the variability within transects is lower than when the entire transect is considered (for example, areas > $0.5 \mathrm{~m}$ typically had more constant rates within a backwater than across the entire transect), and within-lake variance was ignored when forecasting sedimentation.

Similar to what we found when trying to explain withinlake variance with connectivity metrics, among-lake variance was poorly correlated with the selected covariates. Specifically, we included the same connectivity variables listed previously in a stepwise regression analysis with sedimentation rate as the response variable. The best model included fetch, sill, and effective connections. However, the explanatory power of the model $\left(\mathrm{R}^{2}=.22\right)$ was deemed too low to reasonably account for sedimentation rate variability among lakes. 


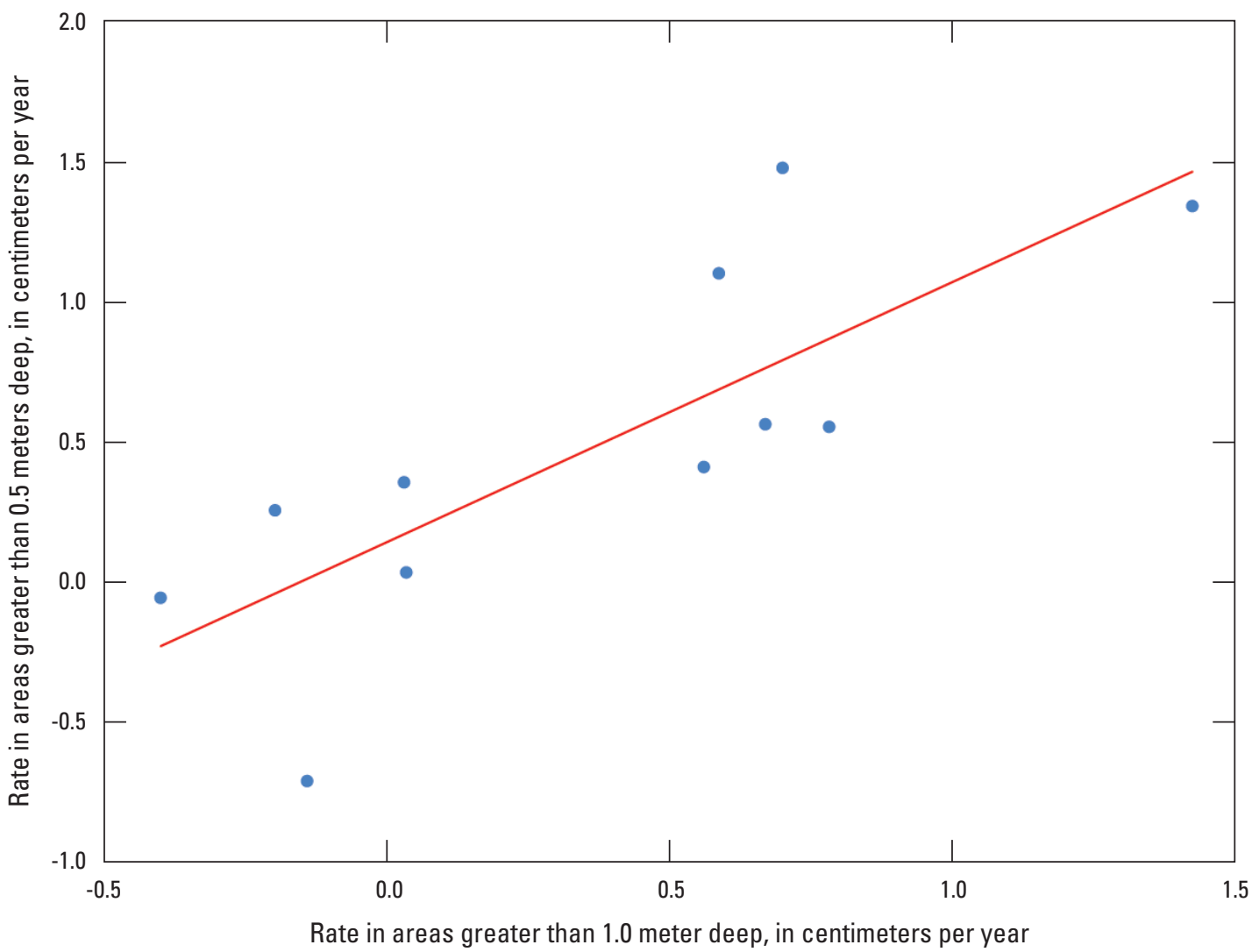

Figure 3.1 Relationship between mean sedimentation rates in areas greater than 0.5 meters and areas greater than 1.0 meters for all transects in pools 4 and 8.

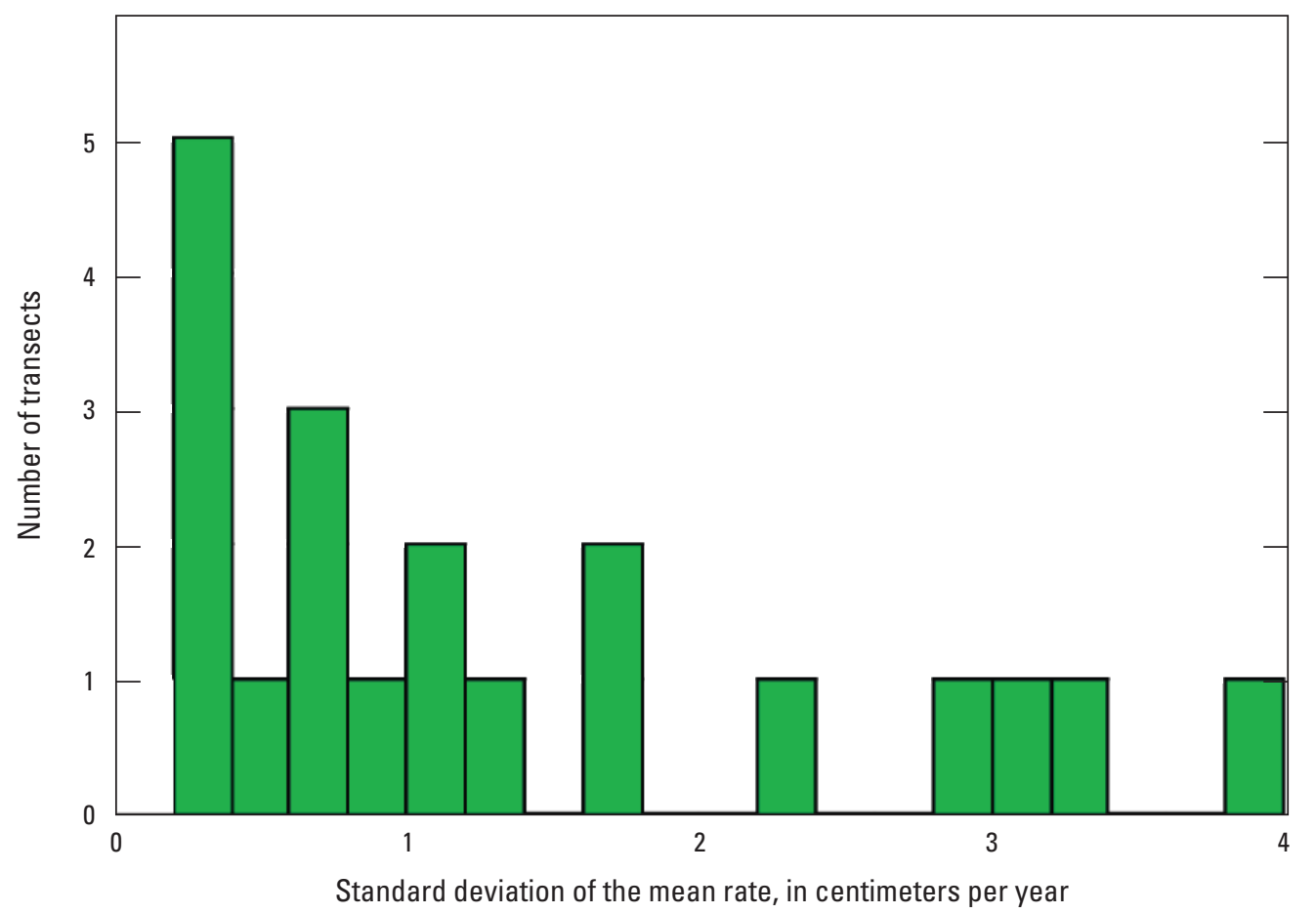

Figure 3.2 Distribution of the standard deviation for the mean of each transect. 
Because the statistical models we explored did not provide meaningful predictive power, we used a very simple approach to forecast future conditions. The estimated sedimentation rates for each transect in areas $>0.5 \mathrm{~m}$ observed in the 1997-2017 data were used to extrapolate out across all backwaters in the system. Sedimentation rates were randomly selected from the distribution of rates observed in the 19972017 study (table 3.2) and assigned at the backwater-lake scale such that a single randomly selected rate was applied to each lake. Though this approach does not account for how the rates may truly be dispersed across individual lakes, it provides an estimate of expected changes at the pool scale that allows for variability in the rates among backwaters. As such, it is more informative than applying a single mean rate across all backwaters in the UMRS.

The future bathymetric conditions were only predicted in areas where depth of the 2017 survey was greater than $0.5 \mathrm{~m}$, and predictions were only used to reassign functional classes and recalculate areas $>0.5 \mathrm{~m}$ and areas $>1.0 \mathrm{~m}$ at the pool scale. Results at scales smaller than the pool are not possible with these methods.

Table 3.2 Mean sedimentation rate (centimeter per year) for areas greater than 0.5 meter deep along 24 transects in Pools 4 and 8 from 1997-2017.

[cm, centimeter; yr, year]

\begin{tabular}{lcllc}
\hline \multicolumn{2}{c}{ Pool 4 } & & \multicolumn{2}{c}{ Pool 8 } \\
\cline { 1 - 2 } \cline { 5 - 5 } Transect & $\begin{array}{c}\text { Mean } \\
\text { sedimentation } \\
\text { rate (cm/yr) }\end{array}$ & & Transect & $\begin{array}{c}\text { Mean } \\
\text { sedimentation } \\
\text { rate (cm/yr) }\end{array}$ \\
\hline 1R & 0.56 & & $1 \mathrm{R}$ & 0.02 \\
5R & 0.56 & & $2 \mathrm{R}$ & 1.14 \\
7R & 1.10 & & $3 \mathrm{R}$ & 0.67 \\
9R & 0.48 & & $4 \mathrm{R}$ & 0.83 \\
11R & 0.70 & & $5 \mathrm{R}$ & -0.52 \\
1B & 0.55 & & TLE & 0.26 \\
2B & 0.95 & & BYN & 0.98 \\
3B & -0.71 & & BYS & 1.09 \\
4B & 1.13 & & LLN & -0.05 \\
BLN & 0.04 & & LLS & 0.20 \\
GLN & 0.60 & RLS & 0.36 \\
GLS & 0.41 & & \\
RLE & 1.10 & & \\
\hline
\end{tabular}

\section{Caveats and Future Refinements}

There is potential for a more complicated model to provide better predictive capability (potentially at the backwaterlake scale). Currently we are constrained by the sample size (only 24 transects with areas deeper than $0.5 \mathrm{~m}$ ), but this may improve in the future as surveys in Pool 13 are completed and additional transects are recovered.

The forecasts of future depth are produced by combining sedimentation rates derived in the previous section and bathymetry data collected over a 20-year period from 1990 through 2010. Using this bathymetry data as the baseline omits any sedimentation that occurred from the date of bathymetric survey to the present. Therefore, all present conditions for deeper lentic areas are overestimated, more so for areas surveyed longer ago. This doesn't have any obvious effects on our estimates of depth distribution; no correlation between year of bathymetric survey and the amount of deeper lentic areas is apparent in the present conditions (for example, pools with older bathymetric surveys were not found to have more deep lentic areas). We acknowledge some bias resulting from year of survey may remain in the data. Such a bias would likely cause overestimation of deeper lentic areas losses, because many deeper areas were lost between the year of bathymetric survey and 2017 (for example, the year of present condition). Additionally, the effect of Upper Mississippi River Restoration- Habitat Rehabilitation and Enhancement Projects construction on bathymetry may or may not be incorporated (depending on location), but those changes would be expected to be a small percentage of all backwater area.

Because of high water and poor ice formation, surveys in the fall of 2016 and the winter of 2016-2017 were incomplete. Previous surveys along those same transects covered the period 1997-2002, and it would have helped this investigation by adding more transect data if rates over that earlier period could have been used for predicting future change. However, we found the difference in the rates between the 1997-2002 period and the 1997-2017 period was too large to do this effectively, with individual transect rates differing among periods by as much as 3.3 centimeters per year $(\mathrm{cm} / \mathrm{yr})$. Annual average rates tended to be generally higher $(0.33 \mathrm{~cm} / \mathrm{yr})$ for the 1997-2017 period, but differences vary greatly (standard deviation $=1.08 \mathrm{~cm} / \mathrm{yr}$ ).

Two potential changes that could result from sedimentation were not addressed: (1) transition from aquatic to terrestrial, or from terrestrial to aquatic; and (2) formation of new deep backwater habitats. However, we believe both would have minor effects based on the survey data. We found little evidence that shoreline changes are widespread. Although surveys show that some areas are maintaining depths or scouring in some deep areas, there was little evidence that existing shallow areas are getting deeper. 
There are also two potential changes in backwater depths that we lack the data to assess. These include (1) delta formation and (2) deep channel abandonment. Deltas are localized features formed by tributaries or channels flowing into backwaters that can result in substantial changes. Those changes are also believed to be more permanent, as the sediments deposited are high in sand content. New backwaters formed from channel abandonment could result in new deep backwater habitat, but these formations are rare based on decadal aerial photography-derived land cover databases. A more complete analysis of those data would provide a more definitive understanding of the frequency at which these habitats are created.

The focus here was on direct changes in water depth. Sedimentation also influences water exchange rates through backwaters filling and altered connections to channel environments. This work did not address any aspects of water exchange rates that may change because of sedimentation.

\section{References Cited}

Rogala, J. T., P. J. Boma, and B. R. Gray. 2003. Rates and patterns of net sedimentation in backwaters of Pools 4, 8, and 13 of the Upper Mississippi River. U.S. Geological Survey, Upper Midwest Environmental Sciences Center, La Crosse, Wisconsin. An LTRMP Web-based report available online at http://www.umesc.usgs.gov/data_library/sedimentation/documents/rates_patterns/page1.html. (Accessed December 2017.) 



\section{Appendix 4}

\section{Methods for Forest Simulation Modeling}

\section{Background}

LANDIS-II is a process-based spatially explicit model that represents forest generative processes (such as dispersal, growth, and competition) as well as forest degenerative processes (such as senescence and disturbance related mortality) at large spatial scales (>1,000 ha) and over long temporal scales (centuries) (Mladenoff and others, 1993; Mladenoff and He 1999). As a modelling platform, LANDIS-II allows investigators to address questions about the effects of multiple processes and disturbances that may interact to impact forest succession across space and time through the use of extensions that plug into the core model (Scheller and others, 2007). We investigated the interactive effects of flood inundation and an exotic wood boring insect Agrilus planipennis (emerald ash borer) on forest succession in the floodplain of the Upper Mississippi River System (UMRS) using the LANDIS-II platform and associated extensions (fig. 4.1). This document outlines how input files and parameter settings were developed for forest succession modelling and how flooding and insect disturbances were parameterized within the model.

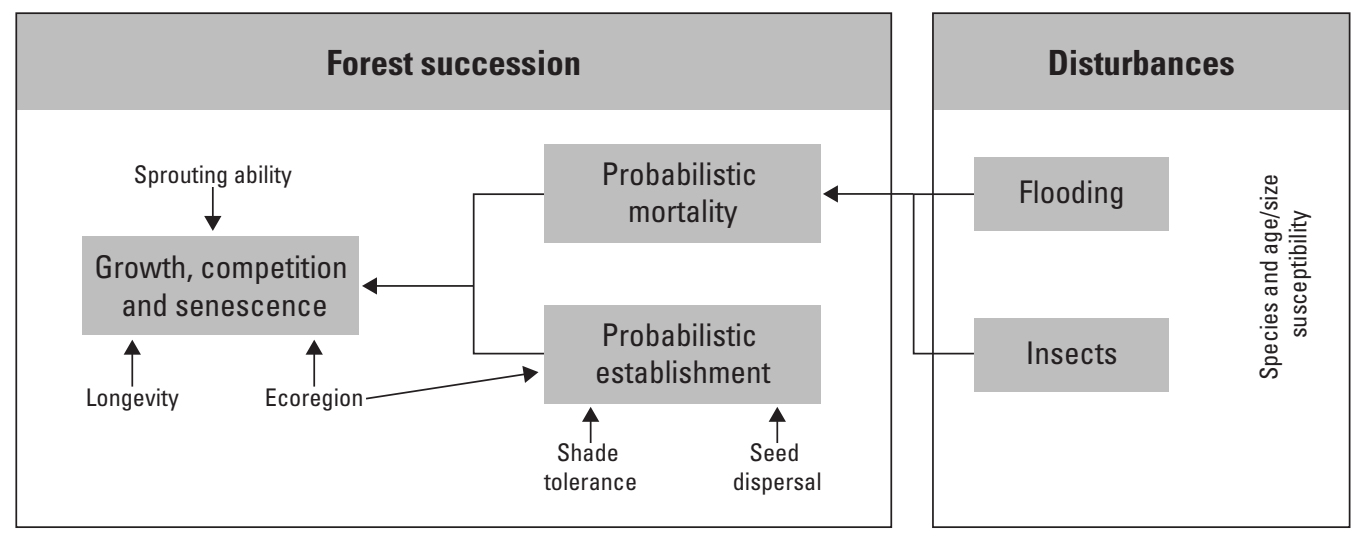

Figure 4.1 A diagram of major processes within the LANDIS-II modelling platform. Forest successional processes, such as establishment, growth, competition, and succession are simulated by the core LANDIS-II model and the Biomass Succession extension (see text for details). Additional species and age-specific mortality occurs in response to various disturbances. In the Upper Mississippi River System floodplain, effects of flooding and insects were simulated for Habitat Needs Assessment II. 


\section{Initial Species-Age Distributions}

In LANDIS-II, trees are represented as species-age cohorts, which requires: (1) identifying species to include in the model, (2) estimating tree age, (3) aggregating trees into age-specific cohorts, and (4) approximating the initial location of species-age cohorts in the landscape. To accomplish these tasks, we used two sources of forest inventory data. The first data set, hereafter referred to as permanent plot data, consisted of permanent sampling points established by the US Army Corps of Engineers (De Jager and others, 2012). Approximately one plot was established per every 202.3 hectares (ha) of forest cover for long-term monitoring of forest stand dynamics. Each sampling point consisted of a 0.04 ha fixed radius large plot, three nested 0.004 ha fixed radius subplots, and three nested 0.001 ha fixed radius microplots. Within the large plots, all trees greater or equal to 0.127 meters (m) diameter at breast height (dbh) were sampled. Within the three subplots, all trees greater than or equal to $0.0254 \mathrm{~m}$ dbh, but less than $0.127 \mathrm{~m}$ dbh, were measured. Finally, within the three microplots, trees and shrubs less than $0.0254 \mathrm{~m} \mathrm{dbh}$ and greater than $0.3048 \mathrm{~m}$ in height were measured. Per tree measurements included species, density, dbh, height, and crown class. This data set was primarily used to quantify the existing species composition and age structure of UMRS forests because size classes were represented within the data set. However, any species-age class that is overrepresented or underrepresented in the permanent plot data will be overrepresented or underrepresented in the simulation model.

The second source of forest inventory data, hereafter referred to as stand mapping data, was collected to map the distribution of floodplain forests based on representative dominant and codominant individuals and from a much higher density of sample points than the permanent plot data. Sample plots were established by the US Army Corps of Engineers and spaced approximately $100 \mathrm{~m}$ apart on a spatial grid established across extensive tracts of Upper Mississippi River (UMR) floodplain habitat (for example, 1 plot per hectare). Cores from trees considered to be representative of the dominant and codominant species-age cohorts at that location were also collected from one-fifth of these plots (for example, 1 age tree per 5 hectares). These data were used to estimate tree age from diameter.

We used the permanent plot data to identify species to include in the model and to group species that were rare but which shared similar life history traits. We were generally inclusive of rare species because although they constitute a very small proportion of forest biomass at a landscape scale, their presence within plots was considered to have important local impacts on forest succession (table 4.1).

Next, we estimated tree age from diameter using the stand mapping data by developing regression equations between tree diameter and estimated tree age from cores of dominant and codominant individuals. For some species there were too few individuals to construct reliable regression equations. In these instances, we aggregated species into groups (table 4.1). These equations were then applied to the permanent plot data to estimate the age of each sampled tree. We then grouped the trees of each species within each plot at 10 -year increments to represent 10-year age cohorts.

Finally, we spatially imputed the information contained within the permanent plot data into all forested cells within the UMRS as follows. First, the species composition of each forest plot was used to match plots with forest types in a land cover dataset. We used the UMRS's land-cover and land-use data for the year 2010 (Dieck and others, 2015) and identified four forest types (fig. 4.2): floodplain forest, lowland forest, Populus community, and Salix community. The species used to define the floodplain forest class included: silver maple (Acer saccharinum), American elm (Ulmus americana), green ash (Fraxinus pennsylvanica), river birch (Betula nigra), boxelder (A. negundo), American sycamore (Platanus occidentalis), and swamp white oak (Quercus bicolor). The species used to define the lowland forest community type included red oak (Q. rubra), bur oak (Q. macrocarpa), swamp white oak (Q. bicolor), common hackberry (Celtis occidentalis), bitternut hickory (Carya cordiformis), and shellbark hickory (C. laciniosa). The species used to define the Populus community consisted of eastern cottonwood ( $P$. deltoides). Finally, the Salix community consisted of sandbar willow ( $S$. interior) and/or black willow (S. nigra). The species and ages of each 10 -year cohort within each permanent plot was then randomly imputed into the cells (pixels) of each corresponding forest type. This process was done independently for forest plots in three reaches of the UMR (pools 3-10, pools 11-22, pools 24-26 plus the open river and the La Grange and Alton pools of the Illinois River) to prevent species not found in a reach from being imputed into that reach. To better match the size of forest inventory plots, we reduced the resolution of the landcover data to $30 \mathrm{~m}$ pixel size. This process resulted in initial community geographic information system data and provides an approximation of the location of each species-age cohort across the landscape. Similarly, this dataset can be thought of as the current demographics of each forest type across the landscape. 
Table 4.1 The species selected for LANDIS-II modelling on the Upper Mississippi River floodplain. Some rare species were grouped with other species (LANDIS-II symbol) in order to retain their local role in modifying forest succession. Y-intercepts, slopes, r-square values, and sample sizes (N) are for regression equations that relate the $\ln (\mathrm{dbh})$ to $\ln (\mathrm{age})$ for cored trees. For species without adequate sample sizes, 'like' species were used to generate relationships. Any species with identical regression equations were grouped to derive age based on diameter. Any species with identical LANDIS-II symbols were grouped for modeling purposes based on small sample size.

\begin{tabular}{|c|c|c|c|c|c|c|c|}
\hline Genus species & Common name & $\begin{array}{c}\text { USDA } \\
\text { symbol }\end{array}$ & $\begin{array}{c}\text { LANDIS-II } \\
\text { symbol }\end{array}$ & Y-INT & SLOPE & $\mathbf{R}^{2}$ & $\mathbf{N}$ \\
\hline Acer negundo L. & Boxelder & ACNE2 & ACNE2 & 1.7397 & 0.7558 & 0.5927 & 223 \\
\hline Acer saccharinum L. & Silver Maple & ACSA2 & ACSA2 & 1.7449 & 0.8026 & 0.5819 & 840 \\
\hline Betula nigra $\mathrm{L}$. & River Birch & BENI & BENI & 2.3417 & 0.5726 & 0.3449 & 87 \\
\hline Carya illinoinensis (Wangenh.) K. Koch & Pecan & CAIL2 & CACO15 & 2.2372 & 0.6575 & 0.3572 & 135 \\
\hline Carya cordiformis (Wangenh.) K. Koch & Bitternut Hickory & CACO15 & CACO15 & 2.2372 & 0.6575 & 0.3572 & 135 \\
\hline Carya laciniosa (Michx.f.) G. Don & Shellback Hickory & CALA21 & CALA21 & 2.2372 & 0.6575 & 0.3572 & 135 \\
\hline Celtis occidentalis $\mathrm{L}$. & Common Hackberry & CEOC & CEOC & 2.2419 & 0.6409 & 0.285 & 23 \\
\hline Cephalanthus occidentalis L. & Common Buttonbush & CEOC2 & CEOC2 & 1.5248 & 0.8108 & 0.7262 & 263 \\
\hline Diospyros virginiana $\mathrm{L}$. & Common Persimmon & DIVI5 & DIVI5 & 1.5859 & 0.876 & 0.3379 & 20 \\
\hline Forestiera acuminata (Michx.) Poir. & Eastern Swampprivet & FOAC & FOAC & 1.5248 & 0.8108 & 0.7262 & 263 \\
\hline Fraxinus pennsylvanica Marshall & Green Ash & FRPE & FRPE & 1.975 & 0.7244 & 0.3994 & 1529 \\
\hline Fraxinus nigra Marshall & Black ash & FRNI & FRPE & 1.975 & 0.7244 & 0.3994 & 1529 \\
\hline Morus rubra L. & Red mulberry & MORU2 & MORU2 & 1.77 & 0.7257 & 0.8868 & 15 \\
\hline Platanus occidentalis L. & American Sycamore & PLOC & PLOC & 1.2803 & 0.8986 & 0.703 & 57 \\
\hline Populus deltoides $\mathrm{W}$. & Eastern Cottonwood & PODE3 & PODE3 & 1.593 & 0.8051 & 0.6489 & 117 \\
\hline Quercus bicolor Willd. & Swamp White Oak & QUBI & QUBI & 2.4912 & 0.6353 & 0.4626 & 208 \\
\hline Quercus macrocarpa Michx. & Bur Oak & QUMA2 & QUMA2 & 2.6992 & 0.5299 & 0.3433 & 21 \\
\hline Quercus palustris Münchh. & Pin Oak & QUPA2 & QUPA2 & 2.2468 & 0.6143 & 0.4016 & 35 \\
\hline Quercus rubra L. & Red Oak & QURU & QURU & 2.2468 & 0.6143 & 0.4016 & 35 \\
\hline Quercus velutina Lam. & Black Oak & QUVE & QURU & 2.2468 & 0.6143 & 0.4016 & 35 \\
\hline Salix interior Rowlee & Sandbar Willow & SAIN3 & SALIX & 1.5248 & 0.8108 & 0.7262 & 263 \\
\hline Salix nigra Marshall & Black Willow & SANI & SALIX & 1.5248 & 0.8108 & 0.7262 & 263 \\
\hline Ulmus americana $\mathrm{L}$. & American Elm & ULAM & ULAM & 2.1891 & 0.6235 & 0.3585 & 343 \\
\hline
\end{tabular}




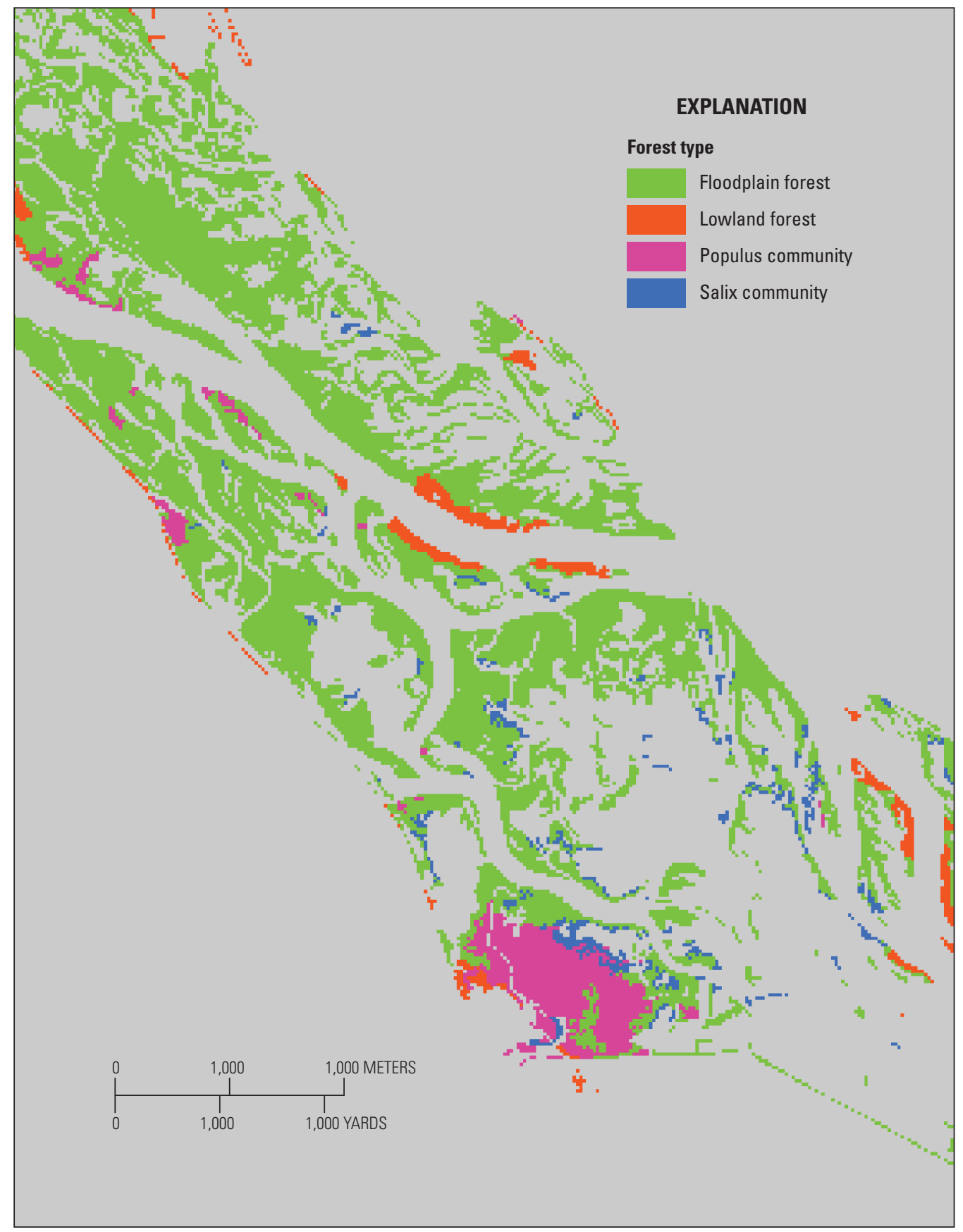

Figure 4.2 An example of the distribution of forest types based on land-cover data for a section of the Upper Mississippi River floodplain. Forest inventory (plot) data was randomly imputed into the cells of each like forest type to estimate the location of each species-age cohort across the landscape. 


\section{Species Life History Attributes, Potential Species Establishment, and Potential Growth Rates}

To simulate succession, we used the Biomass Succession extension (version 3.2) (Scheller and Mladenoff, 2004), which simulates the processes of establishment, growth, competition, and senescence based on the life histories of taxa as they influence and are influenced by the biomass of cohorts at a site. We developed basic life history information for each species using Burns and Honkala (1990) and our own experiences working in the UMR floodplain (table 4.2).

The Biomass Succession extension requires a file that specifies spatial variability in potential establishment and growing conditions across the landscape. Actual establishment and growth rates within the LANDIS-II model are reduced below potential rates due to factors such as seed availability, shading effects, and competition with other species-age cohorts at a site. Typical applications of LANDIS-II utilize climate and soil data to develop ecoregions within which temperature, precipitation, and soil types are considered to be homogeneous. Within such zones, the growth of different species is simulated using physiological models such as Linkages (Pastor and Post, 1986) or PnEtt-II (Aber and Federer, 1992) to determine maximum potentials. However, soils data for the UMR floodplain do not exist at a resolution fine enough to characterize differences in potential establishment or growing conditions. Furthermore, it is unclear how various aspects of climate (such as temperature and precipitation) influence potential establishment and growth rates of lowland forest species. Both Linkages and PnEtt-II rely on the sensitivity of upland species to drought stress but do not take into account soil water logging conditions. We therefore used empirical methods to parameterize species-specific establishment and growth rates (see following section).

To estimate spatial variability in potential species establishment rates, we related the relative abundance of each species to long-term average flooding conditions. Previous research had shown that the long-term average growing season flood inundation duration is a good predictor of soil texture in the UMR (De Jager and others, 2012). Further, soil texture may interact with seed size to impact germination rates of wetland species (Jurik and others, 1994). We therefore intersected the location of permanent plots with maps of the 40-year mean growing season flood duration developed using a flood inundation model (see appendix B). The abundance of each species within 10-year inundation zones, relative to their total abundance, was then used to estimate potential establishment rates (figures 4.3 and 4.4). 
Table 4.2 Basic life history attributes relevant to forest simulation modelling on the UMRS.

\begin{tabular}{|c|c|c|c|c|c|c|c|}
\hline \multirow{2}{*}{ Genus species } & \multirow{2}{*}{ Common name } & \multirow{2}{*}{$\begin{array}{l}\text { LANDIS-II } \\
\text { symbol }\end{array}$} & \multirow{2}{*}{ Longevity } & \multirow{2}{*}{$\begin{array}{l}\text { Sexual } \\
\text { maturity }\end{array}$} & \multirow{2}{*}{$\begin{array}{c}\text { Shade } \\
\text { tolerance }\end{array}$} & \multicolumn{2}{|c|}{ Seed dispersal } \\
\hline & & & & & & Effective & Maximum \\
\hline Acer negundo L. & Boxelder & ACNE2 & 80 & 10 & 3 & 100 & 7,500 \\
\hline Acer saccharinum L. & Silver Maple & ACSA2 & 150 & 10 & 3 & 100 & 7,500 \\
\hline Betula nigra $\mathrm{L}$. & River Birch & BENI & 110 & 10 & 1 & 100 & 7,500 \\
\hline Carya illinoinensis (Wangenh.) K. Koch & Pecan & CACO15 & 250 & 30 & 2 & 25 & 1,000 \\
\hline Carya cordiformis (Wangenh.) K. Koch & Bitternut Hickory & CACO15 & 250 & 30 & 2 & 25 & 1,000 \\
\hline Carya laciniosa (Michx.f.) G. Don & Shellback Hickory & CALA21 & 250 & 40 & 4 & 25 & 1,000 \\
\hline Celtis occidentalis L. & Common Hackberry & CEOC & 150 & 20 & 3 & 100 & 7,500 \\
\hline Cephalanthus occidentalis L. & Common Buttonbush & CEOC2 & 50 & 10 & 1 & 100 & 7,500 \\
\hline Diospyros virginiana $\mathrm{L}$. & Common Persimmon & DIVI5 & 150 & 10 & 4 & 100 & 7,500 \\
\hline Forestiera acuminata (Michx.) Poir. & Eastern Swampprivet & FOAC & 50 & 10 & 2 & 100 & 7,500 \\
\hline Fraxinus pennsylvanica Marshall, & Green Ash & FRPE & 150 & 15 & 3 & 100 & 7,500 \\
\hline Fraxinus nigra Marshall & Black ash & FRPE & 150 & 15 & 3 & 100 & 7,500 \\
\hline Morus rubra L. & Red Mulberry & MORU2 & 125 & 10 & 3 & 100 & 7,500 \\
\hline Platanus occidentalis L. & American Sycamore & PLOC & 250 & 10 & 1 & 100 & 7,500 \\
\hline Populus deltoides W. & Eastern Cottonwood & PODE3 & 140 & 5 & 1 & 200 & 10,000 \\
\hline Quercus bicolor Willd. & Swamp White Oak & QUBI & 250 & 20 & 3 & 50 & 5,000 \\
\hline Quercus macrocarpa Michx. & Bur Oak & QUMA2 & 275 & 35 & 2 & 50 & 5,000 \\
\hline Quercus palustris Münchh. & Pin Oak & QUPA2 & 150 & 20 & 2 & 50 & 5,000 \\
\hline Quercus rubra L., & Red Oak & QURU & 250 & 30 & 2 & 50 & 5,000 \\
\hline Quercus velutina Lam. & Black Oak & QURU & 250 & 30 & 2 & 50 & 5,000 \\
\hline Salix interior Rowlee & Sandbar Willow & SALIX & 100 & 10 & 1 & 200 & 10,000 \\
\hline Salix nigra Marshall & Black Willow & SALIX & 100 & 10 & 1 & 200 & 10,000 \\
\hline Ulmus americana L. & American Elm & ULAM & 80 & 25 & 3 & 200 & 10,000 \\
\hline
\end{tabular}




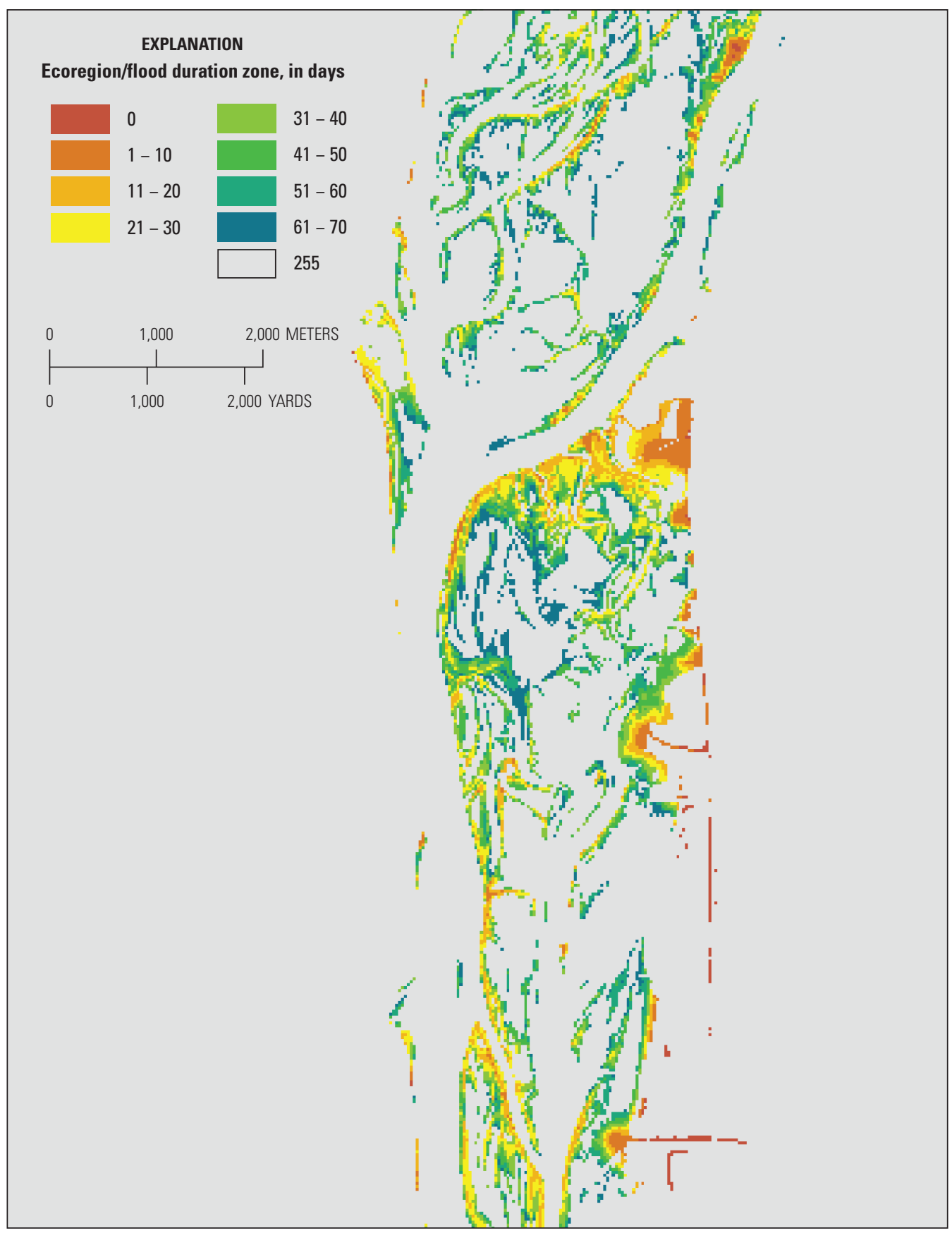

Figure 4.3 Example of the ecoregion/flood duration zone map for a portion of the Upper Mississippi River System. Areas with no data include permanently aquatic areas, areas outside of the Upper Mississippi River System floodplain, and areas in nonforest cover. Each flood duration zone is defined by the average duration of flooding that occurred during the growing seasons of 1972 to 2011. 



Ecoregion / flood duration zone

Figure 4.4 Probability of establishment coefficients used in LANDIS-II modelling for species typically considered highly flood tolerant (upper panel), flood tolerant (middle panel) and less flood tolerant (lower panel). Ecoregions were defined by 10-day increments of mean growing season flood inundation duration (fig. D-3). The last zone (70) consists of any flood duration lasting longer than 60 days. 
Within the LANDIS-II model, actual species establishment rates depend on the ecoregion-specific maximum establishment rate (fig. 4.4), the shade tolerance of a given species (table 4.2), and the amount of canopy cover at a site in a given year. Canopy cover is approximated by a relationship between the total biomass at a site and the maximum biomass possible at a site (see Scheller and Mladenoff [2004] for full details). As the total biomass at a site approaches the maximum possible biomass, establishment rates are reduced according to user-supplied coefficients, which are multiplied by the speciesecoregion specific maximum establishment rates (fig. 4.5).

Once present at a site, all cohorts compete for available growing space, which becomes more available as a disturbance or senescence causes loss of biomass from competing cohorts. The model relies on four user-supplied parameter estimates to simulate growth: ANPPmax and MaxBiomass, which are the maximum annual net primary productivity and maximum total biomass that a species can biologically attain, respectively; and GrowthShape and MortalityShape, which define the rate at which a species reaches ANPPmax and the rate at which biomass declines as the species approaches longevity (senescence), respectively. The extension calculates the ANPP of each cohort as a function of the maximum biomass the site can support such that, in the absence of competition from other cohorts, ANPP increases with cohort age using a growth function that is defined by ANPPmax, slowing asymptotically as total site biomass approaches its maximum. The GrowthShape parameter defines how rapidly a given species approaches its maximum ANPP. A second function removes some of the accumulated cohort biomass to represent competition-related mortality at a rate that also reaches its maximum at maximum site biomass. A third function removes cohort biomass as the cohort approaches its longevity, with the rate defined by the MortalityShape parameter. In the following discussion, we outline how we derived these four parameters for UMRS tree species.

We derived MaxBiomass and ANPPmax for each species by estimating the biomass of individual trees within the same forest inventory data used to define initial species-age-cohort distributions (see previous description). We used regression equations developed by Jenkins and others (2003) relating tree diameter to aboveground biomass. We then converted per-tree biomass to a unit area by estimating biomass under hypothetically 'fully stocked' conditions, using crown area estimates from Larsen and others (2010). This resulted in a hypothetical species maximum biomass in grams per square meter (MaxBiomass). Next, we estimated ANPPmax from MaxBiomass using regression equations developed by Keeling and Phillips (2007).



Figure 4.5 User-supplied establishment coefficients (multipliers) as a function of an index of canopy closure (percent of ecoregion maximum biomass). The establishment of shade intolerant species (shade class 1 ) is reduced to 0 when a site reaches 20 percent or more of its maximum possible biomass. For shade tolerant species (shade class 4), establishment is reduced to 0 when a site reaches 80 percent or more of its maximum possible biomass (see table D-2 for Upper Mississippi River species shade tolerance classes). 
To estimate the GrowthShape and MortalityShape parameters and make slight adjustments to MaxBiomass and ANPPmax, we compared the hypothetical plot-level biomass estimates associated with each tree's age in the forest inventory data with estimates derived from the LANDIS-II Site Utility (L2-Site; Miranda and Sturtevant, 2016; https://sites. google.com/site/landismodel/projects/veg-site-tool). L2-Site is a Microsoft Windows-based utility that implements the cohort and biomass growth and senescence equations of the Biomass Succession Extension (v3.2) for up to six species on a single site. We used the MaxBiomass and ANPPmax estimates described previously as starting parameters in the site utility, along with arbitrary starting parameters for GrowthShape and MortalityShape. We then iteratively simulated the growth of a single cohort of each species and adjusted each parameter so that time (age) specific biomass estimates would encompass the upper-bound of the empirical age-biomass data (fig. 4.6). Species-specific longevity estimates were first derived from Burns and Honkala (1990) and were later adjusted to reflect maximum species ages from the plot-data, if the estimated age was greater than that reported in the literature.

Finally, we made slight further adjustments to some parameters for some species to achieve an approximate 1:1 relationship between plot-level biomass estimates and those produced by the full LANDIS-II Biomass Succession Extension for year 0. The Biomass Succession extension uses a spin-up process to establish initial biomass estimates for each species-age cohort on the landscape. To do this, it begins simulating each cell at a time equal to the oldest cohort and then adds cohorts at a time corresponding to their age. Results from the spin-up process ought to differ from those developed using the L2-Site utility because the full model incorporates competition among multiple species-age cohorts for growing space. Using the initial community dataset described previously, we used the spin-up process to develop initial biomass estimates for each species by forest type and region and compared them with the empirical data (fig. 4.7). We used species-specific data for ACSA2 (silver maple), PODE3 (eastern cottonwood), and Salix spp (black and sandbar willow). We grouped CACO15 (Bitternut hickory and Pecan), CALA21 (shellbark hickory), QUBI (swamp white oak), QUMA2 (bur oak), QUPA2 (pin oak), and QURU (red oak). All remaining species were grouped into the 'other' group. Minor increases to the growth of Salix spp. were required from the initial parameters to achieve an approximate 1:1 relationship. Minor decreases were required from the initial parameters to achieve an approximate 1:1 relationship for the Oak-Hickory species. Although the relationships are not 1:1 for all species groupings within all reaches, further adjustment of parameter estimates began to alter the biomass of other competing species. The resulting parameter estimates represent a compromise among all species and yet provide a reasonable fit to the data (table 4.3). 

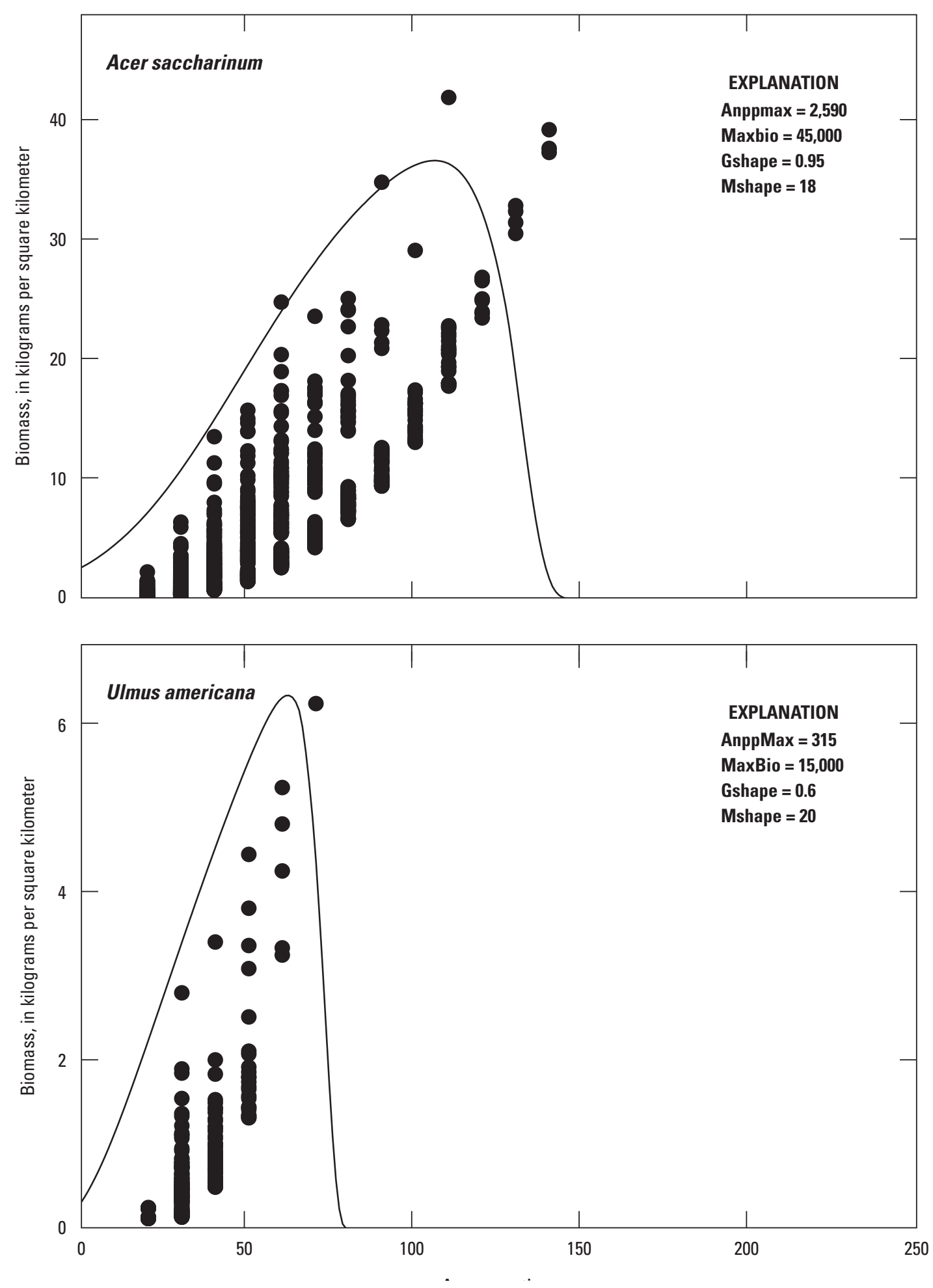

Figure 4.6 Plots of age-biomass relationships for forest inventory data (dots) and simulated time-biomass relationships using the LANDIS-II Site Utility (see text for details). Species-specific parameters were developed by fitting the simulated results to the upper-bound of the plot-level estimates. 



LANDIS-II predicted biomass, in kilograms per square kilometer

\section{EXPLANATION}

\begin{tabular}{|c|c|c|c|}
\hline - & Floodplain forest (p3-10) & 0 & Salix community (p3-10) \\
\hline & Floodplain forest (p11-22) & ○ & Salix community (p11-22) \\
\hline & Floodplain forest (p24-0R2) & - & Salix community (p24-0R2) \\
\hline & Lowland forest (p3-10) & - & Populus community (p3-10) \\
\hline & Lowland forest (p11-22) & ○ & Populus community (p11-22) \\
\hline & Lowland forest (p24-0R2) & 0 & Populus community ( $\mathrm{p} 24-0 \mathrm{R} 2$ ) \\
\hline
\end{tabular}

Figure 4.7 Relationships between mean (plus or minus a standard deviation) predicted biomass from LANDIS-II Biomass Succession and biomass estimated from forest inventory plots. The $y$-axis is the estimated observed biomass from forest permanent plot data for individual species or groups of species (see text) within a given forest type and reach of the Upper Mississippi River System (see figure explanation). The x-axis is the LANDIS-II simulated biomass for individual species or groups of species within a given forest type and reach of the Upper Mississippi River System. 
Table 4.3 Final species-specific growth and mortality parameters.

[See table 4.2 for the complete names of species]

\begin{tabular}{lrccc}
\hline Species & ANPPmax & BiomassMax & $\begin{array}{c}\text { Growth } \\
\text { shape }\end{array}$ & $\begin{array}{c}\text { Mortality } \\
\text { shape }\end{array}$ \\
\hline ACNE2 & 450 & 18,000 & 17 & 0.4 \\
ACSA2 & 2590 & 45,000 & 18 & 0.95 \\
BENI & 700 & 22,000 & 17 & 0.3 \\
CACO15 & 1600 & 35,000 & 10 & 0.85 \\
CALA21 & 1600 & 35,000 & 10 & 0.85 \\
CEOC & 1043 & 28,000 & 18 & 0.75 \\
CEOC2 & 145 & 10,000 & 15 & 0.65 \\
DIVI5 & 839 & 25,000 & 20 & 0.95 \\
FOAC & 145 & 10,000 & 15 & 0.65 \\
FRPE & 1043 & 28,000 & 15 & 0.8 \\
MORU2 & 300 & 10,000 & 10 & 0.3 \\
PLOC & 2374 & 43,000 & 22 & 0.9 \\
PODE3 & 2374 & 40,000 & 22 & 0.9 \\
QUBI & 1950 & 40,000 & 10 & 0.85 \\
QUMA2 & 2000 & 39,000 & 18 & 0.95 \\
QUPA2 & 2350 & 42,000 & 18 & 0.95 \\
QURU & 1950 & 40,000 & 10 & 0.85 \\
SALIX & 600 & 20,000 & 22 & 0.5 \\
ULAM & 750 & 24,000 & 20 & 0.6 \\
\hline
\end{tabular}

\section{Parameterizing Insect and Flood Disturbances}

Within LANDIS-II, disturbances remove cohorts or a portion of cohort biomass from individual cells based on the spatial and temporal distribution of the disturbance and the susceptibility of different species and ages to the disturbance. For HNA-II, we focused on simulating disturbances known to cause tree mortality in the UMRS floodplain and for which it is reasonable to expect continued effects of the disturbances into the future.

\section{Insect Disturbance}

There is widespread concern regarding the future effects of the introduced Agrilus planipennis (emerald ash borer [EAB]), in upland, lowland, and urban forests across North America (Anulewicz and others, 2007). Since it was discovered in 2002, EAB has been responsible for the deaths of millions of ash trees in the Midwestern United States. Ash species are the only known hosts of EAB (Anulewicz and others, 2006, 2007) and complete mortality of infested trees of all size classes is expected within a decade (Siegert and others, 2014). Short-range dispersal of EAB is determined by how far an insect can fly, which has been reported to be near 1.7 kilometer $(\mathrm{km})$ in a 24-hour period (Taylor et al. 2010). Longer-range dispersal depends on the contiguity of ash trees (are they within the maximum flight distance) and human-aided transport. Longer-range spread rates for EAB in landscapes with a relatively continuous distribution of ash trees have ranged from approximately 4 kilometers per year to as fast as 40 kilometers per year when substantially aided by human transport (Straw and others, 2013).

We simulated tree mortality due to EAB using the Base Biological Disturbance Agent extension (version 3.0.1) (Sturtevant and others, 2004). Base Biological Disturbance Agent simulates tree mortality following major outbreaks of insects and (or) disease. Insect outbreaks are probabilistic at the site (cell) scale, with each site assigned a disturbance probability, which is then compared to a uniform random number to determine if the site is disturbed. The disturbance probability at a site, in turn, depends on whether an insect host is present on a site. If a site is disturbed, species and cohort level mortality occur according to user-defined susceptibility parameters.

We modeled the spread of EAB as though it was not dispersal limited (following Gustafson and others, 2017). Because the floodplain forests of the UMRS are highly fragmented (De Jager and Rohweder, 2011), it might be argued that the dispersal of EAB could be limited. However, single individuals can fly up to $6 \mathrm{~km}$ per day (Taylor and others, 2010) which is a distance greater than a typical distance between forested islands in the UMRS. Furthermore, the lateral forested edges of the UMRS are typically connected to forested uplands, which also contain abundant host ash trees. Within the model, all age classes were considered to be suitable hosts for EAB. Annual susceptibility probabilities were set to 0.55 for age classes greater than 5 years, which corresponds to a 7-year cumulative mortality probability $>0.99$ (Siegert and others, 2014). This worst case scenario resulted in the loss of ash species from the landscape within the first 10 years of model simulations, but also resulted in continued establishment of new ash cohorts where light conditions were favorable. However, over the longer-term ash cohorts have a $>$ $99 \%$ probability of mortality by age 12 . Our primary objective in simulating EAB disturbance was to understand how UMRS forests may respond to EAB outbreaks, rather than to understand how EAB outbreaks occur.

\section{Flood Disturbance}

Flood inundation is a fundamental driver of successional patterns in floodplains. Past research has documented speciesspecific differences in flood tolerance of UMRS tree species (Yin and others, 1993), and corresponding differences in spatial patterns of tree community composition (De Jager and others, 2012). For this effort, we developed a new extension for the LANDIS-II platform. The extension utilizes annual 
maps of flood-inundation duration during the growing season. These maps were developed according to the methods outlined in appendix B. Each map was then used to influence tree survival based on how long species-age cohorts can tolerate inundation.

We developed new statistical models for how the survival of tree cohorts relates to tree size (dbh) and the duration of flooding. To do this, we used tree mortality and duration flooding data collected following the 1993 flood (Yin and others, 2009). For simplicity, we first grouped species into three flood tolerance categories based on previous studies (Whitlow and Harris 1979; Yin and others, 1993) and used multiple logistic regression models to relate the mortality of species within each category to inundation duration during 1993 and the size of the stem (dbh) (table 4.4; fig. 4.8). We then used these equations to implement probabilistic mortality for each year, based on the distribution of annual flooding patterns within the model.

The results of multiple logistic regression models indicate that all species tend to be highly susceptible to flood-induced mortality when they are small (young) and when subjected to increasingly long inundation durations (fig.4.8). Highly flood tolerant (tolerance $=3$ ) species tend to have lower mortality rates across all size classes and inundation durations. The primary difference between species considered intolerant of flooding (tolerance $=1$ ) and those considered tolerant of flooding (tolerance $=2$ ) occurs as these species age. Both types of species are highly susceptible to long inundation durations when they are young, but diverge in their tolerance as they age. The implication of these model results is that intolerant species remain susceptible to flood-induced mortality for a longer portion of their life than flood tolerant species.

We simulated a 100-year business-as-usual scenario for flooding effects by utilizing annual maps of total flood inundation duration during the growing season for each of the past 40 years. These maps were then recycled for years $41-80$, and the first 20 years were again recycled for years $81-100$ to simulate a possible 100-year scenario.

\section{Data Analysis}

We examined changes in total forest area and the area within the same four forest classes used to develop the initial communities. First, we used the maximum age of speciescohorts at each site to identify areas that may have converted from forest cover to nonforest cover. Any cell that had a maximum species age of less than 10 was considered to be a site that did not support forest recruitment over the longterm. Such cells were then removed from further analysis. To estimate the amount of forest cover in the four community types, we reclassified maps of total biomass by species. The sum of the biomass for the following species was used to determine the potential to include each pixel in the floodplain

Table 4.4 Multiple logistic regression model parameters for different flood tolerance groups used in LANDIS-II modelling. The form of the logistic regression equation was Logit $\mathrm{P}=$ yint $+\left(\mathrm{B} 1^{*}\right.$ Flood $)-\left(\mathrm{B} 2^{*} \mathrm{DBH}\right)$.

[See table D-2 for the complete names of species]

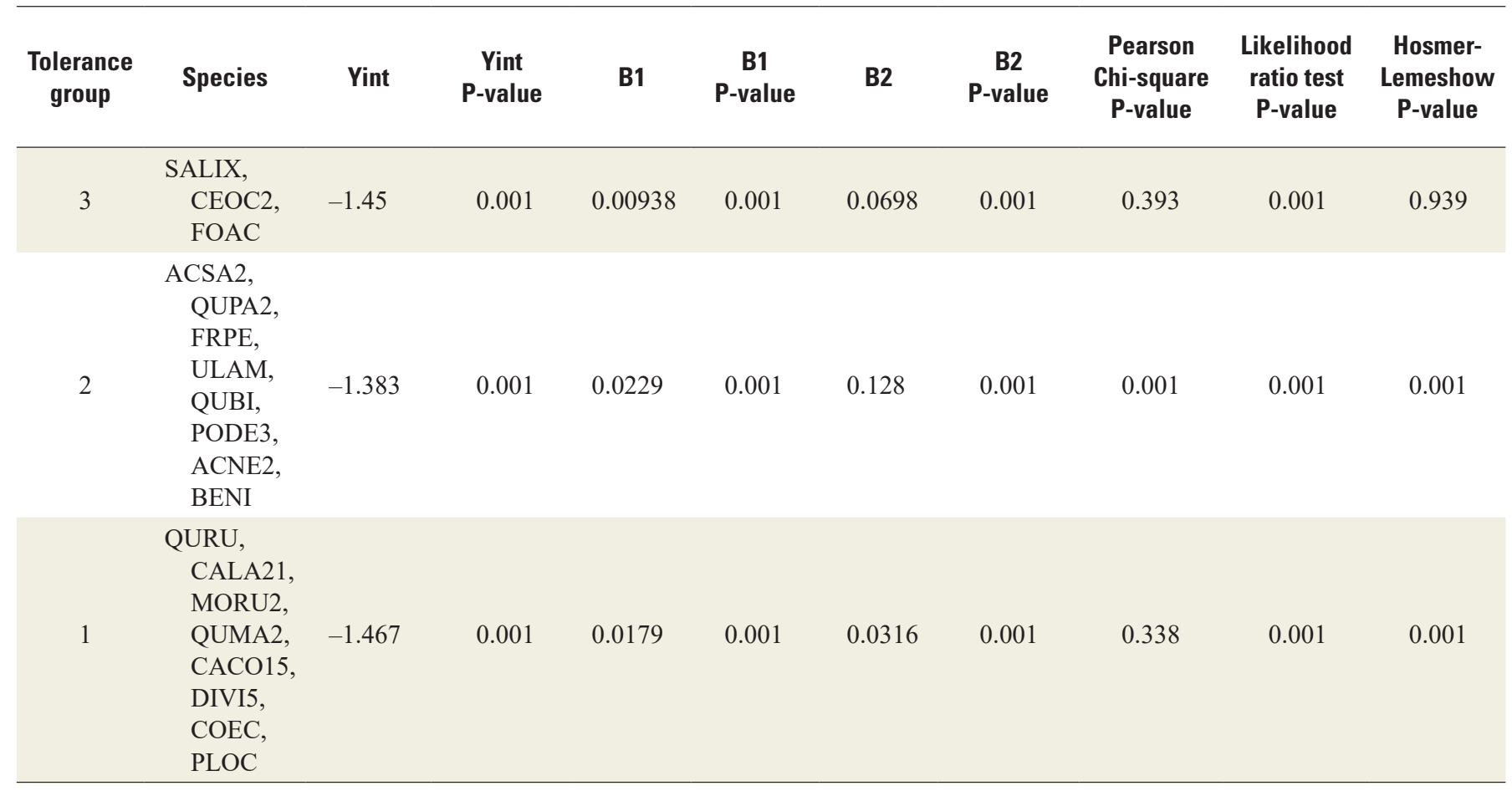



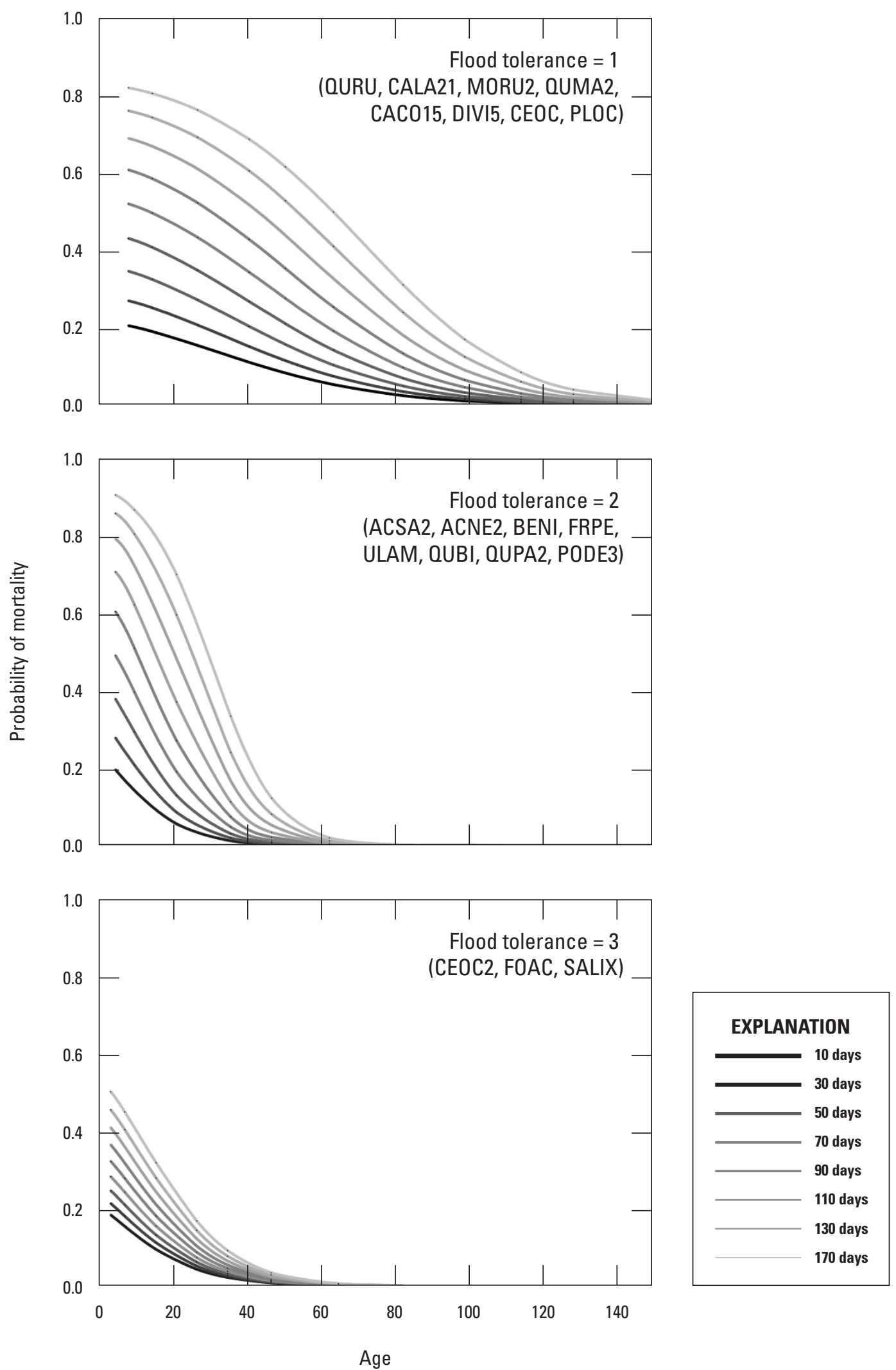

Figure 4.8 Multiple logistic regression model results for mortality of three groups of species as a function of tree size (expressed here as age) and annual growing season flood inundation duration. More tolerant species generally have lower mortality rates for all flood durations and sizes. However, all species are generally more tolerant of inundation as they age. 
forest class: silver maple (Acer saccharinum), American elm (Ulmus americana), green ash (Fraxinus pennsylvanica), river birch (Betula nigra), boxelder (A. negundo), American sycamore (Platantus occidentalis), and swamp white oak (Quercus bicolor). The sum of the biomass for the following species was used to define the lowland forest community type: red oak (Q. rubra), bur oak (Q. macrocarpa), swamp white oak (Q. bicolor), common hackberry (Celtis occidentalis), bitternut hickory (Carya cordiformis), and shellbark hickory (C. laciniosa). The species used to define the Populus community consisted of eastern cottonwood (P. deltoides) and the Salix community consisted of sandbar willow (S. interior) and/ or black willow (S. nigra). The forest type with the sum of the biomass that was greatest was then assigned to each pixel. Finally, total forest area was the sum of the area of all four forest types.

\section{References Cited}

Aber, J.D., and Federer, C.A., 1992, A generalized, lumpedparameter model of photosynthesis, evapotranspiration and net primary production in temperate and boreal forest ecosystems: Oecologia, v. 92, no. 4, p. 463-474.

Anulewicz, A.C., McCullough, D.G., and Miller, D.L., 2006, Oviposition and development of emerald ash borer (Agrilus planipennis)(Coleoptera-Buprestidae) on hosts and potential hosts in no-choice bioassays: Great Lakes Entomologist, v. 39, p. 99-112.

Anulewicz, A.C., McCullough, D.G., and Cappaert, D.L., 2007, Emerald ash borer (Agrilus planipennis) density and canopy dieback in three North American ash species: Arboriculture \& Urban Forestry, v. 33, p. 338-349.

Burns, R.M., and Honkala, B.H., 1990, Silvics of North America-2 Hardwoods. Agricultural Handbook 654 v. 2: Washington, DC, U.S. Department of Agriculture, Forest Service, $877 \mathrm{p}$.

De Jager, N.R., Thomsen, M., and Yin, Y., 2012, Threshold effects of flood duration on the vegetation and soils of the Upper Mississippi River floodplain, USA: Forest Ecology and Management, v. 270, p. 135-146.

De Jager, N.R., and Rohweder, J.J., 2011, Spatial scaling of core and dominant forest cover in the Upper Mississippi and Illinois River floodplains, USA: Landscape Ecology, v. 26, no. 5 , p. $697-708$.

Dieck, J.J., Ruhser, J., Hoy, E., and Robinson, L.R., 2014, General classification handbook for floodplain vegetation in large river systems (ver. 2.0, November 2015): U.S. Geological Survey Techniques and Methods, book 2, chap. A1, 51 p., accessed May 23, 2018, at https://pubs.er.usgs.gov/ publication/tm2A1.
Gustafson, E.J., de Bruijn, A., Lichti, N., Jacobs, D.F., Sturtevant, B.R., Foster, J., Miranda, B.R., and Dalgleish, H.J., 2017, The implications of American chestnut reintroduction on landscape dynamics and carbon storage: Ecosphere, v. 8, no. 4, p. e01773.

Jenkins, J.C., Chojnacky, D.C., Heath, L.S., and Birdsey, R.A., 2003, National scale biomass estimators for United States tree species: Forest Science, v. 49, no. 1, p. 12-35.

Jurik, T.W., Wang, S., and van der Valk, A.G., 1994, Effects of sediment load on seedling emergence from wetland seed banks: Wetlands, v. 14, no. 3, p. 159-165.

Keeling, H.C., and Phillips, O.L., 2007, The global relationship between forest productivity and biomass: Global Ecology and Biogeography, v. 16, no. 5, p. 618-631.

Larsen, D.R., Dey, D., and Faust, T., 2010, A stocking diagram for Midwestern Eastern Cottonwood-Silver MapleAmerican Sycamore Bottomland forests: North American Jouranal of Applied Forestry, v. 27, p. 132-139.

Miranda, B.R., and Sturtevant, B.R., 2016. LANDIS-II-Site v2.4 User Guide. Published online by the LANDIS-II Foundation (https://sites.google.com/site/landismodel/tools/ veg-site-tool), accessed March 2016.

Mladenoff, D.J., Host, G.E., Boeder, J., and Crow, T.R., 1993, LANDIS-A spatial model of forest landscape disturbance, succession, and management, in Goodchild, M.F., Steyaert, L.T., Parks, B.O., Johnston, C., Maidment, D., Crane, M., and Glendining, S., eds., GIS and environmental modeling: Fort Collins, CO, USA, GIS World Books, p. 175-179.

Mladenoff, D.J., and He, H.S., 1999, Design, behavior and applications of LANDIS, an object-oriented model of forest landscape disturbance and succession, chap. 6 of Mladenoff, D.J., and Baker, W.L., eds., Spatial modeling of forest landscape change-Approaches and applications: Cambridge, UK, Cambridge University Press.

Pastor, J., and Post, W.M., 1986, Influence of climate, soil moisture, and succession on forest carbon and nitrogen cycles: Biogeochemistry, v. 2, no. 1, p. 3-27.

Scheller, R.M., and Mladenoff, D.M., 2004, A forest growth and biomass module for a landscape simulation model, LANDIS-Design, validation, and application: Ecological Modelling, v. 180, no. 1, p. 211-229.

Scheller, R.M., Domingo, J.B., Sturtevant, B.R., Williams, J.S., Rudy, A., Gustafson, E.J., and Mladenoff, D.J., 2007, Design, development and application of LANDISII, a spatial landscape simulation model with flexible temporal and spatial resolution: Ecological Modelling, v. 201, no. 3-4, p. 409-419. 
Siegert, N.W., McCullough, D.G., Liebhold, A.M., and Telewski, F.W., 2014, Dendrochronological reconstruction of the epicentre and early spread of emerald ash borer in North America: Diversity \& Distributions, v. 20, no. 7 , p. $847-858$.

Straw, N.A., Williams, D.T., Kulinich, O., and Gninenko, Y.I., 2013, Distribution, impact and rate of spread of emerald ash borer Agrilus planipennis (Coleoptera-Buprestidae) in the Moscow region of Russia: Forestry, v. 86, no. 5, p. 515-522.

Sturtevant, B.R., Gustafson, E.J., Li, W., and He, H.S., 2004, Modeling biological disturbances in LANDIS-A module description and demonstration using spruce budworm: Ecological Modelling, v. 180, no. 1, p. 153-174.

Taylor, R.A.J., Bauer, L.S., Poland, T.M., and Windell, K.N., 2010, Flight performance of Agrilus planipennis (Coleoptera-Buprestidae) on a flight mill and in free flight: Journal of Insect Behavior, v. 23, no. 2, p. 128-148.
Whitlow, T.H., and Harris, R.W., 1979. Flood tolerance in plants: A state of the art review. National Technical Information Service, US Department of Commerce. 1-161.

Yin, Y., Nelson, J.C., Swenson, G.V., Langrehr, H.A., and Blackburn, T.A., 1994, Tree mortality in the Upper Mississippi River and floodplain following an extreme flood in 1993, in Long Term Resource Monitoring Program 1993 flood observations: National Biological Service, Environmental Management Technical Center LTRMP 94-S011, p. 41-60.

Yin, Y., Wu, Y., Bartell, S., and Cosgriff, R., 2009, Patterns of forest succession and impacts of flood in the Upper Mississippi River floodplain ecosystem: Ecological Complexity, v. 6 , no. 4 , p. $463-472$. 

For additional information contact:

Director, Upper Midwest Environmental Sciences Center U.S. Geological Survey

2630 Fanta Reed Road

La Crosse, WI 5460

Publishing support provided by the

Madison Publishing Service Center 


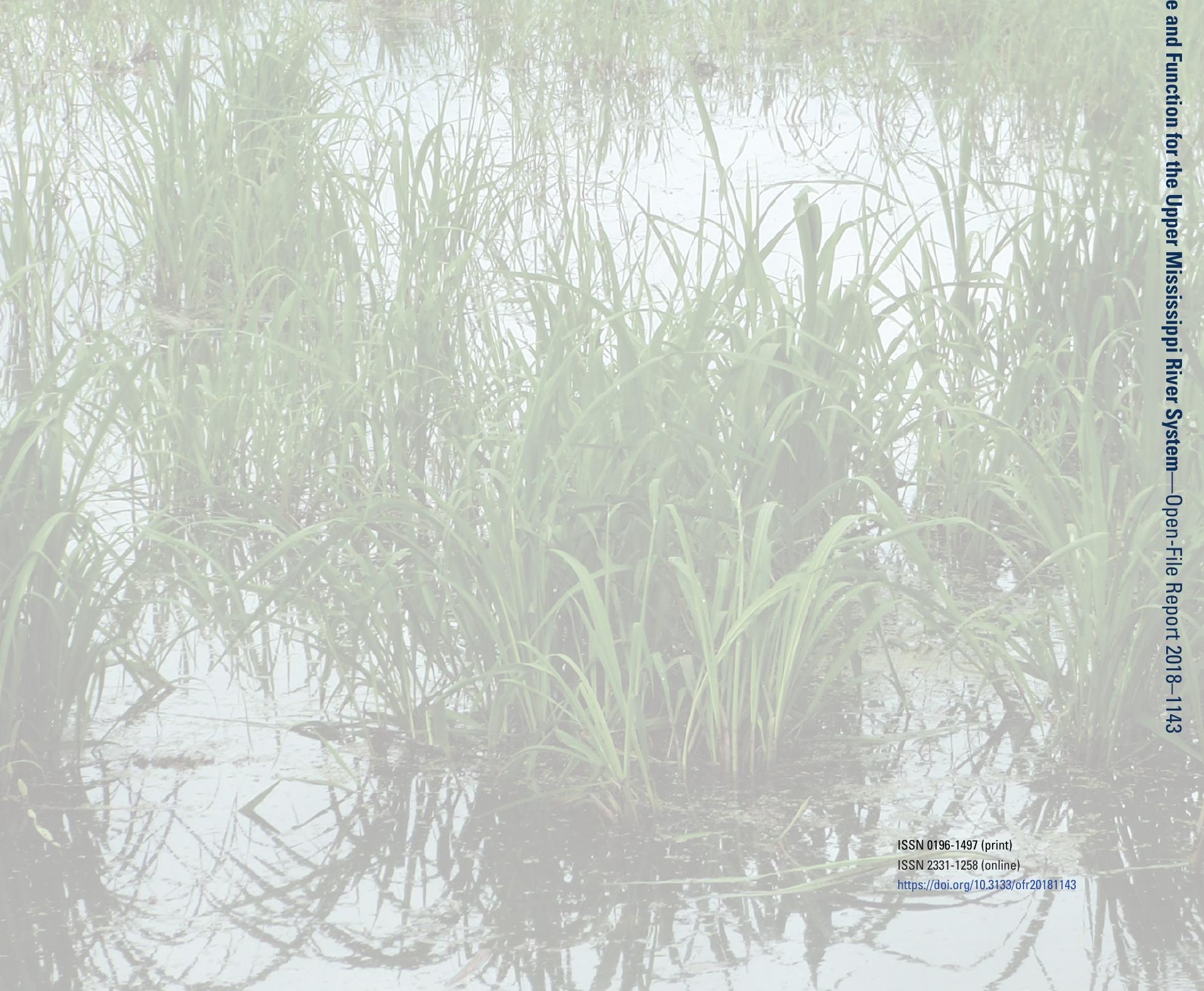

